
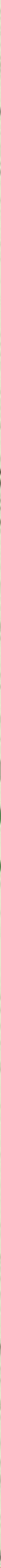

Edited by

James Simpson and Anne Whiteside 


\section{Adult Language Education and Migration}

Adult Language Education and Migration: Challenging Agendas in Policy and Practice provides a lively and critical examination of policy and practice in language education for adult migrants around the world, showing how opportunities for learning the language of a new country both shape and are shaped by policy moves. Language policies for migrants are often controversial and hotly contested, but at the same time innovative teaching practices are emerging in response to the language learning needs of today's mobile populations.

This book:

- analyses and challenges language education policies relating to adult migrants in nine countries;

- provides a comparative study with separate chapters on policy and practice in each country;

- focuses on Australia, Canada, Spain (Catalonia), Finland, France, Ireland, the Netherlands, the UK and the US.

Adult Language Education and Migration is essential reading for practitioners, students and researchers working in the area of language education in migration contexts.

James Simpson is a senior lecturer in language education at the School of Education, University of Leeds, UK.

Anne Whiteside is a lecturer in a Masters in TESOL program at San Francisco State University. 
'Language education for migrants is of critical importance for the promotion of individual life chances and community development. The eighteen substantive chapters in this volume, together with the thoughtful Introduction and Afterword, provide expert accounts of policy dispositions and realities on the ground. This book is a must for anyone interested in language education, language policy and social integration.'

Constant Leung, King's College London, UK

'Adult Language Education and Migration brings together an unprecedented collection of chapters from nine different countries with very unique political and policy backdrops. Readers will find wisdom, optimism, innovation, complexity, and a fresh critical eye among the chapters of this book. Simpson and Whiteside have given us a must-read for educators and researchers working in the dynamic and politically shifting spaces in which adult language learning and migration intersect.'

Martha Bigelow, University of Minnesota, USA 


\section{Adult Language Education and Migration}

Challenging agendas in policy and practice

Edited by

James Simpson and Anne Whiteside 
First published 2015

by Routledge

2 Park Square, Milton Park, Abingdon, Oxon OXI4 4RN

and by Routledge

7II Third Avenue, New York, NY 10017

Routledge is an imprint of the Taylor \& Francis Group, an informa business

(C) 2015 selection and editorial matter, James Simpson and Anne

Whiteside; individual chapters, the contributors

The rights of the editors to be identified as the authors of the editorial material, and of the authors for their individual chapters, has been asserted in accordance with sections 77 and 78 of the Copyright, Designs and Patents Act 1988.

All rights reserved. No part of this book may be reprinted or reproduced or utilised in any form or by any electronic, mechanical, or other means, now known or hereafter invented, including photocopying and recording, or in any information storage or retrieval system, without permission in writing from the publishers.

Trademark notice: Product or corporate names may be trademarks or registered trademarks, and are used only for identification and explanation without intent to infringe.

British Library Cataloguing-in-Publication Data

A catalogue record for this book is available from the British Library

Library of Congress Cataloging-in-Publication Data

A catalog record for this book has been requested

ISBN: 978-0-4I5-73359-5 (hbk)

ISBN: 978-0-4I5-73360-I (pbk)

ISBN: 978-I-3I5-7I836-I (ebk)

Typeset in Baskerville and Gill Sans

by Saxon Graphics Ltd, Derby 


\section{Contents}

\section{List of illustrations}

Notes on contributors

Acknowledgements

Introduction

JAMES SIMPSON AND ANNE WHITESIDE

1 Shaping Australian policy for Australian adult migrant English language learning

HOWARD NICHOLAS

2 Connecting with community: helping immigrant low literacy ESL learners in local contexts

LAURA CHAPMAN AND ALAN WILLIAMS

3 French language education policy for adult immigrants in Quebec

PAULA BOUFFARD

4 Justice-oriented citizenship in Canadian ESL classes: the views of experienced teachers

DOUGLAS FLEMING

5 Language education for adult migrants in Catalonia: nation-state ambitions without nation-state resources

ALBERT BRANCHADELL

6 A multilingual, collaborative and functional approach to nongovernmental Catalan classes 
7 Integration policies and adult second language learning in Finland

8 Stay-at-home mothers learning Finnish

9 Language training for adult migrants in France: history, policies and institutions

10 Plurilingual literacy practices in a creative writing workshop with adult second language learners

11 English, everywhere and nowhere: ESOL policies in Ireland

12 Getting to grips with the English language SANDRA DOYLE

13 The shifting landscape of Dutch integration policy: from L1 literacy teaching to literacy in Dutch as entrance criterion to the Netherlands

14 ICT-based applications for civic integration in the Netherlands: policy drivers and limits in practice MASSIMILIANO SPOTTI AND JEANNE KURVERS

15 English language learning for adult migrants in superdiverse Britain

JAMES SIMPSON

16 Whose integration? A participatory ESOL project in the UK MELANIE COOKE, BECKY WINSTANLEY AND DERMOT BRYERS

17 Green Card English: new possibilities and enduring challenges in US immigration reform 
18 Educational programming for low-literate adult migrants in the US

MARGUERITE LUKES AND JOHN LYONS

\section{Afterword}

MARILYN MARTIN-JONES

Index

264 


\section{Illustrations}

\section{Figures}

6.1 Duwa's completed student form, given out in the first

Catalan lesson in the residential project (9 September 2008) 97

6.2 Where are you from? Unit $1 \quad 99$

6.3 Triangle of images in the Catalan classroom. The action research contributions are shown in italics. $\quad 99$

6.4 Did you know that? Unit 2: Health system information in Catalan and its translation into Tamazight 103

12.1 Lesson plan: challenging racism and discrimination 167

13.1 Dutch legislation on admission and civic integration $\quad 175$

13.2 Sample text with questions $\quad 180$

16.1 'She's gone modern' 221

\section{Tables}

11.1 Self-report data from Ireland's census on English language ability

13.1 Average exams per month and pass rates by educational level, before and after implementation of the new entrance exam (1 April 2011) 


\section{Notes on contributors}

\section{Hervé Adami}

ATILF, Université de Lorraine and CNRS

Hervé Adami is professor of sociolinguistics and of language education (applied linguistics). His expertise is in language teaching for and integration of adult migrants. He also works on questions related to the articulation between language work and training. He is particularly interested in wage-workers and linguistic insecurity in written and oral communication, for native and non-native speakers of French. Before becoming a university professor, he was an adult educator.

\section{Paula Bouffard}

French Studies Department, Concordia University

Paula Bouffard is an Associate Professor at the French Studies Department at Concordia University in Montreal. Her teaching and research interests include French linguistics, French as a second language, the history of the French language in Quebec, and language planning and language policy. Paula recently published the third Canadian edition of Chez nous, branché sur le monde francophone, a complete introductory French teaching program designed for adult learners in the Canadian college and university contexts.

\section{Albert Branchadell}

Faculty of Translation and Interpreting, Universitat Autònoma de Barcelona

Albert Branchadell, BA in Philosophy, PhD in Catalan Language and Literature (both from the Universitat Autònoma de Barcelona) and PhD in Political Science (Universitat Pompeu Fabra). His main areas of research are sociolinguistics, language policy and translation studies. He is currently lecturer at the Faculty of Translation and Interpreting at the Universitat Autònoma de Barcelona. 


\section{Dermot Bryers}

English for Action, London

Dermot Bryers is the chief executive of EFA London (English for Action), a popular education charity he co-founded in 2009. He teaches ESOL in several communities across London, trains teachers in participatory pedagogy and campaigns with students and colleagues on a range of social justice issues. He has also worked as a community organiser for Citizens UK and campaigns consultant for ActionAid's Reflect ESOL project. He studied Modern History and English at Oxford University and has a Masters degree in Development Studies from SOAS. He is particularly interested in the relationship between adult education and taking action to effect change.

\section{Laura Chapman}

Carringbush Adult Education, Melbourne

Laura Chapman teaches ESL/EAL to adult migrants and refugees in TAFE and community settings. She has collaborated on action research in the area of low literacy background learners with limited formal education. Her published ESL teaching resources include the Get Wise series for youth in the Adult Migrant English Program. Laura has delivered professional development training on cross-cultural awareness, intercultural communication and TESOL strategies for low literacy learners. She is particularly interested in community partnerships that facilitate community participation for learners.

\section{Melanie Cooke}

King's College, London

Since 2004, Melanie Cooke has worked in the Department of Education and Professional Studies and the Centre for Language, Discourse and Communication at King's College, London, having previously taught ESOL in London and EFL in Spain. From 2004 to 2008 Melanie worked on ESOL projects for the National Research and Development Centre for adult literacy and numeracy (NRDC). She is particularly interested in participatory pedagogy and the role of socio-political issues in ESOL. Her doctoral research is into the teaching of citizenship to ESOL students. She is the co-author of ESOL: A Critical Guide (OUP, 2008, with James Simpson).

\section{Sandra Doyle}

Laois and Offaly Education and Training Board, Ireland

Sandra Doyle is an adult literacy Resource Worker and ESOL co-ordinator at the Portlaoise Adult Education Centre, Laois and Offaly Education and Training Board. She has over twenty years' experience teaching English and ESOL, providing literacy and language support to adult learners. 
During her teaching career she has initiated and implemented a range of award-winning learner centred adult education projects that demonstrate high levels of collaboration among participant groups. She is a graduate of the National University of Ireland Maynooth and the School of Lifelong Learning and Education, Waterford Institute of Technology.

\section{Douglas Fleming}

University of Ottawa

Douglas Fleming is an Associate Professor in Education at the University of Ottawa. His research and teaching focus on second language education, equity, multicultural communities, qualitative research methods, teacher education and critical notions of citizenship. Prior to entering academia in 2007, Douglas taught for 20 years for the Toronto (Ontario) and Surrey (British Columbia) School Districts. He has over 50 publications and invited contributions to date and has worked on numerous professional, curriculum and materials development projects for government, school districts, teacher associations and NGOs.

\section{Maria Rosa Garrido}

Universitat Internacional de Catalunya/Universitat Autònoma de Barcelona

Maria Rosa Garrido is a member of the CIEN Research Group affiliated to Universitat Autònoma de Barcelona, where she recently completed her $\mathrm{PhD}$ in the field of English Studies. She is an Adjunct at the School of Education at Universitat Internacional de Catalunya. Her research interests include language, mobilities and social exclusion; multilingual approaches to teaching language(s); and the sociolinguistic construction of transnational identities in international NGOs and social movements. She has experience teaching Catalan, Spanish and English as a foreign language in different contexts.

\section{Minna Intke-Hernandez}

University of Helsinki, Finland

Minna Intke-Hernandez is a doctoral student at the Institute of Behavioral Sciences at the University of Helsinki. Her research interests lie in how immigrant stay-at-home mothers build their active citizenship through language education and socializing mother-child activity groups.

\section{Jeanne Kurvers}

Tilburg University

Jeanne Kurvers is Associate Professor in the department of Culture Studies, School of Humanities, Tilburg University, the Netherlands. Her main research interests centre around the fields of literacy and second language acquisition of children and adults. She has participated in 
research projects on literacy acquisition in multilingual contexts in the Netherlands, Eritrea and East Timor. She was co-editor of a special volume of Compare on multilingual literacies in the global south, and has also edited several proceedings of the LESLLA conferences on second language and literacy acquisition of low-educated adults.

\section{Marguerite Lukes}

City University of New York

Marguerite Lukes, PhD oversees Project R.I.S.E. at Internationals Network for Public Schools. The project is a five-year federally funded school reform initiative that supports higher levels of achievement for English language learners (ELLs). Marguerite has taught and directed programs in English as a Second Language, adult literacy and basic skills in English and Spanish, and has designed, implemented and evaluated programs for K-12 and adult education. She received her doctorate from New York University, where she conducted research on educational experiences of immigrant high school non-completers and designed professional development for schools serving immigrant students across New York State. She is on faculty at the City University of New York.

\section{John Lyons}

New York University

John Lyons started his career as an adult education teacher of English for Speakers of Other Languages (ESOL). He has since filled the roles of professional developer, program developer, database manager, grant writer and program director. He has developed and managed programs in ESOL, GED preparation, Family Literacy and Disconnected Youth. His research interests centre around adult literacy teacher quality, adult migrant students, dropouts, disconnected youth and college transition for urban youth. John holds an MA in Language and Literacy from the City College of New York and is completing his PhD in English Education at New York University.

\section{Marilyn Martin-Jones}

University of Birmingham

Marilyn Martin-Jones is an Emeritus Professor based at the MOSAIC Centre for Research on Multilingualism, University of Birmingham. She was the founding Director of the MOSAIC Centre (2007-2010). Over the last 35 years, she has been involved in critical ethnographic research on multilingualism and literacy in classroom and community contexts in the UK. She has a particular interest in the ways in which language and literacy practices contribute to the construction of identities, in local life worlds and in educational settings, and with the ways in which such practices are bound up with local and global relations of power. 


\section{Noëlle Mathis}

Simon Fraser University and Université d'Avignon et des Pays de Vaucluse Dr. Noëlle Mathis is a language and creative writing teacher for adults at university. She recently completed two doctoral degrees in cotutelle - a joint double degree - with Simon Fraser University (Canada) and Université d'Avignon et des Pays de Vaucluse (France). Her PhD dissertation examines plurilingual identities and textual creation in French as a Second Language by taking a sociolinguistic approach to writing workshops. She also facilitates creative writing workshops in the community at large with the non-profit organisation Les Mots Voyageurs (www.lesmotsvoyageurs.com).

\section{Howard Nicholas}

School of Education, La Trobe University

Howard Nicholas is Senior Lecturer in Language Education at La Trobe University in Melbourne, Australia. Between 2001 and 2007 he was Senior Researcher with the Adult Migrant English Program Research Centre, a federally funded research centre between the National Centre for English Language Teaching Research at Macquarie University and the Faculty of Education at La Trobe University. He has held visiting appointments at University of Hawaii, Manoa, Concordia University, Montreal, the University of Western Australia and Paderborn University, Germany. He has published widely in the areas of second language acquisition, language education and learning with mobile devices. His most recent book (with Donna Starks) is Language Education and Applied Linguistics: Bridging the Two Fields, published by Routledge in 2014.

\section{Xavier Oliva}

\section{Universitat Internacional de Catalunya, Barcelona}

Xavier Oliva holds a BA in Primary Education, specialising in English as a foreign language, from Universitat Autònoma de Barcelona and is currently studying for a degree in Educational Psychology at Universitat Oberta de Catalunya. He works as an English teacher with children and adult students at schools in the Barcelona area. He is an Associate Lecturer at the School of Education at Universitat Internacional de Catalunya and runs a workshop on pluriligualism in a socio-educational project at Universitat Autònoma de Barcelona. Nowadays, he carries out action research in the field of Catalan language teaching for newly-arrived migrants.

\section{Sari Pöyhönen}

Centre for Applied Language Studies, University of Jyvaskyla, Finland Sari Pöyhönen is professor at the Centre for Applied Language Studies, University of Jyvaskyla, Finland. Her research focuses on language education policies, minorities and language rights, adult second language 
education, and notions on language and identity. Her recent publications deal with linguistic rights of Russian-speakers in Finland; ethnic and linguistic identities of Ingrian Finnish teachers in Russia; discourses on migration, integration and work; and policies and practices in adult second language teaching.

\section{Vera Sheridan}

School of Applied Language and Intercultural Studies, Dublin City University

Vera Sheridan is lecturer in the faculty of Humanities and Social Sciences, Dublin City University. Dr Sheridan researches identity across educational, organisational and national settings with an interest in social justice. She has published widely in the field of migration, identity and belonging and recent publications include articles on international students, reflection on transition from school to university learning, academic identity, LGB identities and Life in Post-Communist Eastern Europe after EU Membership, edited by Donnacha $\mathrm{O}$ Beachain, Vera Sheridan and Sabina Stan (Routledge, 2012). Current research interests focus on refugees in Ireland, past and present.

\section{James Simpson}

University of Leeds

James Simpson is a senior lecturer in language education at the School of Education, University of Leeds, UK, where he has worked since completing his PhD at the University of Reading in 2003 and where he leads the Language Education academic group. He has two main research interests: the teaching of English to multilingual students in migration contexts, and language learning with new technology in the developing world. He is the co-author of ESOL: A Critical Guide (OUP, 2008, with Melanie Cooke), and the editor of The Routledge Handbook of Applied Linguistics (2011).

\section{Massimiliano Spotti}

Tilburg University

Massimiliano Spotti is Assistant Professor at the Department of Culture Studies of the Faculty of Humanities at Tilburg University, The Netherlands. He is also deputy director of Babylon - Centre for the Study of Superdiversity, at the same university. Among his publications: Developing Identities (Aksant, 2007); Language Testing, Migration and Citizenship: Cross-National Perspectives (Continuum, 2009). He has also been co-editor of two volumes of the Diversities Journal (UNESCO/Max Planck) on language and superdiversity. He is currently involved in a research project on superdiversity and asylum seeking 2.0, examining asylum seeking-related identity practices through social media. 


\title{
Mirja Tarnanen
}

Department of Teacher Education, University of Jyvaskyla, Finland Mirja Tarnanen is a professor of language education (Finnish as a L1 and L2) in the Department of Teacher Education at the University of Jyvaskyla, Finland. Her research interests lie in the areas of language teaching and learning in different settings, and teacher education. Her recent publications deal with migrants in professional communities; policies and practices in adult second language teaching; literacy and assessment practices; learning in multilingual settings; language awareness and beliefs of pre-service teachers.

\section{Anne Whiteside}

English Department, San Francisco State University

Anne Whiteside taught adult ESL and native language literacy for many years at City College of San Francisco, where her research looked at multilingual transnationals, and language development barriers for students with few years of formal schooling. After completing her PhD (University of California Berkeley) she taught linguistics at Universidad de Oriente in Mexico and was part of a team developing the first test of competency in Yucatec Maya for bilingual schoolteachers. She has published on L2 emergent literacy, transnationalism and adult ESL, and lectured in Ireland, UK, France, Spain and Algeria. She is currently a lecturer in a Masters in TESOL program.

\begin{abstract}
Alan Williams
University of Melbourne

Alan Williams is an honorary fellow at the Melbourne Graduate School of Education, University of Melbourne. He worked in TESOL teacher education for over 20 years. He used content-based approaches to ESL when working with school-aged new arrival immigrant students in the 1980 s, and was involved in a number of projects involving content-based approaches to teaching ESL and to meeting the needs of low-literacy ESL learners in adult ESL. He was content manager for the development of the Get Wise teaching materials developed for the Australian Adult Migrant English Program.
\end{abstract}

\section{Becky Winstanley}

Tower Hamlets College, London

Becky Winstanley is an experienced ESOL teacher and teacher educator working in Tower Hamlets and the Institute of Education, London. Her particular areas of interest include participatory approaches to education, emerging language and language and literacy development for social change. She worked on ActionAid's Reflect ESOL project, adapting the international Reflect model for language learning in the UK, and trained 
with Reflect practitioners in Liberia. She has been an active trade unionist for many years and is interested in teachers' and students' struggles in education and beyond.

\section{Heide Spruck Wrigley}

Literacywork International

Heide Spruck Wrigley is president of Literacywork International, where her work focuses on the intersection of policy, research and practice, with projects across the United States and in Rwanda. A Fellow with the Migration Policy Institute's Center on Immigrant Integration Policy, she specialises in adult immigrant education. She has served as adviser to various groups: a panel advising the US Immigration and Citizenship Service; panels of the National Academy of Sciences; the City of Seattle's Office of Immigrant and Refugee Affairs; One America, a national immigrant advocacy group; and the Service Employee International Union. She was a researcher on the American Institutes for Research What Works study, and is lead author of The Language of Opportunity: Expanding Employment Prospects of Immigrants. 


\section{Acknowledgements}

Many people have supported the genesis and development of this book, and we would like to thank everyone who has helped in one way or another. The original idea for the book emerged from a seminar we jointly led at King's College London, and the subsequent paper published in the KCL Urban Language and Literacies series. Thank you to Ben Rampton for bringing us together. Motivation for the book also came from many discussions at the annual meetings of the LESLLA group, a worldwide network of scholars and practitioners concerned with the language and literacy development of adult migrants without foundational schooled experience. We would like to thank too each and every one of the chapter authors, for their unalloyed enthusiasm for the project, for reacting so swiftly and well to editorial queries, and for the important work they do in language education, migration and social justice.

We are each lucky to have a particular person who is a constant and continual source of inspiration, and whom we would like to acknowledge here: (for James) Melanie Cooke; and (for Anne) Claire Kramsch.

With one editor in Yorkshire, UK, and the other in California, US, our editorial meetings have all been online, and have happened at odd times of the day and night. For putting up with this - and for everything else - we would like to thank our families: Mary, Joe, Dan and Lucas (in the UK) and Jonathan, Nina and Hannah (in the US and Spain).

The editors would like to thank Paul Bryers for providing the illustration in Chapter 16. 
This page intentionally left blank 


\title{
Introduction
}

\author{
James Simpson and Anne Whiteside
}

This book is motivated by a recognition that linguistic, political and pedagogic dimensions of language learning in migration contexts are changing fast. National policy responses to the dynamic diversity associated with migration can be uneven and contradictory. At the same time novel pedagogic practices are emerging to enable newcomers to gain access to the languages of wider communication, practices that often involve the adoption of a critical stance. This book brings these two tendencies together, juxtaposing chapters examining the policy landscape with those exploring an aspect of practice in each of nine states in the developed west and north.

As we would expect, there are great differences between the countries that we have included - at the scale of both national policy and local pedagogic practice. However, readers will note that there are commonalities - in some cases startling similarities - too. Through these chapters run two strongly inter-related threads. Firstly, and implicit in the chapters on policy, national government responses to the language learning needs of adult migrants seem to be at odds with what actually happens 'on the ground'. This mismatch is not only in terms of the expected content and focus of language education, but also of the very nature of today's language use itself. Secondly, implicit in the chapters examining practice is a sense that policies that are imposed can also be appropriated, subverted, and interpreted in new ways. Indeed policies themselves can emerge in local contexts of practice.

The book therefore aligns with two current trends in the fields of sociolinguistics and language education. People's mobility, and the mobility of communication, has led to the development of a sociolinguistics of globalisation. Our book likewise addresses a concern with how global processes are played out in the warp and the weft of actual practice (Blommaert 2010; Duchêne et al. 2013). Moreover, in ethnographically informed studies of language policy there is a related concern with scale. Attention in this tradition is upon language policies not as formations created at abstract scales but as processes (Ricento and Hornberger 1996) 
and as locally situated sociocultural practice (McCarty 2011; Johnson 2013). The remainder of this introduction expands on these themes more fully, before we give an overview of the chapters.

\section{One nation one language}

In-migration across the states that are the concern of this book outpaces the development of policies and infrastructure which address the presence of new migrants, and the linguistic diversity that their arrival entails. National policies concerning language education for new arrivals in most states represented here are inconsistent, contentious and contradictory, responding in uneven ways to the dynamic diversity associated with migration. This is not to deny that national governments accept that new arrivals should use the dominant language of their new country. Indeed, political and public rhetoric frequently makes reference to the obligation that migrants have to 'speak our language', often in the name of national unity. Such discourse is informed by deeply entrenched language ideologies, i.e. 'beliefs, feelings, and conceptions about language structure and use which often index the political interests of individual speakers, ethnic and other interest groups, and nation states' (Kroskrity 2001: 1). The ideology of a standard language that should be used in the public (and even private) sphere across a country is particularly well established. This 'one nation one language' ideology is interlaced with other beliefs about national identity, for example the ideal that the nation state should be as homogeneous as possible, and that a dimension of that homogeneity is monolingualism.

The notion of a stable distribution of languages following national boundaries - and indeed the notion of languages as stable and bounded entities - runs counter to lived language experience. Daily language use in migration contexts inevitably involves individuals drawing upon their multilingual repertoire as situations demand (Creese and Blackledge 2011). But although multilingualism is the norm on the ground, monolingualism is hegemonic in many places: that is, it is accepted as an unquestioned common sense 'given' by the majority of people that one language stands above others as having particular status as the national language of the country. Monolingualist policies appeal to and resonate with everyday understandings of the importance of a standard language as a unifying 'glue' for a nation. The mobility of contemporary globalisation presents something of a problem to such fixity, i.e. to the idea of the nation as a fixed entity. The imagined homogeneity of a nation (in linguistic terms) is maintained by national policy and political discourse, but is challenged by mobility and diversity.

A number of the chapters addressing policy in this book engage in discussion of the hegemony of the standard language. Adami describes 
the centralizing tradition in France, where French is promoted as a tool for the integration of migrants in the name of republican universalism. Simpson discusses how in the UK, policy and public rhetoric in recent years promotes the dominance of standard English to counter religious and political extremism. Nicholas explains how in Australia, where an understanding of cultural pluralism has only recently developed, the learning of English has historically been considered part and parcel of the process of assimilation into an Anglo-Australian culture. Wrigley outlines adult migrant language education and immigration policy in the US, which, though confused, is underpinned by a largely unquestioning acceptance of English as the de facto national language. For language users, however, what constitutes the national language is also contested as never before: there is a growing post-national sense not only of English and French but of other languages such as Dutch and Finnish.

It should come as no surprise, though, that the understanding of language education for migrants at the scale of national policy rarely embraces multilingualism, that is, the development of competence in the dominant language as part of a multilingual repertoire. Even in places where multiculturalism is promoted and diversity is embraced, such concern tends not to extend to linguistic diversity. And in some cases, monolingualism is explicitly promoted to counter a view of multiculturalism which understands ethnic communitarianism as ghettoisation (Oakes 2011; cf. Adami, this volume). This sentiment resonates with a concern that where difference is valued, it can still be used to organise society hierarchically. In Hymes' terms (1996) where there is difference, there is inequality. It is certainly easy to marginalise the linguistic 'other', i.e. a user of a language other than the standard or dominant one.

State-driven discourses of homogeneism are somewhat paradoxically also prominent in countries which have some sort of official status as bior multilingual. In those which are engaged in a process of nation building, and in those which have strong regional nationalist movements, such discourses are strongly evident. Branchadell and Bouffard explore the relationship between languages in Catalonia and Quebec respectively. Bouffard describes Quebec's co-option of language in the service of immigration policy to bolster the numbers of Francophone migrants coming in to the state, and hence enhance the position and status of French across Canada as a whole. As Branchadell explains, the status of Catalan has changed greatly in recent years. Under the Franco dictatorship in Spain it was a forbidden language and developed an identity as the language of an insider group. Today Catalan is promoted by political elites and supported by much public discourse and the media as a dimension of Catalan nationalism, and is employed as a tool of nation building as the dominant language of an autonomous state, one that aspires in some quarters to further autonomy from Spain and to 
independence. A contrasting picture of minority language use is evident in Ireland, an officially bilingual country with a symbolically central language, Irish. There is not a great appetite for learning Irish in Ireland's urban centres, where it is little used. Language education for migrants there focuses on English for pragmatic reasons, as Sheridan describes, though in something of a policy vacuum.

\section{Language learning and integration}

Many chapters in this book engage with the notion that understanding and using the dominant language of the new country is a sine qua non of integration and social cohesion. This stance assumes that acquiring competence in the standard variety of a language equips newcomers with the means to navigate a fresh social context. This extends to competence in reading and writing: an assumption is easily made that literacy in the standard variety is a pre-requisite for daily life and is the route to a successful future. From here it is but a short step to another easy assumption - one that many make - that once competence in the language has been achieved, all the problems one faces as a migrant will be solved - as if all social groups using the standard variety are natural allies. But this rests on a misunderstanding of competence: language development, like the development of cultural competence, has no 'end state'. There is no one set of linguistic and cultural resources that suffices to meet the complexities of urban life. Moreover, linguistic homogeneity certainly does not correspond with socio-cultural and political alignment. Speaking the same language does not preclude conflict. There is no doubt that proficiency in the national language - including its written form - can confer advantage, be it economic (finding and keeping a good job, for example) or social (the ability to gain and develop a voice that can be heard in the public domain). But access to the powerful language of a country is not sufficient to overcome unequal distribution of social capital like education (Wiley 2005).

A further question about language learning and integration is 'integration into what?' This is pertinent in an age of globalisation and mobility, where the nation state is no longer the stable entity it perhaps once was. Historically the equation has been that immigrants gain loyalty to a new state and culture by relinquishing ties to older ones: what Portes and Rumbaut (2006) call 'subtractive assimilation'. Today's migrants though need multiple cultural competences and translingual awareness (Canagarajah 2013): their learning of the new language is part of the development of a complex mosaic of multilingual and multicultural communicative competence. Subtractive assimilation becomes obsolete.

Dual nationality, circular stays and sojourns, and online media eliminate either/or scenarios, e.g. affiliation to this country or that one, 
and the social contexts of receiving countries themselves become increasingly diverse and polycentric. New arrivals are not joining an established homogeneous insider group, but are part of globalised, transnational culture. Yet presenting language learning as being for integration discursively positions newcomers as outsiders who are by definition not yet 'integrated'. As Nagel (1986) has shown, states thus create 'ethnic minorities' by treating disparate groups as though they were part of some aggregate defined arbitrarily by a set of external differences from the majority.

An insight into how governments understand integration can be gained by examining how they invest in the participation of new members of society. Integration equates with assimilation into an economically productive workforce. A broad neo-liberal agenda is sweeping the countries that are represented in this book, and others like them, and many chapter authors comment on this. Language education for migrants often aligns with a discourse of employability: access to statutory classes is limited to those seeking work, and content is restricted to job-hunting or generic preparation for low-grade employment - as if people's only concern was finding a job. Such a narrow understanding of language education does not value the economically unproductive, that is, those not in the workforce or actively seeking work. Chapman and Williams and Intke-Hernandez provide examples of programs where the broader concerns beyond employability are addressed, in Australia and Finland respectively. Fleming in Canada shows that teachers' understandings of citizenship go well beyond an instrumental, banal integration of the pliant would-be citizen into the workplace and the administrative culture of the host society. On the other hand, as Lukes and Lyons show, programs in the US designed to provide workforce skills training often require levels of English proficiency and formal schooling that excludes adults with basic level English, interrupted schooling or emergent literacy.

\section{Language and citizenship testing}

A number of the chapters focusing on policy draw attention to a relatively recent arrival on the political scene - the use of language testing in the service of immigration policy in the form of language and citizenship tests. The implementation of these tests varies. The language proficiency required to pass them ranges from high (the UK) to low (Spain). The tests can be prohibitive for less educated adults (the Netherlands) or relatively symbolic, as in the US. They can also be cripplingly expensive.

McNamara and Ryan (2011) suggest we pose two questions about language tests for citizenship, residency and entry to a country: the first relating to their fairness (do they test what they should?); and the second to their justice (should they test what they do?). On the first question, 
Kurvers and Spotti describe an entry test to the Netherlands which is assessed using voice recognition software, seriously disadvantaging applicants whose expert language's phonological system does not relate closely to that of Dutch. On the second question, we might ask, what makes language, and particularly literacy, such an important criterion for entry to a country and for residence? For an answer, we can consider firstly the role of language in the building and shoring up of national identity in the face of progressive globalisation. Secondly citizenship tests often but not always purport to cover general knowledge of the values and customs deemed essential to civic participation. But the level of proficiency required (at least in some countries) hardly ensures the ability to read about or understand debates about political or legal issues, or discussion and critical engagement with the nature of supposed core values. Citizenship tests, as chapters here demonstrate, are not for the benefit of the prospective citizen. In effect they are language and literacy tests acting as gatekeeping devices (Gumperz 1982; Reay 2001) in immigration control.

\section{The CEFR}

A notable feature of both language learning programs and the citizenship and language tests that migrants have to pass to remain in - or even gain access to - their new country is the widespread use of the CEFR - the Common European Framework of Reference for Languages. The CEFR, frequently mentioned in this book, evolved from work begun in the 1970s by the Council of Europe, which aimed to provide a common understanding and set of descriptors of language competence for educated Europeans, to aid the design of language learning programs and assessments (Council of Europe n.d.). Today's CEFR has six levels, from Al ('the ability to communicate in short and simple sentences in a familiar context') to C2 (near-native use of oral and written language). The CEFR has become widely used as a description of what constitutes acceptable language performance remarkably quickly, and in recent years in learning contexts beyond those originally envisaged (e.g. in schooling for migrant children; in assessment of adults with little competence in literacy). This, as well as its employment outside Europe, and its inappropriateness in situations of linguistic diversity, has received critical comment (Leung and Lewkowicz 2013; Janssen-van Dieten 2006), as has its use as a benchmarking tool for the requirements of language and citizenship. On that point, the CEFR is used (or abused) as a very effective gatekeeping device. Extreme examples of this tendency are seen in the Netherlands and the UK (as described by Kurvers and Spotti and by Simpson, this volume). In these cases visa applicants have to pass language tests at particular levels on the CEFR even before they enter the 
country. This in effect extends a country's borders globally, with profound implications for peoples' mobility and their family lives (Blackledge 2014).

\section{Divergent themes}

A contribution of this book then is to uncover certain commonalities: a mismatch between national policy and practice on the ground; the tendency of policy to treat languages and literacies as singular, homogeneous, autonomous and stable entities when they are not. Although commonalities abound, apparent also in the chapters addressing policy are idiosyncratic patterns in the development of migration policies related to divergent geographical, historical and ideological factors. In terms of geography, the long, sparsely populated US border has facilitated the historical exploitation of Mexican guest workers (braceros) and undocumented laborers. Canada, with its vast under-populated areas, has embraced immigration, whereas Australia, with its Anglo majority but its proximity to Asia, has a history of exclusionary migration policies. Post-colonial and imperialist ties with 'sending' countries have characterised much policy, except in countries with no such historical relationships (e.g. Finland and Ireland). Countries with long histories of inward migration like the US, the UK and France, and historically diverse populations, have layered trajectories in language integration policies, in contrast to Finland and Ireland, both historically sending countries which are experiencing population diversity for the first time.

Also notable in these chapters is the hand national ideology plays in policy discourse. Terms common to the discourses of immigration in the UK and US like 'ethnic community' and 'multiculturalism' are understood differently in France, for example, where the core concept of fraternité makes a recognition of diversity problematic (Oakes 2011). And in the US, federalism versus individual State rights are crucial factors in debates about immigration reform.

\section{Challenges to teaching practice}

The political battles and unresolved migration and language policy debates of recent years have dealt adult immigrant language education a series of blows, setbacks and reversals. A concern identified by a number of the chapters on policy is that while new arrivals are exhorted to use the dominant language of the new country, opportunities to learn that language are often difficult to identify. Migrants tend to understand the importance of being able to gain access to the powerful language of their new environment and the powerful varieties of that language. For many, therefore, learning the language is a primary concern. Yet in most states represented in this volume the trend is towards cutting funding and 
shifting responsibility for language education to charity-based and other non-governmental agencies. This has often been done in the name of austerity, in response to economic downturns.

There are exceptions: France and Quebec have increased public control over language programs. Finland still provides relatively generous subsidies for immigrant language study, although right wing political opposition to immigration there is growing, placing funding under threat. In the US the picture is mixed: public funding ignores bilingual and literacy programs despite their recognised effectiveness, and language planning efforts linked to immigration reform are thwarted by political stagnation.

The nine chapters in this volume focusing on teaching practice are rays of light in a rather gloomy sky. There is an unintended but beneficial consequence of governmental indifference towards - and abrogation of responsibility for - adult migrant language education: spaces open up for experimentation and the development of approaches to teaching more suited to the realities of migrants' lives in superdiverse, multilingual neighbourhoods and workplaces. These are spaces where tensions related to perceived ethnic, racial, class and cultural difference are rife. The teaching practices described in these chapters represent creative and resourceful responses to the challenges of transnational migration. Rather than shying away from complexities, the approaches described here put them front and centre, considering them affordances for developing language, critical awareness and agency.

Their authors demonstrate the need for experienced and linguistically trained teachers, knowledgeable in emergent literacy and bi-literacy, and with some cultural competence and linguistic awareness of the populations they serve. Yet ironically, as the need for a broader cultural and linguistic knowledge base grows, funding reductions in many cases have instead led to the deprofessionalisation of teaching: teachers of marginalised students are themselves forced to the periphery, and ill-funded programs rely on unpaid or part-time workers. The studies in our book depict resourceful teachers who compensate for lack of funds by creating their own materials, enlisting higher-level students to do translations and interpreting (as in Catalonia) and drawing upon volunteers (as in Ireland). These solutions are hardly sustainable long-term. The broad pattern of reduced funding has also diminished access to statutory classes for working adults, with hours of instruction diminished to inadequate levels (from 20 to two-four per week in Ireland; in Catalonia, the entitlement is a total of 45 hours). Many of the courses described were of short duration (in the UK 'Whose Integration?' lasted five weeks) or a scant few hours (in Finland and Ireland, two hours per week).

The authors of the practice chapters, all experienced and well-qualified teachers, show the difficulties of designing and implementing programs 
that provide relevant language learning experiences for communication in the various domains of life encountered by new arrivals, and for critical examination of those domains. As we noted earlier, and as Nicholas (this volume) points out, new immigrants need explicit help with understanding and adapting to increasingly plural and complex contexts and the linguistic and cultural challenges they pose.

\section{Challenging policy agendas with innovative classroom practices}

As McCarty (2011), Hornberger and Johnson (2007) and others have shown, bottom-up language planning and policy is actualised by incremental shifts in discourse practices at the ground level. In these chapters on practice, we detect the beginnings of a seismic shift in the discourses of monolingualism and the practice of teaching a national language to newcomers. The teachers and researchers involved have rejected a language pedagogy that focuses only on the transmission of language facts. They recognise that adult migrant language students are often plurilingual but with what Blommaert refers to as 'truncated repertoires' (Blommaert 2010) - that is, only limited competence in a number of languages and/or their scripts. The authors recognise that the students have varying degrees of literacy in several scripts to begin with, that some may have missed out on formal education as children; and that they may have little exposure to the host country national language in their daily lives. In adult migrant language education classes, policy tends to be realised in practice. For example, the dominant language is normalised while others are marginalised, or it is over-interpreted as the language of equality and emancipation. The classrooms described in this book, though, are spaces where multilingualism, translanguaging and interculturality are the norm, where hybrid forms are accepted, where teachers explore and then draw on students' linguistic and non-linguistic communicative resources, available designs (Kern 2000) and skills to gradually help them increase their control over their participation in their new contexts.

\section{'Teaching does not go from top down'}

All of the chapters on practice reject pre-designed syllabi in favour of emergent curricula. The authors describe classroom dynamics that shift responsibility for decisions about content to students. Intke-Hernandez in Finland for example describes a family learning program where the students - the mothers - effectively control the learning. Some show how local assessments of needs determine topics. Doyle in Ireland explains how her students experienced racism locally, and racism became a topic. 
The programs our book describes see teachers as facilitators who can help students - who are in many cases subject to social inequality - transform their lives through increasing critical awareness of and control over new social relations, language practices, and access to resources (they become 'justice-oriented' citizens, as described by Fleming in Canada) and promote a sense of citizens as agents who transform their contexts (e.g. the projects in Australia outlined by Chapman and Williams).

\section{'Whose Integration?'}

The teachers who are the authors of these chapters adopt a critical approach to engagement with language and literacy, understanding that the new language is used to read 'the word and the world' (Freire and Macedo 1987). Some describe explicitly Freierean pedagogy (e.g. Cooke, Winstanley and Bryers, in the Whose Integration? project). Recognizing that unschooled migrants in particular face further marginalisation, the teachers strive to avoid delegitimizing students with little or no formal education. These students are referred to in some chapters as 'LESLLA' students, i.e. Low Educated Second Language and Literacy Acquisition, after an international group of teachers and language acquisition researchers of that name which has advocated for these students in particular (see www.leslla.org).

Criticality for Garrido and Oliva in Catalonia means including students' multilingual voices and experiences in pedagogy. For Mathis in France, it entails making room in higher education for the complexities of plurilingual identities in student writing. Critical of what they see as national agendas that promote docile, assimilated citizens (e.g. chapters by Fleming; Spotti and Kurvers) the authors here express a strong commitment to social justice and equity. They view integration as a two way street, recognizing the rationality of choices and strategies immigrants use to manage their new circumstances (Doyle in Ireland). The teachers encourage their students to challenge stereotyped and assigned identities (Mathis in France). They invite discussion of race and class and differences in cultural values, using these discussions to introduce vocabulary and structures (Cooke, Winstanley and Bryers in the UK).

\section{'This is not just learning. This is being with people'}

A focus on communicative competence in second/other language teaching has led to the production of language learning materials which imagine prototypical communicative events. These often bear little resemblance to the lived experiences of poor and marginalised immigrants, who are more likely to encounter supermarkets where no one talks, recalcitrant bureaucrats, impatient doctors. Language learning materials produced 
specifically for immigrants also tend to focus on heavily functional language, dealing with basic survival and adjustment to life in the new country. The chapters on practice in this book all describe language learning as being situated, i.e. not idealised versions of national culture, but grounded in the realities of local practice. The authors of these chapters push beyond 'survival' language by taking their cues from concrete local experiences, shifting control over topics and activities to students, whose experiences then drive the curriculum (Australia, Finland). Using these activities as context for language practice, students are socialised into particular activities such as filing legal complaints ('It's Your Right', Australia), accessing health care (Spain), attending parentteacher conferences (Finland) and using language as a vehicle for increased participation.

\section{New agendas for the top}

Although the programs described in these chapters are a mere drop in the ocean of adult migrant language education, they offer insights into the efficacy of locally situated curricula, collaborative projects and partnerships. For example, Doyle describes adult education which involves links between new arrivals and the local population. Programs described here are flexible and differentiated: Chapman and Williams introduce us to a course with a focus on water safety for 16-24-year-olds and the 'Hands on English' program for older adults in Australia; Spotti and Kurvers compare programs involving differentiated digital literacies in the Netherlands.

There are considerable difficulties in implementing the approaches advocated in the book, such as emergent and critical curricula, on a large scale or at institutions and in policy regimes where accountability requires standard and predictable outcomes. Yet the stakes are high: where immigrant populations are not given the opportunity to develop competence in the dominant language of their new country they risk being denied a voice with which to challenge the conditions of their lives. There are way-marked paths: Luke (2000) discusses the institutionalisation of critical literacy in adolescent education in Australia. He suggests that two keys to the effective implementation of critical approaches are 1. state accountability systems that do not rely on reductionist measures of progress and 2. a teaching core willing to engage with new theories. This is not straightforward, and implies a need for cultural change in national policy, in inspection regimes and in teacher education. As Auerbach (2001) acknowledges, adopting critical language teaching poses considerable challenges in each new context. Nonetheless policy makers have much to learn from models which support mutual engagement with, and engagement between, newcomers and an established population, 
where all voices are heard. Bringing together overviews of the policy landscape and examples of practice in different places makes it possible for those in policy roles to learn from an array of practitioners and their students. Our chapters on practice suggest that what happens locally -i.e. policy-making on the ground - is more salient than much national policy. This is particularly the case where national policy is falling away, is incoherent or lacks direction.

Our initial aim in fact was to represent a broader range of countries in this book, to encompass other global areas. This would, we felt, avoid promoting a discourse of 'global core' versus 'global periphery', of north versus south. However, the exigencies of publishing precluded this. We hope this book will inspire others to continue the enterprise and to examine practice and policy in adult migrant language education in countries with yet more diversity of experience.

\section{Overview of chapters}

There are eighteen chapters in this book, two chapters for each of the nine countries covered, addressing - in turn - policy and an aspect of practice in adult migrant language education.

Howard Nicholas traces the contentious history of language policy in relation to migration in Australia, from an Anglo-Australian past to the contested multiculturalism of today. He frames his discussion around the idea of two competing axes: the first orienting towards the continued dominance of English, and the second towards an inclusive yet contested linguistic pluralism and multiculturalism that better reflects Australia's geographical location on the Pacific rim. His chapter echoes other shifts, in particular towards a narrow understanding of language learning in the service of employability in a neo-liberal world order. He argues that a language policy that would effectively counter this shift is frustrated for want of a clear understanding of an integrated view of plurilingualism and a corresponding inability of those in authority to change language practices.

In their chapter on practice in Australia, Laura Chapman and Alan Williams identify and discuss four English language and literacy programs for young adult migrants without foundational literacy in their expert languages. They describe these programs as transformative, in that they combine instruction in language and literacy with practical engagement with local communities: such engagement, suggest Chapman and Williams, has the potential to change the communities themselves as well as the new arrivals who are joining them. The role of the teacher in the process is as an advocate in the community, a participant in the activities, and a learning mentor. The four examples are drawn from the authors' prolonged involvement with the programs, including participation in action research and materials development projects. 
Paula Bouffard describes the evolution of language policy in Quebec, charting attempts by Quebec's governments to manage migration, integration and policy on French language and language learning for adult migrants. Grounding her arguments on detailed accounts of the demographic make-up of Quebec from the eighteenth century to the present day, she considers the position of English and the maintenance of French in a predominantly Francophone province, though one where a dominant francophonie across the province masks a number of key issues at more local level. Her general position is that an ongoing process of francization - broadly desirable in her view for reasons of unity in this language-minority province, is threatened by faster migration to nonfrancophone parts of Canada, and by a lack of recognition by new arrivals of the role of French in Quebec's daily life.

Douglas Fleming contrasts the ideologies encoded within a key Canadian language policy document with the views of experienced teachers of English for migrants to Canada in his qualitative study of teachers' orientations towards citizenship. His analyses of successive iterations of the Canadian Language Benchmarks (CLBs) lead him to conclude that citizenship is treated in a cursory way in this document, which provides the basis of language programs for adult migrants across Anglophone Canada. In its more recent iteration, the CLB treats only 'responsible' citizen participation, but notably absent is a concept of citizen whose agency includes the pursuit of justice. In contrast ESL practitioners espouse forms of active and justice-oriented citizenship in their teaching. Fleming finds that they integrate meaningful citizenship content into pedagogy, even for beginner learners, either explicitly or implicitly.

Albert Branchadell, in his chapter on language policy in Catalonia, notes parallels and differences between his context and Quebec. Like Quebec, Catalonia has a status as an autonomous region (or 'minority nation') within the sovereign state (in this case, Spain). Unlike Quebec though, it has no specific control over matters of immigration. A very strong ideology, however, promotes Catalan as the language of Catalonian unity, driving regional demands that newcomers should learn the language, a move somewhat undermined by Catalan's status as a language of affiliation rather than one of habitual use. The chapter describes efforts by successive Catalan governments to strengthen the position of the Catalan language in society, including a string of policy moves that aim to put conditions in place for the tuition of Catalan for new arrivals, which are currently under-resourced and have had varying degrees of success.

Maria Rosa Garrido and Xavier Oliva demonstrate how an established volunteer-run program for teaching Catalan integrates the multilingualism and polyvocality inherent in the lives of the young homeless migrants whom it serves. The program adopts a critical perspective on a teaching and learning context whose teachers hitherto had subscribed to a 
monolingualist ideology, and who had previously discounted students' non-European language backgrounds. The authors - teacher-researchers on this action-research project - were able to transform it into a program based on Freirean principles which admitted other languages into the classroom, and hence freer expression of identity, reflecting the hybridity of language use that the students encounter in their daily lives.

Sari Pöyhönen and Mirja Tarnanen document the trajectory of Finnish language education policies. They draw upon Johnson's (2009) distinction between policy creation, interpretation and appropriation in the policy-making process, noting how policies developed at a national scale can be appropriated and contested by locally based practitioners. They identify five phases in immigration policy and discourse over the past five decades, culminating in the phase of 'contested immigration'. This is a familiar notion in current sociopolitical life: the discourse of migration has become 'heavily problemoriented' to use the authors' term, a pattern repeated across many of the countries represented in this volume. Other aspects of the situation Pöyhönen and Tarnanen describe in Finland will also resonate with readers familiar with the contemporary European political landscape. In particular they will recognise the accompanying rise of the populist right, and a neo-liberal discourse of language education for employment training.

Minna Intke-Hernandez describes a Finnish language education program, the Capable Parent program, for a sector often invisible to the workforce education agenda: stay-at-home mothers. Adopting an ethnographic approach to her study of the teaching and learning at a family centre near Helsinki, she came to understand that 'the learning was in the hands of the mothers themselves'. As she notes, being a mother in a new country creates a certain imperative to gain access to the language of public life in that country. Yet at the same time, the demands of caring for young children severely restricts parents' access to mainstream language learning opportunities. A participatory program, drawing on the concept of shared 'funds of knowledge' (Moll et al. 1992) redresses this situation for the students in this program, and moreover includes the children themselves in the learning experience.

Hervé Adami, in his chapter on immigration and language policy in France, describes a brand new framework for the provision of French for Integration recently introduced, which through its funding mechanisms has introduced a new level of competition into the field of French language education for adult migrants. He draws attention to a position often overlooked in arguments promoting multiculturalism: that is, that inequality is inherent in diversity. This, he suggests, is at the root of a claim that favors linguistic homogeneity above the multilingualism that is part and parcel of contemporary multiculturalism. Adami aligns himself with this position, which stems from a firmly held understanding of standard French as the language of democracy and the revolution. 
A contrasting position on multilingualism in France is taken by Noëlle Mathis, however. She maintains that at least in pan-European-influenced official discourse, multilingual education is encouraged. She does however point out that very few teachers adopt a multilingual stance in their language classrooms. She draws a distinction between multilingualism (with a focus on societal contact) and plurilingualism (with a focus on the individual). In the writing classes for tertiary-level students that she devised and describes in her chapter, learners are encouraged to draw upon the full extent of their linguistic repertoires as a means to encourage language learning, plurilingual competence and plurilingual identity development. Her work stresses the importance of valuing the less powerful, usually silent 'other' voices of individual language and literacy learners. She ends with a call for such valorisation to extend beyond the classroom.

Vera Sheridan discusses the curious position of English in Ireland, and describes sustained, continuing and competing efforts to develop an appropriate policy framework for - and understanding of - the country's new ESOL learning population. The Irish language, today not widely spoken, holds a special historical and cultural status, whereas English, the language of the colonial power, is widely used but little discussed at policy level: as Sheridan puts it, English is 'everywhere and nowhere'. She sketches out five 'overlapping shifts in attitude' towards ESOL provision in Ireland, broadly corresponding with phases of inward migration to this small country where out-migration until recently was the norm, and with corresponding oscillations in Ireland's economic fortunes. Current government policy is to promote both Irish and English, positioning the latter as the language of international communication.

In Sandra Doyle's chapter, the practitioner's voice is clearly audible as she describes a grass-roots learner-centreed ESOL program in an area of Ireland experiencing migration-related social diversity for the first time. Doyle's work in Portlaoise has a focus on enabling new arrivals in this small Irish town to participate locally. The project engages with the concept of integration by recognizing it as a 'two-way street': taking a 'whole centre' approach to practice, the activities on the program involve new arrivals, longer-term residents and the local-born population in a series of activities, including addressing racism at a local level. Doyle's project was introduced at a time of budget cuts and the continued marginalisation of ESOL in policy. Thus she draws attention to a political tendency that encourages migration in times of plenty, yet fails to put in place an infrastructure to support the development of their social and linguistic capital once migrants have arrived.

Jeanne Kurvers and Massimiliano Spotti describe the recent introduction of successive policies which restrict the ability of migrants to gain access to, and residence in, the Netherlands. Language and literacy are heavily implicated: the authors describe in detail the requirements of 
both the tests that applicants for citizenship have to take when they are in the Netherlands, and the new language tests to be taken in people's home country even before entry. They explain how these tests especially disadvantage people who do not come from literate backgrounds and whose schooled experience is minimal or non-existent. They associate the progressive raising of the language barrier with a strongly antiimmigration turn in Dutch political life.

In their corresponding chapter on practice in the Netherlands, Massimiliano Spotti and Jeanne Kurvers report on a project examining three innovative ICT-based applications designed to support language and literacy development for new arrivals. They identify both the benefits and the shortcomings of these, illustrated with case study data. The original research was sponsored by the European Commission, and they note at the outset that both language education and digital inclusion are prominent in EU policy. While the applications described would seem to support such inclusion, the authors note that their successful use depends on a measure of knowledge of the new language and of computer literacy, rendering them inaccessible to those with no previous experience of ICT or indeed literacy.

James Simpson contrasts policy responses to linguistic diversity in the UK to the heterogeneous reality of daily life for adult migrant learners of English for Speakers of Other Languages (ESOL). He argues that the policy rhetoric surrounding English and migration is underpinned by an ideology rooted in the concern to strengthen the borders of the nation state. Tracing the history of ESOL provision from the 1960s to the present day, he notes a contradictory condition that despite the persistent demand that migrants learn English, opportunities to do so are increasingly curtailed. State provision of English classes is only available to particular groups, and the ESOL sector is increasingly marginalised, fragmented and un-funded.

Melanie Cooke, Becky Winstanley and Dermot Bryers report on an action research initiative where they, the teacher-researchers, explored critical participatory ESOL pedagogy with their adult migrant students in London. The authors describe their work as part of a growing movement in UK ESOL practice which draws upon Freirean-inspired techniques that relate language and literacy learning to the critical concerns of students' lives, and on the students' own terms. This, they suggest, can equip students with critical skills which can be transferred beyond the classroom to effect social action. Their example is the Whose Integration? project, addressing a contemporary concern of which - as Cooke and colleagues put it - 'ESOL students are often the referents, but about which they are rarely asked their opinions'.

Heide Wrigley explores contemporary debates on US immigration reform. An entrenched English Only ideology argues that English 
proficiency (of an indeterminate level) should be required for legal residence ('Green Card English'). This exploration is in the context of adult English language provision that is fragmented and under-funded. Focusing on the half million migrant youth in the US with little or interrupted learning, Wrigley notes federal and state obstacles to funding programs for this group, and describes foundation-funded initiatives that have stepped in. As for reform, there is no consensus on the standing of English vis-à-vis the multiplicity of languages in common use, or what to do about the significant numbers of long-term residents without legal status. This, combined with legislative stagnation resulting from an increasingly polarised electorate, renders the future of public initiatives unclear.

Marguerite Lukes and John Lyons point out how diverse migrant language learners in the US are, across a number of dimensions - not only place of origin and language background, but age, educational and work experience, knowledge of literacy, inter alia. Their chapter concerns community-based programs in New York catering for migrants with little schooled experience, including first language literacy programs, how they succeed and how, currently, they are under threat as never before. The marginalisation of this population of learners relates to the predictable practical issues concerning funding but also to a strong monolingualist streak in adult education discourse in the US.

\section{References}

Auerbach, E. (2001) 'Yes, but...': Problematizing participatory ESL pedagogy. In P. Campbell and B. Burnaby (eds) Participatory Practices in Adult Education. Mahwah, NJ: Lawrence Erlbaum Associates, 267-306.

Blackledge, A. (2014) Language, marriage, migration and the law. Presentation at Sociolinguistics Symposium 20, Jyväskylä, Finland, 16 June 2014.

Blommaert, J. (2010) The Sociolinguistics of Globalization. Cambridge: Cambridge University Press.

Canagarajah, S. (2013) Translingual Practice: Global Englishes and Cosmopolitan Relations. London: Routledge.

Council of Europe (n.d.) The Common European Framework of Reference for Languages: Learning, Teaching, Assessment. Available online at www.coe.int/t/dg4/linguistic/ Cadre1_en.asp (accessed 16 December 2014).

Creese, A. and Blackledge. A. (2011) A separate and flexible bilingualism in complementary schools. Journal of Pragmatics 43: 1196-1208.

Duchêne, A., Moyer, M. and Roberts, C. (eds) (2013) Language, Migration and Social Inequalities: A Critical Sociolinguistic Perspective on Institutions and Work. Bristol: Multilingual Matters.

Freire, P. and Macedo, D. (1987) Literacy: Reading the Word and the World. London: Bergin \& Garvey.

Gumperz, J. (1982) Discourse Strategies. Cambridge: Cambridge University Press. 
Hornberger, N. and Johnson, D. C. (2007) Slicing the onion ethnographically: layers and spaces in multilingual language education policy and practice. TESOL Quarterly 41(3): 509-532.

Hymes, D. H. (1996) Ethnography, Linguistics, Narrative Inequality: Toward an Understanding of Voice. London: Taylor \& Francis.

Janssen-van Dieten, A. M. (2006) Common European Framework of Reference and L2 learners with a low level of education. In I. van de Craats, J. Kurvers and M. Young-Scholten (eds), Low-Educated Second Language and Literacy Acquisition: Proceedings of the Inaugural Symposium, Tilburg University, August 2005. Utrecht: LOT, 143-153.

Johnson, D. C. (2009) Ethnography of language policy. Language Policy 8: 149-159.

Johnson, D. C. (2013) Ethnography of language policy: theory, method and practice. International Journal of the Sociology of Language, Special Issue: 219.

Kern, R. (2000) Literacy and Language Teaching. Oxford: Oxford University Press.

Kroskrity, P. (2001) Language ideologies. In J. Verschueren, J-O. Österman, J. Blommaert and C. Bulcaen (eds) Handbook of Pragmatics. Amsterdam: John Benjamins.

Leung, C. and Lewkowicz, J. (2013) Language communication and communicative competence: a view from contemporary classrooms. Language and Education 27(5): 398-414.

Luke, A. (2000) Critical literacy in Australia: a matter of context and standpoint. Journal of Adolescent and Adult Literacy 43(5): 448-461.

McCarty, T. L. (ed.) (2011) Ethnography and Language Policy. New York and London: Routledge.

McNamara, T. and Ryan, K. (2011) Testing identity: language tests and Australian citizenship. In C. Norrby and J. Hajek (eds), Uniformity and Diversity in Language Policy: Global Perspectives. Bristol: Multilingual Matters.

Moll, L. C., Amanti, C., Neff, D. and Gonzalez, N. (1992) Funds of knowledge for teaching: using a qualitative approach to connect homes and classrooms. Theory into Practice 31(1): 132-141.

Nagel, J. (1986) The political construction of ethnicity. In J. Nagel and S. Olzak (eds), Competitive Ethnic Relations. Orlando, Florida: Academic Press, 93-112.

Oakes, L. (2011) Regional languages, the European Charter and Republican values in France today. In C. Norrby and J. Hajek (eds), Uniformity and Diversity in Language Policy: Global Perspectives. Bristol: Multilingual Matters.

Portes, A. and Rumbaut, R. G. (2006) Immigrant America: A Portrait (3rd edn). Berkeley: University of California Press.

Reay, D. (2001) Finding or losing yourself? Working class relationships to education. Journal of Education Policy 16(4): 333-346.

Ricento, T. and Hornberger, N. (1996) Unpeeling the onion: language planning and policy in the ELT professional. TESOL Quarterly 30(3): 401-427.

Wiley, T. G. (2005) Literacy and Language Diversity in the United States. Washington D.C.: Center for Applied Linguistics. 


\title{
Shaping Australian policy for Australian adult migrant English language learning
}

\author{
Howard Nicholas
}

\section{Introduction}

Although now seen as exemplary, Australian language policy has a fraught history that is, in many ways, anything other than principled. From early beginnings where language policy was used to exclude specific non-Europeans, there evolved a much more positive and comprehensive framework culminating in the publication of a government language policy statement in 1987 after a process that began in 1982 with a Senate Enquiry. However, key features of the design and implementation of that framework undermined its potential.

The initial surge in the development of adult ESL policy began when Australia was 'safely' distant from sources of migration. Potential migrant and refugee settlers could be taught in the relative quarantine of the sixweek boat trip from Europe to Australia and then dispersed throughout the country to where jobs were available. In a climate of economic growth and almost universal yearning for security and political calm, and at a time when migration focused on groups who were minimally different from the dominant Anglo cultural group, English language learning was constructed instrumentally in terms of both language learning and cultural assimilation. Both language and culture content were framed as 'Anglo-Australian'. With high employment and economic growth, language learning was often part-time, stretching over years and without constraints on resources.

As migrant and refugee populations have diversified and economic circumstances tightened, the provision of support has also narrowed. It has narrowed in terms of time and access, but also in terms of its cultural and linguistic content. This results in a contradiction. The entering communities need more explicit and extended exploration of a 'new cultural system'. At the same time, the 'new cultural system' is far less clear than it was and the nature of the cultural interaction requires negotiation by all parties. In daily life, there is a high level of accommodation to cultural diversity, but there remain larger tensions as a result of insufficiently powerful frames for engagement with pluralism 
(multiculturalism) that acknowledge the complex, varied and pervasive nature of pluralism (see Martin 1976).

In part the lack of clarity about this new culture is a result of an active and profound embracing of a philosophy of multiculturalism that has been given distinctive urgency by the recognition of the so-called 'Asian century'. In part it is because the shifts in the population have given rise to issues in cultural values that are more profound than the original framing of multiculturalism allowed for. In the face of these shifts, tightening economic circumstances have limited the amount of English language learning that is supported on an essentially arbitrary basis, and efforts to combat potential unemployment have led to a radical narrowing of the focus of English language programs. This has also led to separation of the dimension of economic (workforce) preparation from the dimension of cultural engagement (settlement). In this chapter I explore these tensions and their implications for adult ESL provision.

As the above comments foreshadow, Australian migration and language policy history is characterised by two competing axes. The first axis reflects the establishment and preservation of English as the dominant language of the nation. The second and competing axis is built around attempts to create a more diverse and inclusive culture in which multilingualism and multicultural perspectives are more positively and proactively embraced. These axes sit in an uneasy relationship with one another, revealing an antagonistic embrace of varying degrees of severity. In addition to the obvious tension between the monolingualism of the one axis and the multilingualism of the other, the multilingual axis is further divided between a fragmented (monolingual) and an integrated perspective on what it means to be plurilingual (Grosjean 1985, 1989). Grosjean's identification of the idea of fragmented bilingualism (two or more separate languages in the one body) helps understand how policy can deal with only one of the languages of a plurilingual in isolation from the other languages that are part of that person's life. Fragmented perspectives contrast with integrated perspectives that acknowledge the totality of the plurilingual's resources and therefore motivate/mandate engagement with all aspects of that plurilingualism. A fragmented perspective sees an adult plurilingual as, for instance, (only) a learner of English. An integrated perspective acknowledges and connects with the other languages that that person has access to.

This unrecognised triangular set of influences has given the development of adult English language learning policy an uncertain base for what appears on the surface to be a strong shift from exclusion to inclusion (see Nicholas 2015 for discussion of this issue in relation to languages other than English in schools). The dynamics within the relationship are motivated by interactions of principled and pragmatic factors that are sometimes not as different as they appear and reflect a 
complex interplay of local and international forces. Fragmented plurilingualism limits engagement with the full potential of the user's communicative resources (Nicholas and Starks 2014) and as a result English language programs with such framings get trapped in a monolingual framing of $+/$ - English.

\section{Early beginnings}

'Australia' as the continent is now known has a much longer history than is sometimes realised. After some 40,000 to 60,000 years of population by up to 250 different Aboriginal language groups, it was only in 1788 that the British colony of New South Wales was established. The initial location of this colony was in and around what is now Sydney. With English consequently established as the language of potential power, there was the beginning of a tension between a desire for overall control and the necessities of local and/or sectional communication that has continued in various forms over the subsequent $200+$ years.

As successive separate British colonies were established to cover the current territory of Australia, this tension between overall control and local practices was elaborated and codified in distinctive pieces of legislation. When gold was discovered in different colonies from roughly the middle of the nineteenth century, mass migration from many different parts of the world led to various colonial governments using language proficiency as a migration control mechanism. In what would become an increasingly overt additional tension, this tool was characterised by a perversely 'inclusive' approach designed to achieve maximum discriminatory effect. In keeping with a general intention to create/preserve the dominance of a 'European/ English-speaking' population, the various pieces of legislation/regulation focused on excluding Asian, mainly Chinese, gold-seekers by use of a dictation test in 'any European language'. Port inspectors were instructed to identify any European languages that the unwanted person could NOT speak and then to administer the dictation test in one of those languages. The intention to exclude particular populations became entrenched in the spirit of the new Federation in 1901. Intent on controlling migration to achieve an English-dominant monoculture, the seventeenth act of legislation passed by the parliament of the newly minted Australian Federation in 1901 was an Immigration Restriction Act to be administered by the Department of External Affairs.

Section 3 of the Immigration Restriction Act stated that among various classes of prohibited immigrants would be:

Any person who when asked to do so by an officer fails to write out at dictation and sign in the presence of the officer a passage of fifty words in length in an (sic) European language directed by the officer ... 
In speaking to the act, the Parliament of Australia's (2012) official record noted that the then Prime Minister, Edmund Barton stated:

I do not think either that the doctrine of the equality of man was really ever intended to include racial equality. There is no racial equality. There is that basic inequality.

But the same Act also noted in Section 19 that:

This Act shall not apply to the immigration of Pacific Island labourers under the provisions of the Pacific Island Labourers Acts, 1880-1892, of the State of Queensland.

This contradiction built into the Act between Section 3 and Section 19 makes overt the tension between the enactment of general principles and the pragmatic adjustment to local needs. The general principles were often negative in their exclusionary and discriminatory design and effect. While appearing different, the local pragmatism was not necessarily better motivated, shaped in this case by a need for a cheap source of labour for the sugar cane industry in Queensland.

In 1905 the Act was amended to permit the test to be administered in 'any prescribed language', which while on the one hand appearing to be more inclusive, on the other hand only increased the capacity of assessing officers to choose a language not spoken by the particular applicant (Parliament of Australia 2012).

A similar disingenuous phrasing was used during the First World War in efforts in various states to prevent German-English bilingual schools from continuing to operate as they had, in some cases, for more than fifty years. As these schools were not government schools, legislation was passed in various states to prevent instruction in private schools in subjects other than 'languages' in languages other than English. In some cases, e.g., Victoria, this legislation lasted until around the turn of the twentieth/ twenty-first centuries even if it was ignored in practice in the latter part of the twentieth century. Again, the specific language of the targeted group was buried in a more general phrasing.

In these early phases of the new nation increasing the population was a priority, but non-English-speaking migration was discouraged. In attempting to address this contradiction, increasing emphasis was placed on the (sometimes assisted) migration of settlers from Britain under the auspices of the Empire Settlement Act 1922. The tension between general principles and pragmatism continued. The general principle was one of increasing the population while retaining the presumed English-speaking character of the populace and so keeping the program under strict control was required. Pragmatic solutions were developed through which 
migrants from Italy, Greece and Macedonia were not granted high profile even though some of them were also assisted to migrate. One example of such a pragmatic solution was the admission of Afghan camel drivers when there was a need to sustain work in desert environments to build railways or explore for gold in the late nineteenth century (Kabir 2010: 41ff). While Afghans were clearly understood as not conforming to the English-speaking priorities of the time, their roles and location kept them 'neatly' separated from dominant groups. Whether they were preferred because they came with the camels or because they could be paid less, both dimensions allowed a convenient local, pragmatic solution.

\section{Major re-orientations}

Only in 1945 did Australia seek to develop a more inclusive approach to migration. In doing so, a distinct Department of Immigration was established to take over responsibility from the Department of the Interior and to actively promote migration from a wider range of source countries. This shift in general principles was brought about by the pragmatic need to expand Australia's industrial base, a need that had been made dramatically obvious by the experiences of the Second World War.

While the Commonwealth had responsibility for immigration, States retained formal responsibility for education, both in schools and for older learners. Therefore, the Commonwealth did not have a direct line of authority that would enable it to control and manage educational activities and was required to negotiate through the States and Territories for educational provision. In 1948 the Commonwealth Office of Education was in a position to implement the Adult Migrant Education Program (AMEP) to teach English as an additional language. The processes that had been designed to exclude migrants who were not from Europe meant that English learning could be treated as a more technical process, not requiring extensive engagement with cultural or other life issues. Martin (1999: 5) notes that McCusker (1954) had already pointed to the greater emphasis in this program on language than on other life skills in Australia when compared to other English dominant countries. Nevertheless, the program was framed and labelled as an 'education' rather than an 'English' program. The AMEP began first in settlement camps in Australia and subsequently also in countries of origin and on the boats bringing refugees and migrants to Australia from war-torn and later low income Europe. In 1951 all States formally agreed to work with the Commonwealth government to implement the AMEP, which meant that the State Departments of Education delivered the program and the Commonwealth covered their costs (see Martin 1999: 6ff).

As the need for migrants to support economic and industrial growth became more generally accepted, so too did the pragmatically based 
tolerance of linguistic and cultural diversity within the program, even if not within the wider community, at least initially. Diversity in the migration program increased in a carefully stage-managed process over approximately a quarter of a century. The dominant presentations by the Ministry of Immigration of the benefits of this migration program gradually moved away from the initial presentation of a blonde and blueeyed norm that (ironically) typified those profiled as desirable immediately after the defeat of fascism. Migration of war-brides from Japan played a part in this process. By the early 1970s the dominant national groups had shifted from England, Baltic and Northern European countries to include larger proportions of Southern European and Mediterranean countries. Thereafter, and bound up with the ending of Australia's involvement in the war in Vietnam and with the opening of tourism and trade relationships with the People's Republic of China (and also with the increasing nationalism in Malaysia that disadvantaged ethnic Chinese in that country), a much greater focus was placed on support for migration from Asian countries, initially involving recognition of long-term residents from various countries in Asia.

As indicated earlier, the Commonwealth/State tension that has bedevilled much education policy in Australia and the competing economic and cultural motivations shaping both migration and additional English language support for adults was a feature of the design of the Australian constitution. Only specifically selected powers were allocated to the national government, among them taxation, immigration and defence. As a consequence, after 1942 only the national government had the power to tax, but State governments had responsibility for large expenditure domains such as education. This led to some arms of the bureaucracy having money and others having responsibility to implement activities. Martin (1999: 8-9) notes that the program and policy framework for adult English learning was co-ordinated by the Commonwealth Department of Immigration. The Commonwealth Office of Education provided materials and teacher professional development and the State Departments of Education recruited the teachers and managed the teaching programs.

Early experiences noted differences between male and female participation, with women less likely to attend. Innovations such as lessons offered over the radio and by correspondence soon became a feature of the program. In large measure the program was seen as a slow and gradual learning pathway designed to accompany settlement into the new society and to be combined with other activities such as work. This approach continued for some twenty years until, in association with the arrival of refugees after the invasion of Czechoslovakia, a greater focus on intensive language instruction prior to employment began to emerge. By 1971 the Immigration (Education) Act brought about a shift from general 
settlement support (mediated by English learning) to a more focused approach on teaching English.

The shift in focus created space to do two things: to address the English language learning needs of child migrants and to target specific individuals for instruction (Martin 1999: 13).

For all of the time up to this point, the separation of language and culture learning had been made possible by an assumption (and strong social imperatives) for migrants to assimilate to the dominant Englishspeaking and Anglo norm. The dictation test had been abolished as mandatory in the 1958 revised Migration Act as a result of increasingly sporadic, but clearly racially targeted use (Palfreeman 1958; Robertson et al. 2005). Nevertheless, Australia did not move broadly to embrace more inclusive approaches to definitions of Australian culture and identity until the early 1970s (see Gurry and Tavan 2004). At this time, Australia moved formally to rescind the White Australia Policy and gradually to adopt a formal policy of multiculturalism. Again elements of pragmatism entered the picture as the formation of the European Common Market in the late 1960s (the signing of the Brussels Merger Treaty in 1965 that came into force two years later) blocked entry of Australian exports to Europe. Accompanied by the maturing to educated adulthood of the children of post-war migrants, the twin forces of economic and population change forced Australia to reconsider the general principles shaping social organisation.

Zubrzycki (1995) traces a connection between the early interventions of Sir Peter Haydon and interactions with academics such as Jean Martin (1976, 1978) and himself:

The origin of the ideas that later coalesced in the ideology and practice of multiculturalism in Australia had their point of origin several years before [Minister for Immigration] Al Grassby 'discovered' multiculturalism during his official visit to Canada in early 1973. But in Canada the term multiculturalism designated no more than official programs of cultural maintenance unveiled by Prime Minister Pierre Trudeau in October 1971 ... In Australia, however, the origin of what later became known as 'multiculturalism' was at first linked with the issues of equity in the emerging critique of Australian society during the late sixties and early seventies.

The fact that Haydon had been a senior member of the Department of External Affairs prior to taking over as Head of Immigration (Gurry and Tavan 2004: 136) probably reinforced the connection between the internal organisation of Australian society and international perceptions of Australia. In part, this led to a more explicit view of 'English' as a domestic individual issue rather than as part of the development of 
cultural and linguistic capacity to effectively participate in social life in Australia (although this was not recognised at the time). The tension was between a widening view of 'Australian' culture accompanied by an increasing focus on the learning of English as part of social integration processes. This initially small distinction progressively increased as English separated from the wider issue of social and cultural structure and became increasingly aligned with pragmatic issues of employment participation.

By the late 1960s to early 1970s there was growing informal acceptance of the fact that migrants from diverse linguistic backgrounds had become part of Australian society (Betts 2002: 25). There was clear evidence of perceptions that the large-scale migration had benefited Australia both economically (see discussion in Pope and Withers 1993) and socially (see discussion in Jones 1997) but other data has shown how complex it is to produce any singular view of what was influencing perceptions (Goot 1993). Particularly at the national level, interest began to emerge in incorporating the languages of migrant communities into educational programs (Steering Committee for the Inquiry into Schools of High Migrant Density 1975; Committee on the Teaching of Migrant Languages in Schools 1976). At the same time there was increasing concern with the quality of cultural life and issues of social rights for diverse populations. By this time, therefore, English language learning was seen as distinct from learning, and learning about, 'the' Australian culture, as could also be seen in the provision of temporary refuge to people fleeing war zones (see Hajncl 2000; Hunt and Masters 2000). The sense of independence from the United Kingdom was growing, though not without resistance, as a result of an emerging belief that a distinctive culture was either emerging or had emerged (see discussion in Warhurst 1993). These conditions reinforced a separation of English language learning from both education in its broadest sense and English as part of participation in the wider culture. This reflected a view that the plurilingualism of the learners, while not a disadvantage, could be separated into two monolingualisms. In turn this meant that attention could be focussed on learning and teaching English separately from the plurilingualism of the individual and the social engagement of that whole individual.

From the early 1970s, increasingly, the pragmatic purposes of adult English language instruction for workplace survival emerged - even if the full implementation of this view was a slow process that would take over a quarter of a century to appear in its more explicit forms. This shift was underpinned in part by the way that multiculturalism was elaborated as profiling engagement with diversity and in part by the concurrent larger changes in policy paradigms from social justice to economic rationalism. In the early stages of the development, these directions were not apparent. 
The early stages suggested a much more principled and multilingual approach across a wide range of fronts.

\section{The potential and perils of multiculturalism}

Multiculturalism (Zubrzycki 1977a) was formulated in support of a process of social integration rather than cultural assimilation in an attempt to embrace the emerging sense of a distinctive Australian culture. Its key elements involved respect for and sharing between multiple cultures rather than seeking to impose one set of cultural values on all members of the society. However, in the context of Australian migration and social elaboration, multiculturalism had some unrecognised pitfalls.

In the elaboration of Australian cultural identity, it was only in 1968 that there had been any recognition of Aboriginal membership of Australian society. Reflecting some form of recognition of the distinctively destructive way in which post-1788 Australia had imposed itself on the original inhabitants of the continent, legal recognition of the existence of Australian Aborigines was separated from processes of engagement with other forms of linguistic and cultural identity. As recognised in the deliberations of the Federation of Ethnic Communities' Council sponsored National Conferences on Language Policy and responses to them (FECCA 1982; Fesl 1982), while there was good will between indigenous and community language migrant groups, their interests were not the same. Both stood outside the Anglo tradition, but their relationships with and critiques of that tradition and its institutions were different. These considerations meant that multiculturalism as a philosophy had an uncertain relationship with Aboriginal Australians.

Multiculturalism also had an uncertain relationship with other aspects of cultural diversity where that diversity had to embrace more substantial differences in belief structures and practices than were apparent in the largely European-based post World War 2 migration programs. In the 1970s Australia had not yet engaged with the presence of Asian communities. From 1975 larger numbers of refugees from Vietnam and Cambodia had started arriving in Australia, but those groups brought two key characteristics with them - a shared history with Australia of combating communism and a commitment to humanist-inspired traditions of education as well as cultural values that largely worked against 'standing out'. In the formulation of multiculturalism, therefore, the view of cultures largely reflected acknowledgement of variation within the Western Judeo-Christian tradition - one might almost think of it as variations on a single theme.

Martin (1976) pointed out that this incomplete engagement with pluralism was possible because multiculturalism had two forms, cultural and structural: the former relating dominantly to issues of ethnicity; the 
latter embedding and problematising ethnicity as one element of social organisation, incorporating power, discrimination and economic relations. Martin (1976: 21) argued that:

In Australia, the predominance of theories of cultural, as compared with structural, pluralism has obviated the need to face uncomfortable questions of pluralism in relation to order, power and conflict. The still generally accepted 'solution' to this problem pre-dates any serious acknowledgement of cultural pluralism.

Martin's observations notwithstanding, these moments were ones of dramatic change. They were hard-won political and academic battles. What was not recognised as missing (despite the contributions of writers such as Martin, 1976) was a sufficiently powerful frame to resist the seduction of economic rationalism. This is not to say that there was not the potential for such a framework. Australia is generally recognised internationally for the work done by a very effective coalition of community activists, academics and politicians in elaborating just that. The 1984 Report of the Senate Select Committee on Education and the Arts Enquiry into a National Language Policy (1983) and the 1987 'National Policy on Languages' (the Lo Bianco Report) reflect some of this work. However, while these were two powerful documents that embraced both individual plurilingualism and societal multilingualism, they were largely informed by what Grosjean $(1985,1989)$ characterised as a 'monolingual' view of plurilingualism, a view where the plurilingual user is framed by a monolingual perspective on each of the languages used. This view separates the languages involved (in part also from the user) and therefore does not engage with the challenges for the user in moving between the different worldviews and sometimes practices that the languages encode. While there is great educational advantage to this perspective because of the way that it encourages deep engagement with the specifics of the languages and cultures involved, if it is the only perspective used, it fails to sufficiently engage with the underlying realities of the users' lives and in particular the complexity of the cultural realities that they and consequently others have to engage with. This perspective was, in part, permitted by the view of multiculturalism that Martin (1976) characterised as one of cultural diversity. A more powerful framing that engaged with structural pluralism was needed if the ideas that were being promoted were to achieve the status of a policy and hence to be powerful enough to engage productively with economic rationalist arguments.

To understand this more clearly, it is helpful to step back and ask how we can recognise and distinguish between a 'policy' and an 'action program'. A policy is enduring; an action program lasts until the next budget. Meehan (1985: 307) defined 'a policy as an action program intended to reify a 
priority structure'. One of Meehan's purposes in creating his general definition was to enable people to understand the nature of the work that needs to be done to create a policy. His key term is 'priority structure'. The priority structure is the set of values that frame the policy as a whole and shapes the nature of the action. Without an established 'priority structure', all that is left is a vulnerable action program.

Spolsky and Shohamy (2000: 2) pointed to an additional element in creating a policy, that of legitimate authority. They described language policy as:

an official statement, usually but not necessarily contained in a formal document, about language use. More specifically we will restrict it to cases where the maker of the policy has some form of authority over the person expected to follow it.

They distinguished 'policy' from 'practice' (what is habitually done) and 'ideology' (what is believed) (p. 2). Spolsky (2012: 8) later reshaped this distinction when he used 'language policy' to encompass the three elements of 1) a community's language practices, 2) the values assigned to particular language varieties and 3) management, the attempts by those with authority to achieve change in the language practices of others. Spolsky's approach includes some aspects of Meehan's notion of 'action program' and also some aspects of 'priority structure' when considering 'values' but Meehan's distinctive focus on the priority structure is not so apparent in Spolsky's framing. Spolsky's notion of line of authority is, however, crucial. Meehan's definition enables us to ask how a particular line of action may be made enduring through establishing agreement on the key values (the priority structure) that inform the plan as a whole. Spolsky highlights that the priority structure is not sufficient. There must also be a legitimate line of authority to enact the priority structure. What Martin's (1976) distinction pointed to was that the key values (the priority structure) underpinning the policy developments in the decade between 1977 and 1987 were sufficiently ambiguous as to enable them to be implemented as action plans rather than policies. What the implementation strategies for the 1987 plans revealed was that the line of authority was also insufficiently robust.

Interestingly, in 1977, Zubrzycki in his work on behalf of the Australian Ethnic Affairs Council had foreshadowed some of the same problem. He acknowledged that he had benefited from extended interaction with Jean Martin (Zubrzycki 1977b). In identifying the priority structure of the Council's view of multiculturalism, he had argued that the informing values were: social cohesion, equality and cultural identity (Zubrzycki 1977b: 3) and showed how these could be used to identify the implications for adult English programs: 
In terms of our equality yardstick, egalitarian processes are undermined to the extent that the non-English speaking migrant's access to work and social resources is adversely affected by a consideration knowledge of English - that is not intrinsic to the job to be done or to the service required.

In terms of our yardstick of cultural identity, the concentration of people of certain ethnic origins in low socioeconomic strata - which is associated with lack of knowledge of English - devalues and stigmatises that ethnic community in the eyes of the larger society and threatens the identity and self-esteem of its members.

In terms of our yardstick of social cohesion, the economy is deprived of full access to the migrant's skills and experience, and the devaluation of groups of non-English speaking low status workers is a source of social tension.

(Zubrzycki 1977b: 8)

The implication of his statement identifying the underpinning priority structure is that this structure was being missed in the way in which policy makers were engaging with the work that he and his colleagues had been doing on the elaboration of the construct of multiculturalism. Elsewhere (Nicholas 2015), I have argued that the failure to encode an integrated view of plurilingualism as part of the priority structure accompanied by an uncertain line of authority for the funders of these programs prevented programs for child plurilingualism from being taken up as policy. Exactly the same conditions applied and apply to the formulation of adult English programs.

\section{What happens when you lack powerful views of both individual plurilingualism and culture?}

Moore (2001) explored events in the Adult Migrant English Programs some 15 to 20 years after Zubrzycki's attempt to frame a priority structure for it. Although she did not frame it this way, she documented how the lack of a priority structure and the lack of a clear line of authority (not only between Commonwealth and State authorities but also between various Commonwealth instrumentalities) enabled pragmatic decisions to be made on a number of fronts that undercut any principled engagement with the elaboration of widespread individual plurilingualism for adult migrants. For example, she showed how the decision to allocate 510 hours of financial support for individual English language learners resulted from an arbitrary decision based on the average overall hours of enrolment in the program, which resulted in, at least initially, no acknowledgement of the individual needs of learners with, for example, different levels of first language literacy or 
different experiences of torture and trauma (see Moore et al. 2009). Similarly, with the 2013 change of government and the more pronounced view of the Commonwealth responsibility for immigration as being control of entry into the country (as symbolised by the change of name from the Department of Immigration and Citizenship to the Department of Immigration and Border Protection), it has been possible to shift the location of the Adult Migrant English Program from the Department of Immigration and Citizenship to first the Department of Employment and then to the Department of Industry as part of vocational and skills training (Department of Industry 2014). This double shift results in a complete subordination of the AMEP within vocational training and renders unclear (at best) how to address issues such as the equality yardstick identified by Zubryzcki (1977b).

While it could be argued that the ' $E$ ' in AMEP could re-assume an educational meaning in this context, it is more likely that ' $\mathrm{E}$ ' will remain associated with English and English will remain associated with a skillsbased progression into employment. As such, any attempt to elaborate a framework in which Australia might draw on the previous skills or knowledge of migrants (see Zubrzycki's yardstick of social cohesion) is also at best uncertain in its direction and line of authority.

\section{Conclusion}

I have attempted to re-position some of the analysis of Australian 'second' language policy development to show how it has reflected a continuing tension between general principles (either laudable or discriminatory in the extreme) and local pragmatic activities. I have argued that features of the construction of the modern Australian state created a context in which pragmatic, technical views of the nature and purpose of adult English learning could readily dominate despite opportunities for alternative framings and endeavours to construct wider views of individual plurilingualism and societal multilingualism. One consequence of this is that innovations that address the empowerment of individual learners are increasingly being left to the creativity and (sometimes subversive) activity of local teachers as described by Chapman and Williams (this volume).

\section{References}

Barton, E. (2012) 'Immigration Restriction Bill', House of Representatives, Debates, 26 September 1901, p. 5233. Available online at http://parlinfo.aph. gov.au/parlInfo/search/display/display.w3p;query=Id\%3A\%22hansard80\%2F hansardr80\%2F1901-09-26\%2F0023\%22 (accessed 4 June 2012). 
Betts, K. (2002) Immigration and public opinion: understanding the shift. People and Place 10(4): 24-37.

Committee on the Teaching of Migrant Languages in Schools (1976) The Teaching of Migrant Languages in Schools. Canberra: Australian Government Publishing Service.

Department of Industry (2014) Adult Migration English Program. Available online at www.industry.gov.au/skills/ProgrammesandAssistance/AdultMigrantEnglish Program/Pages/default.aspx (accessed 17 December 2014).

Federation of Ethnic Communities' Councils of Australia (FECCA) (ed.) (1982) National Language Policy Conference Report. Sydney: Federation of Ethnic Communities' Councils of Australia (mimeo).

Fesl, E. (1982) Address to Federation of Ethnic Councils' Conference on National Language Policy. National Language Policy Conference Report, 141-143. Sydney: Federation of Ethnic Communities' Councils of Australia (mimeo).

Goot, M. (1993) Multiculturalists, monoculturalists and the many in between: attitudes to cultural diversity and their correlates. Journal of Sociology 29(2): 226-253.

Grosjean, F. (1985) The bilingual as a competent but specific speaker-hearer. Journal of Multilingual and Multicultural Development 6(6): 467-477.

Grosjean, F. (1989) Neurolinguists, beware! The bilingual is not two monolinguals in one person. Brain and Language 36(1): 3-15.

Gurry, M. and Tavan, G. (2004) Too soft and long-haired? The Department of External Affairs and the White Australia Policy, 1946-1966. Australian Journal of International Affairs 58(1): 127-142.

Hajncl, L. (2000) Keeping the Good Things in Our Hearts: Education Programs in the Kosovar and East Timorese Safe Havens in Victoria Australia 1999. Melbourne: Adult Multicultural Education Services.

Hunt, C. and Masters, J. (2000) Learning to Live Again: The AMEP and the Australian Safe Haven Experience. Sydney: Department of Immigration and Multicultural Affairs \& National Centre for English Language Teaching and Research.

Jones, F. (1997) Ethnic diversity and national identity. Journal of Sociology 33(3): $285-305$.

Kabir, N. (2010) Muslims in Australia: Immigration, Race Relations and Cultural History. Abingdon: Routledge.

Lo Bianco, J. (1987) National Policy on Languages. Canberra: Australian Government Publishing Service.

Martin, J. (1976) Ethnic pluralism and identity. Melbourne Studies in Education 18(1): 11-27.

Martin, J. (1978) The Migrant Presence: Australian Responses, 1947-1977: Research Report for the National Population Enquiry. Sydney: Allen \& Unwin.

Martin, S. (1999) New Life, New Language: The History of the Adult Migrant English Program. Sydney: National Centre for English Language Teaching and Research.

McCusker, J. (1954) The development of migrant education in Australia 1945-54. Unpublished Bachelor of Education thesis, Melbourne Teachers' College (now part of the University of Melbourne).

Meehan, E. (1985) Policy: constructing a definition. Policy Sciences 18 (4): 291-311. 
Moore, H. (2001) Although it wasn't broken, it certainly was fixed: interventions in the Australian Adult Migrant English Program 1991-1996. In J. Lo Bianco and R. Wickert (eds), Australian Policy Activism in Language and Literacy, 93-120. Melbourne: Language Australia.

Moore, H., Nicholas, H. and Deblaquiere, J. (2009) Opening the Door: Provision for Refugee Youth with Minimal/No Schooling in the Adult Migrant English Program (Project 2.1 'Modes of delivery for SPP youth'). Sydney: NCELTR. Available online at www.ameprc.mq.edu.au/docs/research_reports/research_report_ series/Opening_the_door.pdf (accessed 17 December 2014).

Nicholas, H. (2015) Losing bilingualism while promoting second language acquisition in Australian language policy. In Y. Slaughter and J. Hajek (eds) Challenging the Monolingual Mindset, 165-181. Bristol: Multilingual Matters Ltd.

Nicholas, H. and Starks, D. (2014) Language Education and Applied Linguistics: Bridging the Two Fields. London: Routledge.

Palfreeman, A. (1958) The end of the dictation test. The Australian Quarterly 30(1): $43-50$.

Parliament of Australia (2012) The Immigration Debate in Australia: From Federation to World War One. Available online at www.aph.gov.au/About_Parliament/ Parliamentary_Departments/Parliamentary_Library/pubs/BN/2012-2013/ ImmigrationDebate\#_ftn20 (accessed 8 October 2013).

Pope, D. and Withers, G. (1993) Do migrants rob jobs? Lessons of Australian history, 1861-1991. The Journal of Economic History 53(4): 719-742.

Robertson, K., Hohmann, J. and Stewart, I. (2005) Dictating to one of 'Us': the migration of Mrs Freer. Macquarie Law Journal 5: 241-275.

Senate Select Committee on Education and the Arts (1983) Senate Standing Committee on Education and the Arts (Reference: The Development and Implementation of a Co-ordinated Language Policy for Australia): Submissions and Incorporated Documents. Canberra: Commonwealth Government Printer.

Senate Select Committee on Education and the Arts (1984) A National Language Policy. Canberra: Australian Government Publishing Service.

Spolsky, B. (2012) What is language policy? In B. Spolsky (ed.) The Cambridge Handbook of Language Policy, 3-15. Cambridge: Cambridge University Press.

Spolsky, B. and Shohamy, E. (2000) Language practice, language ideology and language policy. In R. Lambert and E. Shohamy (eds) Language Policy and Pedagogy: Essays in Honor of A. Ronald Walton, 1-42. Amsterdam: John Benjamins Publishing Company.

Steering Committee for the Inquiry into Schools of High Migrant Density (1975) Report of the Inquiry into Schools of High Migrant Density. Canberra: Australian Government Publishing Service for the Australian Department of Education.

Warhurst, J. (1993) Nationalism and Republicanism in Australia: the evolution of institutions, citizenships and symbols. Australian Journal of Political Science 28(4): $100-120$.

Zubrzycki, J. (Chair) (1977a) Australia as a Multicultural Society. Canberra: The Australian Ethnic Affairs Council, Australian Government Publishing Service.

Zubrzycki, J. (Chair) Australian Ethnic Affairs Council (1977b) Australia as a Multicultural Society - Submission to the Australian Population and Immigration 
34 Howard Nicholas

Council on the Green Paper, Immigration Policies and Australia's Population. Canberra, Australian Government Publishing Service, 1977, 1-2 and 4-19.

Zubrzycki, J. (1995) The evolution of the policy of multiculturalism in Australia 1968-95. Presentation to the Global Cultural Diversity Conference. Available online at www.immi.gov.au/media/publications/multicultural/ confer/06/speech29a.htm (accessed 2 November 2013). 


\title{
Chapter 2
}

\section{Connecting with community \\ Helping immigrant low literacy ESL learners in local contexts}

\author{
Laura Chapman and Alan Williams
}

\section{Introduction}

There is strong policy and program support in Australia for adult immigrants for learning English to meet their needs of living in the community and moving into the workforce. However, the circumstances of LLB (Low Literacy Background) ESL (English as a Second Language) learners are often very specific due to their unique prior life experiences, limited or interrupted experience of formal education and low levels of literacy in both their first language and in English. ESL teachers working with LLB ESL learners have responded to the need for very concrete, experience-based and learner-centred approaches to learning in several ways. This chapter describes four transformative approaches (Freire 2007) to meeting these needs, where ESL teachers use content-based methodology to engage students with different aspects of life in their local community. These involve practical involvement in a range of community events and collaboration with providers of services in the learners' community. They illustrate how helping immigrants to learn about life in their new communities can and should go well beyond telling learners about things someone (policy makers or teachers) think they should know.

The approaches described illustrate the expanded possibilities for LLB ESL learners to achieve practical tasks and engage with their communities. The consequent learning expands their available designs (Kern 2000) in the second language (English) and in literacy, and helps develop a transformative understanding of themselves and their social context. This takes place when significant and engaging settlement content is delivered concurrently with language and literacy learning outcomes, even within potentially restrictive policy and assessment frameworks of publicly funded English language training programs.

Nicholas (this volume) describes how the ideological and the pragmatic have interacted in Australia's immigration policy. Since World War 2, the post-arrival English language program has been a constant, albeit with 
periodic policy shifts. While it was originally called the Adult Migrant Education Program (AMEP), which implied a settlement and general education focus, in the 1990s the shift to 'English' as the focus raised the status of literacy skills in English (Martin 1998: vi). This reflected changing imperatives and emphases (including an emphasis on literacy, which has generally been restricted to something of relevance only in English) in Australia's work force and planning. Under successive governments from the mid-1990s, led by Prime Ministers Howard (Liberal), Rudd and Gillard (Labor) and Abbott (Liberal), good 'citizenship' has come to have greater emphasis in public debate about immigration, and teaching understanding about settlement has again been emphasised in guidelines issued to teachers working in the AMEP (AMES 2012), reviving the educational aspect of the program.

The emphasis on workplace English in government-funded language programs, aimed at getting immigrants to engage in employment within a short period of time from their arrival in Australia, places pressure on such programs to pursue these aims. To enable meaningful participation in workplaces and support learners to develop realistic pathways to employment, language programs have combined vocationally specific content-based language instruction with work experience and volunteer work placements, and collaborative delivery with vocational training programs, careers counsellors, local businesses and industry representatives. However, many of these programs have been separated out from the general Adult Migrant English Program delivery, and do not cater to LLB students.

There are two issues in articulating a distinct focus in the AMEP. The first is the nature and extent of the focus on settlement. The second is the nature of the engagement with literacy. The concern of government with settlement information is still evident in the 'Living in Australia' website of the Department on Immigration and Border Protection (DIBP 2013). This website contains links to a booklet intended for recent immigrants, Beginning Life in Australia, which is provided as a download in 37 languages (including English). The guidelines of the Adult Multicultural Education Services (AMES Vic) - the state government lead provider of the AMEP in the state of Victoria - draw teachers' attention to this resource. The booklet provides information on a range of aspects of life in Australia, from health checks, to driving cars, to the monetary system, support services and so on, in print rich, dense texts. The booklet could be a useful first language reference for immigrants providing they are literate in one of the available languages. However, it also represents a transmission process, which Freire (2007) terms a 'banking pedagogy' that assumes immigrants' interactions will preserve the existing social order.

There is a challenge here for teachers of LLB ESL learners in both the AMEP and in other adult ESL programs, especially in the local learning 
centres that make up much of the community sector. While many AMEP providers are large institutional providers of adult education and training, such as TAFE (Technical and Further Education) and AMES consortia, their support is limited from the basic entitlement of 510 up to the extended entitlement of 910 hours, made available to refugee humanitarian entry students, who are very often LLB students. There are also some employment pathways and workplace preparation program entitlements for some students, which involve a short-term placement in a workplace. For most LLB ESL learners these entitlements are not adequate to meet their full language and learning needs to the point where they can find employment. As a result, local learning centres often support immigrants' longer term learning needs either as partners in AMEP delivery, or in programs funded by state government or other bodies to meet the English language learning needs of learners unable or disinclined to access language programs in large institutional contexts. For a substantial portion of these learners, the cultural and technical issues of both settlement and literacy present a major challenge.

The requirement to provide settlement-related information poses a dilemma for teachers working in these programs. How are they to conform to these policy requirements in ways that avoid a transmissionbased pedagogy? How are they to provide settlement-related information in ways that empower learners by giving them knowledge and skills to manage and improve their lives in Australia? This is in contrast to subjecting learners to 'teaching' which requires them to 'learn' a constructed representation of 'life in Australia' which, at worst, may represent no more than the imaginations of government policy makers, curriculum writers and teachers whose lived experience is quite different from that of recently arrived low literacy ESL learners.

The challenge is how to deliver significant and often cognitively complex information while providing relevant language learning experiences for communication in the domains of life in the community, settlement information and services. Accessing complex information can present a greater challenge for LLB ESL learners, who often come from small or isolated communities with very different socio-cultural contexts and lack of access to technology. They need to not only adjust to a new language and the cultural values of living and working through that language, but must also adjust to living in literacy-saturated, technologically oriented urban communities.

Leaders and teachers in the AMEP and associated ESL programs have utilised the insights of content-based language learning (usually referred to as Content-based Instruction, CBI, in North America, and Content and Language Integrated Learning, CLIL, in Europe) to address this challenge (see, for example, Crandall 1987; Coyle et al. 2010; Crandall and Kaufmann 2002; Mohan 1986; Brinton et al. 1989). One such 
response was the production of content-based modules for LLB young adult learners in the AMEP, which resulted in the 'Get Wise' Series of teaching materials (AMEPRC 2007a, 2007b, 2008a, 2008b, 2008c, 2008d; Williams and Murray 2010) specifically intended for low literacy young adult learners in the AMEP. These materials are comprehensive in their scope and content, and were developed in a national project, which employed professional writers working with AMEP teachers, in consultation with a steering committee of experts from around the country.

The materials provide content-based information through video scenarios that deal with different aspects of life in Australia, such as identifying learning and training pathways for young adults to realise vocational ambitions, issues in managing money, health and nutrition, recreation, water safety and interpersonal relations in multicultural contexts. Written worksheets, audio components and visual materials such as charts or games provide language, literacy and numeracy tasks that build further learning from the information presented in the video. While this represents the potential of a top-down and well-funded national approach, its impact is limited over a longer period of time as the single print run was only distributed once to AMEP providers. Additionally, the content needed to be generically constructed in an effort to have relevance across the country, and is therefore devoid of specific local references which would be incomprehensible to learners in other locations.

A content-based approach has also been utilised in local contexts by teachers working in adult ESL programs to meet the needs of adult LLB ESL learners. These approaches have sought to blend learning of relevant language skills with essential knowledge to navigate daily interactions and access services in the local community. An important consideration in the design of the materials and the associated activities has been a desire to do more than simply teach these learners about an aspect of life in their new communities, which risks a one-way transmission of information, leaving the learners as passive recipients, being acted upon, rather than acting and enacting.

The AMEP has always had a settlement and community access focus, ideally delivered with local content integrated into the course at a pace and intensity determined by client need. In 2011, the AMEP introduced the explicit delivery of settlement information through a Settlement Course with specific knowledge outcomes. Small community centres integrated the Settlement Course into general English classes, measuring progress against both stipulated settlement knowledge and language competency outcomes. This created a three-way tension between delivering settlement content to meet the requirements of external bodies, designing a locally relevant syllabus to meet the needs of a class, 
and measuring knowledge outcomes in a realistic timeframe for individual learners.

What follows are descriptions of four dynamic local language programs within nationally funded ESL programs, which illustrate the potential and challenges of content-based approaches to empower LLB ESL learners in ways that both integrate and extend the language learning outcomes required by funding bodies. The four programs present innovative practices developed by different ESL providers for LLB learners in the states of Tasmania and Victoria. The writers were involved in numerous projects over an eight-year period with these organisations, including action research projects for the AMEP Research Centre and the development of teaching materials specifically for LLB ESL learners.

These short qualitative studies describe how engagement with different types of content can be implemented for LLB ESL learners. Each example represents different approaches: the use of local activities to involve the students in problem-solving content-based tasks; the adaptation and enhancement of nationally developed materials; addressing an important safety need through integrated language learning; and finally, the potential of connecting with providers of non-language services to enhance the learning of important settlement information, while delivering relevant language and literacy skills. Each example illustrates the benefits of engagement with content, as well as the types of additional work teachers need to undertake in order to facilitate successful language, literacy and content learning.

The examples also illustrate how it is possible to involve LLB ESL learners in meaningful activities which transform their understanding and experience of the world, themselves and their involvement in the communities in which they live. These learning experiences expand the available designs of LLB ESL learners (Kern 2000), and the resources they can draw on for living in their new communities. The learners' experience of scaffolded practical activities relating to life in their communities builds up language, literacy, problem solving and learning skills they can draw on as they engage with the communities in which they now live.

They also describe practices that allow students to learn about aspects of life in Australia, but in ways that let learners respond to what they learn, and make informed decisions for themselves.

\section{TasTAFE Hands on English program for older low literacy background ESL learners}

The Hands On English program was developed in response to concerns that older low literacy adult learners were having difficulty relating to, and progressing in, the environment of a formal ESL language classroom. 
It was developed by Migrant Education, a department of Tas(mania) TAFE, which delivers the nationally accredited Certificates of Spoken and Written English (CSWE) within the AMEP. The program was developed in consultation with representatives from the learners' cultural and linguistic communities, including community leaders, elders and students, who met with ESL teachers, with community members acting as interpreters. The resulting recommendation was a pilot program of project-based experiential learning, which would take students outside the classroom to engage on a practical level with their local community. Migrant Education established weekly classes of 'hands on' activities delivered in English, with an ESL teacher managing projects in partnership with community organisations. Students were involved in community-based projects, with classroom language teaching directly related to the students' projects.

One collaboration involved Landcare, an Australia-wide organisation with local chapters that work within their communities on environmental restoration projects and public awareness campaigns. In Hobart, the state capital of Tasmania, this involved the regeneration of a waterway, enabling students to learn about and improve their local environment. Another project was a display for a garden show in the grounds of an aged-care facility. Activities were instructed in English, with support from the class ESL teacher; costs were minimised with the use of recycled and donated materials, and involved practical gardening and creative display-building tasks. Students from backgrounds of trauma could experience therapeutic aspects of gardening, and for students originating from rural areas, gardening was a means of connecting back to prior experience and putting their skills into practice. The student entry in the garden show won a prize consisting of trees and shrubs, which were to be planted in a city park in a continuing contribution to the community, and increased the self-esteem and sense of achievement of the students.

In collaboration with Urban Smart Projects, a community arts initiative to enhance city streets through creative community engagement, the Hands On English students painted a traffic signal box in their central business district. Language, literacy and numeracy skills were developed around practical tasks; measuring the box, collaborating on designs, developing and submitting working drawings, undertaking occupational health and safety training, and painting. The group won a community award of art supplies to enable further creative projects to be developed. The successful completion of practical tasks and public recognition of their outcomes enhanced the learners' sense of achievement as community members. The lead ESL teacher on the project reported that teachers "would often comment on how proud their student was as they pointed out the 
traffic signal box that they had helped paint ... this feedback was very important as it showed the students had a sense of pride in their involvement in their new community' (Buchanan 2013: 1).

Both of these projects incorporated English language tuition to develop competency in specific language, literacy and numeracy learning outcomes, largely built around situational texts that arose from the community-based activities. Language tasks directly related to practical activities, such as following and giving spoken instructions, recognising symbols and reading signs, describing and recounting activities, reading and creating information texts and a variety of vocabulary-building and literacy activities. The students developed folios documenting and describing their activities with identifying vocabulary accompanied by pictures, photos and their awards. Many of the tasks the students undertook were aligned to assessment criteria within the CSWE, the text and competency-based assessment framework used to assess student learning in the AMEP. Learning outcomes included recognition of symbols and signs, reading familiar words and sentences, demonstrating understanding of information texts and participating in transactional oral exchanges. The program therefore enabled learners to successfully complete modules of an accredited language course while undertaking practical tasks.

These projects illustrate how delivering content-based activities beyond the classroom into the community enabled students to contribute to the development of that community, which in turn led to greater success in both language learning and significant non-linguistic learning.

\section{Integrating human rights resources into content-based delivery}

Content-based language instruction is a difficult balance of language and subject matter, which risks misinformation where teachers lack expertise in content areas. The delivery of accurate and relevant information in specialist fields requires professional resources and expertise. Settlement and government services have recognised that ESL programs can facilitate the delivery of key community messages, and consequently have developed teaching resources designed by professional bodies in collaboration with ESL educators.

It's Your Right (Power 2009) is a teaching resource developed by the Australian Human Rights Commission in partnership with Adult Migrant Education Services (AMES) Victoria. The resource explores human rights and responsibilities in Australia for adult ESL learners. While developing English language skills, students learn about unfair treatment and discrimination, Australian laws relating to human rights and how to seek professional advice, make formal complaints and obtain legal support. 
The resource engages learners with a range of cultural role models and realistic scenarios built around the narrative of Hayat, a Muslim Ethiopian woman, who is discriminated against in the workplace and unfairly dismissed, but learns about services available to her and makes a formal complaint. The resource delivers key messages to immigrants who may be unaware of their rights in the workplace or how to protect themselves, and are therefore particularly susceptible to exploitation.

The draft resource was extensively trialled in adult ESL programs around Australia and evaluated by teachers and learners before publication, resulting in rights-based materials being developed for use across the country. The final teaching pack consists of a DVD, readers and workbooks with activities and texts mapped to the four certificate levels of CSWE, so learners are able to develop language competency in preparation for assessment outcomes.

Although the resources are not aimed at LLB ESL learners, teachers at TasTAFE were able to use the videos and adapt materials to deliver key content and develop language skills for low literacy learners in multi-level classes. The school organised guest speakers from both the Fair Work Ombudsman and the Office of the Anti-Discrimination Commissioner. On an educational online site, students were provided with links to the Office of The Anti-Discrimination Commissioner, with information in community languages and mechanisms for reporting discrimination.

The combination of guest speaker presentations and content-based instruction about workplace rights was particularly valuable to students who attended an evening ESL program outside their working hours. Through language and literacy activities, audio-visual presentations, guest speakers and internet tasks, these learners gained an awareness of their rights relating to their own workplaces, and relevant support services available to them. As a result, students checked the conditions of their work contracts, approached colleagues to discuss working conditions, and one student reported a case of discrimination and unfair workplace practices by an employer accused of exploiting migrant workers. The case was referred to relevant authorities for investigation.

The impact of this program on students, who related the content to their personal circumstances, demonstrates that a national resource can be delivered on a local level for a specific audience. However, this model of practice could in turn be disseminated outwards to other educational providers in an ongoing dialogue between practitioners. At the time of writing, CBI resources such as this, and others on various topics including Emergency Services, Health and Employment, are available nationally, but there is no state or national forum for professional development or a community of practice to demonstrate models that enable learners to engage with their communities and act upon the knowledge and skills they gain. 


\section{Y-MEP Water Safety for young adult learners}

Y-MEP (Young Migrant Education Program) at TasTAFE provides English courses for 16- to 24-year-old learners in order to enable them to progress to vocational courses in mainstream TAFE, further study in school or higher education or employment. Y-MEP has developed programs to meet students' needs to learn important settlement content and skills, English language learning and general education through collaboration with community organisations. One course unit focused on 'water safety', considered a basic survival skill in Australia, where children are routinely taught to swim at an early age. Both younger and older immigrants face greater safety risks as they often lack this training, and can be deceived by the apparent ease with which they see others entering and playing in the water, at the beach, in inland waterways or in public swimming pools.

The Australian Water Safety Council (2012) reported that immigrants are at a greater risk of drowning than non-immigrants due to lack of awareness of risks, being unfamiliar with Australian aquatic conditions and lower levels of foundation aquatic skills. The council advocated community development strategies for participation of CALD (culturally and linguistically diverse) communities who are 'far less likely to access programs via traditional modes'. Y-MEP responded to this need with Water Safety Program activities that included:

- $\quad$ water safety and swimming lessons conducted at a local aquatic centre;

- Marine Safety Tasmania boating safety talks and boating excursions;

- beach excursions with demonstrations of safety/flotation equipment and supervised swimming;

- fishing excursions organised by Tasmanian Recreational Fisheries.

Y-MEP teachers coordinated the activities, with a syllabus created by the ESL teachers in partnership with local organisations. Teachers produced learning resources to support the language and literacy development of the participants around content knowledge, including picture and word recognition resources, instructional texts on safety, symbols and sight signs. In class, students worked on understanding and producing texts involving instructions and advice about safety in and around water. Language lessons also used available teaching resources such as those published on Surf Lifesaving Sites and the Get Wise: Your Time Out (AMEPRC 2008a).

Some of the students learned to swim, and others learned how to feel comfortable and stay safe in and around water, and what to do in an emergency. The program went beyond one-off 'ESL excursions', and involved partnerships that contributed to a comprehensive water safety 
program with tangible language learning. Suzanne Peacock, a teacher in the program, explained, 'Not only have we been able to tap into the expert knowledge that these organisations provide, but they have helped to fund a water safety program that is comprehensive, engaging and very cost effective' (Peacock 2013: 1). Learners developed language and literacy competency in reading visual symbols and public signs that convey water safety messages, demonstrating understanding of instructional texts, participating in spoken transactional exchanges for information regarding swimming lessons and safety, writing recounts of their experiences and making emergency phone calls.

\section{Making connections with local service providers}

At the smaller end of the scale in adult ESL education, community organisations provide the AMEP and nationally accredited ESL courses in local urban and regional settings. This enables community members of immigrant backgrounds, who may not otherwise have a chance to attend school, to access local language classes and achieve certificate-level qualifications that are recognised in the national training system. The Fitzroy Learning Network (FLN) is a community learning centre in Melbourne with a diverse group of migrant and humanitarian clients who primarily reside in social housing estates at close proximity to the school.

Immigrants can access their AMEP entitlement at any time from registration and commencement up to a five-year limit, and other learners are able to join programs during any of the four terms per year. Therefore teachers at FLN face continuously changing class dynamics through ongoing student enrolment and variable individual course lengths depending on students' learning pace and study intensity. In smaller community programs, options for streamed placement are limited without the critical mass to divide classes into a range of skill levels. This results in highly disparate classes of learners with no prior formal education or literacy in their first language, learners who have first language literacy but no knowledge of the Roman alphabet and beginner English learners with varying levels of oral/aural and English literacy skills.

Continuous enrolment poses many challenges at the syllabus level, necessitating highly flexible delivery. Courses at FLN are generally structured under a thematic cyclical syllabus, in which content is revisited through a variety of approaches to consolidate the knowledge and skills of continuing students, while concurrently introducing new students to content areas and associated language. The CSWE frameworks largely follow a genre approach to whole texts (Feez 1998; Rose and Martin 2012), facilitating competency-based training in which skills must be transferrable, requiring learners to perform language tasks in a variety of contexts. 
FLN has addressed the challenge of delivering settlement information within language programs through collaborations with local specialist services, such as North Yarra Community Health, a not-for-profit local community health organisation supporting culturally diverse clients. This collaboration aimed to break down barriers between health services and the community, to enable access to a broad range of services and deliver key health information. By running sessions in the school in 2013, North Yarra Community Health (NYCH) was able to reach community members, who may not otherwise attend their services, in an environment familiar to them. Partnerships offer a way of pooling resources to meet desirable outcomes in a context where financial resources are limited.

Essential to this collaboration was the provision of onsite interpreters to deliver key health messages with health service professionals, and answer questions on detailed information. Students learned about and discussed health issues in their expert languages in sessions led by medical and health professionals. NYCH provided vocabulary lists for teachers to develop resources around, and posters with diagrams and simple health messages. Teachers prepared students for the sessions through classroom activities with key texts and continued to expand on the information with content-based ESL activities and excursions. With up to 10 different languages in each class group, bilingual educational support is not a practical or affordable option, hence the use of interpreters for specific sessions. When government departments and settlement services provide bilingual or translated documents, such as those on specific health issues, these are utilised in training.

The combination of health content information with scaffolded language activities developed learners' skills and confidence to engage in practical tasks. Many language tasks related directly to assessment outcomes under the CSWE, such as participating in transactional exchanges by making appointments with health service providers. The success of this combined approach is evident in the experience of a beginner student as documented in a teacher diary (Chapman 2013):

3rd July 2013 -Thi [a pseudonym] proudly reported (through mime and short English phrases) that she had gone to the reception of the health centre and, without an interpreter or other support, requested an appointment for a vaccination, having learned about vaccinations through the information sessions delivered at the school. She had taken the appointment card with the relevant time and date, returned for the vaccination and spoken to the nurse in a few words of English. She wanted to share this achievement with the teacher and other students, and thanked me personally, saying that English school helped her achieve this. 
This example clearly shows that the program enabled learners to use newly gained language and knowledge to independently act upon their world and meet essential needs.

\section{Discussion and conclusions}

These programs are transformative in that the learners have developed skills related to life in their local communities, and acted in ways that either transformed their communities, or had the potential to change the way they participated in them. These transformative experiences add to the language, literacy and content knowledge learners can utilise in subsequent participation in the communities, thereby adding to the personal resources (Kern 2000) that are important factors in the on-going language and literacy development of second language learners. The significance of such experience lies in the discordance between the assumptions of a modern western technologically oriented society, and the prior life and learning experiences of LLB ESL students.

These transformations resulted from ESL teachers broadening their perspectives, and using the insights of content-based language teaching. This led to language learning that was relevant to the learners' lived experience in their communities, and content learning that dealt with the experiences and challenges learners face on a daily basis. The content and language learning that emerged was profound, in that it enabled learners to have greater control over significant aspects of their lives in Australia. It involved learning and activities that went beyond the language classroom, and frequently involved learning from others in the community, in ways that connected with the language learning opportunities designed by ESL teachers. These approaches raised learners' self-esteem by proving what they could achieve, and gave them opportunities to capitalise on their non-linguistic skills to support their language and literacy development. These transformations are the result of teachers not only working within the policy guidelines laid down for them, but also taking these requirements beyond a narrow, prescriptive approach to teaching and learning settlement information.

Successful content-based transformative learning takes work, imagination, effort and time. Teachers need time and structured support if they are to create effective local learning activities. Transformative learning is about engaging in practical ways with the environment and community that the students live in. In the building of partnerships, the teacher is an advocate in the community, a participant in the activities and a mentor to the learners.

There are many challenges for teachers using this approach. The ways that learner needs are assessed require careful consideration, and often community consultation, to take teachers beyond the insights they have gained within the ESL classroom. Identifying needs and current levels of 
knowledge, skills and attitudes in relation to language and content means having a broader knowledge of learners than required in solely languagefocused ESL teaching. There are also questions about the boundaries of which aspects of learning we are able to assess within a program, and what we can actually identify as the outcomes and extent of learning. We must consider how such assessment can be done across a range of domains such as language, literacy, numeracy, content learning and learner capacities. Affective factors such as confidence and motivation also need to be taken into account when evaluating a program.

This chapter has provided a brief sketch of the possibilities when ESL teachers look to the needs of the learners, and beyond a language-only focus in order to develop more comprehensive teaching programs for low literacy background ESL learners. Active, practical content-based learning that is relevant to life in the community and connects with others in that community can have a powerful effect on learner empowerment, capacity and development.

In the cases we have described, the outcomes presented have been possible because the prescribed language assessment framework, common to all these programs, is based upon generic text-types and competencies. Community-based content learning can therefore be related to assessment tasks developed at the relevant level for learners in these programs. These innovations have been made possible within a prescriptive policy and funding framework, because paradoxically the common core curriculum can be adapted creatively when local programs show initiative. In our examples, ESL teachers have related the local needs they identify to what is expected in the curriculum and policy guidelines. The needs of lowliteracy background ESL learners are as profound as their individual life experiences, and warrant these creative approaches.

\section{References}

AMEPRC (2007a) Get Wise: Your Future; Work and Study. Sydney: NCELTR, Macquarie University.

AMEPRC (2007b) Get Wise: Your Money. Sydney: NCELTR, Macquarie University. AMEPRC (2008a) Get Wise: Your Time Out. Sydney: NCELTR, Macquarie University.

AMEPRC (2008b) Get Wise: Your Communications. Sydney: NCELTR, Macquarie University.

AMEPRC (2008c) Get Wise: Your Health and Well-being. Sydney: NCELTR, Macquarie University.

AMEPRC (2008d) Get Wise: You and Me. Sydney: NCELTR, Macquarie University. AMES Vic (2012) Teaching in the AMEP Settlement Course Teachers' Notes, Melbourne: AMES.

Australian Water Safety Council (2012) Australian Water Safety Strategy 2012-2015. Sydney: Australian Water Safety Council. 
Brinton, D., Snow, A. and Wesche, M. (1989) Content-based Second Language Instruction. New York: Newbury House.

Buchanan, L (2013) Hands on English Project Report. Unpublished internal document. Migrant Education, TasTAFE.

Chapman, L (2013). Teacher Observation Diary. Unpublished internal document. Fitzroy Learning Network.

Coyle, D., Hood, P. and March, D. (2010) Content and Language Integrated Learning. Cambridge: Cambridge University Press.

Crandall, J. (1987) ESL through Content-based Instruction: Mathematics, Science, Social Studies. Englewood Cliffs, NJ: Prentice Hall Regents.

Crandall, J. and Kaufmann, D. (eds) (2002) Content-based Instruction in Higher Education Settings. Alexandria, VA: TESOL Inc.

DIBP (2013) Beginning Life In Australia. Available online at www.immi.gov.au/livingin-australia/settle-in-australia/beginning-life/ (accessed 30 October 2013).

Feez, S. (1998) Text-based Syllabus Design. Sydney: NCELTR.

Freire, P. (2007) Pedagogy of the Oppressed. New York: Continuum.

Kern, R. (2000) Literacy and Language Teaching. Oxford: Oxford University Press. Martin, S. (1998) New Life: New Language: The History of the Adult Migrant English Program. Sydney: NCELTR.

Mohan, B. (1986) Language and Content. Reading MA: Addison-Wesley.

Peacock, S. (2013) YAMEP Program Report. Unpublished internal document. Migrant Education, TasTAFE.

Power, M. (2009) It's Your Right. Sydney and Melbourne: Australian Human Rights Commission and AMES.

Rose, D. and Martin, J. R. (2012.) Learning to Write, Reading to Learn: Genre, Knowledge and Pedagogy in the Sydney School. London: Equinox.

Williams, A. and Murray, D. E. (2010) Get wise: content-based teaching for LESLLA refugee youth in adult programs, in T. Wall and M. Leong (eds) LowEducated Second Language and Literacy Acquisition: 5th Symposium Proceedings, Banff, Canada 2009. Calgary: Bow Valley College, 15-24. 


\title{
French language education policy for adult immigrants in Quebec
}

\author{
Paula Bouffard
}

\section{Introduction}

A vast territory with a relatively sparse population (less than 35 million), Canada has one of the most ambitious immigration policies in the world. Seeking to increase its population by 1 per cent per year, Canada has set the target number of annual admissions at over a quarter of a million for the current decade. Yet Quebec, with its peculiar demographic situation and its minority-majority linguistic situation, faces a serious challenge with regard to immigration: maintaining French as the common language of public life within its borders, in a continent where the overwhelming majority speaks not only a different language but the language of globalisation. That Francophones form a minority in North America is not the only factor making the linguistic situation in Quebec unique; rather the internal composition of the province itself contributes to the challenge posed by the integration of immigrants.

Tensions around which language arriving immigrants should learn have played out in the development of policies related to integration and language education, responsibility for which shifted from non-profits to the public sector. While in the 1950s the lack of services to immigrants in Quebec was made up for by charitable organisations such as the FrancoCanadian Reception Agency and the Catholic Immigrant Aid Society, today a designated Ministry of Immigration and Cultural Communities provides integration services to newcomers. In just a few decades, Quebec became a host society where French language learning opportunities for immigrants evolved from voluntary language teaching initiatives held in local parishes to a full-blown, subsidised governmental program.

With 8 million inhabitants, Quebec represents 23.1 per cent of Canada's population and 1.7 per cent of North America's population. French is the only official language of Quebec and one of the two official languages of Canada. In the 2011 census, 78.9 per cent of the population of Quebec reported having French as a mother tongue. This compares with 8.3 per cent reporting English, and the remaining 12.8 per cent a language other 
than French or English. Census terminology commonly refers to these three groups as Francophones, Anglophones and allophones, respectively but it's worth noting that these categories are not as clear-cut as they may seem (Jedwad 2008). The percentage of Canadian Francophones, excluding those who live in Quebec, has steadily declined and is currently at 4 per cent. For this reason Caron (2013: 52) points out: 'Quebec is the only place in North America where French is the majority language and the only place where it still has a future as such'.

The historical roots of the French-speaking population are deep: of the nearly 6 million Francophones in Quebec, the majority are descendants of the settlers of the New France period. The second major language group, approximately 600,000 speakers, is the (historic) Anglophone community. The latter is a diverse group, which includes descendants of the early British settlers but also Americans, the Irish and early immigrants of a variety of ethnic origins reporting to have English as a first language in language censuses (Jedwad 2008). Quebec is also home to 11 Aboriginal nations making up 1.8 per cent of the population. Lastly, Quebec is the new place of residence of nearly 850,000 immigrants from every corner of the world speaking more than 100 languages.

Although useful, these numbers bear only some relation to actual language use on the ground. They also hide important regional differences in terms of language diversity (or uniformity). The distribution of language groups based on mother tongue in Quebec City, for example, shows that Francophones make up 95.3 per cent of its total population (Statistics Canada 2006). By contrast, Montreal Island saw the percentage of native French speakers drop below 50 per cent, with the following distribution: 48.6 per cent Francophones, 17.5 per cent Anglophones, and 32.3 per cent allophones (Statistics Canada 2011).

The region of Montreal is thus crucial to the linguistic future of Quebec (Caron 2013; Castonguay 2012; Curzi 2010). It accounts for nearly half of Quebec's total population, and it is where 85 per cent of immigrants choose to settle and consequently where the bulk of linguistic integration takes place. Montreal is also home to the majority of the province's Anglophones, who, thanks to their presence and well-established institutions, constitute an English stronghold in the metropolis. Census data bearing on the language used most often at home show that among the 41.4 per cent of immigrants living in Montreal who chose to live in a language other than their native language, 43 per cent opted for French while 57 per cent elected English (Caron 2013: 54). Because of the low fertility rate of Francophones (1.4 per cent), it is believed that ' $[\mathrm{t}] \mathrm{he}$ integration of immigrants into one community or the other [will] determine the linguistic future of Montreal' (McAndrew 2013: 18).

The appeal of English to immigrants is not new and has been one of the factors behind Quebec's language and immigration policies. With 90 
per cent of newcomers choosing to integrate into the minority English speaking community in the 1960s, the Quebec government had to establish the primacy of its language on its territory, while at the same time becoming a host society with a common public language. In such a situation, French language learning opportunities for adult immigrants emerged as a key component of the province's language planning policy for two reasons. First the use of French is associated with social cohesion and equality of chances. Second it is viewed as a way of fostering the longterm survival of the French language in North America, a geographical context in which its presence hasn't ceased to decline.

One may wonder what keeping French alive in the Americas exactly means. Francophones in Quebec have been living their everyday life in French for more than four centuries. Shaped by its geographical position and its history, the French language in Quebec incorporates sounds, words, expressions and syntactic structures that reflect the overall human experience of its speakers on the continent. Of course, French in Quebec is spoken in a variety of ways. According to many studies (e.g. Corbeil 2007), the distance between the norm of reference shared by the Francophone world and colloquial or popular French is greater in Quebec than it is France. Some even argue that Quebecers are in a diglossic situation (Meney 2010). The reality is that whatever the level of language used in their homes and the linguistic specificity of their regions, children learn standard French in schools.

Obviously, the norm taught in Quebec schools is not that of France. Rather it integrates cultural and linguistic specificities of the North American context. Apart from pronunciation, the main difference between Standard Quebec French and international standard French relates to vocabulary (De Villers 2005; Corbeil 2007). Quebec French has archaisms (e.g. menterie 'lie' in addition to modern French mensonge) and neologisms (e.g. courriel for 'email' instead of the French mail). Other words describe elements that belong to the North American context (e.g. motoneige 'skidoo') and local institutions (e.g. Cégep 'college'). In this sense, French in North America is truly unique. The testimony that it brings to life is not that of the Anglophones sharing the same continent, nor that of the French in France. It is what is commonly called the French 'américanité' (French 'American-ness').

\section{Citizenship training in the French Canadian context}

During the two hundred years between the cession of New France to Britain in 1763 and the Quiet Revolution ${ }^{1}$ in the 1960s, immigration towards the British colonies, later to become Canada, was primarily Anglophone and allophone (Monnot 2012: 23). As Jedwad (2002: 1) observed: 'Historically, immigrants helped strengthen the position of the 
English-speaking population while the Francophone population relied primarily on natural increase for population growth.' The steady influx of English-speaking settlers during the first century of the British regime instilled what would become a recurring concern among the FrenchCanadian population: the fear of assimilation.

The British North America Act (BNAA), which officially created Canada in 1867, gave shared jurisdiction to the federal and provincial governments with regard to immigration. Quebec participated in the five federal-provincial conferences on immigration between 1868 and 1874 and created administrative structures for reception and settlement services for newcomers. This early effort ended in 1875 when 'provinces recognised full responsibility of the central government to prospective immigrants and accepted the abolition of their agencies' (Juteau 1999: 66). Quebec immigration remained contingent upon Canada's policies, which evolved from an open door policy in the nineteenth century to a discriminatory policy based on ethnic criteria in the twentieth century.

At the end of World War II the federal government loosened its immigration policy, seeking to increase the overall population of Canada, and following Quebec's persistent request, it added France to the list of countries (all English-dominant) from which immigrants were allowed. Although 5000 French settlers made their way to Canada in the twenty years that followed the end of the war, they represented only 3 per cent of the overall number of immigrants admitted. During the same period, 60 per cent were Anglophones (Daniel 2006: 44). Perceived as serving the interest of English Canadians, immigration emerged as a major concern for French Canadians.

When the discriminatory system was abolished in 1962, the source countries of immigrants became more diverse. An increasing number of newcomers spoke neither English nor French, which made an integration policy an urgent necessity. The Canadian Citizenship Act, passed in 1946, sought to promote a sense of pride in Canada among Canadians and foster a sense of belonging among immigrants by offering them training in citizenship:

As a result of the flow of new immigrants to Canada [...] and the probable large increase of such immigration in the future, coupled with the requirements set up by the passing of "The Canadian Citizenship Act' in 1946, the matter of citizenship training of these additions to our population has become one of marked urgency. In order to fulfill its responsibilities the [Canadian Citizenship] Council will be required most actively to collaborate with, and assist departments of governments, employers, agencies and materials and services to aid these new immigrants.

(Ottawa c.1948) 
Evening French language classes for adult migrants in Quebec appeared in this context, administered by religious and civil society organisations. In the BNAA, education was an area of provincial responsibility as long as religious rights were respected. Under the clergy's pressure, education in Quebec was entrusted to the authority of a Department of Public Instruction made up of a Protestant committee and a Catholic committee, the equivalent of school boards. The latter was further divided into a French-school sector and a smaller English-school sector. As early as 1948, the Catholic Committee sketched a proposal to provide training to adult immigrants, emphasising the religious, economic and social aspects of living in Quebec. During the same year, the Neo Canadian committee, which had been created the year before to come up with a solution to the problematic integration of Catholic children from different ethnic origins within French Catholic schools, was also making plans to conduct special classes for adult migrants two evenings per week. Their proposal entailed the hiring of already integrated Neo Canadians to teach their compatriots French and the contribution of the French Canadian nation in building the country. The lecture would be followed by a practice activity where Francophones from the parish would volunteer to provide authentic French input while at the same time getting to know the new members of their community. This program was allocated a budget of $\$ 1000$, allowing classes to begin in three Montreal parishes in 1949. It was an immediate success: within a month, the number of Slovaks in the first class grew from 9 to 30; the number of Germans, in the second class, went from 7 to 27; and the number of Hungarians in the third one increased from 12 to 40. By the fall, the committee had received 347 registration requests (Lanouette 2004: 146-148).

If the effort made to start this adult language-training program was praiseworthy, it was not without problems. As the Catholic committee made clear in their correspondence with government representatives, two fundamental issues regarding the integration of immigrants had to be urgently addressed:

- Immigrants were not being made aware of the linguistic and cultural specificity of Quebec. It was recommended that in their recruitment and selection efforts, federal immigration officers present a description of Canada that included the presence of Francophones.

- Training opportunities were based in Montreal and needed to be extended to the other major cities and mining towns of the province where migrant workers were also present but without much support.

According to the Catholic committee, language (and religious) education for adult immigrants ought not to be the result of a charitable local initiative; rather it should take the form of a thoroughly financed 
provincial governmental program. On the ground, language evening classes were still in progress but had an unexpected outcome. A brochure prepared in 1949 to promote the program mentioned that the school board was providing courses taught by teachers from different nationalities to immigrants in order for them to learn the 'official language' of their choice. A note at the bottom of the brochure reminded the learners that French, being the language of 80 per cent of the population, was useful (Lanouette 2004: 151).

However, despite this note, a growing number of immigrants began to request English evening classes. Uneasiness among the members of the Catholic Committee and the Neo Canadian committee was expressed when a large number of new landed Italian immigrants openly requested English evening courses. The organisers were facing a dilemma: eliminate English classes altogether, and risk having immigrants attend 'Canadian citizen' evening classes with the Protestants, or teach English and retain the newcomers under the 'good grace' of the Roman Catholic Church. The Catholic committee opted for the teaching of English (or French) and the Roman Catholic religion (Lanouette 2004: 153).

The appeal of English among immigrants was noted in the report Le problème scolaire des Néo-Canadiens (1957). This report offered a detailed overview of the challenges the government of Quebec was facing with its laissez-faire attitude towards immigration. The first challenge was that the province was receiving significantly fewer immigrants than its neighbour, Ontario, a situation which would, if it persisted, further reduce Quebec's demographic importance within Canada, all the more so since immigrants' relocation in other parts of the continent was frequent. Several factors were behind the predilection for the English language. The integration into the English community was perceived by immigrants as a way of ensuring their mobility in the North American continent (cf. Branchadell, this volume on Spanish and Catalan in Catalonia). Moreover, in a context in which Quebec Anglophones were economically dominant, fluency in English was associated with being more competitive in the job market.

At the time this report was published, 75 per cent of immigrants were sending their children to English schools. In the absence of leadership on the part of the French sector, the English sector played an important role in integrating the children and, as a side effect, in integrating the parents. The indifference and sometimes anti-immigrant attitude which some state officials displayed was denounced by leaders of civil society and policy entrepreneurs as bearing not only on Quebec's demographic weight within Canada, but also as threatening the fragile linguistic balance within the province. Their call for action by the Quebec State made immigration a policy issue. In 1961 the French Canada Overseas Service, then a recently created segment of the Ministry of Cultural Affairs, was put in charge of overseeing the integration of new citizens. Rather than 
fulfil its mandate, the service focussed on cultivating relationships with Francophone communities in North America (Pâquet 1997: 12). In 1967 an inter-ministerial report strongly recommended that French be taught to all Neo Canadians (Corbeil 2007). The Ministry of Education implemented this recommendation in the same year by creating a structure of services dedicated to the orientation and the Francization of adult immigrants (Pâquet 1997: 17). Language training was entrusted to school boards, mainly those of the Montreal region where the majority of immigrants were concentrated. Offered in both French and English, the courses dealt with language and also with relevant aspects of French Canadian society.

However desirable, consolidated integration services would not be sufficient to counterweigh the appeal of the English language among immigrants. The Royal Commission inquiry on Education launched in the 1960s shed new light on this issue by placing it in its larger context: the lack of socio-economic motivation (even for Francophones) to master French given that English was the language of the workplace in Montreal (Corbeil 2007). Within the same decade, the Royal Commission on Bilingualism and Biculturalism demonstrated that in all fields of professional practice, Francophones were disadvantaged in comparison to Anglophones, even in Quebec. Those who were able to get higher rank jobs used mostly English at work (Corbeil 2007). Covered daily in the media, these findings were instrumental in showing French Canadians in Quebec that in order to increase the prestige of their language among the immigrant population, the rules of the game with regard to the use of English and French in the workplace had to change (Corbeil 2007). As a result Francophones in Quebec, the only province in Canada where they were a majority, began calling for the State to protect their language and culture.

\section{Francization in the Québécois context}

Quebec language planning policy was put in place in the overall context of the Quiet Revolution, a period during which the provincial government was determined to take control over areas that were important for its cultural, social and economic development. The French Canadian nation, which became concentrated in Quebec, was fully integrating the territorial dimension of its self-affirmation. As a consequence, a terminological shift in the discourse from 'French Canadian' to Québécois occurred, especially among the younger generation. The clerical nationalism that had hitherto provided the foundation for French-Canadian identity evolved into a new form of nationalism, one that revolved around the French language rather than the Roman Catholic religion. 
Putting an end to the lack of prestige of French and the socioeconomic disadvantage that came with it became a State affair. Canada's Official Languages Act of 1969, which instituted State bilingualism, was not seen as suitable for resolving Quebec's linguistic imbalance. A distinct unilingual French language planning strategy was growing in the province. Language legislation occupied the centre-stage of Quebec's politics during the following decade. Three language laws were then passed. The first, Bill 63 (1969), stipulated that means be taken to ensure that immigrants acquired a working knowledge of French upon their arrival in the province. This is when the integration services for adult immigrants established two years earlier were centralised under Centers of Orientation and Francization of Immigrants (COFI for short). The second, Bill 22, passed by the Quebec Liberal party in July 1974, made French the official language of Quebec. The third, tabled in the Quebec National Assembly by the Parti québécois and voted in as the Charter of the French language (Bill 101) on 26 August 1977, transformed the face of Quebec society.

Following the enactment of Bill 101, immigrant children were sent to French schools, ${ }^{2}$ and companies of $50+$ employees underwent a mandatory Francization process whereby French was enforced as the language of internal communication. French was also used in public and commercial signage, conferring to the metropolis a Francophone personality hitherto underrepresented. By making French the predominant language of the public sphere and targeting the language of the workplace, the legislation provided the kind of socioeconomic motivations instrumental in language choices made by immigrants, especially non-Francophones whose interest in French did not necessarily stem from a connection to a national history.

Strengthening French through language legislation was just one part of the language planning strategy the Quebec government devised during the Quiet Revolution to ensure the sustainability of the French language and culture within its borders. The other equally strategic part of the plan was the establishment of an immigration policy as a means to support linguistic vitality. Since immigration had until then been a federal government prerogative, the unilateral creation of the Quebec Ministry of Immigration in 1968 rapidly opened the way for negotiations between Ottawa and Quebec, which gave greater autonomy to Quebec, whose immigration policies now operate relatively independently of the federal government, unlike other sub-state jurisdictions (see Branchadell in this volume). The latest agreement, the Gagnon/McDougal agreement, signed in 1991, enshrined Quebec's exclusive jurisdiction over the selection of independent immigrants (Quebec selects two-thirds of its immigrants) and gave it full responsibility for their integration (Monnot 2012: 64).

But what did integration mean in this emerging legal context? 'Just like the word bilingualism, the word integration is an attractive, reassuring 
and multipurpose word that hides complex personal and social phenomena' (Corbeil 2007: 201). The notion of integration presupposes in its core semantics some kind of relationship between a foreign element, the immigrant, and an already constituted group, the host society. It designates a personal path undertaken by the immigrant towards the host society as well as the willingness on the part of members of that host society to welcome the immigrant. In that respect, Quebec's policy framework to manage integration, just like Quebec society, was undergoing important changes.

One year after the adoption of the Charter of the French Language, the Parti québécois turned its attention to establishing its ideological position on integration. Wishing to distance itself from the American policy viewed as 'slow or forcible assimilation' and the Canadian policy perceived as the 'conservation of the cultures of origin behind the wall of segregation', the Québécois government chose the path of 'exchanges within a Quebec culture' (Quebec, MÉCD 1978). A Quebec 'tree' into which various rootstocks would be grafted was the metaphor used to represent how 'the development of ethnocultural communities was dependent upon the vitality of Quebec French society' (Ramos 2009: 124). As McAndrew (2013: 8) observed, 'this statement reflected the state of interethnic relations during a period where the French community was just becoming the host society to which immigrants were invited to integrate'. As its title suggests, the policy Quebecers, Each and Every One, fostered a more inclusive definition of Quebecers (Quebec, MÉDC 1981). Its conceptual framework with regard to immigrant integration remained one of convergence of cultures between what was depicted as a relatively homogenous Quebec French language and culture majority on the one hand, and minority cultures on the other. It sought to maintain and develop ethnocultural communities, promote their contribution among Francophones and favour their integration to Quebec society through Francization.

Nearly ten years later, the Quebec Liberal Party published a policy statement called Let's Build Quebec Together (Quebec, MCCI 1990), which shifted the focus from community to individual integration. Still serving as the cornerstone of current provincial integration policy, this document conceptually frames integration as a moral contract between the immigrant and the host society. The commitment of both parties to work together in building a tolerant and prosperous society is presented as the only acceptable way to go forward. Quebec must undertake its responsibilities and duties regarding immigrants. In return, in choosing Quebec, immigrants, represented in the policy as individuals rather than members of an ethnocultural community, freely accepted to adhere to the following core principles and values of Quebec as:

1 A society in which French is the common language of public life; 
2 A democratic society where the participation and contribution of all are both expected and promoted;

3 A pluralistic society, open to multiple contributions, within the limits imposed by fundamental democratic values and the need for intercommunity exchanges.

(Quebec, MCCI 1990: 16)

Although not entirely assimilationist in nature, the first principle nevertheless clearly implies the effort expected of the non Frenchspeaking newcomer when integrating into the new society. It also poses the precondition for the second principle, as immigrants' participation and contribution to Quebec society is largely dependant on their ability to use French. The third principle departed from the 'Francophones' versus 'cultural communities' dichotomy of the previous policy and 'provided for much blurring of distinct identities, a trend which reflected the shifting reality of plurality in Quebec' (McAndrew 2013: 8), especially in Montreal.

Since the adoption of this policy, the number of immigrants admitted yearly in the province has increased steadily. Between 1991 and 2003, Quebec welcomed an average of 35,000 immigrants every year. This number rose to 40,000 immigrants a year between 2004 and 2010, and to 50,000 between 2011 and today (Leclerc 2014). With regard to Francization of immigrants, Quebec has from the outset adopted a twopronged approach: an upstream selection policy that seeks to increase the number of immigrants who already know French, and a linguistic integration policy that works downstream to Francize non-Francophone immigrants by means of French classes.

In terms of immigrant selection, Quebec recruits its immigrants mainly in French-speaking countries, and the selection process heavily favours knowledge of French. As a result, the proportion of immigrants who claim French as a first language has steadily increased. This proportion was 39 per cent in 1996-1997 but rose to 57.3 per cent in 2005-2006 (Corbeil 2007: 213), and to 64 per cent in 2009 (Monnot 2012: 83). As another result, the profile of Quebec immigration became quite different from that of the rest of Canada. Morocco, Algeria and France were the top three sources of immigrants for Quebec in 2011 whereas China, Philippines and India were the top three sources for Canada generally (Monnot 2012: 88). Despite the significant increase in the number of Francophones, the demand for Francization continued to grow because the overall level of immigration was also continuously increasing.

The Ministry of Immigration and Cultural Communities (MICC) has taken a leadership role in language training since it brought Francization services under its authority in 1975. Until the 1990s, its approach towards the integration of newcomers was structured around the concept of 
COFI, whose 'primary function was the delivery of French language instruction and services to non-Francophone immigrants' (Jedwad 2002: 32). In 2000, following a reform that was designed to bring Francization services closer to the institutional mainstream, COFIs were replaced with Carrefours d'intégration whose role has been to evaluate the needs of new immigrants and refer them to the appropriate training services. This decentralised approach allowed for a much-needed diversification of the offer in terms of language training, spanning literacy, Francization and more advanced training in reading and writing.

At present, adult immigrants have access to a wide range of free French language education services in a variety of settings. Francization services for immigrants are offered in partnership with Francophone institutions (colleges and universities), and community organisations. Adult immigrant students can be either full time, in which case they receive a weekly financial allowance, or part-time. For part-time students, specialised courses addressing specific needs in relation to different job areas are offered in addition to basic Francization. The MICC has also partnered with companies and organisations to offer Francization services in the workplace. Workers can take up to 12 hours per week either during or after work hours. Francization is available through governmental employment programs. French courses, including Francization and literacy for less educated immigrants, and French as a second language, are also offered through the adult education programs of school boards. Finally, French training opportunities are available in various community and cultural settings.

In order to avoid the balkanisation of its language training services, the MICC in partnership with Citizenship and Immigration Canada has developed a common reference framework for the Francization of immigrants in Quebec. First published in 2000 and updated in 2011, the Quebec Proficiency Scale is an adaptation by Quebec academics and practitioners of the Canadian Language Benchmarks (see Fleming this volume) (MICC 2011). As Laurier (2011: 6), the leader of the project, summarises it, the proficiency scale "provides a common language to people who are concerned: learners, teachers, advisors, training centres, employers, organisations etc.' thus facilitating mobility from one training centre to the other, language certification and the setting of language norms for the job market.

\section{The situation today}

Despite the steady increase in the level of immigration Quebec's demographic weight in the country is still decreasing. In 1991, Quebec's population represented 25.2 per cent of the Canadian population. Ten years later, this proportion shrank to 23.8 per cent (Monnot 2012: 81) and 
at 2013 it stood at 23.1 per cent (Caron 2013: 49). According to the pro rata formula defined in the Gagnon/McDougal agreement, the province could absorb up to 28.4 per cent of the immigration flow; but until today it has been unable to reach a level proportional to its demography. As mentioned earlier, Canada set its target number of annual admissions between 240,000 and 265,000 for the current decade. In 2011 the country exceeded annual targets by admitting 280,000 immigrants. Of that number, 51,746 landed in the province of Quebec. This number represents 20.8 per cent of the Canadian percentage, still below the 25 per cent to 30 per cent set by Quebec for it to maintain its share of the Canadian population. At the same time, according to the Organization for Economic Cooperation and Development, welcoming 55,000 immigrants every year for a population estimated at 7.8 million is proportionally equivalent to receiving 15 per cent more than Britain, 86 per cent more than the United States and 150 per cent more than France (Leclerc 2014). As Monnot (2012: 82) points out: 'The bar is thus set very high for Quebec'.

There is no doubt that an increased level of immigration comes with a moral obligation for the government to facilitate integration. The report of the Bouchard-Taylor Commission on accommodation practices related to cultural differences published in 2008 reminded the government of the importance of integration services and Francization programs. Indeed despite the fact that most immigrants selected by the province are highly qualified, and have a high level of education " $\mathrm{t}] \mathrm{h}$ he unemployment rate among immigrants between 25 and 54 years of age who have lived for less than five years in Quebec is nearly three times higher than the rate among native-born Quebecers' (Bouchard and Taylor 2008). Insufficient knowledge of the language was among the contributing factors. Yet as Pagé (2005: 220) reports, there are still serious shortcomings in essential areas of integration given that 'year after year, 35 per cent of the individuals asking for French courses did not obtain any'. In fact, according to Laurier (2005), Francization programs reach less than half the targeted population of immigrants.

Some of these immigrants are willing to sign up for French language courses but are faced with the following issues (Longpré, 2013):

- the number of French courses is not at the level of the demand;

- the waiting lists are too long;

- the financial compensation does not benefit all in need;

- funding is often discontinued before the end of the training;

- the level of proficiency attained at the end of the training remains below what is required by the job market, etc.

Other immigrants choose not to sign up for these courses at all, not realizing the economic limitations that result from a lack of French 
proficiency. A qualitative study conducted by Saint-Laurent and El-Geledi (2011) examined the linguistic perceptions of allophone immigrants who integrate the English-speaking community when settling in Montreal rather than taking the path of Francization towards the majority Francophone community. The study reports that many immigrants believe that knowing English is enough for their integration. They see that Montreal city is multicultural, and very bilingual on the institutional level, that they can be served in English in businesses as well as in public services, that they can live in mostly Anglophone neighbourhoods, receive instruction in Anglophone colleges or universities and have access to English culture through radio, television, newspapers, movie theaters, etc. In addition to the multilingual reality on the ground, many immigrants 'believe that Canadian official bilingualism necessarily translates into a de facto bilingualism across the country' (p. 22). They may not become aware of Quebec's official French monolingual policy until the time comes for them to find work. The study also reveals that immigrants who failed to learn French realise that their lack of knowledge of the official language seriously restricts their career prospects, and is a barrier to finding appropriate employment.

In response to the shortcomings in integration raised by a number of practitioners and researchers and confirmed by the Bouchard-Taylor report in 2008, the MICC put forward the action plan To Enrich Quebec: More French Better Integration the same year, seeking to reinforce, as the title suggests, the integration measures of the 1990 policy. The new approach with regard to French language education falls into three categories:

- earlier Francization 'by offering immigration candidates the opportunity to learn French prior to their arrival in Quebec' (Quebec, MICC 2008: 2);

- better Francization with the introduction of courses tailored to occupational sectors; and

- more Francization, which consists in reaching as many individuals as possible through the different programs, including online courses for learners who have reached an intermediate level.

The new approach also aimed at stressing the importance of the French language in Quebec society. Since 2008, applicants must sign the declaration on the common values of Quebec society embedded in the selection certificate form for their application to be processed. The declaration opens with the following general statement:

Québec provides services to immigrants to help them integrate and participate fully and completely in Québec society in order to meet 
the challenges of a modern society such as economic prosperity, the survival of the French fact and openness to the world. In return, immigrants must adapt to their living environment.

(MICC 2013: 7)

Immigrants are thus explicitly invited to commit to the societal project of ensuring the survival of the French language. They are told, 'Québec society is [...] governed by the Charter of the French language, which makes French the official language of Québec. Accordingly, French is the normal and usual language of work, instruction, communications, trade and business.' And finally they are asked to commit 'to learn French if [they] do not speak it already' (MICC, 2013: 7).

Meanwhile, in the metropolis, the bilingual requirements of the job market come as an unpleasant surprise to the French-speaking immigrants who end up having a hard time finding a job because of their lack of knowledge of English. The Charter did a lot to increase the use of French in the workplace, but it has its limits. Quebec businesses and service industries operate in the North American context where most external communications are in English. As players in a globalised economy, Quebec businesses must make use of the English language in their external communication. Immigrants are now given access to free English language courses (Dutrisac 2008).

In the fall of 2013, the then newly elected Parti québécois tried to rewrite and toughen the Charter of the French Language (Bill 101). Its aim was two-fold: (i) ensure that requiring English in a job was justified and (ii) extend mandatory Francization to companies of $25+$ employees in order to strengthen the link between professional insertion and the use of the French language. This new version of the bill was not passed: this was a minority government and faced strong opposition in the legislative assembly. While the language issue continues to cause tension in the polis, a large number of immigrants seem to have found their own way through the 'linguistic problem': they simply learn the two languages (Pagé 2005, 2010). This comes as no surprise since Montreal offers an international context within which multiple identities and language configurations are taking shapes. While this may sound optimal, there is the risk that the linguistic and cultural chasm between the major metropolitan area and the regions will continue to grow.

\section{Conclusion}

As immigrant language education in Quebec shifted away from religious and community based programs and towards government provision, policies emerging from the Provincial Government began explicitly promoting a Francization program. Seeking to bolster a proportionately 
declining French-speaking population, policies tend to favour the recruitment of French-speaking immigrants to Quebec, and have increased the availability and diversity of French language education opportunities. Yet the increasingly multilingual realities of some areas of Quebec, especially Montreal, Gatineau and Sherbrooke, continue to pose a challenge to Quebec's monolingualist state language policy, with English as the world lingua franca that is portable, and the bilingualism of daily life in those areas leading many immigrants to question the utility of learning French.

\section{Notes}

1 The term 'Quiet Revolution' refers to the time of great political and social change that occurred in Quebec from the late 1950s to the late 1960s (see section on Francization in the Québécois context).

2 Those who descend from a clearly established and documented Englishspeaking background could be exempted and given the right to attend English-speaking schools.

\section{References}

\section{Government documents and reports}

Ottawa. circa 1948. Memorandum on Training for Canadian Citizenship (Draft Only). ANQQ: E13 1993-06-007/266, no 557.

Québec (1957) Le problème scolaire des Néo-Canadiens. Rapport du Comité d'enquête soumis au Comité catholique du Conseil de l'Instruction publique. Québec, 1 May, p. 8. ANQQ: E13 1993-06-007/266, no 557.

Québec. Ministère d'État au Développement Culturel (MÉDC) (1978) Cultural Development Policy. Québec: Éditeur officiel.

Québec. Ministère d'État au Développement Culturel (MÉDC) (1981) Autant de façon d'être Québécois: Plan d'action du gouvernement du Québec à l'intention des communautés culturelles. Québec: Ministère des Communications.

Québec. Ministère des Communautés Culturelles et de l'Immigration du Québec (MCCI) (1990) Au Québec pour bâtir ensemble. Énoncé de politique en matière d'immigration et d'intégration. Québec: Direction des communications du ministère des Communautés culturelles et de l'immigration du Québec.

Québec. Ministère de l'Immigration et des Communautés Culturelles (MICC) (2008) TO ENRICH QUÉBEC. Better integration. Measures to strengthen Québec's action with respect to the employment integration of immigrants (courtesy translation). Québec: Direction des affaires publiques et des communications of the Ministère de l'Immigration et des Communautés culturelles. Available online at: www.micc.gouv.qc.ca/publications/en/mesures/Mesures-Integration-Brochure 2008-Anglais.pdf (accessed 17 March 2014).

Québec. Ministère de l'immigration et des communautés culturelles (MICC) (2011) Échelle québécoise des niveaux de compétence en français des personnes immigrantes adultes. Québec, Direction des affaires publiques et des communications. 
Québec. Ministère de l'Immigration et des Communautés Culturelles (MICC) (2013) Application for Selection Certificate - SKILLED WORKER, Form A-0520AA (2013-08). Available online at: www.immigration-quebec.gouv.qc.ca/ publications/en/dcs/A-0520-CA-dyn.pdf (accessed 23 March 2014).

\section{Books, articles and reports}

Bouchard, G. and Taylor, C. (2008) Building the Future. A Time for Reconciliation, abridged report. Québec: Government of Québec.

Caron, J. (2013) Choisir le progrès national. Montréal: Druide.

Castonguay, C. (2012) Libérer la langue française. In G. Paquette, A. Binette and E. Palacio-Quintin (eds), L'indépendance, maintenant! Collectif des intellectuels pour la souveraineté. Montreal: Michel Brûlé, 41-65.

Corbeil, J.-C. (2007) L'embarras des langues. Origine, conception et évolution de la politique linguistique québécoise. Montreal: Québec Amérique.

Curzi, P. (2010) Le grand Montréal s'anglicise. Esquisse du vrai visage du français au Québec. Analyse de la situation. Available online at: http://archive.pierrecurzi.org/wp-content/ uploads/201 1/07/Version-Finale-V25.pdf (accessed 15 February 2014).

Daniel, D. (2006) La politique d'immigration du Québec. In J. Crête (ed.), Politiques publiques: le Québec compare. Québec: Les Presses de l'Université Laval, 43-70.

De Villers, M.-É. (2005) Le vif désir de durer. Illustration de la norme réelle du français québécois. Montreal: Québec Amérique.

Dutrisac, R. (2008) Québec aide les immigrants à parler l'anglais. Le Devoir, 1 May.

Jedwad, J. (2002) Immigration and the Vitality of Canada's Official Language Communities: Policy, Demography and Identity. Canada: Minister of Public Works and Government Services.

Jedwad, J. (2008) How shall we define thee? Determining who is an Englishspeaking Quebecer and assessing its demographic vitality. In R. Y. Bourhis (ed.) The Vitality of the English-Speaking Communities of Quebec: From Community Decline to Revival. Montreal, Québec: CEETUM, Université de Montréal, $1-18$.

Juteau, D. (1999) L'ethnicité et ses frontiers. Montreal: Presses de l'Université de Montréal.

Lanouette, M. (2004) Penser l'éducation, dire sa culture. Les écoles catholiques anglaises au Québec, 1928-1964. Doctoral dissertation, Université Laval.

Laurier, M. D. (2005) La maîtrise du français dans la formation des immigrants adultes. In A. Stefanescu and P. Georgeault (eds), Le français au Québec: les nouveaux defies. Anjou: Fides, 191-231.

Laurier, M. D. (2011) Different frameworks for different needs: the Quebec Proficiency Scale and the development of instruments. 4th ALTE International Conference - The Impact of Language Frameworks on Assessment, Learning and Teaching: Policies, Procedures and Challenges, Krakow, 7-9 July. Available online at: www.alte. org/2011/presentations/pdf/michel-laurier.pdf (accessed 10 March 2014).

Leclerc, J. (2014) La question de l'immigration au Québec. In L'aménagement linguistique dans le monde. Available online at: www.axl.cefan.ulaval.ca/amnord/ Quebec-4immigration.htm (accessed 24 February 2014). 
Longpré, T. (2013) Québec cherche Québécois pour relation à long terme. Comprendre les enjeux de l'immigration. Montreal: Stanké.

McAndrew, M. (2013) Québec immigration, integration and intercultural policy: a critical assessment. Canadian Diversity 10(1): 16-21.

Meney, Lionel. (2010) Main basse sur la langue. Idéologie et interventionnisme linguistique au Québec. Montreal: Liber.

Monnot, L. (2012) La politique de sélection des immigrants du Québec. Un modèle enviable en péril. Montreal: Hurtubise.

Pagé, M. (2005) La francisation des immigrants au Québec en 2005 et après. In A. Stefanescu and P. Georgeault (eds), Le français au Québec: les nouveaux defies. Anjou: Fides, 569-587.

Pagé, M., with the collaboration of P. Lamarre (2010) L'intégration linguistique des immigrants au Québec. Étude IRPP 3. Available online at: /http://irpp.org/ $\mathrm{fr} /$ research-studies/l'intégration-linguistique-des (accessed 25 March 2014).

Pâquet, M. (1997) Toward a Quebec Department of Immigration, 1945 to 1968. Canada's Ethnic Groups, Series no. 23. Ottawa: the Canadian Historical Association.

Ramos, E. (2009) Les politiques du gouvernement du Québec concernant l'intégration des minorités culturelles à la société québécoise (1978-1985). Master's dissertation, Université du Québec à Montréal.

Saint-Laurent, N. and El-Geledi, S. (2011) L'intégration linguistique et professionnelle des immigrants non Francophones à Montréal, Québec: Conseil supérieur de la langue française.

Statistics Canada (2006) 2006 Census. Available online at http://www12.statcan. gc.ca/census-recensement/2006/index-eng.cfm (accessed 9 January 2014).

Statistics Canada (2011) 2011 Census. Available online at http://www12.statcan. gc.ca/census-recensement/index-eng.cfm (accessed 9 January 2014). 


\title{
Justice-oriented citizenship in Canadian ESL classes \\ The views of experienced teachers
}

\author{
Douglas Fleming
}

\section{Introduction}

The field of adult ESL (English as a Second Language) plays a significant role in immigrant citizenship education and acculturation, yet we know very little about how citizenship is actually viewed and treated by second language education (SLE) teachers throughout their careers (McCartney 2013). This lack of empirical research is significant, given the marked decrease in citizenship engagement in western democracies in recent years. Lankshear and Knobel (1997) make the case that meaningful citizenship education can only take place within second language and literacy education when teachers deliberately adopt justice-oriented paradigms in their curricular work. Shohamy (2007) argues, however, that SLE teachers often find that their curricular development choices are restricted by agendas embedded within assessment instruments.

In this chapter, I discuss a study which explores what veteran ESL teachers can tell us about treating citizenship from the vantage point of social justice, even at beginning levels of proficiency. Looking at alternatives to current Canadian second language curriculum policy and curriculum implementation using data gleaned from a set of these experienced SLE teachers, I argue that second language educators should challenge the tendency to infantilise second language learners that is embedded ideologically within a key Canadian curriculum and assessment document.

Drawing upon the data discussed below, this chapter addresses how such a justice-orientation to citizenship could be concretely understood with a view to challenging the ideologies commonly found within official curriculum and assessment documents.

This chapter first presents critiques of the 2000 and 2012 versions of the Canadian Language Benchmarks (Pawlikowska-Smith 2000; Hajer and Kaskens 2012) before presenting the theoretical backgrounds for the study reported here: first, the notions of citizenship and acculturation and second, of justice-oriented citizenship. This is followed by an outline 
of the methodology and findings pertaining to a study recently conducted with veteran ESL/literacy teachers in Ontario and British Columbia with regard to their classroom treatments of citizenship. I conclude with a discussion of the implications for teaching practice and how this practice speaks to second language pedagogy and curriculum planning.

\section{The Canadian Language Benchmarks 2000}

The Canadian Language Benchmarks 2000: ESL for Adults (PawlikowskaSmith 2000) was an attempt to define English language proficiency organised into 12 levels, from beginner to full fluency. As Norton Pierce and Stewart (1997) noted, the policy initiatives that gave rise to this document were framed around the need to develop a systematic and seamless set of English language training opportunities out of the myriad federal and provincial programs that existed previously.

A French version of the CLB entitled Standards Linguistiques Canadiens was released in 2002 (Canadian Centre for Language Benchmarks 2002). According to Marianne Kayed, the Senior Program and Partnerships Manager for the Canadian Centre for Language Benchmarks (personal correspondence, 4 February 2014), the original French version was met with a great deal of criticism because it was simply a translation of the English. In fact, the Quebec government commissioned its own French language assessment procedures (Ministère de l'Immigration et des Communautés Culturelles 2006) for utilisation within that province.

Nevertheless, after an extensive consultation process primarily with practitioners, a second French version of the CLB was released in 2006: the Niveaux de Compétence Linguistique Canadiens: Français Langue Seconde pour Adultes (The Canadian Centre for Language Benchmarks 2006). This latest version differs significantly from both the 2000 and the later 2012 English versions, in terms of both its theoretical framework and citizenship content. The theoretical framework is more closely and explicitly aligned with Bachman's construct of communicative competence (1990). Moreover, the citizenship content within the latest French version is substantially more extensive than in the English versions. Task exemplars within the French version, for example, describe the need to participate in social and community-based politics (p. 65; p. 241) regardless of language ability. This emphasis on participation is lacking within the English versions of the CLB. Given the substantial differences between the French and English versions of the CLB, and the fact that the French version of the CLB is seldom utilised either in Quebec or the rest of French Canada, I will not treat the French version further here. (See Bouffard, this volume, for a discussion of language policy in Quebec.)

The bulk of the content found in both the 2000 and 2012 English versions of the CLB was arranged for each level in a series of matrices that 
correspond to the language skills of reading, writing, speaking and listening. As in the Common European Framework for Languages, each benchmark (or level) contains a general overview of the tasks to be performed upon completion of the level, the conditions under which this performance should take place, a more specific description of what a learner is expected to do with examples, and criteria used to determine whether the task performance has been successful.

Given the fact that the $C L B$ is quite clearly task-based, some scholars have referred to it as a de facto curriculum document (e.g. DeVoretz et al. 2002) despite contrary claims made within the first version of the CLB. As I have argued elsewhere (Fleming and Walter 2004), the empirical content of pedagogical tasks are of key importance, particularly when they are represented as exemplars in documents used to inform curriculum development. Practitioners inevitably use the CLB as a set of guidelines to inform pedagogical choices, particularly in view of a lack of nationally prescribed curricula (Shohamy 2007). In effect, given the official nature of the $C L B$, the document privileges content found within the sample tasks they provide. To be meaningful in terms of assessment or pedagogy, tasks have to have clear reference to non-linguistic content (Nunan 2004). Thus, the $C L B$ specifies what should be given priority in terms of English language training and, in view of its official character, represents itself as an instrument of national language policy.

In the entire 2000 document there were only three references to tasks or competencies broadly associated with citizenship. These were to 'understand rights and responsibilities of client, customer, patient and student' (p. 95); 'indicate knowledge of laws, rights, etc.' (p. 116); and 'write a letter to express an opinion as a citizen' (p. 176). Unfortunately, these competencies are not elaborated upon further, and so remain rather vague and incomplete. Most revealing is what was missing, especially in terms of how language is connected to exercising citizenship. For example, the word vote did not appear in the document.

In addition, through admission and omission the document represented good citizens as obedient workers. Issues related to trade unions and collective agreements were given next to no attention in the document. References to labour rights, such as filing grievances or recognising and reporting dangerous working conditions, were nonexistent. Employment standards legislation is covered in a single vague reference to knowledge about the existence of minimum wage legislation. The 2000 CLB fails to mention other aspects of standards of employment legislation, workers' compensation, employment insurance or safety in the workplace. However, a lot of space in the document was devoted to giving polite and respectful feedback to one's employer, participating in job performance reviews and meetings about trivial issues such as lunchroom cleanliness. 
While the document did represent language learners as having rights and responsibilities, these were almost exclusively related to being good consumers. Learners were to understand their rights and responsibilities as a 'client, customer, patient and student' (p. 95), but not as a worker, family member, participant in community activities, or advocate. Adult English language learners enrolled in programs informed by the CLB often complain about consistently having been denied overtime pay and access to benefits, being forced to work statutory holidays or being fired without cause (Fleming 2010). It was also disconcerting to note the limitations placed on the few references to citizenship and the manner in which they were often couched. Only one of the three instances noted above (writing a letter) provided a view of citizenship as active, albeit fairly limited, engagement. The other two were decidedly individualistic, vague, passive and abstract. No content linked citizenship to collective action or group identity.

Significantly all three of the competencies referring to citizenship occurred at the very highest benchmark levels, at which point students are writing research papers at universities. The document thus implied that opinions expressed in languages other than English had little value and that voting not informed by a high level of proficiency is an activity that warrants little engagement, a position that recalls the ways in which voting rights have been denied in other jurisdictions on the basis of low levels of education.

\section{The Canadian Language Benchmarks 2012}

The new version of the CLB (Hajer and Kaskens 2012) is based on an extensive process designed to establish the validity and reliability of descriptors included within the document. As noted by the Canadian Centre for Language Benchmarks (2014), these revisions were made in consultation with selected experts in the field of language testing, who evaluated the document in light of technical guidelines provided by the American Education Research Association (1999) and the Council of Europe (2011). Unlike the 2000 version, the new version is forthright about claims that it is designed to be 'a national standard for planning curricula for language instruction in a variety of contexts' (Hajer and Kaskens 2012: v).

Although the focus on consumer rights continues to dominate in the new version of the CLB, a few references to labour rights were added. Benchmark 5, for example, contains an exemplary task that requires an understanding of employment standards legislation (Hajer and Kaskens 2012: 89). Within benchmark 7 there is reference to pedagogical tasks in which one "participate[s] in a union meeting to discuss workload, wages and working conditions' (p. 57). These are laudable, if somewhat scant, improvements. 
However, citizenship rights remain undeveloped in the new version. Voting is mentioned only twice and in reference to passive activities: once within an exemplar task in which a learner is expected to 'listen to an allcandidates' debate during an election campaign to analyse and evaluate arguments presented by each candidate and determine which candidate to vote for' (Hajer and Kaskens 2012: 35), and a second task almost identical in content that appears on the same page. Both references are found in the passive listening framework at benchmark 12 (the highest in the document), the level at which one is writing graduate level assignments.

\section{Notions of citizenship and acculturation}

Citizenship has long been a contested notion both locally and globally, especially in terms of its relationship to civil liberties (Tully 2008). For Giddens (1995), citizenship is a form of belonging that defines one's inclusion in (or exclusion from) civil society. The exclusionary and inclusionary aspects of citizenship existed in classical Athens, where citizenship was limited to educated male property owners who controlled the labour of others (particularly slaves and women) and had a claim to Athenian bloodlines (Lape 2010). Those falling outside that definition might live in Athens, but were excluded from citizenship.

Isin and Wood (1999) suggest two major frameworks to describe overall orientations towards modern citizenship. The first, jus soli (right of the soil), is a political- and economic-based framework associated with the French philosopher Ernest Renan that defines citizenship in legalistic terms. Renan argued that one could still be a full citizen of France without belonging to the cultural or linguistic group historically associated with being French. One must only be born or naturalised within the nation's geographical boundaries and be bound by the state's legal strictures. The second framework, jus sanguinis (right of the blood), is an ethnic-culturallinguistic framework associated with the German philosopher Johann Fichte that establishes what constitutes a normal citizen. Older than the one that emerged from the French Revolution, this framework draws on notions of race and ethnicity in ways that predate the modern nationstate. To be German meant that one adhered to the perceived norms of German culture, language and tradition. One did not even have to set eyes on Germany as a geographical entity. Fluency in what is perceived to be a particular national language is an important marker used to categorise people in this manner.

The concepts jus soli and jus sanguinis are not always clear-cut or a mutually exclusive means of establishing a person's national membership. In Canada, for example, acceptance of bilingualism and multiculturalism is often taken as an important normative marker for being Canadian and can be interpreted as an appeal to norms corresponding to jus sanguinis. 
Much of Charles Taylor's (1994) influential work, in fact, revolves around how respect for multiculturalism and bilingualism has been a catalyst for Canadian unity. However, multiculturalism and bilingualism in the Canadian context is also a legalistic concept because it forms a central part of the national constitution and a plethora of significant policy documents. This is an appeal to notions more closely associated with jus soli frameworks.

Notions of citizenship in the field of second language education have been strongly influenced by the work of Gardner (1985) and Schumann (1978). Central to Gardner's work was what he called integrative motivation: the desire to learn the target language based on positive feelings for the community to which that language belongs. Schumann's acculturation model (1978) outlined the factors involved in whether or not groups of learners have a propensity to learn the language of the majority population. Norton (2000) critiques these two models by noting that 'differences between language learners and target language speakers are not theorised in terms of power, which compromise efforts by language learners to interact with target language speakers and promote SLA' (p. 119). For Norton, acculturation is a two-way street, not simply a matter of having second language immigrants learn the more powerful dominant culture of the target community. Belonging to a nation is a reciprocal process in which the newcomer contributes to how citizenship evolves and is newly defined.

Tully (2008) sees the struggle for expanded notions of citizenship as a move away from limited neoliberal notions of national belonging. Citizens should be more than obedient workers who periodically cast votes in general elections.

\section{Justice-oriented citizenship}

As I have argued elsewhere (Fleming 2008), citizenship has historically been a common component in Canadian ESL programming. Debates about how to define citizenship, still central in the academic literature (Crick 2007), have also found a central place in research on Canadian English as a Second Language (ESL) provision (Derwing 1992; Derwing and Thomson 2005). They increasingly treat citizenship as an active, participatory role, rather than a passive status simply conferred by a nation state (Kennedy 2007).

Westheimer and Kahne (2004) have argued that education for citizenship should encourage students to become critical citizens who explore the causes of social problems in order to work for substantial societal change. Their framework posits three different types of roles as part of one's civic identity: the personally responsible citizen, the participatory citizen and the justice-oriented citizen. The personally responsible citizen, who is honest, self-disciplined and hard working, may contribute time or 
money to charitable causes and do such things as volunteering at a food bank over a holiday period. Voting is the quintessential activity that this form of citizenship takes. The second form of citizenship, the participatory citizen, has the attributes of the first type, but is more involved and has a greater understanding of the inner workings of government and civic institutions. This citizen organises charitable activities such as food banks, develops relationships that feature common understandings and commitments, and might seek political office for the purposes of making a contribution to existing institutions and traditions in uncritical ways. The third form of citizenship, the justice-oriented citizen, shares the attributes of the other two, but has also developed a critical understanding of civic institutions and overall societal contexts. This type of citizen seeks fundamental change that addresses social inequality and redress in the context of pressing current issues but does not limit his or her activities to voting. Instead, citizens of this sort work to connect a critical analysis of pressing social issues to collective social action. As Westheimer and Kahne (2004) put it, justice-oriented citizens 'critically assess social, political and economic structures and explore strategies for change that address root causes of problems' (p. 29).

The lack of empirical research pertaining to citizenship education in adult ESL is a significant problem given its importance to Canada, with its large immigrant population (see Bouffard in this volume). As I detail below, the experienced teachers who participated in this study have much to tell us about citizenship focused on social justice.

\section{Methodology}

The research question guiding this study was, 'How do veteran ESL and literacy teachers understand the purposes of ESL and literacy education?' Based on my practical knowledge of the field, I decided that eight participants from different geographical locations would be sufficient to establish patterns in the data. The eight participants in the sample, who worked in Ontario and British Columbia, the two Canadian provinces that receive the first and second most newcomers to the country each year, were recommended to me by the supervising managers of two largest public school continuing education departments in their respective provinces. Each administrator was asked to identify four instructors who could give me the most complete picture of the issues I wanted to examine, based on their extensive employment in a wide variety of capacities in their respective departments. The University of Ottawa's Ethical Review Board approved the ethical protocols for the study.

Semi-structured interviews were the principal method of data collection. Informed consent was obtained from participants prior to these interviews after the Ethical Review Board at the University of 
Ottawa approved the research plan. Although an initial start list of questions was utilised (see below), the interviews were conducted informally. The participants were first asked to describe the highlights of their careers and then encouraged to provide definitions of ESL and literacy. The interviews then focused on what the participants believed to be the overall purposes of these forms of education. Finally, the participants were asked about how their understandings changed over time and encouraged to provide concrete examples from their teaching, particularly in how their instructional experiences were shaped by their conceptions of citizenship.

The interviews were audio taped, transcribed and thematically coded through the use of qualitative research software. Coding was conducted in terms of identifying emerging themes and patterns that were related to demographic information, training, teaching experiences, career paths, opinions as to the purposes of ESL and literacy instruction and conceptualisations of citizenship. I have supplied two appendices at the end of this chapter that summarise the characteristics of the eight participants for this study. In the discussion that follows, the numerals used to identify the participants refer to those assigned to them in the appendices.

\section{Summary of findings}

I have arranged the summary that follows under subheadings into the three themes that emerged from the data: strong endorsements of justiceoriented citizenship and critical literacy, endorsements of participatory citizenship and literacy, and rejections of justice-oriented citizenship and critical literacy.

\section{Strong endorsements of justice-oriented citizenship and critical literacy}

Half of the participants in this study (\#1, \#2, \#4, \#7) strongly endorse justice-oriented versions of citizenship and critical orientations towards literacy and language learning. They also make strong links between these notions. These teachers make connections between language learning and being involved in one's community as citizens. They stress the need to help learners be active participants in local community events. They make explicit references to class and privilege. Moreover, they emphasise that the role of teachers in this context is to instil confidence in their learners so that they can be articulate about their rights and needs.

One of these participants (\#1) cited a research report (Ontario Literacy Coalition 2007) in support of her contention that overlaps in the knowledge base related to the fields of ESL and literacy education are not 
new and have serious practical implications in terms of how citizenship is treated. Although 'citizenship is extremely important' in both ESL and literacy education, she feels that one should tailor-make curriculum development and programming appropriately for the two fields.

For this participant, justice-oriented citizenship lies at the core of literacy education. As she puts it:

This is what the value of literacy is. It is about citizenship. It is about how you get involved, how you understand what your community is, what it is as a citizen, what you are entitled to, what you should be giving back and the whole concept of citizenship at large.

Moreover, according to this participant, learners from lower socio-economic backgrounds need to be shown that their desires for social change are 'legitimate'. This teacher strongly endorses a justice-oriented notion of citizenship in ways that echo Westheimer and Kahne's (2004) framework.

Another of these participants (\#2) taught elementary school for six years and has had several decades' worth of experience in ESL and literacy programs. She corroborates many of the things my first respondent noted and stresses that for many students who lack literacy skills, issues related to citizenship are 'really foreign to their personal lives. [Citizenship] is something they haven't considered because they are in a day-to-day struggle, so they don't see things from other perspectives and what their role or responsibility is as a Canadian'. This participant thus notes that the economic pressures on these learners and their limited access to media give them a restricted sense of the overall forces at play in society. By implication, she notes that limits to literacy in turn limit citizenship.

This participant stresses that literacy education must engage learners in an awareness of what happens in society by finding specific ways to discuss voting rights in the classroom through the context of the everyday issues affecting one's learners and their community. She thus closely links critical forms of literacy to justice-oriented forms of citizenship.

Another participant (\#4) has over ten years' teaching experience in both ESL and literacy education and has worked for five years as an editor of a national literacy magazine. She told me that many beginning ESL classes typically develop a focus on broadly based notions of literacy because many immigrants from poorer backgrounds or warzones have limited experience in formal classroom situations. Literacy cannot be conceptualised in these circumstances simply in terms of skills. She notes that at the start of her teaching career, she found that her students lacked the ability to attend to classroom tasks, goal setting, cognitive restructuring and self-evaluation. This participant makes the link between literacy and citizenship explicit by noting that literacy helps one clarify; 
how one feels about oneself as a part of this community and a part of this place, it is about the stuff that happens around the learning to read. As people learn to read, they start to analyse class and privilege. One of the things that people do in literacy programs is they start to make connections.

The final participant (\#7) whose remarks relate to this theme had been teaching full time in an ESL program for about four years at the time of the interview. Previously she taught part-time in a literacy program for the same school district and was a teachers' aide in a local elementary school for about eight years. When asked whether there is a skill component to literacy, this teacher strongly emphasises that it is more than that'. She indicates that literacy instruction does have a skill-based dimension, but that there is a second level that 'is like trying to invent a third language' in which students learn self-confidence and autonomy. As this teacher expresses it, 'confidence, yes, because if learners feel they are less competent ... they cannot articulate their rights and needs'. This teacher shows an orientation that goes beyond a skill-based notion of literacy and clearly links this to a justice-oriented notion of citizenship.

\section{Endorsements of participatory citizenship and literacy}

Two respondents (\#5, \#6) feel that dealing with citizenship means helping learners relate daily struggles with participating in citizenship. They talk about providing role models of compassion and generosity, and use activities such as debates and mock elections in their classrooms. Although their orientation might not be termed critical, they do think of citizenship in terms of active participation and go beyond skill-based notions of literacy.

One of these participants (\#5) taught extensively in both the ESL and literacy before becoming an administrator. She emphasises that an ESL classroom is 'a very complex classroom environment' because one is not only dealing with the 'nuts and bolts of the English language' but also with the 'very real needs the students have in terms of settlement, day to day life, frustrations and struggles'. Given the diversity of needs of these learners, treating literacy in the classroom involves working with learners with beginning second language skills.

For this participant, dealing with citizenship means helping learners make an 'inquiry into the culture of being Canadian and what it means to be a Canadian'. As she expresses it, 'we most certainly do not limit ourselves to teaching to a citizenship test'. Rather, she and her colleagues interweave principles related to 'participatory citizenship into everything they do', so as to help students who are becoming Canadian and 'attempting to navigate in our culture and sort of juggling their own culture at the same time'. 
Participant \#6 argues that literacy programs are designed for students who need 'safe learning environment[s]'. Literacy teachers have to pay attention to the special needs of these learners and avoid developing rigid or linear curricula. Part of this participant's mandate is to prepare students for the multiple choice citizenship tests that feature the set of normative 'facts'. However, my respondent stresses the need to go beyond these tests in order to develop students' own thinking about what it means to be Canadian by organising such activities as debates and mock elections.

As this teacher explains, her overall goal is to help students make independent and informed judgments about issues related to the local community and to Canada as a whole. In essence, these learners are exploring the meaning of:

being a good person, being a good citizen, and being a role model for others and bringing in the compassion and the generosity to help others, the vision for future ... You need to have basic knowledge of what it is you are looking into, what the country needs ... a good citizen would be a person who is doing his or her best for the betterment of humanity.

\section{Rejections of justice-oriented citizenship and critical literacy}

Two respondents (\#3, \#8) conceive of literacy as being more than a set of decoding skills. However, they do not emphasise participatory or justiceoriented forms of citizenship. These teachers explicitly endorse the orientation of teaching students the dominant culture as stable factual knowledge to which their learners are to conform. They also emphasise a skill-based orientation towards literacy. However, as I note below, one of these two respondents acted in variance with her expressed beliefs and participated in school-wide activities that endorsed critical notions of citizenship.

Most of the twenty-year work experience of the first of these two respondents (\#3) has been as a supervisor of joint ESL/literacy programs. In her estimation, second language literacy learners do not simply lack graphic language skills. They also quite commonly have limited vocabulary and an incomplete command of syntax in the target language. In addition, these learners lack an understanding of the culture of the surrounding social environment. Literacy learners whose first language is English, on the other hand, usually possess a command of common vocabulary and have few problems understanding anything that an interlocutor says to them. Significantly, these other learners identify themselves as belonging to the surrounding culture. For these reasons, this participant believes that it is important to cover citizenship explicitly for the foreign-born learners in her classes.

Although this participant conceptualises literacy as being more than a set of decoding skills, she does not stress critical notions related to the 
interrogation of the underlying assumptions inherent within texts. Significantly, in terms of my focus here, she also does not emphasise justice-oriented forms of citizenship.

My other participant in this theme (\#8) also has a skill-based definition of literacy and a 'fact-based' notion of citizenship. Even so, this teacher conducts multimodal literacy activities and is involved in school participatory citizenship education projects in which learners debate local political issues. So, even this teacher's classroom practice is in great variance with the rather conservative attitude towards citizenship education that she professes.

This participant had been teaching in literacy and ESL programs for 21 years at the time of the interview. The class that she taught was specifically designed to meet the needs of learners at the basic levels of English language proficiency and literacy. She emphasises factual knowledge by focusing on memorising the answers to the multiple-choice questions that constitute the content of the Canadian citizenship test. Nonetheless, she participates fully in the activities described above by the sixth respondent that are designed to inculcate a participatory orientation towards citizenship.

Given the needs of her particular students, this teacher has adopted what she feels by necessity is a skill-based definition of literacy. At first glance, she could be characterised as having imposed limits on how both literacy and citizenship are treated in her classroom. However, I think it important to emphasise that she believes that these limits are a function of the basic proficiency and skill levels of her students, rather than representing some universal or invariable limitations.

\section{Conclusion: implications for practice and curriculum planning}

As I have noted above, citizenship has been a common programming component historically in ESL education. The majority of the veteran teachers who participated in this study believe that justice-oriented citizenship and critical notions of literacy can be utilised even at the most basic levels of English language proficiency. Although the teachers in this study might not have explicitly referred to the theoretical models espoused by such theorists as Westheimer and Kahne (2004), the majority adopted curricular orientations very similar to the ones these academics recommend. There is no need, as the two versions of the CLB do, to link citizenship exclusively to high levels of English language proficiency. Moreover, as the veteran teachers in this study understand, citizenship education does not have to consist of the rote learning of a static set of facts in preparation for a test.

In the example given by the sixth participant above, citizenship education can be treated at a very basic level of English language 
proficiency. The issues dealt with in the activities lead by this teacher and her colleagues, as noted above, are important to her learners. As this teacher explained, this collaborative activity involved elaborate and creative planning, especially in terms of language scaffolding and the adaptation of teaching material. Despite this extra work, these activities are highly rewarding because they assist learners in the development of independent and informed opinions about specific issues that are at once local, provincial and national. This is accomplished regardless of the level of English language proficiency of the learners in question.

To deny learners opportunities to explore meaningful and active civic engagement on the basis of their English language proficiency is to do great disservice not only to them, but also to Canada. Most adult second language learners will not reach the point at which they will write graduate papers, as is described in level 12 of the CLB. Instead, learners have been engaged with notions of active citizenship and a commensurate treatment of critical literacy skills long before they leave their classrooms. I believe that Canada needs newcomers who utilise critical literacy skills (both traditional and digital) to engage in justice-oriented forms of citizenship. In this way, the nation moves forward.

\section{Appendices}

Appendix I: Ontario-based participants

\begin{tabular}{|c|c|c|c|c|}
\hline Participant & I & 2 & 3 & 4 \\
\hline Experience & $\begin{array}{l}\text { I5yrs+ as a } \\
\text { teacher, } \\
\text { program } \\
\text { supervisor, } \\
\text { curriculum } \\
\text { writer and } \\
\text { director of a } \\
\text { literacy } \\
\text { organisation. }\end{array}$ & $\begin{array}{l}\text { 6yrs elementary } \\
\text { teaching } \\
\text { experience; } \\
20 y r s+\text { adult } \\
\text { literacy, ESL } \\
\text { teaching and } \\
\text { supervisory } \\
\text { experience. }\end{array}$ & $\begin{array}{l}\text { 20yrs+ years as } \\
\text { teacher, } \\
\text { professional } \\
\text { development } \\
\text { trainer and } \\
\text { supervisor in } \\
\text { joint ESL/literacy } \\
\text { programs. }\end{array}$ & $\begin{array}{l}\text { IOyrs+ } \\
\text { experience in } \\
\text { both ESL and } \\
\text { literacy } \\
\text { education; } 5 y r s+ \\
\text { as editor of a } \\
\text { national literacy } \\
\text { magazine; } 5 y r{ }^{+} \\
\text {as volunteer } \\
\text { community } \\
\text { tutor. }\end{array}$ \\
\hline $\begin{array}{l}\text { Attitude } \\
\text { towards } \\
\text { citizenship } \\
\text { education }\end{array}$ & $\begin{array}{l}\text { Explicitly stated } \\
\text { justice-oriented } \\
\text { notion of } \\
\text { citizenship that } \\
\text { was linked to a } \\
\text { critical } \\
\text { orientation } \\
\text { towards literacy. }\end{array}$ & $\begin{array}{l}\text { An implicit } \\
\text { justice-oriented } \\
\text { notion of } \\
\text { citizenship and a } \\
\text { critical } \\
\text { orientation } \\
\text { towards literacy. }\end{array}$ & $\begin{array}{l}\text { Although } \\
\text { conceived of } \\
\text { literacy as more } \\
\text { than a set of } \\
\text { decoding skills, } \\
\text { did not stress } \\
\text { critical notions } \\
\text { or justice- } \\
\text { oriented forms } \\
\text { of citizenship. }\end{array}$ & $\begin{array}{l}\text { Explicitly stated } \\
\text { justice-oriented } \\
\text { notion of } \\
\text { citizenship that } \\
\text { was linked to a } \\
\text { critical } \\
\text { orientation } \\
\text { towards literacy. }\end{array}$ \\
\hline
\end{tabular}


Appendix 2: British Columbia-based participants

\begin{tabular}{|c|c|c|c|c|}
\hline Participant & 5 & 6 & 7 & 8 \\
\hline Experience & $\begin{array}{l}\text { I0yrs+ ESL and } \\
\text { literary teaching } \\
\text { experience; } \\
\text { 6yrs+ in a } \\
\text { supervisory role. }\end{array}$ & $\begin{array}{l}\text { 2lyrs teaching } \\
\text { high school and } \\
\text { I lyrs+ in adult } \\
\text { ESL and literacy. }\end{array}$ & $\begin{array}{l}\text { 8yrs+ as ESL and } \\
\text { literacy teacher's } \\
\text { aide and } 4 \text { yrs+ } \\
\text { as an ESL } \\
\text { teacher. }\end{array}$ & $\begin{array}{l}2 l y r s+\text { in adult } \\
\text { ESL and literacy. }\end{array}$ \\
\hline $\begin{array}{l}\text { Attitude } \\
\text { towards } \\
\text { citizenship } \\
\text { education }\end{array}$ & $\begin{array}{l}\text { Endorsed a } \\
\text { participatory } \\
\text { notion of } \\
\text { citizenship and } \\
\text { an orientation } \\
\text { that went } \\
\text { beyond } \\
\text { skill-based } \\
\text { definitions of } \\
\text { literacy. }\end{array}$ & $\begin{array}{l}\text { Participatory } \\
\text { notion of } \\
\text { citizenship that } \\
\text { came very close } \\
\text { to being } \\
\text { justice-oriented; } \\
\text { a definition of } \\
\text { literacy that } \\
\text { went clearly } \\
\text { beyond } \\
\text { skill-based } \\
\text { notions. }\end{array}$ & $\begin{array}{l}\text { An orientation } \\
\text { towards literacy } \\
\text { that went } \\
\text { beyond } \\
\text { skill-based } \\
\text { notions; clearly } \\
\text { linked this to a } \\
\text { justice-oriented } \\
\text { notion of } \\
\text { citizenship. }\end{array}$ & $\begin{array}{l}\text { Although defined } \\
\text { literacy as skills } \\
\text { and citizenship } \\
\text { as factual } \\
\text { knowledge, } \\
\text { engaged in } \\
\text { activities that } \\
\text { stressed } \\
\text { participatory } \\
\text { citizenship and } \\
\text { multimodal } \\
\text { forms of literacy. }\end{array}$ \\
\hline
\end{tabular}

\section{References}

American Education Research Association (1999) Standards for Educational and Psychological Testing. Washington, DC: AERA Publications.

Bachman, L. (1990) Fundamental Considerations in Language Testing. Oxford: Oxford University Press.

Canadian Centre for Language Benchmarks (2002) Standards Linguistiques Canadiens. Ottawa: Citizenship and Immigration Canada.

Canadian Centre for Language Benchmarks (2006) Niveaux de Compétence Linguistique Canadiens 2006: Français Langue Seconde pour Adultes. Ottawa: Citizenship and Immigration Canada.

Canadian Centre for Language Benchmarks (2014) Revisions to the CLB/NCLC. Available online at www.language.ca/index.cfm? Voir $=$ sections\& Id $=17298$ $\& \mathrm{M}=4037 \&$ Repertoire_No=2137991327 (accessed 20 February 2014).

Council of Europe (2011) Common European Framework of Reference for Languages: Learning, Teaching, Assessment. Brussels: Council of Europe.

Crick, B. (2007) Citizenship: the political and the democratic. British Journal of Educational Studies 55(3): 235-248.

Derwing, T. (1992) Instilling a passive voice: citizenship instruction in Canada. In B. Burnaby and A. Cumming (eds), Socio-Political Aspects of ESL. Toronto: OISE Press.

Derwing, T. M. and Thomson, R. I. (2005) Citizenship concepts in LINC classrooms. TESL Canada Journal 23(1): 44-62.

DeVoretz, D. J., Hinte, H. and Werner, C. (2002) How Much Language is Enough? Some Immigrant Language Lessons from Canada and Germany. Bonn, Germany: IZA (ERIC Document Reproduction Service No. ED472783). 
Fleming, D. (2008) Becoming citizens: Punjabi ESL learners, national language policy and the Canadian language benchmarks. In M. Manteno, P. Chamness and J. Watzke (eds), Readings in Language Studies: Language Across Disciplinary Boundaries. St. Louis, MO: International Society for Language Studies, $143-158$.

Fleming, D. (2010) Racialized forms of citizenship and the Canadian language benchmarks. Canadian Journal of Education 33(3): 588-616.

Fleming, D. and Walter, P. (2004) Linking teacher professionalism and learner autonomy to experiential learning and task design. TESL Canada Journal Special Issue 4: 58-72.

Gardner, R. C. (1985) Social Psychology and Second Language Learning: The Role of Attitudes and Motivation. London: Edward Arnold.

Giddens, A. (1995) Politics, Sociology and Social Theory: Encounters with Classical and Contemporary Social Thought. Stanford: Stanford University Press.

Hajer, A. and Kaskens, A. (2012) Canadian Language Benchmarks 2012. Ottawa, ON: Centre for Canadian Language Benchmarks.

Isin, E. F. and Wood, P. K. (1999) Citizenship and Identity. London; Thousand Oaks, Calif.: Sage.

Kennedy, K. (2007) Student constructions of active citizenship: what does participation mean to students? British Journal of Educational Studies 55(3): 304-324.

Lankshear, C. and Knobel, M. (1997) Critical literacy and justice-oriented citizenship. In S. Muspratt, A. Luke and P. Freebody (eds), Constructing Critical Literacies: Teaching and Learning Textual Practice. Cresskill, NJ: Hampton Press, 95-124.

Lape, S. (2010) Race and Citizen Identity in Classical Greek Democracy. Cambridge: Cambridge University Press.

McCartney, A. (2013) Teaching civic engagement: debates, definitions, benefits, and challenges. In A. Millett, E. Bennion and, D. Simpson (eds) Teaching Civic Engagement: From Student to Active Citizen. Washington, D.C.: American Political Science Association, 9-20.

Ministère de l'Immigration et des Communautés culturelles (2006) L'Échelle Québécoise des Niveaux de Compétence en Français des Personnes Immigrantes Adultes. Quebec, QC: Ministère de l'Immigration et des Communautés culturelles.

Norton Pierce, B. and Stewart, G. (1997) The development of the Canadian Language Benchmark Assessment. TESL Canada Journal 8(2): 17-31.

Norton, B. (2000) Identity and Language Learning. Harlow: Pearson.

Nunan, D. (2004) Task-Based Language Teaching. Cambridge: Cambridge University Press.

Pawlikowska-Smith, G. (2000) Canadian Language Benchmarks 2000. Ottawa, ON: Centre for Canadian Language Benchmarks.

Schumann, J. (1978) The Pidginization Process: A Model for Second Language Acquisition. Rowley, Mass.: Newbury House Publishers.

Shohamy, E. (2007) The power of English tests, the power of the English language and the role of ELT. In J. Cummins and C. Davison (eds), The International Handbook of English Language Teaching. New York: Springer, 521-532.

Taylor, C. (1994) Multiculturalism and the Politics of Recognition. Princeton: Princeton University Press. 
Tully, J. (2008) Two meanings of global citizenship: modern and diverse. In M.A. Peters, A. Britton and H. Blee (eds), Global Citizenship Education: Philosophy, Theory and Pedagogy. Rotterdam: Sense, 15-41.

Westheimer, J. and Kahne, J. (2004) What kind of citizen? The politics of educating for democracy. American Educational Research Journal 41(2): 237-269. 


\title{
Chapter 5
}

\section{Language education for adult migrants in Catalonia \\ Nation-state ambitions without nation-state resources}

\author{
Albert Branchadell
}

\section{Introduction}

The goal of this chapter is to assess Catalan language education policy for foreign adult migrants in the autonomous region of Catalonia, with an eye on the language ideology that underpins it. Right at the outset, the uniqueness of the Catalan case must be stressed. Catalonia is not a sovereign state, but rather a 'minority nation' (Zapata 2006) or a 'substate minority' (Aubarell et al. 2004). As such, it regained political autonomy in the 1980s and is now a setting in which 'language is at stake in identity politics of an ethnolinguistic conflict' (Pujolar 2010; Mamadouh et al. 2011), to the extent that the status of Catalan is one of the main threads in the rationale behind the present secessionist challenge to Spain. But unlike other minority nations like Quebec, Catalonia does not have powers in migration matters and Catalan is not the dominant language of Catalonia. (See Bouffard, this volume, for a discussion of language policy in Quebec.) These two circumstances do not prevent Catalonia from having a de facto immigration policy propelled by a nation-state language ideology which endeavours to promote Catalan as the common language of Catalonia through a 'monolingual, consecutive, and literacy-based language provision' (Garrido and Oliva, this volume). This chapter tries to map the wide distance between this grandiose policy and the poor results it has yielded so far.

\section{Linguistic background}

In surveys about Catalan, a triple distinction is made between initial language (the language one acquired first at home), language of identification (the language one considers his or her own) and language of habitual use. Although Catalan statisticians have not explicitly relied on this stance, this three-way distinction is reminiscent of Rampton's (1990) alternatives for the concept of native speaker: 'language inheritance' nears 'initial language' and 'language affiliation' is close to 'language identification'. 
(Catalan surveys do measure 'language expertise' but we leave this dimension aside for now.) The latest available survey (Government of Catalonia 2013) shows that Catalan is not the majority language in any of these categories. In terms of language of identification, Catalan gets its highest score. Catalan was the language of identification of 36.4 per cent of the interviewees (47.6 per cent mentioned Spanish, 7 per cent mentioned both and 8.6 per cent other languages, starting with Arabic).

The renewed pre-eminence of Spanish and the percentage of people who identify themselves neither with Spanish nor with Catalan provide a glimpse of the sociolinguistic impact of foreign immigrants, who pose a new challenge for the linguistic equilibrium of Catalonia, as was the case with internal Spanish (and Spanish-speaking) immigration in the second half of the twentieth century. From 2000 to 2010 the foreign population in Catalonia multiplied by more than 6 . The 181,590 foreign residents in 2000 (3 per cent of the population in round figures) became 1,198,538 in 2010 (almost 16 per cent).

As Mamadouh et al. (2011: 78) put it, 'from the point of view of the parties involved in a language conflict, immigrants can be seen as possible recruits for the language group. Will they choose the dominant or the minority language?' There is ample evidence that foreigners tend to choose the dominant (i.e. Spanish) language. In a 2006 survey focused on people of Moroccan, Ecuadorian, Romanian and Chinese origin, the following conclusion was reached:

The predominant language in the family and with friends is that of the country of origin, although Spanish is also widely used with acquaintances. At work, the prevalence of Spanish is overwhelming, especially when compared to Catalan. The use of Catalan is very scant and few immigrants understand it.

(Institut d'Estadística de Catalunya 2006)

A later survey in 2010 gave similar results:

Spanish is the main language of respondents in all areas, although most keep their language of origin, especially at home. The presence of Catalan in daily life is minimal.

(GESOP 2010)

This minimal presence of Catalan in daily life is not always due to the lack of Catalan-speakers in the networks of respondents, but also to a deepseated social norm according to which Spanish, not Catalan, is the language to be used with foreigners (even if they happen not to know it). This is part of the status quo that Catalan immigration policy is intended to challenge. 


\section{Catalonia does not have real powers ...}

Immigration is an arena of political tension between Catalonia and Spain. According to section 149 of the 1978 Spanish Constitution, the State shall have 'exclusive competence' over 'nationality, immigration, emigration, status of aliens, and right of asylum'. Accordingly, the 1979 Catalan Statute of Autonomy (the equivalent of a regional constitution) did not mention immigration among the powers of the Catalan autonomous government. In the first years of the twenty-first century, Catalan political parties, seeking greater regional self-government and national recognition, promoted a new Statute of Autonomy, which was finally passed by the Spanish Parliament and approved in a Catalan-wide referendum in 2006. Section 138 of this new Statute granted the Catalan government:

a) exclusive power regarding the initial reception of immigrants, which includes health care, social services and guidance [i.e. educational] activities, $b$ ) development of the integration policy for immigrants in the framework of its powers, $c$ ) establishment and regulation of the measures necessary for social and economic integration of immigrants and for their social participation, $d$ ) establishment by law of a referential framework for the reception and integration of immigrants.

The conservative Partido Popular (People's Party) challenged the new Statute of Autonomy before the Spanish Constitutional Court. After a protracted discussion, key provisions of the new Statute were overturned in a controversial ruling issued in 2010 (STC 31/2010). The present upsurge of secessionism in opinion polls (44.5 per cent would vote for independence according to the latest poll released in December 2014 (Government of Catalonia 2014)) can be seen as a reaction. It stands in direct relationship to this ruling, which was contested by more than 1 million people who took to the streets of Barcelona on 10 July 2010. As for immigration, the ruling stated that section 138 has to be interpreted to mean that 'immigration' refers not to the corresponding state power but rather to other aspects of the management of immigration, over which the Catalan government does have powers, like health and social care.

Political tensions surrounding immigration matters did not end here. Following section 138.1.d) of the Statute, the Catalan Parliament passed Act 10/2010, on the reception of immigrants and returnees to Catalonia (see below). In an unprecedented move, the Spanish Ombudsman challenged this act before the Constitutional Court. Act 10/2010 runs a very high risk of being overturned given the leaning of the Court, which would only hinder Catalan plans on immigration and fuel political conflict between Catalonia and Spain. 


\section{... but it does have a de facto immigration policy}

Despite these political shortcomings, Catalonia has had an immigration policy since the early 1990s. In 1993 there were 76,244 foreign residents who made up a scant 1 per cent of the population. Small as this figure might appear, it was big enough for the Catalan government (headed by Convergència i Unió, a right wing nationalist coalition) to launch its first Interdepartmental Plan for Immigration. This Plan aimed at promoting 'a global policy of integration of foreign immigrants who live in Catalonia', where 'integration' was implicitly understood to be a one-way, top-down process through which the administration moulds foreigners according to local norms. Among the stated goals of the Plan, no explicit mention of the Catalan language was made. In 2001, the Catalan government launched its second Interdepartmental Plan. Despite a reference to Catalan language and culture in the presentation of the Plan (immigrants were supposed to assume the importance of it), the Catalan language was not yet among its stated goals, the first of which was again 'to promote a global policy of integration of foreign immigrants who have settled in Catalonia'.

As far as language is concerned, the turning point came in 2005, with the first immigration plan of a new left-wing and nationalist party coalition in government. Among the challenges of this new plan was 'to turn Catalan into the vehicular language of immigrants'. This turning point coincided in time with a shift in the language ideologies underpinning the overall Catalan language policy. In terms of Woolard's celebrated distinction (2008), an ideology of authenticity gave way to an ideology of anonymity: the goal was to move from a conception that locates the value of a language in its relationship to an historically specific social group to the supposedly neutral hegemonic language associated with the public sphere of nineteenth and twentieth century nation-states. According to this framework, Catalan was supposed to become the common language of Catalonia, as French is the common public language of France and so on. Woolard (2008) incidentally welcomed a move away from both authenticity and anonymity to an approach better suited to a post-modern Catalonia with hybrid, fluid identities and languages. According to Branchadell (2010) a closer look at actual public discourses about language does not sustain the notion that this move has occurred.

This treatment of Catalan as a common language was inspired by Quebec sources (see Bastardas 2002 for an explicit effort to draw lessons from Quebec practices). For the first time, then, the Catalan language acquired a paramount role in an immigration plan. In the process of turning immigrants into citizens (the key idea of this plan), the mastery of Catalan was a necessary condition. The term linguistic welcome (acollida lingüistica) was coined to devise a new approach to the teaching of the 
Catalan language to foreigners, and linguistic welcome was included in a comprehensive welcome program. For 2005, seven pilot plans of linguistic welcome were implemented. The next year there were 22 such plans in place, one for each branch of the Consortium for Language Normalisation. (The Consortium is a joint venture between the Catalan government and a number of local authorities. Its major aim is to deliver Catalan language courses for non-Catalan speaking adults, now mostly migrants.)

One of the products of this Plan was the National Agreement for Immigration, which was formally signed on 19 December 2008. One of its three axes was integration into a common public culture that encourages participation in public life, the use of Catalan as a common language, coexistence in a context of multiple beliefs and religions, gender equality and the strengthening of social policies'. This principle of Catalan as Catalonia's common language was taken from the National Agreement and incorporated into the fourth immigration plan, the Citizen and Immigration Plan. This fourth immigration plan was launched in 2009 by the same left-wing and nationalist party coalition and was maintained by the right-wing nationalist coalition of Convergència i Unió after it won the 2010 Catalan regional election. In April 2014 the fifth plan (Citizenship and Migration Plan: Horizon 2016) was adopted by the Catalan government.

On the legislative side, the most important legacy of the National Agreement for Immigration was Act 10/2010 on the reception of immigrants and returnees to Catalonia, which was passed by the Catalan Parliament in 2010. According to section 7 (the official English translation is quoted here), 'the right of access to the first reception service begins in Catalonia from when the person is included on the population register'. Section 8 states that the first reception service includes 'training activities' whose minimum contents are 'basic language skills', 'labour knowledge' and 'knowledge about Catalan society and its legal framework'. As for basic language skills, section 9 states that 'over the course of the process of integration into Catalan society' both Catalan and Spanish are to be learned, with Catalan offered first and Spanish provided 'to those people who have attained basic skills in Catalan and request or require it'. Specifically regarding Catalan, section 9 read as follows:

2 The first reception service shall provide the training and resources needed to acquire basic skills in Catalan to people holding the right of access to first reception services and who do not speak the language, wherever possible through the Consortium for Language Normalisation.

3 The minimum baseline to be achieved in terms of the language skills referred to in the Common European Framework of 
Reference for Languages established by the Council of Europe shall be set by regulation.

4 Catalan, as Catalonia's own language, is the common language for implementing reception and integration policies. It also is the language of training and information, a basic instrument for full integration in the country. To that end, the language learning offered by first reception services shall begin with the acquisition of basic skills in Catalan.

As I mentioned above, this Act awaits a ruling of the Spanish Constitutional Court. Beyond this new political clash between Spanish and Catalan authorities, section 9 does raise a number of questions: what are the 'training and resources needed'? When is language training 'completed'? Shall training begin and end with 'basic skills'? What about foreigners who are not at the 'first reception' stage anymore? In the next section I specifically address the controversial issue of what is the 'minimum baseline to be achieved in terms of language skills'.

\section{Linguistic requirements for immigrants: the hope}

In a survey carried out in 2010 by the Council of Europe (Extramiana and van Avermaet 2011), Spain came out as one of eight member states which make language knowledge a requirement neither for (a) admission to the country, (b) permanent residence, nor (c) acquisition of citizenship. Of the 31 states which replied, 23 'were concerned by at least one of the administrative situations identified' - among them all big EU member states, namely France, Germany, Italy and the UK.

In this context, it is no wonder that in the (Spanish or Catalan) juridical literature, little work has been done on the issue of linguistic requirements for migrants. In a pioneering work, Milian (2008) noticed that most works on immigration do not deal with its linguistic dimension. That is why he set out to design a proposal on language requirements for foreigners who settle in Catalonia. According to him, a linguistic demand that is both 'reasonable' and 'legally permissible' would be to establish a requirement to take Catalan language courses from the moment that a foreigner registers in the padrón (a municipal register) of the municipality where he or she dwells. It must be borne in mind that all foreign residents (whether they remain legally in Spain or not) are supposed to register in the padrón, which gives them right to certain benefits like schooling, medical assistance and social services.

Although not a linguist, Milian went as far as to suggest a number of hours (135) for these Catalan language courses. In the proposed scenario, Milian suggested a deadline of two years (from the inscription in the padrón) to complete the courses and be awarded a certificate. However, 
non-compliance could not be a reason to refuse the renewal of the inscription; the right of every newcomer cannot be curtailed for linguistic reasons. This circumstance notwithstanding, Milian was of the opinion that non-compliance should lead to 'some punitive measure'. One possibility would be to have the offender pay the real cost of the unattended courses (otherwise there are no tuition fees). A major penalty would lie in the connection of the Catalan courses to a benefit like the issuing of a residence permit (see below).

To what extent did Milian's insights inform public policy? In an interview held shortly after the Act was passed, Oriol Amorós, Immigration Secretary at the time, spoke coincidentally of 135 hours for Catalan language courses, but the 'regulation' to implement it was not passed. Since 2011, his successor, Xavier Bosch (later Director-General for Immigration) has promised a number of times that the regulation is about to be passed. On 6 March 2012 he went so far as to give the number of hours necessary to get a certificate of 'first reception' ( 90 hours in the case of Catalan).

Why has no regulation been passed? There seem to be both financial and political reasons. At the time of writing Catalonia was amidst a wave of huge budgetary cuts that made the provision of any extra funding to implement the Act unlikely. On the political front, it must be recalled that the Act is overseen by the Constitutional Court and the language provisions that the unpassed regulation is supposed to implement could be declared unconstitutional overnight. But a certain lack of interest on the part of the Catalan government should not go unnoticed. Significantly enough, no mention was made of the Act 10/2010 in the 150-page long manifesto of the ruling party (Convergència i Unió) for the 2012 election. And again there was no mention of the regulation in the agreement of stability signed by CiU and Esquerra Republicana (Republican Left) for the 2012-2016 tenure.

\section{Linguistic requirements for immigrants: the reality}

Despite this procrastination on the normative side, things moved on the practical front. In April 2011 the Spanish government passed a royal decree (557/2011) that set a new regulation to implement Act 4/2000 relating to the rights and duties of newcomers. This decree gave new prerogatives to autonomous communities in the administrative procedures concerning foreigners. Thanks to this regulation, from July 2011 the Catalan government has been in charge of issuing informes d'estrangeria (reports for foreign citizens) to accredit, among other things, the degree of integration required to obtain a temporary residence permit (informe d'arrelament social, social settlement) and the integration effort necessary to renew the temporary residence permit 
(informe d'integració social). Up to May 2013 the Catalan government issued 55,190 reports of various types. Of these 30,105 were of arrelament (settlement) and 1,015 of integració (to renew a temporary residence permit).

This new Spanish regulation opened a window for the verification of Catalan language skills within these administrative procedures. To demonstrate social settlement, the report is mandatory for applicants without family ties to other foreigners who are already permanent residents. In the renewal of a residence permit the integration effort of the applicant can be assessed by means of another kind of report. In both cases (reports of arrelament social and of integració social), there is a section in the form that applicants have to complete under the heading of 'language skills', in which they have to indicate the course(s) they have taken and the number of hours of each course.

The new Spanish regulation also forced the Catalan government to make decisions about 'the minimum amount of knowledge' to be certified. So the Catalan government established that 20 hours was the minimal length of a Catalan course for foreigners to get a positive report of arrelament social or of integració social. This 20 hour minimum was later raised to 45 when authorities realised that most migrants quit courses after the twentieth hour. No research has been done about this lack of persistence, which might be linked to the mismatch between the linguistic complexity of the situation on the ground for migrants and the anonymity ideology that underpins language provision and its monolingual slant.

\section{The role of the Consortium for Language Normalisation}

Be it 20 or 45 hours, somebody has to provide Catalan language courses for adult migrants. In Catalonia there are several public bodies that provide Catalan classes to adults - migrants or not. These are the official language schools, the Centres for Adult Training, and the Consortium for Language Normalisation (Consorci per a la Normalització Lingüística). Private actors are also involved in this, albeit to a much lesser extent. (For an example see Garrido and Oliva, this volume.) The main public provider of Catalan language courses for adult migrants in Catalonia is the Consortium for Language Normalisation: 130,000 students in 2009, compared to 10,000 in the Centres of Adult Training.

As for migrants, the Consortium made a very modest start (see Puig 2000; Branchadell 2004; Rovira 2004 and Van den Bogaert 2005 for early critiques focused on lack of means; and Miquel 2005 for a specific complaint about poor teacher training). Things improved over the years but, all in all, the Consortium is a perfect illustration of what Woehrling noticed already in his pioneering paper (2008: 52): 'there is often a lack of congruence between the linguistic obligations placed on immigrants 
and the financial resources states are prepared to dedicate to the learning facilities available to immigrants'.

In the first years of the Consortium, adult migrants were not its main target at all. Between 1994 and 2000 just 36 specific courses for foreign migrants were organised. Non-EU citizens had scant representation in the general Catalan courses: in 1997-1998 only 1,637 students (or 3.3 per cent) were of that origin. But two years later the number had climbed to 3,046 (7.22 per cent). The arrival of large numbers of new immigrants refocused the Consortium's priorities. And the shift in language ideologies that I identified above meant the allocation of more resources (Pujolar 2010). In parallel to the linguistic welcome plans, a program of Language Volunteering was started. In this program every language pair (learner and volunteer) is supposed to share a minimum of 10 hours of conversation. In an initial assessment Solé et al. (2005) acknowledged that 10 hours 'is clearly not time enough to be able to acquire a basic working knowledge', and recommended increasing the minimum number of hours to 20. This recommendation was not taken up: at the time of writing 10 hours, 1 per week, was still the expected commitment for volunteers. The number of language pairs multiplied by 6 in the first years of the scheme, from 1,522 in 2003 to 9,437 in 2008.

In the case of language courses, no evaluation is yet available. The usual indicator of the Consortium's activities is the sheer number of courses offered and the number of enrolments. The golden years started in 2006, when the record of 3,000 courses was broken. The number skyrocketed to almost 5,000 in 2009. In 2006 the number of registered students neared 80,000 and the peak came also in 2009 with more than 130,000 registrations. If we count only initial and basic levels, where around 90 per cent of students are foreigners, between 2002 and 2006 the number of courses more than doubled, from 793 to 1,874 , and the number of students almost multiplied by three, from 15,074 to 42,177. Even so the numbers are still modest. A contemporary survey (2006) showed the limited impact of courses: between 85 and 90 per cent of all interviewees had not received a single course. Moreover, this surge in enrolments was not accompanied by a corresponding growth in professional development activities. No specific courses for teachers of new immigrants have been systematically organised. A full master's degree to train teachers in the field of 'linguistic welcome' was not launched until 2010 by the Autonomous University of Barcelona and the Consortium - at a time when due to financial hardship the Consortium had virtually stopped recruiting new teachers.

In recent years, both the number of courses and the number of enrolled students have started to decline: from 4,725 courses in 2008 to 4,304 in 2011, and from 73,194 students to 64,389. According to the Consortium's report for 2011, 'there is not a problem of lack of supply, but decline in 
demand', although it also acknowledged that in some municipalities supply did decline 'due to present financial hardship'. As a matter of fact, the Consortium experienced a budgetary cut of $€ 6 \mathrm{~m}$ between 2010 and 2011. Why numbers of enrolled students declined precisely after the passing of the Act that was supposed to create incentives for learning Catalan is an intriguing question that remains open for future research, not least because free tuition is not the problem.

But we should go beyond sheer numbers and try to assess the success of courses. As for attrition, the data are telling. In 2011 more than a third of all students in the initial and basic levels did not finish the course in which they had enrolled. The Consortium's report for 2011 admitted that 'one of the challenges for the Consortium is to reduce attrition at the basic levels', but no specific course of action has been taken so far. Consortium managers tend to put the blame on learners, but quality of teaching is also an issue here. As for attainment, the report for 2011 calls it 'very satisfactory': more than 80 per cent of students who took an exam passed it. But if we compare the number of enrolled students with the number of students who passed, this optimistic balance must be nuanced: fewer than half of the enrolled students $(17,706)$ actually passed. This is a drop in the ocean. As Milian (2007) put it, the remarkable increase in the number of courses in the 2000s was not enough: 'in 2005 157,375 foreigners registered in Catalonia, far behind the 3,440 basic level certificates that $[\ldots]$ were awarded. In short: a dismal failure'.

\section{Conclusion}

Catalonia is an autonomous region in Spain that has developed an immigration policy of its own despite the political impediments that derive from the division of powers between national authorities and regional ones. Within this policy, in which integration has always been the keyword, language made a poor start but acquired great prominence after Catalan political elites adhered to the ideology of anonymity and duplicated the Quebec principle that Catalan was to become the common language of Catalonia, the language in which all residents, regardless of origin, should communicate among themselves. This is a great ambition compared to the poor resources devoted to it and the poor results in terms of real language proficiency. If Catalonia has been depicted as a success story in reversing language shift, it is not also a success story in turning adult migrants into all-purpose Catalan users. The problem lies not only in the relatively small number of courses and the often discouraging quality of teaching, but also in the larger approach to language education for adult migrants. First, there is a deep-seated idea that 'basic skills are enough'. As García (2011: 10) remarked: 
if threshold [read $\mathrm{B} 1$ ] is the minimal level to be able to communicate in Catalan in any everyday situation and this is achieved through the elementary level, why do linguistic welcome plans always have the goal that immigrants only need to reach the basic level [read A2]?

Secondly, the belief is also held that Catalan language skills can be solely acquired in the classroom with a 'monolingual, consecutive and literacybased language provision', which probably does not fulfil most of the migrants' actual needs (Garrido and Oliva, this volume). Independence would free Catalonia from Spanish law and give her full powers in immigration matters, but it is not clear whether it would also free her from such questionable beliefs. As Rovira (2004: 55) put it, "not everything can be attributed to the lack of state powers'.

\section{References}

Aubarell, G., Coll, A. N., Ros, A. and Híjar, A. R. (2004) Immigració i qüestió nacional. Minories subestatals i immigració a Europa. Barcelona: Editorial Mediterrània.

Bastardas, A. (2002) Llengua i noves migracions: les experiències canadenques i la situació a Catalunya. Revista de Llengua i Dret 37: 153-190.

Branchadell, A. (2004) 'L'ensenyament del català als nous immigrants adults: too little, too late?'. Dins: Fargas i Riera, Assumpta; Puntí i Juvany, Teresa (coords.) Actes del $3 r$ Simposi sobre l'ensenyament del català a no catalanoparlants. Conferències, ponències, comunicacions i conclusions. Vic, 4, 5 i 6 de setembre de 2002. Vic: Eumo Editorial.

Branchadell, A. (2010) One nation, one (common) language? Language and nationalism in 21st century Catalonia. RECODE Online Working Paper 10.

Consorci per a la Normalització Lingüística (2011) Memòria CPNL 2011. Barcelona: Consorci per a la Normalització Lingüística.

Extramiana, C. and Van Avermaet, P. (2011) Language Requirements for Adult Migrants in Council of Europe Member States: Report on a Survey. Strasbourg: Council of Europe.

García, A. (2011) La continuïtat en l'aprenentatge del català dels aprenents poc o gens alfabetitzats. (Unpublished masters thesis). Universitat Autònoma de Barcelona.

GESOP (Gabinet d'Estudis Socials i Opinió Política) (2010) La percepció de la realitat social i política de Catalunya dels ciutadans d'origen estranger. Barcelona: Fundació ACSAR.

Government of Catalonia (2013) Language Use of the Population of Catalonia. Key Results of the Survey on Language Use of the Population 2013. Barcelona: Generalitat de Catalunya. Available online at http://lengua.gencat.cat/web/.content/documents/ publicacions/altres/arxius/EULP2013_angles.pdf (accessed 24 December 2014).

Government of Catalonia (2014) Survey about the Current Political Situation in Catalonia. Barcelona: Generalitat de Catalunya.

Institut d'Estadística de Catalunya (2006) Sondeig a la immigració. Estudi pilot sobre el perfil de la immigració marroquina, equatoriana, romanesa $i$ xinesa installada a Catalunya. Barcelona: Generalitat de Catalunya. 
Mamadouh, V., Mansvelt, J. and Scrhiiver, F. (2011) Negotiating belonging through language: immigration and integration in contexts of ethnolinguistic conflict. Paper delivered at the Second International Scientific Conference on Concepts and Consequences of Multilingualism in Europe 2. Tetovo, 8-9 October 2010.

Milian, A. (2007). Immigració i llengua. Integrar lingüísticament la població arribada. Butlletí del Cercle XXI 6. Available online at www.cercle21.cat/ butlleti/06/milian.html (accessed 24 December 2014).

Milian, A. (2008) Globalización y requisitos lingüisticos: una perspectiva jurídica. Supraestatalidad, libre circulación, inmigración y requisitos lingüisticos. Barcelona: Atelier.

Miquel, L. (2005) Reflexions sobre la metodologia d'ensenyament de llengua a immigrants. Llengua i Ús 34: 60-66.

Puig, B. (2000) Llengua i nova immigració: una experiència de dinamització lingüística. Treballs de Sociolingüistica Catalana 14/15: 133-150.

Pujolar, J. (2010) Immigration and language education in Catalonia: between national and social agendas. Linguistics and Education 21: 229-243.

Rampton, B. (1990) Displacing the 'native speaker': expertise, affiliation, and inheritance. ELT Journal 44/2: 97-101.

Rovira, M. (ed.) (2004) Anàlisi de l'oferta de cursos de català als immigrants adults extracomunitaris. Barcelona: Editorial Mediterrània.

Solé, J., Castaño, J. and Díaz, A. (2005) 'Volunteers for language', Linguistic Integration Programme in Catalan: facts for evaluation. Noves SL SpringSummer 2005.

Van den Bogaert, A. (2005) Immigraction et usage du catalan à Barcelone. Bruxelles: Université Libre de Bruxelles.

Woehrling, J. (2008) Linguistic requirements for immigrants, specifically with regard to languages that enjoy official status in part of the territory. In A. Milian, B. de Witte, J. Woehrling, I. Urrutia, and M.A. Orriols (eds) Mundialització, lliure circulació i immigració, i l'exigència d'una llengua com a requisit. Barcelona: Institut d'Estudis Autonòmics, 133-172.

Woolard, K. A. (2008) Language and identity choice in Catalonia: the interplay of contrasting ideologies of linguistic authority. In K. Süselbeck, U. Mühlschlegel and P. Masson (eds), Lengua, nación e identidad. La regulación del plurilingüismo en Espana y América Latina. Frankfurt am Main: Vervuert/Madrid: Iberoamericana, 303-323.

Zapata, R. (2006) Immigració i govern en nacions minoritàries: Flandes, el Quebec $i$ Catalunya en perspectiva. Barcelona: Fundació Ramon Trias Fargas. 


\title{
A multilingual, collaborative and functional approach to nongovernmental Catalan classes
}

\author{
Maria Rosa Garrido and Xavier Oliva
}

\section{Introduction: language, migration and NGOs in Catalonia}

The nongovernmental settlement program which we describe here, and where we developed a program of critical pedagogy, ${ }^{1}$ responds to new migrations to Catalonia, Spain, and to a neoliberalising welfare state at the turn of the century. The migrant population of Catalonia grew rapidly from only 2.9 per cent of the total population in 2000 to 11.42 per cent in 2005 and a peak of 17.36 per cent in 2009 , with a slight decrease to 15.70 per cent in 2011 (Idescat 2013). The arrival of migrants coincided with the increasing offloading of public services to the third sector, especially those for marginalised populations like the homeless. The Catalan law on reception for immigrants and returnees to Catalonia, Llei d'Acollida (Generalitat de Catalunya, 2010), stipulates that nongovernmental organisations (NGOs henceforth) can legally provide settlement services to newcomers in collaboration with local administrations. Despite the universal character of this law, people who were not registered with the town hall (padró municipal) could not access publicly funded social services, according to Spanish law. Thus, they had to contact NGOs, such as the one we collaborated with, which do not have this legal requirement.

The rationale for Catalan classes in this welfare project for homeless, undocumented migrants corresponds to the "integration-throughlanguage' discourses that entail re-socialisation into legitimate social practices, moral values and forms of knowledge mediated by 'national' language(s). According to Pujolar (2009), Catalan language classes in NGOs are strongly linked to specialist welfare discourses like, for instance, healthy habits. The promotion of Catalan as the vehicle for settlement services by the Llei d'Acollida has motivated a linguistic turn to Catalan in nongovernmental language provision, where Spanish had generally been taught, thereby reinforcing Spanish as the interlanguage with and for non-Catalans (Pujolar 2009). In spite of this official support and civic discourses promoting Catalan as the common language, the actual 
practices in Catalan institutions, and especially NGOs, reveal the commonsense tendency to speak Spanish with foreign users which impedes the social use of Catalan, still considered to be an ethnic and a (middle-class) social class marker.

This chapter explores an action research project among researchers, practitioners and adult migrant learners in a nongovernmental Catalan language education program in the Barcelona area. It is organised as follows. First, we will briefly describe the ethnographic context, in particular the sociolinguistic and pedagogic reasons motivating our action research. Second, we will discuss the functional and critical goals of our intervention. Third, we will present the collaborative, Freirean methodology that we have followed. In the ensuing section, we shall present the multilingual approach to teaching Catalan with a focus on translanguaging (García 2009) and intercultural debate. To finish, we will draw some reflexive conclusions on our teaching and language practices.

\section{Context: ethnographic findings on language and pedagogy}

The institutional context for our pedagogic intervention is a three-month residential project for eight undocumented, newly arrived migrants in a post-industrial city located in the outskirts of Barcelona (Garrido 2010). ${ }^{2}$ This nongovernmental project has two main objectives, a first to cover the homeless migrants' basic needs and a second of social insertion, where official language learning is central. The NGO makes decisions in a topdown fashion which largely excludes the migrant participants' perspectives, language repertoires and cultural practices. The volunteers who organise these classes are a group of Catalan-Spanish bilingual retired primary school teachers without specialised training in foreign language teaching. As a result, the Catalan classes observed draw on traditional methodology focusing on the written mode and linguistic forms, with an emphasis on lexis and conjugation through drilling exercises (role plays and repetition) and infantilising visual materials.

During fieldwork (2007-2011), most participants were young men from Morocco and Senegambia from a wide variety of social, educational and ethnic backgrounds. Each participant spoke between two and six languages among which the most represented ones collectively were Wolof, Mandinka, Tamazight, Arabic, Hausa, Djola, Fula, English and French, all with different degrees of hybridity. Since this is a temporary project, the Catalan class is not only a heterogeneous group of people with different transnational and educational trajectories, but also a changing group where new students join every week.

Catalan and Spanish are the institutional languages that allow access to the legal and social services on offer, aligning with integration discourses 
in Catalonia generally. The NGO constructs multilingualism as an exceptional concession to newcomers restricted to the two international linguae francae, English and French, during the first weeks of participation and only with those NGO agents who can minimally speak them. English and French are considered transitional languages to learning Catalan and/or Spanish and by extension to integration goals, partly because these languages presuppose literacy in the Roman alphabet and a common European cultural baggage. In our fieldwork, African participants were categorised as either Anglophone or Francophone by virtue of the colonial past of their countries of origin. By contrast, African languages such as Mandinka and Tamazight were seen as impediments to integration so the NGO representatives silenced them as legitimate languages of public discourse. Moreover, learners with few or no years of formal schooling were pulled out from the mainstream class and taught decontextualised literacy skills using first grade literacy booklets.

The personal information form (Figure 6.1) illustrates the institutional sanctioning of global linguae francae and the silencing of indigenous African languages. Duwa is a Gambian Soninké male who is considered to be a student with learning difficulties, as he is not fully literate, having learned languages 'on the street' and without much formal schooling. As a result, the teacher helps him complete his form and writes the information relating to occupation and languages herself. She exclusively includes global European languages 'castellà anglès' [Castilian (Spanish) English] at the bottom left. When Maria Rosa asks students about 'other languages', Duwa proudly writes 'Mandink, Wolof, Pula, Sonike' at the bottom right himself, defying the institutional order.

The NGO constructs bilingualism as the sum of two separate monolingual systems (Cummins 2000) and insists on consecutive learning of Catalan and Castilian in monolingual spaces for learners to produce standard linguistic performances. The linguistic objectives are based on the idealised (monolingual) native speaker model. As a result, the two majority Romance languages in Catalonia are taught consecutively in separate 'monolingual classrooms'. For NGO agents, monolingual outputs in Spanish or Catalan reflect the success of the classes and in turn, the migrants' effort to integrate. Those learners who translanguage are said to be 'confused' and 'not to speak either language well'. However, the urban sociolinguistic context is characterised by translanguaging in migrants' social networks, frequent Catalan-Spanish code switching and hybridity at large.

Despite the NGO's celebratory discourses, the NGO agents that implement the project do not integrate multilingualism and interculturality in their everyday practices. Alongside their (subconscious) assimilationist goals, volunteer teachers project a celebratory stance in 'multicultural moments' that celebrate cultural (but not linguistic) diversity. These occasional activities tend to revolve around migrants' nation-states of 


\section{NOM:}

\section{COGNOM:}

PAÍs: the GamBita

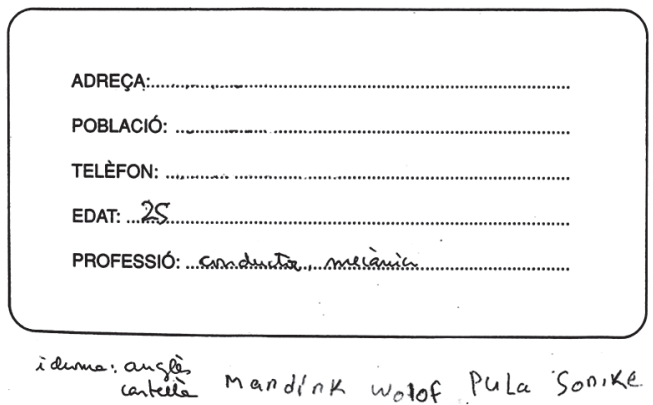

Figure 6.I Duwa's completed student form, given out in the first Catalan lesson in the residential project (9 September 2008). Personal details have been deleted

origin and cultural exchange with locals, which actually reinforce essentialised identities and boundaries between us/them. For example, participants are identified according to postcolonial nation-states such as Senegal rather than their relevant ethnic affiliation(s) such as Wolof.

\section{Social goals and functional literacy in a Catalan language program}

Our action research is a transformative, functional response to the topdown, 'banking' language program described above. A banking approach is based on teacher-centred monological transmission of legitimate knowledge to students considered as tabula rasa (Freire 1970). Our project addresses more specifically the lack of appropriate teaching methods and materials for multilingual adult learners of Catalan in this NGO. Thanks to our experience as volunteer teachers, we identified a shared goal for the NGO coordinators, the volunteer teachers, the migrant students and the two authors in our shoes as teacher-researchers. This collaborative, 
voluntary project has run since 2010 with periods of more or less intense engagement. The common goal is to jointly design, elaborate and implement suitable acolliment lingüistic (language reception) materials for newly arrived adult migrants who participate in this project. Our own transformative goal is to include learners in the NGO's top-down decisionmaking processes so that their multilingual voices, settlement experiences and learning practices form part of the Catalan language class.

The materials begin with learners' social needs and problems to identify content-obligatory language and critically discuss sociocultural knowledge and legal information. Each teaching unit starts with a social objective (We will learn how to ...), with essential language functions, and related socio- and intercultural debate topics (We will speak about ...). For example, unit 2 sets We will learn how to access and use the Catalan health system as its main objective. The unit lists the basic language resources migrants might need to accomplish this overall goal: expressing our state of health, making medical appointments for different tests and professionals and interpreting a prescription. The separate but related debate objectives feature, on the one hand, the Catalan health system, particularly types of health establishments and how to obtain a health card; and on the other, an intercultural debate about different health systems and medicine around the world.

We have integrated a functional and critical literacy approach (Baynham 1995) to design appropriate materials to enhance learners' agency in their settlement process through Catalan. Our collaborative workshops seek to explore and understand social needs and problems, learning styles and language repertoires among and with learners. In so doing, the action research legitimises learners' plurilingual resources and funds of knowledge for daily learning processes rather than folkloristic moments. The resulting pedagogy constructs continuity between the Catalan classroom, the social networks in this city and the learners' trajectories.

The shared goal is to teach a monolingual variety, Catalan, in its role as the national language in a welfare program as stated in the Llei d'Acollida (Generalitat de Catalunya 2010). This linguistic objective is highly interconnected with the social context because the classroom is saturated with urgent issues linked to the learners' precarious social situation. In addition, this social approach must cater to a heterogeneous group, especially with regard to bringing together low-educated learners and better-educated learners. Therefore, the teaching materials emphasise orality through audiovisual dialogues and intercultural debates, as well as functional literacy through authentic text genres for everyday life and legal procedures in Catalonia, like information forms or CVs.

Our goal is to promote collaborative relations of power by means of interactions between educators and learners where our identities are negotiated in ways that recognise diversity for a critical, multilingual and 


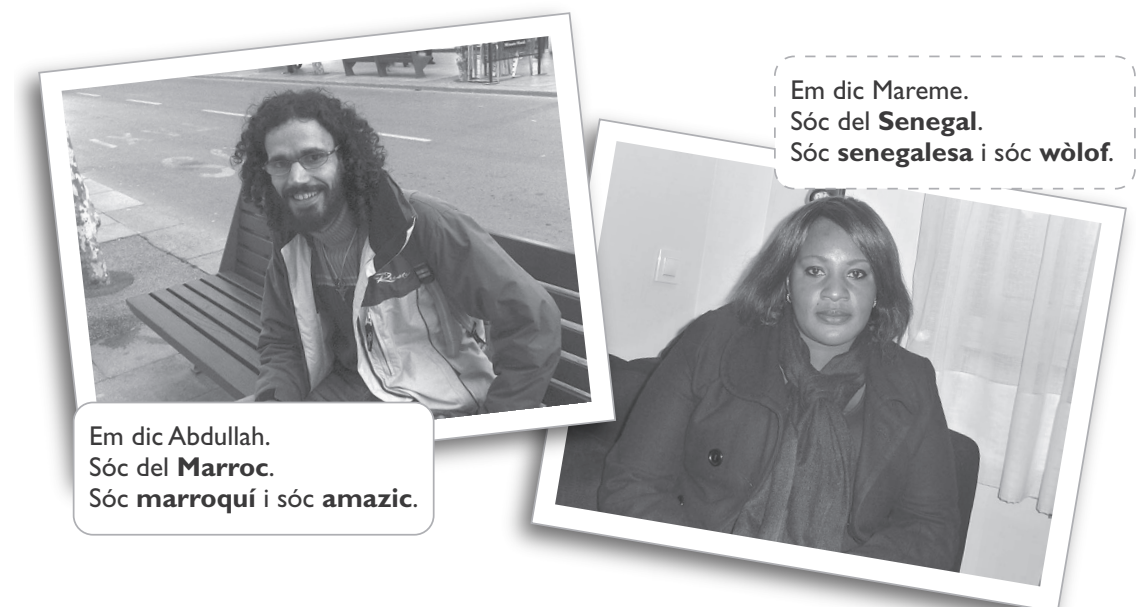

Figure 6.2 Where are you from? Unit I

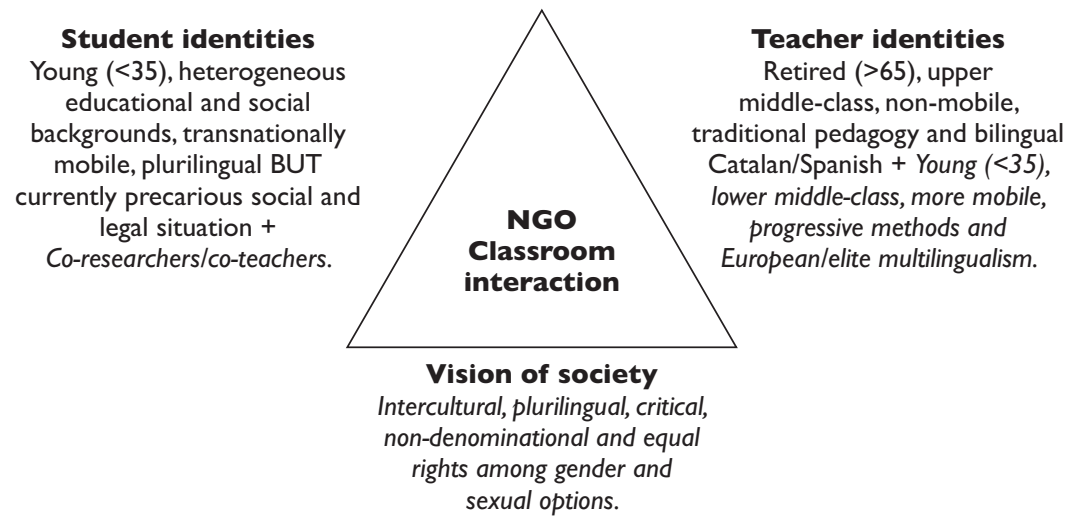

Figure 6.3 Triangle of images in the Catalan classroom. The action research contributions are shown in italics

intercultural society. The example in Figure 6.2 shows that this project recognises not only postcolonial nationalities which are relevant for legal procedures, like Moroccan, but also ethnic ascriptions which are ethnographically salient, such as Amazigh.

According to Cummins (2000: 48), transformative pedagogy centres on the negotiation of a triangular, interrelated set of images in classroom interaction: (a) an image of our own identities as teachers, (b) an image of the identity options for our students and (c) an image of the societal 
relations which we envisage. In our action research, we have transformed students and teachers into partners who work for an inclusive society as shown in Figure 6.3. The formerly disempowered students now become the nexus of our project, whose voice is central not only in the collaborative workshops to create materials but also in the tandem teaching which brings together researcher-teachers and former students as co-teachers.

\section{Collaborative process: Freirean inspiration for a foreign language intervention}

Freire's pedagogy (1970) was our main inspiration in the design and implementation processes for the teaching materials. Thus, the methodology we used for our action research is dialogical, collaborative and critical. Furthermore, it basically focuses on 'the oppressed', who are more literate and less literate migrant students. Ours is not a literacy project based on the students' L1s or postcolonial languages. Instead, we aim to teach Catalan as a foreign language through dialogue to transform society by following Freirean stages:

- Stage 1: Describing the context and identifying problems.

- Stage 2: Determining the most meaningful issues to be taught for social actors in this specific context (Generative themes and words).

- Stage 3: Codifying those issues into teaching materials and collectively reflecting about them through implementations (Codification and decodification).

Our longitudinal engagement as voluntary teachers, and also as ethnographers in Maria Rosa's case, allowed us to critically analyse and understand the sociolinguistic and pedagogic context for our collaborative action research. We consider this ethnography and our previous teaching work together as our first stage.

Regarding the second stage, we organised several collaborative workshops with the learners on the one hand, and with the volunteer teachers on the other, to identify the most relevant themes for the Catalan language materials. We asked the multilingual learners (a) what they wanted the classes to be like, (b) where they used Catalan in social situations and (c) which problems they encountered in institutions of the state, labour market and social relations. The project started with 'reading the world' (Freire 1970) together through discussing the construction of social inequalities and language-related obstacles in their everyday experiences. Hence, we identified key themes to facilitate the migrants' settlement processes through Catalan. These were (1) registering with the town hall, (2) accessing the public health system, (3) entering the labour 
market, (4) moving around the city and using local services, (5) renting or buying a home, (6) making economic exchanges and (7) participating in civic society. These are not critical themes in and of themselves and are common in other acolliment lingüistica materials, but our critical perspective targets the monolingual, ethnocentric bias in actual implementation.

Moreover, the workshops created safe spaces (Santos and Shandor 2011) where the learners could share with us their experiences and points of view on their immediate context outside the NGO, in a less threatening environment. We encouraged multilingual discussions in linguae francae such as Wolofrançais, English and Arabic and intercultural debate in relation to those topics which could be controversial among different cultures. The creation of multilingual and intercultural safe spaces made the meetings more motivational for the students and more profitable for us as educators as well. Thus, our Freirean inspiration made us lean more towards 'the oppressed' and the silenced social actors, namely the learners. Simultaneously, we also presented those themes to the institution and to the rest of the teaching staff. With this objective, we 'read the words' (Freire 1970) in Catalan for learners not to be silenced, to facilitate access to institutions and to reimagine people's social trajectories accordingly.

Once students' immediate sociolinguistic needs were identified, we codified them into teaching materials - which corresponds to Freirean stage 3. We developed those materials in textual, oral and audiovisual modes to cater for both more and less literate students. In every single unit, there is essential sociocultural and legal information for the newcomers to Catalonia. This information is written in Catalan and translated into different languages by former students. This is still an ongoing project as we have only developed five teaching units that are available on a webpage (www.mouteencatala.com) where practitioners worldwide can have free access to the materials. We are working on the materials with former learners, who act as consultants, as actors/models in the recordings and images for the materials and as translators of key information as well. In our workshops, the students continue to analyse the codified generative themes into teaching units to give us feedback to facilitate future implementation.

Based upon our in-class experiences, we can also highlight the importance of making all the teachers collaborate with students as equals. We are not working closely with the volunteer teachers at the time of writing but we see avenues for collaboration because of common ideological grounds. Most volunteer teachers in the NGO are leftist activists in the city, which implies a social approach to classes as part of a 'comprehensive welcome program' within the residential project (vs. state agencies' 'linguistic welcome', see Branchadell, this volume). Despite their altruistic ethos, the volunteer teachers behave as unaware oppressors (Moraes 1996) when they interact with the students. This is due to their 
traditional banking approach that infantilises low-educated adult learners with a formal literacy focus. Therefore, both the teachers and the students (the oppressors and the oppressed in Freirean terms) are responsible for the whole educational process to empower students and transform social structures of inequality.

\section{Multilingual approach: translanguaging and intercultural debate}

Our pedagogic intervention stems from a multilingual and intercultural approach that cultivates diverse language and cultural practices through their use for teaching and learning, which goes beyond their acceptance or tolerance in the classroom (Creese and Blackledge 2010). Both the collaborative process and the teaching implementation seek to provide alternative, safe and multilingual spaces for the institutional goal of teaching Catalan. This project has a monolingual target which is reflected in the largely monolingual materials, with the marked exception of translations of key social and legal information into the learners' languages (see Figure 6.4). However, the collaborative process, including classes, has the transformative goal of changing the top-down sociolinguistic order and enabling greater agency for learners. In addition, both our process and product incorporate intercultural debates and sociocultural information which make more visible the learners' perspectives, cultural practices and transnational trajectories.

According to García (2009), translanguaging refers to the language practices of plurilingual people who select features from their common, interdependent linguistic repertoire. A translanguaging pedagogy rests on the assumption that the more languages you speak, the easier it is to learn a new one thanks to cross-linguistic transfers and common underlying proficiencies. Translanguaging as a pedagogic approach is appropriate in this multilingual city and especially with learners who have mainly learned languages in naturalistic contexts characterised by hybridity. In the host society, it is necessary to learn how to move between Castilian Spanish and Catalan to fully participate in bilingual, sometimes hybrid, playful and polivalent, communicative events, genres and registers. Within our multilingual workshops and classes, translanguaging serves two main purposes: to maximise learning and comprehension for a heterogeneous group and to construct continuity with their daily, multilingual lives. In our Catalan input, we do not 'purge' our Catalan language dialogues of Castilian discourse markers such as pues, hybrid forms like bueno and even Castilian turns and words.

In late modernity, it is essential to leave behind the ideology of authenticity and native speaker standards so that Catalan becomes the 


\section{SABIES QUÈ?}

${ }^{3}$ La Targeta Sanitària Individual i els serveis socials primaris.

La Targeta Sanitària Individual (TSI) és un document personal i intransferible que ens permet l'accés al sistema de salut i als serveis socials públics. També és necessària per adquirir els medicaments a les farmàcies amb una recepta oficial. Aquesta targeta s'obté de manera gratuïta a qualsevol Centre d'Atenció Primària (CAP). L'únic requisit per obtenir-la és estar empadronat al municipi on es resideix i identificar-se amb NIE o passaport del teu país d'origen. Els serveis d'atenció social primària ofereixen (1) Gestió de les prestacions públiques municipals i de la Generalitat de Catalunya com ara beques escolars, (2) Atenció a persones que no tenen domicili i (3) Servei d'Atenció Domiciliària a persones amb manca d'autonomia (amb discapacitat, malaltia, problemes sociofamiliars etc.) entre d'altres prestacions.

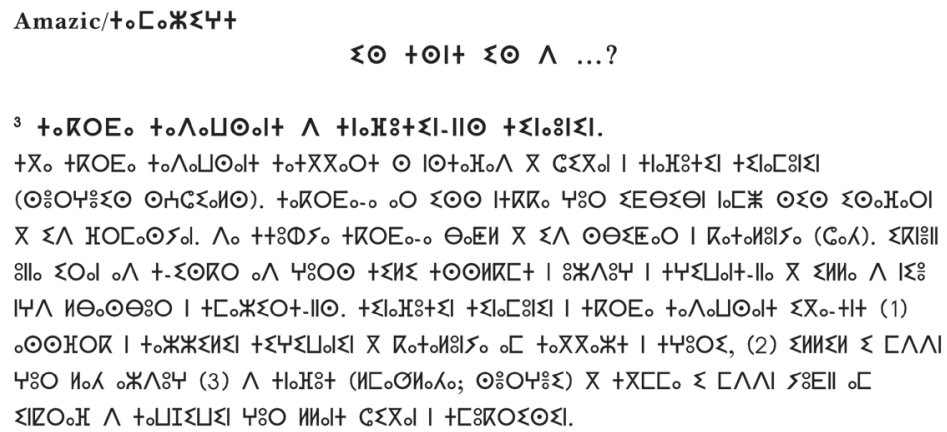

Figure 6.4 Did you know that? Unit 2: Health system information in Catalan and its translation into Tamazight

common, everyday language. In Catalonia, there has been a reorientation from the authenticity of Catalan as an ethnic marker 'from somewhere' towards a more anonymous voice 'from nowhere' that is public, standard and universal (Woolard 2008). The linguistic authority of authenticity is associated with languages that are profoundly rooted in a particular community. Thus the social value attached to the 'authentic voice' or native-speaker ideal complicates the everyday use of this language by non-members who do not 'own' the language ideologically (Pujolar 2009). Integration discourses are vested in the authentic value of the native-like voice as an index of social control and regimentation for non-members in the 'national' territory constructed through standard language. In fact, 
Catalan as an identity marker has constrained the acquisition and use of the language as a foreign language for generations (Woolard 2008, see Branchadell, this volume).

Recent transnational migrants have posed a major challenge to the ideologies of authenticity and reinforced the bid for Catalan to become a public language. These 'new speakers' of Catalan have brought in new plurilingual voices which have been, for the most part, silenced in Catalan institutions like the one reported on here. Our project aims to legitimise their non-standard, hybrid varieties of Catalan as valid models for language teaching and by extension, social participation. That is why we have included these new speakers as actors in audiovisual dialogues and as co-teachers in the classroom. As an illustration, we have featured an elementary Catalan learner from Senegambia with an autochthonous Catalan-speaking server in the video about registering in the town hall. This resembles the experiences of newly arrived migrants who have limited language proficiency. Furthermore, the teaching unit on health features a Venezuelan doctor who has a hybrid variety of Catalan with Venezuelan Spanish intonation, structures and lexical items, as well as a Moroccan receptionist who addresses the Senegalese patient in Castilian.

This transformative educational project moves away from 'banking' approaches that teach dominant knowledge to transnational migrants. Specialist discourses of integration through language are related to tabula rasa discourses that largely categorise African men such as those involved in our project as unskilled, inexperienced and language-less labour, deficient in, for example, nourishment, work habits and training. To counteract this, language educators have to develop a safe but critical pedagogic space which is grounded in the students' experiences and voices, in other words, in the collective funds of knowledge in the diverse Catalan classroom. A departing point is legitimating and discussing of multiple points of view on a topic or problem. This includes interrogating the dominant ones from a critical perspective. Crucially, we teach Catalan through multilingual debates about intercultural issues.

Among the planned intercultural debate objectives, we can find different types of households, the role of women in the labour market and how to greet people in different parts of the world. An illustrative example of a controversial topic that we address (rather than avoid) is families. In our ethnography, the issues of polygamy and gay marriage, as well as adoption and monoparental families, stirred a great deal of debate. Furthermore, we also present sociocultural and legal information, like for example how to obtain a legal residence permit in the Spanish state, which we can ground in people's experiences and analyse from a critical viewpoint. 


\section{Concluding remarks}

1) Foreign language learning/teaching is not the same as teaching and learning literacy. Our action research shows that an oral and functional literacy approach to adult language learning seems to be successful. The previous focus on literacy skills in Catalan as a prerequisite for mainstream language learning has proved to be less successful among low-educated second language and literacy learners like Duwa. Our longitudinal intervention demonstrates that less literate learners can interact in Catalan as fluently as better-educated classmates. Now the project should reach out to other institutions of migration in Catalonia, especially voluntary Catalan language programs.

2) This action research has empowered students and researchers alike, because we have learned how to read the world and the words together. The weak point of our action research is that we have concentrated on the adult migrants as partners to the detriment of volunteer teachers. We should raise volunteer teachers' awareness of interculturality and multilingualism to avoid establishing oppressive relationships in their classroom interactions with students. In the future, volunteer teachers ought to collaborate with students in workshops, session planning and tandem teaching for the action research to have lasting results. As we have, they will learn how to be more flexible regarding interaction control, teaching contents and collaborative learning processes. Their leftist and altruistic motivations will probably help in this endeavour.

\section{Notes}

1 We would like to thank all the participants who have voluntarily contributed their time, skills and experiences to this action research. This project and publication would not have been possible without Dr Eva Codó's unfailing encouragement and support throughout the process. We are also thankful for the editors' enthusiasm and interest in our project.

2 The ethnographic research on the residential project for homeless migrants carried out by Maria Rosa Garrido (2010) was funded by research grants 2007ARAFI 00018 (Agència de Gestió d'Ajuts Universitaris i de Recerca), HUM-2010-26964 (Ministerio de Ciencia e Innovación) and 2008UAB 2015 (Universitat Autònoma de Barcelona). In this section, all names used are pseudonyms in order to preserve paricipants' anonymity.

\section{References}

Baynham, M. (1995) Literacy Practices: Investigating Literacy in Social Contexts. London and New York: Longman.

Creese, A. and Blackledge, A. (2010) Translanguaging in the Bilingual classroom: a pedagogy for learning and teaching? The Modern Language Journal 94(1): 103-115. 


\section{I06 Maria Rosa Garrido and Xavier Oliva}

Cummins, J. (2000) Language, Power and Pedagogy: Bilingual Children in the Crossfire. Clevedon: Multilingual Matters.

Freire, P. (1970) Pedagogy of the Oppressed. New York: Herder and Herder.

García, O. (2009) Bilingual Education in the 21st Century: A Global Perspective. Oxford: Wiley-Blackwell.

Garrido, M. R. (2010) 'If you slept in Catalunya you know that here it's a paradise': Multilingual Practices and Ideologies in a Residential Project for Migrants. Unpublished MA thesis: Universitat Autònoma de Barcelona.

Generalitat de Catalunya (2010) Llei d'acollida de les persones immigrades i retornades a Catalunya. Barcelona: Departament d'Acció Social i Ciutadania, Secretaria per a la Immigració.

Idescat (2013) Població estrangera per muncipis 2013 [Foreign population by municipality 2013]. Available online at www.idescat.cat/poblacioestrangera/?b=6 (accessed 17 December 2014).

Moraes, M. (1996). Bilingual Education: A Dialogue with the Bakhtin Circle. New York: State University of New York Press.

Pujolar, J. (2009) Immigration in Catalonia: marking territory through language. In J. Collins and S. Slembrouck (eds), Globalization and Language in Contact. London: Continuum, 85-105.

Santos, M. and Shandor, A. (2011) The role of classroom talk in the creation of safe spaces in adult ESL classrooms. In P. Vinogradov and M. Bigelow (eds), Proceedings from the 7th Annual LESLLA (Low Educated Second Language and Literacy Acquisition) Symposium, September 2011. Minneapolis: University of Minnesota, pp.110-134.

Woolard, K. A. (2008) 'Language and identity choice in Catalonia: the interplay of contrasting ideologies of linguistic authority'. In K. Süselbeck, U. Mühlschlegel and P. Masson (eds), Lengua, nación e identidad. La regulación del plurilingüismo en Espana y América Latina. Frankfurt am Main: Vervuert/Madrid: Iberoamericana, 303-323. 


\title{
Chapter 7
}

\section{Integration policies and adult second language learning in Finland}

\author{
Sari Pöyhönen and Mirja Tarnanen
}

Recent global changes (migration, transnationalism) have led to increasing diversification in Finland as well, even though the number of migrants is small compared to many other European countries. Inward migration to Finland has been concentrated in the larger centres in the Helsinki metropolitan area and Southern Finland. According to Statistics Finland (2014), in March 2014 the number of the speakers of 'foreign languages' (293,540, or 5.4 per cent) exceeded for the first time in the country's history the number of the Swedish speakers (290,760, or 5.3 per cent) of the population (5.4 million), permanently living in Finland. The largest language groups were Russian, Estonian, English, Somali and Arabic.

Following Johnson's (2009) lines of thinking and his useful distinction between three broad aspects of policy processes policy creation, interpretation and appropriation (in local practice), in this chapter, we provide a brief overview of integration policies and adult second language learning in Finland. This chapter also serves as an introduction to another chapter in this volume which showcases provision that has been developed in an inclusive way: stay-at-home mothers who have, hitherto, been labelled as being 'problematic' and 'challenging' in terms of social inclusion, employment, and education (see Intke-Hernandez, this volume).

In writing this chapter, ${ }^{1}$ we attempt to get behind official policy interpretations by drawing on insights from two very different projects that we were involved in from 2010 to $2014 .^{2}$ The first project was a politically high-profile educational project, Participative Integration into Finland, which was funded by several bodies, including government ministries responsible for integration policies, and cultural foundations. The terms of reference for the project were actually embedded in the Integration Act (2010). The overall aim was to enhance the prerequisites for the integration of immigrants. It involved facilitating and documenting local initiatives that were developing alternative forms of educational provision for different immigrant groups. These included groups with three different integration paths: adult immigrants seeking employment, adult immigrants needing special support (e.g. stay-at-home mothers, 
Intke-Hernandez, this volume), and children and adolescents. (The project outcomes were reported in Finnish and Swedish in an edited volume: Tarnanen et al. 2013). It also involved collaboration with local practitioners in developing the actual educational contents and initial stage guidance and counselling for migrant groups.

Our role in this project was that of external experts or policy advisors, since our research centre (Centre for Applied Language Studies) was commissioned to write the project's development plan. During the preparation of the plan, we interviewed various stakeholders in order to capture the range of views and get a full picture of the current policies and practices concerning integration and language education for adult immigrants. We conducted 30 individual and focus group interviews with civil servants based in the relevant Ministries, with staff from regional authorities and with local practitioners (social workers, counsellors in employment offices, and teachers) who were working directly with different migrant groups. All the stakeholders interviewed had Finnish as their first language, which illustrates the current stratification patterns in Finnish society. It is highly unusual for a person with a migrant background, who has Finnish as a second language, to be working in the public sector, especially in national and regional level institutions.

Once we had prepared a development plan, we were recruited as scientific mentors for the sub-projects, and we visited local initiatives being carried out in 17 municipalities. During the project, we had direct experience of the policy process, from policy creation to its interpretation and local appropriation.

The second project we are drawing on here is an ongoing research project, Transforming Professional Integration, which was funded by the Academy of Finland for the years 2011-2014. The project aims to critically re-assess the roles and interplay of language proficiency, multilingual and multicultural practices and identities in working age migrants' integration to Finnish work and professional communities. In addition, we explore the significance of education paths regarding employment and connections between education and working life. In the project, the research team conducted 60 interviews with migrants who are either working or seeking a job in Finland.

Our chapter has two broad sections: firstly, we present our historical account of the significant discursive shifts relating to migration that have taken place in government policy and in the media since the 1970s. Secondly, we take a close and critical look at current policy discourses and practices, describing the broad pathway that has been defined for migrants from right of residence to 'integration', taking account of the views expressed by different stakeholders and then identifying some of the issues arising at the level of practice, as the national policy and the curriculum for Finnish as a second language for adults has been 
appropriated - and contested - locally. We conclude with a look at the future directions in integration policies and adult second language learning. We call for research of the type that can unpack the complexity of these issues related to policy appropriation in different local sites.

\section{Finnish legislation and government policy on integration: policy processes and discursive shifts over five decades (1970s-20I0s)}

During the 1970s and 1980s, Finland was still largely a country of outward emigration. Immigration was fairly sporadic and based on governmental responses to international humanitarian crises which led to the arrival and settlement of refugees. This first policy phase can be described as 'fulfilling humanitarian obligations' (Saarinen 2011: 147). Finland joined the other Nordic countries in receiving refugees, mainly from Chile and Vietnam, through the auspices of the UN Commission for Human Rights.

During the second policy phase, in the 1990s, a discourse of a 'nationalethnic obligation' predominated (Saarinen 2011: 148). Immigration mainly consisted of Ingrian Finns, who were repatriated after the collapse of the Soviet Union, and who were granted permanent residence. Ingrian Finns are descendants of Finns who moved, in the seventeenth century, to Ingria (St Petersburg and Leningrad Region), when Finland was still part of the Kingdom of Sweden. In addition to the arrival of the Ingrian Finns, this phase also saw the arrival of significant numbers of refugees from Africa (e.g. Somalia), South-Eastern Europe (e.g. Former Yugoslavia), the Middle East (e.g. Iraq) and parts of Asia (e.g. Afghanistan).

Finland joined the European Union (EU) in 1995. This started a new policy phase, namely that of 'managed immigration' (Saarinen 2011: 148). Several measures were taken to control migration in accordance with the aims of the Dublin Convention and the Schengen Agreement. By the end of the 1990s, Finnish integration policies were aimed at promoting freedom of movement within the terms of the EU legal framework. Finland was one of the first countries in the EU to pass an Integration Act in 1999. The Act emphasised residence-based social security, and did not pay so much attention to work-related inward migration.

In the first decade of the twenty-first century, there was an increase in work-related migration from the Eastern European nation states newly incorporated into the EU (e.g. from Estonia and Poland), along with workrelated migration from outside the EU (e.g. South Asia, especially India), though there was a slight decline during the years of the economic recession. Migrant workers from Eastern Europe were recruited mostly into the construction industry and the service sector, while migration from South Asia was mostly related to the growth of the IT industry. This fourth policy phase has been described as one in which the key discourse was "immigration 
as a resource' (Saarinen 2011: 149). In 2003, the government adopted an 'active immigration policy' in its programme for the years 2003-2007. The Central Party was the leading party at the time and formed the core of the government with the Social Democrats. In practice this meant promoting work-related migration and integration into working life in general, as well as intensified language teaching for adult immigrants. The aim was justified by the demographic trend towards an ageing population and the decline in the size of the workforce, especially in the service sector and in health care. The next government (2007-2011) had similar aims, even though the combination of the political parties in power had changed (the Central Party was still in the leading position, but the National Coalition Party had replaced the Social Democrats).

Views changed quite dramatically after the government program had been published. Economic recession was around the corner, unemployment rates were growing and major initiatives to promote work-related migration did not receive political support. Thus, the 'active immigration policy' soon vanished from the policy agenda. Yet, the aim of intensifying and increasing provision of language courses for adult migrants remained unchanged.

The fifth policy phase has been called one of 'contested immigration' (Saarinen 2011: 150). Over the past decade, Finland has changed from being a country of net emigration into a country of net inward migration. It has been estimated that by the end of 2030 there will be around 500,000 'foreign citizens' in Finland (Ministry of Employment and Economy 2012). Critical voices opposed to migration, integration and multiculturalism have become louder, and the discussion has been heavily problem-oriented.

Critical comments have also been voiced by those who are in favour of integration and multiculturalism. Some have argued that insufficient attention has been given in national debates to migrants' own points of view (e.g. Saarinen 2011). Others have shown concern about the cultural, historical and political differences between migrant groups being erased (e.g. Saukkonen 2013). Yet others have pointed out that no account is taken of the differences, in experience, cultural orientations and communicative repertoires, across the generations, among groups of migrant origin (e.g. Rynkänen and Pöyhönen 2010). Different stakeholders (policy makers, civil servants, teachers, migrants, employers) have different views on the aims and means of appropriation of policies of migration and integration. As we have tracked the discourses on migration and integration over the last five years or so, it has become clear that they are in a state of flux and are sometimes contradictory (Holm and Pöyhönen 2012).

At a time of growing criticism, the Promotion of Immigrant Integration Act was introduced in the end of the year 2010, a few 
months before the Parliamentary elections, and it came into full force in autumn 2011. The Act was meant to take a more holistic view of integration, paying attention to the diversity of migrant groups. In the first sentence of the Act, its purpose is stated 'to support and promote integration and make it easier for immigrants to play an active role in Finnish society' (Integration Act 2010, Chapter 1, Section 1). Official Finnish policy is discursively constructed as tolerant and promoting integration rather than assimilation. The Act (2010, Section 3) defines integration as interactive development involving immigrants and society at large, the aim of which is to provide immigrants with the knowledge and skills required in society and working life, and to provide them with support, so that they can maintain their culture and language.' The legislation emphasises the need for multi-sectoral cooperation, that is between local authorities (e.g. municipalities, job offices, police) and other parties, such as non-governmental organisations, in order to promote integration.

Even though the aims of this version of Finnish integration policy seemed positive on the surface, it generated a good deal of criticism in various arenas, including political parties and trade unions, local authorities, educational institutions, academia, the press and internet discussion forums. The parliamentary elections in April 2011 proved to be a wake-up call for those Finns who were promoting integration and multiculturalism. The populist nationalist party, the Finns Party (previously known as the True Finns), received 19.1 per cent of the vote and gained 39 seats out of 200. Previously, they had held five. The main political agenda of the Finns Party, since its foundation, has been criticism of migration policies, and although its supporters are not uniform in their views, some of its members express outright racist or xenophobic opinions in public. Moreover, the Finns Party now collaborates with right-wing nationalist parties of the EU member states in the European Parliament. After the elections, the party opted out of the negotiations around the formation of a coalition government.

The program of the 2011-2014 government was formed as a result of a pact between the National Coalition Party, the Social Democrats and four other political parties. The government explicitly espouses a discourse of pluralism. It responds to the Finns Party and to other antiimmigration forces with the message that immigrants are a permanent and welcome part of Finnish society' (Government Program 2011: 45). This particular discourse was foregrounded in the 2010 legislation. Yet, in practice, priority has been given to those groups of immigrants who, in the government's view, are able to play a role in enhancing Finland's international competitiveness. The government programme could be said to have incorporated a mixture of left and right wing politics and different discourses: a cocktail of humanitarian aims and discourses and 
a neo-liberal stance on the economy and the labour market, which is manifested in a preoccupation with 'skills'.

\section{Finnish as a second language for adults: official curriculum and pedagogy and stakeholders' views}

Integration training in Finland is based on two pieces of legislation: the Act on the Promotion of Integration (1386/2010) and the Act on Public Employment Service (1198/2009). As the integration training is primarily defined as labour market training, adult migrants, students, are 'clients' of the job office. The aim of the training is to promote vocational competencies, although general education may be acknowledged as part of integration training if it supports further career plans and employment (FNBE 2012a).

From our analysis of the interviews that we conducted with Finnish stakeholders it is clear that stakeholders at all levels (national-regionallocal) supported the official integration policy, its strategic discourse and the plans for implementation. Most of the stakeholders regarded entry into the labour market as the primary goal of integration for adult migrants, as the following quotations suggest:

We start from the assumption that the labour market is what we are aiming for.

(Ministry of Interior)

We sort of train these people for working life right from the beginning. (Finnish language teacher)

The National Core Curriculum for integration training for adult migrants (FNBE 2012a: 11) echoes the ethos of the Integration Act by stating that integration training 'aims to support migrants' integration by developing those linguistic, civic, cultural and life skills that help migrants to cope with everyday life situations in their new environment and be capable of functioning in working life and of applying for further studies.' The curriculum has a legal status, whereas the four previous ones (1993, 1997, 2001 and 2007) were recommendations and were not binding for educational institutions. This shift in the status of the curriculum from a recommendation to a statutory requirement can be interpreted in two ways. On the one hand, it can be considered an attempt to raise the status of integration training in the field of education and the labour market. On the other, as in countries across the EU, it can be seen as a way of furthering integration in the spirit of the current integration policy, which emphasises the importance of learning the target language as a means of access to welfare, participation, and employment (cf. Nohl et al. 2006; Pujolar 2010). 
The scope and content of integration training are supposed to vary according to each student's individual needs and with reference to the baseline level for assessment. Integration training includes Finnish/ Swedish language and communication skills and civic and working life skills. It also includes guidance counselling and one or more work placement periods. The objective of integration training is for a student to achieve skill level B1.1 ('functional basic proficiency') in the Finnish or Swedish language (roughly B1, independent user, on the CEFR), although the skill level to be achieved during the training may vary depending on the student's employment opportunities, educational background and further career plans (FNBE 2012a). For the migrants who have relatively little previous experience with reading and writing in languages other than Finnish or Swedish there is a separate curriculum (FNBE 2012b). Even though the curriculum is called the "National Core Curriculum for Literacy Training' and is informed by the same broadly positive discourse about integration and diversity, the discourse about literacy and the interpretations of the curriculum appear to be cast in largely deficit terms. This is particularly evident in the categorisations of students as: 'people with primary illiteracy', 'people with secondary illiteracy' and 'semi-literate people'. This terminology is reminiscent of deficit discourses about language and literacy that have been widely critiqued in other European settings by a number of researchers (cf. Martin-Jones and Romaine 1986; Stroud 2004; Holm and Laursen 2011).

Most of the interviewees participating in our educational project agreed with the overall idea of perceiving adult learners as active participants in the learning process. However, problem-oriented discourses also surfaced, and the stakeholders brought various images of migrants to the fore. Sometimes, individual interviewees articulated contradictory positions on particular topics within the same interview. A quite common discursive strategy was to represent migrants as distinct groups defined on the basis of the reason for their move to Finland (asylum seekers and refugees vs. work-based migrants). Another common discursive trope was that of categorising migrants on the basis of their language and literacy skills (those with little or no reading and writing skills vs. those with a schooled background).

In addition to the characterisation of groups as distinct, certain groups were seen as being at risk in terms of integration. These groups were adolescent drop-outs, stay-at-home mothers, the elderly and certain ethnic groups, such as the Russians and the Somalis. A recurring theme in the interviews was that these groups faced 'obstacles in integration'. These obstacles were linked to age, social class or ethnicity. Some interviewees, in particular those of migrant origin, raised critical questions regarding this discourse about 'obstacles in integration'. Take, for example, this quotation from one of our interviews: 
If you're willing to integrate yourself it is easier, though I must remind [you] that it's never really up to the person who tries to integrate. Integration happens through the society. You can try as much as you want to be accepted ... if the society doesn't accept you can do whatever you want. You can speak Finnish fluently, you can have a job, whatever, but if people for example don't like you, because of your colour or something there's nothing you can do about it.

\section{Finnish as a second language for adults: issues arising from current practice}

In practice then, integration training consists of Finnish (or Swedish) language classes and work life and civic skills classes, and a work placement period. Classes are arranged during working hours, and the length of training is about 25 hours per week. The participants are usually placed in groups after they have been assessed through the use of a language proficiency scale. There is also an assessment of learning skills in general. The explicit aim of this assessment is to better support individual learning paths and aims. In the interviews we carried out with various stakeholders, this assessment procedure was mostly seen as welcome, particularly by teachers, but it was also criticised for being a political tool that served as a means of creating new categories for social selection (Holm and Pöyhönen 2012).

From the work that we have done on both projects, we have been able to ascertain that the teachers are mainly people who have been trained as Finnish L1 language teachers and who mostly have an MA degree. Civic and working life skills are taught by teachers with various disciplinary backgrounds, such as social studies and anthropology. Even though the teachers are highly educated they have rather weak ties to working life, and thus little direct experience of the kinds of language and literacy resources that are actually needed to be able to cope with various job tasks and/or they have had little experience of using authentic material from working life in their teaching (cf. Roberts and Cooke 2009; Lindberg and Sandwall 2012).

Even though the pedagogic principles of the curriculum seem progressive (e.g. the socio-constructivist approach), they are not necessarily implemented in integration training itself. Classroom instruction has been criticised for being teacher-oriented, grammar-based and textbook- and handout-driven. In addition, the view of adult second language learning underpinning the curriculum and pedagogical practice has been strongly criticised for not taking into account, among other things, the complex, changing and dynamic nature of literacies in contemporary life and their role in identity construction (Holm and Pöyhönen 2012). 
Moreover, the physical layout of classrooms, such as those we have observed in our research, and the asymmetric relation of power between teacher and students inevitably shape the lived experiences of teaching and learning and contribute to the reproduction of dominant discourses about what counts as legitimate knowledge and skills and what counts as being a student in integration training courses. Indeed, one could ask what institutional worlds and pedagogic discourses (Bernstein 1996) the students are being socialised into (see also Baynham and Simpson 2010).

On the whole, progressive proposals for educational policy development, including curriculum development, are based on visions of education which prioritise equalising educational opportunities for all students and which value diversity, action-oriented learning, and individual education paths. It now seems to be generally accepted that the success of such policies depends on the micro-level practices of local educators (Hornberger and Johnson 2007; Egbo 2005; Ramanathan 2002). As we have shown in this chapter, there are ongoing debates in Finland about the question of whether integration training supports the activity, participation and autonomy of students or - quite the opposite - whether it socialises them into becoming regular 'clients' of social services waiting for access to the labour market (see also Intke-Hernandez, this volume). The value of integration training has already been questioned in public forums, although a number of development projects and official bulletins seem to argue for the continued need of integration training in order to achieve full participation in society, including employment. However, there are no statistics available for the employment status of the persons who have gone through integration training. From what we have seen in this field over the last five years, it is likely that the training paths lead either to precarious jobs or to business start-ups rather than to the regular employment contracts anticipated in the training received.

Among policy-makers and integration educators in Finland, there is still a firm belief that language proficiency and literacy skills have the power to change the material circumstances of migrants who are marginalised until they reach the targets defined for integration training and fulfil the aims of integration policy (similar discourses circulate in other national contexts e.g. Blackledge 2006). Yet, there is a mismatch between the content and pedagogical practices of integration training and migrants' needs, whether they are heading for the labour market or trying to find their place in society in other ways. Even though the curriculum is fairly flexible, the practices seem to favour a one-size-fits-all type of approach, e.g. teacher-led classroom practices and paper- and pencil-oriented materials. Integration training is not just about learning the language and civic and work skills, but also about a complex process of identification interfacing with classroom practices that position adult 
participants as 'students' and limit their agency, making it difficult for them to forge new identities in their new country using the communication resources available to them (cf. Norton 2010).

\section{Future directions}

The creation, interpretation and appropriation of integration policies, including adult second language teaching and learning, are complex processes that involve different participants on different scales. As we have shown, there has been a series of changes on a national scale in Finland in both policy and practices. These changes have taken the form of, for example, legislation; changes in the stances of the political parties; reorganisation of the integration administration; curricula and various projects for developing integration training, for introducing measures and co-operation between administrative bodies, for providing guidance and for promoting employment opportunities. It is still too early to assess the impacts of these policy changes, but the changes themselves appear to be the main governmental response to the increasing flow of migrants to Finland and to the growing public debates about inward migration. They also reflect the official migration policy of the European Union, and the principle of 'two-way integration', which is often represented as a process of mutual accommodation between migrants and the receiving societies. These changes have also been accompanied by a changing discourse about setting threshold levels for language proficiency, giving rise to discussions about the profiling of migrants and the possible introduction of new testing regimes for citizenship. These new sets of discourses resonate with discourses circulating in other national contexts (cf. Blackledge 2006; Extra et al. 2009).

There is still no shared political agreement on who will oversee the integration of adult migrants who are temporarily or permanently outside working life, e.g. stay-at-home mothers or adults who have relatively little experience of reading and writing in languages other than Finnish or Swedish. The main responsibility for dealing with the needs of these groups is shouldered by the municipalities, but they are facing difficulties in providing services for all, mainly due to lack of financial resources, but also due to lack of experience. National policies and local realities do not meet each other in this area of provision.

Moreover, there seems to be no end to polarised discussion concerning the future of inward migration and integration policies. Consequently, there will be more debate among politicians, citizens and local authorities as to whether to favour highly skilled migrants instead of unskilled migrants. The voices of migrants themselves will continue to be largely ignored. Immigration policy and questions of integration cover multiple domains and research fields. There are still major gaps in our 
understanding of how processes of policy creation, interpretation and appropriation actually work and how the learning experiences and economic circumstances of individual migrants can be improved. To deepen our understanding and to build a comprehensive picture of the policy processes currently at work in Finland, and other countries in Europe, comparative interdisciplinary research of a critical, ethnographic nature will be needed.

\section{Notes}

1 We wish to thank James Simpson, Anne Whiteside and Marilyn Martin-Jones for their support and valuable comments during the writing process of this chapter.

2 This chapter is part of a research project Transforming Professional Integration (www.isis.jyu.fi) funded by the Academy of Finland (Grant number 137632).

\section{References}

Baynham, M. and Simpson, J. (2010) Onwards and upwards: space, placement and liminality in adult ESOL classes. TESOL Quarterly 44(3): 420-440.

Bernstein, B. B. (1996) Pedagogy, Symbolic Control, and Identity: Theory, Research, Critique. London: Taylor \& Francis.

Blackledge, A. (2006) 'The men say "They don't need it": gender and extension of language testing for British citizenship. Studies in Language E Capitalism 1: 143-161.

Egbo, B. (2005) Critical Pedagogy as Transformative Micro-level Praxis. AE-Extra. Available online at www.unco.edu/ae-extra/2005/6/Art-4.html (accessed 28 May 2013).

Extra, G., Spotti, M. and van Avermaet, P. (eds) (2009) Language Testing, Migration and Citizenship: Cross-national Perspectives on Integration Regimes. London and New York: Continuum.

Finnish National Board of Education (FNBE) (2012a) National Core Curriculum for Integration Training for Adult Migrants 2012. Helsinki: Finnish National Board of Education.

Finnish National Board of Education (FNBE) (2012b) National Core Curriculum for Literacy Training for Adult Migrants 2012. Helsinki: Finnish National Board of Education.

Government Program (2011) Programme of Prime Minister Jyrki Katainen's Government. Prime Minister's Office. Finland.

Holm, L. and Laursen, H. P. (2011) Migrants and literacy crises. Apples - Journal of Applied Language Studies 5(2): 3-16.

Holm, L. and Pöyhönen, S. (2012) Localising supranational concepts of literacy in adult second language teaching. In A. Pitkänen-Huhta and L. Holm (eds) Literacy Practices in Transition: Perspectives from the Nordic Countries. Bristol: Multilingual Matters, 191-210.

Hornberger, N. and Johnson, D. C. (2007) Slicing the onion ethnographically: layers and spaces in multilingual language education policy and practice. TESOL Quarterly 41(3): 509-532. 
Integration Act (2010) Act on the Promotion of Immigrant Integration (1386/2010). Ministry of the Interior. Finland. Unofficial translation.

Johnson, D. C. (2009) Ethnography of language policy. Language Policy 8: 149-159.

Lindberg, I. and Sandwall, K. (2012) Samhälls - och undervisningsperspektiv på svenska som andraspråk för vuxna invandrare. In K. Hyltenstam, M. Axelsson and I. I. Indberg (eds) Vetenskapsrådet: Flerspråkighet - en forskningsöversikt. Göteborg: University of Gothenburg, 368-502.

Martin-Jones, M. and Romaine, S. (1986) 'Semilingualism': a half-baked theory of communicative competence. Applied Linguistics 7(1): 26-38.

Ministry of Employment and Economy (2012) Government Resolution on the Government Integration Programme. The Government's Focus Areas for 2012-2015. Available online at www.tem.fi/files/36397/Periaatepaatos_english.pdf (accessed 12 December 2014).

Nohl, A-M, Schittenhelm, K., Schmidtke, O. and Weiss, A. (2006) Cultural capital during migration - a multi-level approach to the empirical analysis of labor market integration amongst highly skilled migrants. Qualitative Migration Research in Contemporary Europe 7: 3.

Norton, B. (2010) Language and identity. In N. H. Hornberger and S. L. McKay (eds) Sociolinguistics and Language Education. Bristol: Multilingual Matters, 369-370.

Pujolar, J. (2010) Immigration and language education in Catalonia: between national and social agendas. Linguistics and Education 21: 229-243.

Ramanathan, V. (2002) The Politics of Tesol Education: Writing, Knowledge, Critical Pedagogy. New York: Routledge.

Roberts, C. and Cooke, M. (2009) Authenticity in the adult ESOL classroom and beyond. Tesol Quarterly 43(4): 620-641.

Rynkänen, T. and Pöyhönen, S. (2010) Russian-speaking young immigrants in Finland: educational and linguistic challenges to integration. In M. Lähteenmäki and M. Vanhala-Aniszewski (eds) Multilingualism in Finland and Russia. Language Ideologies in Transition. Frankfurt am Main: Peter Lang, 175-194.

Saarinen, A. (2011) Non-work migration, employment and welfare in Finland: three third-country migrant cases and four phases of immigration policies. In M. Pajnik and G. Campani (eds) Precarious Migrant Labour across Europe. Ljubljana: Mirovni Institut, 145-170.

Saukkonen, P. (2013) Multiculturalism and nationalism: the politics of diversity in Finland. In Ö. Wahlbeck and P. Kivisto (eds) Debating Multiculturalism in the Nordic Welfare States. Basingstoke: Palgrave Macmillan, 270-294.

Statistics Finland (2014) Number of Foreign-language Speakers Exceeded that of Swedish-speaking Population. Available online at http://tilastokeskus.fi/til/ vamuu/2014/03/vamuu_2014_03_2014-04-24_tie_001_en.html (accessed 12 December 2014).

Stroud, C. (2004) Rinkeby Swedish and semilingualism in language ideological debates: a Bourdieuean perspective. Journal of Sociolinguistics 8(2): 196-214.

Tarnanen, M., Pöyhönen, S., Lappalainen, M. and Haavisto, S. (eds) (2013) Osallisena Suomessa - kokeiluhankkeiden satoa. Delaktig $i$ Finland - skörden frän försöksprojekten. [Participative Integration into Finland - harvest from the pilot projects]. Jyväskylä and Helsinki: University of Jyväskylä, Finnish Cultural Foundation and Swedish Cultural Foundation. 


\title{
Chapter 8
}

\section{Stay-at-home mothers \\ learning Finnish}

\author{
Minna Intke-Hernandez
}

\section{Introduction}

In Finland, education for migrants is mainly organised by the public sector and targeted to the employment market (see Pöyhönen and Tarnanen, this volume). The provision is often full time, and during the first three years each immigrant receives 10-12 months of language and civic education. However, amongst migrants there are also those who fall outside the employment market, such as the elderly, disabled and stay-athome mothers (Hirsiaho and Vuori 2012).

This chapter draws upon an ethnographic study carried out in a Finnish language course for stay-at-home mothers. The course was part of the Capable Parent project which was implemented (2011-2013), in the Helsinki metropolitan area, as a sub-project of a national educational development project, Participative Integration into Finland (see Pöyhönen and Tarnanen this volume). This chapter will afford ethnographic insights into one particular aspect of adult migrant language education in Finland.

\section{Taking an ethnographic approach}

The aim of my study was to provide an account of: (1) the ways in which learning was taking place in the Capable Parent project; (2) the situated nature of the practices that were emerging; and (3) the participants' perspectives on their language learning processes and the integration process. The questions guiding my study were as follows. What practices are emerging in this project? How is the learning taking place? How do the mothers describe their learning experiences? What are their views, perceptions and feelings about what they are learning?

Ethnographic data were collected through participant observation and by conducting interviews and taking photographs during group activities. Photography has proved to be an innovative way to communicate when interviewer and interviewees do not have a substantial basis for 
communication in a common language (Veintie and Holm 2010). With the help of the photographs, interviewees can remember situations that they have participated in and they can also communicate using gestures and the words they have.

Although the participants were aware of my presence as a researcher all the time, I had several roles in the group right from the start: in some meetings I was accompanied by my two-year-old son and thus my role also became that of one of the mothers. Maybe it was my own motherhood that made it fairly easy for me to establish dialogue with the mothers. Most conversations started with us asking each other how the children were doing, admiring them or pondering together on some questions related to raising children or to the child's present age. In addition to the roles of researcher and mother, my role was that of a fellow traveller. During interviews and conversations, I heard many things about the past of the mothers and their present concerns. They kept returning to these topics and we considered them together. In most cases, they did not ask for my advice but I was an equal partner and listener - as one of the mothers.

Inevitably, we examine everything we observe through our own historical and social experiences. I am a teacher, and as I began this fieldwork, I found it difficult to let go of my teacher identity and the fairly traditional and normative ideas about language learning that I held at the outset. It was difficult to step into the ethnographic position that required examining something old and familiar with new eyes. Initially, I felt critical of the fact that mothers were not offered a printout of the course plan, and that progress was not made according to any pre-planned agenda. It was hard for me to accept this way of working. It was hard to believe that anyone could learn like this. However, over time, I came to realise that learning was in the hands of the mothers themselves.

Although I am the author of this chapter and these are my views reflected in this research narrative, the process of building knowledge about the Capable Parent project was a collaborative one. It involved extended engagement and dialogue with the participants in the research, particularly the mothers of migrant origin. So, wherever possible, their voices are brought into the account I provide in this chapter.

\section{The Capable Parent project}

The main objective of the Capable Parent project was to develop a new form of support for the learning of migrant parents who take care of children at home, and who therefore cannot participate in regular integration training courses. The activities of the project supported participants in their role as parents and provided them with opportunities to learn Finnish, as well as cultural and civic skills. An additional objective 
was to develop support group activities for Finnish language learning, and to identify effective forms of outreach for stay-at-home mothers. One of the concrete activities was a course in the Finnish language and culture for mothers that was organised with their children. Unlike conventional training, the participants were not divided into different groups according to their language proficiency or basic education, and they had not taken a language test designed to assess their starting level. However, the most noticeable difference compared to any conventional education was that in this group mothers and children were together all the time, and activities were planned and carried out in a child-oriented manner. This orientation was reflected in the content of the activities: there were arts and crafts activities, songs were sung and games were played. There was no clearcut advance plan for the meetings - that might not have been possible anyway with such small children (aged between a few months and six years). The group got together weekly on the same day and at the same time for two hours.

Typically, integration training is organised by institutions specialising in adult education. However, this course was organised in a residents' park. The park is a public open access meeting place for children of all ages and their parents and carers. This Mother and Child group convened indoors at the residents' park. Most activities took place in the living room where there is abundant space and where there are toys for the children. In addition to the mothers and children, three instructors participated in the group and the project: they were present as 'hostesses' who opened and locked the doors, made coffee, helped with child care, talked with the mothers, informed them about what was going to happen in the meeting and got the materials ready. Also, they always made sure that nobody was left alone: new mothers were introduced to each other and guided to participate in discussions and activities.

The group consisted of about ten mothers originating from Europe, Africa, Asia and the Middle East. Some of them had lived in Finland for just over a year, others several years. A striking demonstration of the strong significance of motherhood for one's identity was the presence of one lady in the group, Madina, whose own children and grandchildren lived outside Finland. In the past, she had tried other courses offered to her, but she found her niche in this group. Even though she participated on her own, her children and grandchildren were present through her stories. She herself acknowledged that the group filled the void left by having her family so distant.

The group was initially founded with migrant mothers in mind, but the park's local mothers (who spoke Finnish as a first language) wanted to join in the activities as well. Their presence actually contributed to integration since it offered an opportunity for migrant mothers to have contact with them. The group's activities were the same as those of the 
other visitors to the park: baking, handicrafts, small excursions into the immediate surroundings, drinking coffee and chatting. These activities constituted a form of social support, empowerment and an opportunity for mothers of young children to take part in activities within their own area. The activities also had a wider social significance and wider implications: they contributed to the improvement of relationships between people of different cultural backgrounds, to local relations of equality and to social wellbeing. Over a two-year period, the mothers involved in the project discussed issues that mothers typically discuss: children, their upbringing, relationships, the joys and sorrows of everyday life and how to cope with it all.

\section{One session on a cloudy day}

The meetings started the same way each time with a group song, making note of the date written in Finnish, and engaging in general exchange of news and the weather. Below, I include a brief vignette based on my observations and field notes. The vignette depicts the starting point for project activities on one particular day. The names used here are all pseudonyms, so as to preserve confidentiality:

The meeting hasn't yet officially started but Jelena and Aisha are already seated on the sofa discussing a children's second hand shop that has opened nearby. Jelena's daughter is playing by her mother's feet whilst Aisha is breastfeeding her baby.

Laura, the instructor, comes in and begins by inviting everybody to the centre to form a circle. They all, children and mothers, gather together in a circle and take each other by the hand. They then acknowledge everybody's presence by mentioning him or her in a song. The children clearly like this; they dance along. One of the mothers sways along to the rhythm of the song, and there is a smile on the face of each mother as her name is referred to in the song. After the song the mothers sit down on the sofa, chairs or the floor. Laura has attached a date on the cupboard door. She asks the mothers, in Finnish, what the date is. Miriam and Aisha listen attentively. Together they begin to search for the correct words and forms in Finnish. Sawan has moved to the sofa, her son is still asleep in the pram on the porch.

Laura asks what the weather is like today, and points to the cupboard door with weather cards attached to it. Aisha and Miriam observe carefully and respond negatively to Laura's question 'Is it sunny today?', 'Is it warm?' and so on. 'Is it cloudy today?' also gets a negative response although it is a particularly cloudy day. Aisha asks for the correct spelling of the word 'cloudy', Laura moves to the sofa to give guidance. 
Pondering over spelling is interrupted as one of the children has fallen over and starts to cry, and this in turn has made two other children upset and they join in. The bawling is loud but the mothers carry on smiling and calm the children down. As the sobbing wanes Laura explains the plans for the day. The plan is to go to the nearby woods for a walk and get familiar with the environment.

(Notes, 26 September 2012)

The pace of the meetings was dictated by the children and their mothers: everything was halted if circumstances so required. Sometimes the children played together for most of the meeting, while some sat on their mother's lap. On some occasions, calming an upset child took up most of the meeting. However, most children had adopted the place as their own; they were cautious and shy when the group first started, but were later playing happily with the mothers, instructors and each other.

\section{Learning together and from each other}

Being a mother and part of a family was the main basis of membership of this group. Normally, when people join a Finnish course of any other kind, be it a preparation for work or another course, they join as an individual, and their family and life situation are not necessarily brought up unless they choose to do so. An adult may be in the middle of challenging family events, but this is not usually taken into consideration. Teachers and institutions organising courses require attendance and attention to studies regardless of people's circumstances. Instead of supporting the family as a whole, the emphasis is on only one of its members. In contrast, the group participating in my research took into account the family situation, respected it and aimed to support the relationship between mother and child.

The women I interviewed regarded motherhood as the centre of life. They seemed to think through their children and always talked with their child in mind: they attached meanings to their experiences and events by looking at them from their children's point of view. They appreciated most of the group activities, such as the circle in the beginning and at the end of the session, because their children seemed to like them best. Motherhood clearly had a central role in the life of these women. They said that they wanted to learn the language so that they could take their children to see a doctor and independently manage their family's affairs in society. Language is learned for life, not for the sake of language itself. As Lainiala and Säävälä (2010) note, migrant women feel that it is difficult to be a good mother without knowing the local language, because motherhood means looking after the child's welfare, providing nonmaterial security and taking care of the child's affairs with regard to 
institutions such as school and kindergarten. These authors also point out that motherhood creates the need to learn the language, but at the same time its obligations curtail opportunities for language learning. Some of the women had the sole responsibility for childcare in their new home country, because migration had made collective sharing of responsibility impossible as relatives and their safety network had been left behind as they departed from their country of origin (cf. Hrdy 1999). In cases such as these, it might be nearly impossible to participate in a mainstream language course. For some, it was difficult to arrange for childcare, and some felt that they had such a strong bond with their babies that they did not want to be separated from them. Many mothers emphasised that their children also learned in the group, as did the mother in the following interview who regarded learning together with her child as both meaningful and unselfish:

Minna: Which way do you prefer? I mean do you prefer learning like here, with children and by doing things, or do you prefer traditional school learning?

Mother: It's different. Because if you have a little child, one year or two or three years, that is not the time for you to learn. That is not just time for you. You must learn with the baby, to be together in that. Because if you go to school alone, without your baby, that is good for you but not for the child. If the child just stays at home, it's not good for him and that is selfish. You must go to school with your child and learn with your child, you know. My child knows all we have learned here. He can say 'one, two, three' [in Finnish], he can sing all these songs, he can say 'nose, eyes, mouth' in Finnish. And he needs to play with other children, and he plays, he sings, and we learn everything together. That is good for him and good for me.

(Interview, 28 March 2013)

In the Mother and Child group, the teaching and learning was egalitarian in nature and the intention was not to transfer 'information' directly from teachers to students, but learning took place through shared activities instead. This is a clear example of practices where the language planning and policy starts from the bottom up (Hornberger and Johnson 2011). Moreover, it could be argued that there was some evidence of pedagogy of a Freirean nature at work in this Capable Parent project. In Freirean pedagogy, teaching and learning is interactive and derives from the students' needs. It does not merely involve reproducing teacher's words and concepts. Learning is achieved through dialogue which is, in turn, based on trust and on consideration of the students' experiences. A Freirean approach aims to be transformative in nature and to build 
learners' capacity to actively participate in society. It also aims at enabling students to see connections between their individual life circumstances and the social context in which they are embedded. Underpinning this aim is the belief that individuals are active subjects who are able to change their environment and to affect the society they live in (Freire 1970; Freire and Shor 1987).

The key factor uniting the instructors and the migrant mothers in the Capable Parent project was motherhood. They discussed motherhood, children, family and the construction of different femininities as equal players, not as teachers and students. It was not immediately obvious who had ownership of teaching or learning, or the right or duty to decide on the nature of the learning process (Freire and Shor 1987; Hirsiaho et al. 2007). The following vignette highlights this aspect of the practices emerging in the project:

The table has once again been set. Jelena has bought Turkish coffee and Khadija has baked two different types of bread at home. The conversation during the apple pie baking session last week had turned to making bread. They had discussed which ingredients are used for bread in Finland and each other's countries. They had realised that just ordinary everyday bread can be made in many different ways. Inspired by this conversation Khadija has baked two different types of bread earlier in the morning and has brought them for the other participants to taste. They try the breads and ask how they were made. One method sounds laborious - you need to add butter repeatedly and roll the dough over and over again. Khadija explains this, partly by miming, and the others help her by providing her with Finnish words. She can't recall the name for one of the spices, and they can't guess. She fetches her phone from the bag, calls her husband and returns smiling: 'Cumin', she says.

(Notes, 27 February 2013)

The notion of 'funds of knowledge' (Moll et al. 1992) helps us to explain this episode. In developing this concept, Luis Moll and his colleagues were highlighting historically accumulated and culturally developed bodies of knowledge and skills essential for individual and household well-being. They were arguing that these bodies of knowledge and skills have a crucial part to play in places of formal and non-formal learning, and can play a role in student empowerment. This episode highlights the way the traditional roles of teacher and student can give way to real dialogue when students are given a forum for sharing the knowledge that they already have. Khadija was teaching those present that day how traditional bread is made in her place of origin. She was describing and demonstrating the bread making technique in fine detail, and the rest of 
them participated by providing the missing words in Finnish. Even her husband participated indirectly in this learning event by translating Khadija's word from their home language into Finnish over the phone. Which one of them, then, was the student, and who was the teacher on this occasion? Or does it really matter?

\section{Conclusion}

The activities in the Capable Parent project have shown that things can and should be done differently. A more traditional and conventional educational and integration path does not necessarily suit everyone. Migrants are often offered language courses as the first, best and even the only solution for integration. They are promised and led to believe that once they master the language, employment and a full membership in the society will follow. What if we first encouraged them and gave support in other areas of life? How many parents with small children have resources to start learning grammar and vocabulary that do not necessarily relate to their current needs?

Freirean goals and activities were not explicitly adopted in the course. Initially, the group's activities were similar to those of a traditional language course: during the first session mothers were given copies of Finnish language exercises, and occasionally they read short sections from Finnish study books. Soon, however, the instructors started to draw on the learners' 'funds of knowledge' and abandoned traditional, schoollike teaching methods. As a consequence, Freirean-type pedagogy became the most common pattern in the weekly activities of the group.

The mothers with their children dictated the pace of the meetings and even the subject areas that were discussed. They did this by coming along and just being present. They took over the space. The instructors offered, of course, activities for the day but often the situation changed according to the needs of the mothers and children. Learning was intertwined with life in the surrounding residential area and society. Learning cannot be controlled, it is unpredictable, ever growing, inspiring and contagious. I conclude my article with the words that one of the mothers used to summarise her learning experience with the group:

This is not just learning Finnish. No, I don't feel like that. This is not just learning. This is being with people. Meeting other people. Talking with other people. Developing friendship with other people. For my daughter to grow up with other people, I don't only stay at home, I come here to learn with my baby and I feel energy in myself. I want to include myself in this. I am a very happy woman. I talk with people, and that makes me feel like a woman with power. 


\section{References}

Freire, P. (1970/1990) Pedagogy of the Oppressed. London: Penguin Books.

Freire, P. and Shor, I. (1987) A Pedagogy for Liberation: Dialogues on Transforming Education. Basingstoke, Hampshire: Macmillan Education.

Hirsiaho, A. and Vuori, J. (2012) Stories of alphabetisation, stories of everyday citizenship. Nordic Journal of Migration Research 2(3): 232-242.

Hirsiaho, A., Pöyhönen, S. and Saario, J. (2007) Maahanmuuttajat suomalaista yhteiskuntaa lukemassa - lukemisen ja kirjoittamisen etnografiaa paperimaassa [Migrants reading the Finnish society - ethnography of reading and writing in the land of paper]. In O-P. Salo, T. Nikula and P. Kalaja (eds), Kieli oppimisessa - Language in Learning. AfinLA yearbook no 65. Jyväskylä: AFinLA, 93-113.

Hornberger, N. H. and Johnson, D. C. (2011) The ethnography of language policy. In T. L. McCarty (ed.), Ethnography and Language Policy. New York: Routledge, 273-289.

Hrdy, S. (1999) Mother Nature: A history of mothers, infants and Natural Selection. New York: Pantheon.

Lainiala, L and Säävälä, M. (2010) 'Jos äiti osaa maan kieltä, hän on kuin kotonaan'. Mitä helsinkiläiset pienten lasten maahanmuuttajavanhemmat ajattelevat kieliopinnoista? ['If the mother speaks the language, she feels at home'. What do migrant parents in Helsinki think about the language studies?]. City of Helsinki: Opetusviraston julkaisuja A1: 2010.

Moll, L., Amanti, C., Neff, D. and Gonzalez, N. (1992) Funds of knowledge for teaching: using a qualitative approach to connect homes and classrooms. Theory into Practice 31(2): 132-141.

Veintie, T. and Holm, G. (2010) The perception of knowledge and learning of Amazonian indigenous teacher education students. Ethnography and Education 5(3): 325-343. 


\title{
Chapter 9
}

\section{Language training for adult migrants in France History, policies and institutions}

\author{
Hervé Adami
}

\section{Introduction}

In France, as in other developed countries, immigration has been the subject, and often at the very centre, of political debates and conflicts over the last thirty years. It is therefore a sensitive and difficult issue to broach, including from a research perspective, as research itself is embroiled in these debates and conflicts. There are scientific, but also ideological disagreements, which sometimes intermingle. The diverging positions can become exacerbated in a political context where xenophobic rightwing parties are gaining ground. Their political stances are used as counter-examples by democratic parties and charities that systematically distance themselves from the proposals of the far right parties. This strategy, which is an attempt to marginalise the xenophobes, actually positions them systematically in the centre of the political debate and everyone is expected to be for or against the far right. Issues such as the nation, national identity or integration (including linguistic integration) have now become very sensitive topics because they are deemed to be typical issues of the far right. Whole sections of research concerning migrants are now areas which require extreme caution. Language training for adults remained reasonably free from the discussions and conflicts until recently, when it became caught up in these angry polemics.

The history of pedagogical concerns in language training for adults is closely linked to the way migration and French society have evolved. Its evolution is therefore inseparable from the history of post-war France and the history of immigration during that period. Despite the discussions, the field of language training for adult migrants has slowly but surely taken shape and now has operational institutional and pedagogical networks. Its future, as its past, depends directly on political choices. France has an interventionist tradition in linguistic matters, and will carry this on in the context of the European integration and economic globalisation which influence its choices. 


\section{Analysis of French language policies: the language of the citizens}

To understand the policies for language training devised by France, there is a need to analyse them in relation to its history, its dominant political principles, and also its contradictions, and the arguments which pervade French society in the context of globalisation. Since the French Revolution, France has been particularly mindful of its language and has adopted an interventionist policy in linguistic matters. The cornerstone of that linguistic policy came from two speeches given in 1794 by the revolutionary deputies Grégoire and Barère (De Certeau et al. 2002). Although these two speeches had very limited immediate practical impact at the time, they represent the ideological basis of the future linguistic policies in France.

At the time of the Revolution, regional languages were still widely used in France. French had gained ground, but even though it was the international language of the time, most French people did not use it regularly. Grégoire and Barère quite radically called for moves to 'destroy the patois', that is the regional languages. These speeches, which seem undemocratic from a contemporary perspective, should be seen in their historical context along with a consideration of the reasons which led the two revolutionaries to make this proposal. Grégoire and Barère's argument was based on three main points: French had to become prevalent throughout France, and was instrumental in spreading the ideas of the Revolution; the community of free and equal citizens of the new French Republic needed a universal communicative tool for its members; and French was considered a rich and powerful linguistic tool which the citizens of the new democratic nation had the right to take over, as they did political power and the aristocrats' possessions and properties.

This key idea was followed up by a radically democratic proposal for the time: in order for citizens to access the potential of French as a powerful medium for the communication of the most complex ideas, the two revolutionaries suggested that a free, public, compulsory and secular (i.e. free from the interference of the established Church) educational system should be set up for boys and girls alike. The idea would not be implemented until 1884 by the government of the Third Republic. The revolutionaries thus considered that spreading French was fundamentally a democratic measure. French for them was the national language akin to the concept of nation for the revolutionaries of 1794; in other words, a sovereign community of free citizens. The revolutionaries and the republicans, their heirs, thus had a political, not an ethnic concept of language. This is in contrast to the Germans, who at the same time were trying to construct their Nation-State (Baggioni 1997; Thiesse 2001; 
Anderson 2006). From the end of the nineteenth century French language policy tried to promote French and turn it definitively into the language of all the citizens while excising the regional languages, whose use would in fact decline dramatically during the twentieth century. These languages have all but disappeared from daily use by the French. They manage to survive thanks to regionalist activists and schools, but their use as first languages is marginal (Kremnitz 2014). Their disappearance has not been due to a brutal coercion or political oppression, but to schools educating generations of children using French as the only medium of instruction. Rural exodus and urbanisation, movement of people within the country and the development of the media have also contributed to the pre-eminence of French (Lodge 1993). French was thus imposed as the official language to the detriment of regional languages. The French, however, on the whole accepted these language policies despite undergoing four revolutions in under a century, since they corresponded to a massive increase in literacy and thus to increased social mobility among poorer sectors of the population. At the same time however, the democratic conception of the use of the language and access to education was not applied in the French colonies. Colonised populations were ignored and remained largely illiterate. The diffusion of French in the colonies was never a priority for the governments, even the most progressive among them.

French is nonetheless truly the language of the Republic as stated in the Constitution, and is thus considered the main tool for the acculturation and integration of migrants. France today considers migrants' mastery of French as an instrumental necessity (in order to be able to communicate in their daily business) but also as a right (North 2007). It is the same right to the language that the revolutionaries wanted to grant to citizens in 1794. The dominant conception of language in France does not rely on ethno-cultural identity but on a political basis.

\section{Immigration in France: a centuries old history}

France has a long tradition of immigration, since the territory she now occupies has hosted many peoples and countless 'guests', more or less peaceful, succeeding each other, mingling, producing new generations, fighting each other too: artistic cave-dwellers in the South West; Ligurians; Gauls (Celts, who national mythology represents as the ancestors of the French); Greeks; the founders of Marseille; Romans of course, who left an enduring imprint on France's destiny and left their language as a legacy; Germanic tribes, who ravaged what the Romans had left behind; and the countless and endless cohort of individuals, groups and families who came to settle in France over the years. The modern history of immigration begins with the arrival of many Belgian, Italian and Polish 
workers at the turn of the nineteenth and twentieth centuries. They came because of the need for extra labour for industrial development and for re-building after the destructive First World War, and contributed to much needed economic growth. They were followed by Italians and Poles during the 1920s and 1930s, as well as Spaniards fleeing the Francoist dictatorship. Following the Second World War and again the need for reconstruction and economic development, Portuguese, Algerian, Moroccan, Tunisian and sub-Saharan workers joined other immigrants and French workers in industry. Until the 1970s it was essentially a workers' immigration, a to-ing and fro-ing (a 'noria' to quote Noiriel (2006): young individual workers who came to France temporarily for a work contract would return home). Immigrant families settled in France too but their motivations were either work-related or political, like the Spaniards and Portuguese fleeing the oppressive regimes of Franco and Salazar. During the 1970s economic conditions changed resulting in a crisis: France decided to stop work-related immigration, but immigrants kept arriving under a 1974 government decision which authorised migrants legally settled in the country to bring members of their families. This is still the case nowadays, with most immigrants joining family members, and others trying to find work or applying for political asylum.

France's immigration policy has long wavered between a strict control of migrants, with the help of the source countries (which disapproved of the politicisation of their nationals by radical Trade Unions and the French Communist Party) and a deliberate policy of integration (Weil 2004). The most common idea, incidentally among foreigners themselves, was that a stay in France was temporary and the plan was to go back to the home country (Noiriel 2006; Weil 2004). Migrants kept that hope and governments encouraged it. The first attempts at linguistic training had that objective in view: provide migrants with a basic education to help them convert professionally once they got back to their home country.

\section{Developing the institutional and pedagogical framework for language training for adult migrants in France}

\section{A training policy linked to a social and political context}

The history of language training for adult migrants in France started in the 1960s, with evening classes led by primary school teachers (Rivenc 1960) and volunteers. From the onset, adult language education was marginalised from other educational endeavours, as it did not rely on any national or local institutions. The first to tackle the training of adult migrants were workers' unions, left-wing organisations and Christian charities, giving the training an activist dimension, and thus further singling out this field in the educational domain. Moreover its provision 
depended on a string of associations not recognised institutionally and free from any state control. These associations, which often pursued political or trade union objectives, represented for the powers that be, whether administrative or educational, more risk of subversion than real educational partnership. Another reason for this marginalisation is that the learners were neither children nor teenagers, but adults. Theoretical research in education in France in the 1960s and 1970s was essentially concerned with primary and secondary school teaching. A final reason lay in the fact that many of these migrant learners were uneducated or poorly educated. Teaching methods and the materials developed for these adults were based on primary school models which were adapted to exclude the most infantile features. Pedagogy for teaching French to non-native and non-literate adults could rely neither on practice, past experience nor even established theory. The first teachers involved in adult education needed to improvise pedagogical strategies and tools.

Institutionally, the creation in 1958 of the Fonds d'Action Sociale pour les Travailleurs Musulmans en Métropole et leurs Familles, which was to become the Fonds d'Action Sociale pour les Travailleurs Étrangers (FAS) in 1964, represented the cornerstone of the policies concerning migrants. The FAS, the predecessor of all the institutions which followed, has, despite its reorganisation and successive relabellings, survived to this very day. With no coherent long-term strategy represented in successive immigration policies, the tension between the wish to integrate the migrants and conversely to encourage them to leave would continue into the 1980s. Weil (2004) has shown how indecisive the political authorities were regarding immigration until the 1980s and 1990s, when France opted for a clear policy of integration of migrants and the funding thereof. For both migrants and the authorities, the illusion of going back home disappeared and reality set in: migrants in massive numbers made the decision to stay indefinitely and policy-makers had to adapt. Integration became standard policy and France had to rely on its republican ideology to bolster its policy. Should migrants wish to stay, their destiny was to integrate with the French population (Todd 1994) and policies would reinforce and speed up that tendency. That deliberate policy of helping migrants integrate into French society continues today. Although 'integration' is the most widely used and least controversial term used in the discourses of immigration, other possibilities include 'assimilation', 'insertion' and 'inclusion', terms whose nuances in meaning are more political than scientific and correspond to ideological standpoints. Leclercq (2010, 2012), in his research into the history of this field, has shown that language training programs prior to the 1980 s were haphazard and piecemeal. They responded to identifiable needs but lacked overarching vision and especially a political and pedagogical compass. When France opted 
clearly for the integration of migrants, and dropped the idea that they may decide to go home, language training got organised, slowly but decisively.

\section{Setting up and consolidating institutional frameworks}

The main trends in the evolution of language training correspond to several notable features: first, the growing role and intervention of the State, starting mainly in the 1990s, in a field occupied by charities. Rather than directly providing language training, the State organised the market by a system of calls for proposals, funding and assessing the training programs of independent organisations, usually of a nonprofit, charitable status. Second was the spread of professionalisation, which had begun in the 1970s. These two trends led to a change in the way the provision of training was considered. The situation changed dramatically in 1995 when straightforward subsidising was replaced by calls for proposals funded by grants. The 1990s saw the first attempt to align pedagogical practice among trainers of adult migrants, culminating in the creation of a Framework for Basic Language Training by the CUEEP, a research centre specialising in educational science at the University of Lille 1 . This first attempt at alignment, though imperfect in its content, was a pioneering initiative. In the 2000s the parallel creation of the Contract for Welcoming and Integration (CAI) and the Initial Diploma in French (DILF) provided the institutional and didactic framework for the training of adult migrants. The CAI is a contract signed between the State and the migrants: it requires the migrant to respect the values of the Republic, and the State to provide language training for those who need it. The DILF is related to two other diplomas, the Diploma for Studies in French (DELF) and the Advanced Diploma in French (DALF), which already exist in the field of teaching/ learning French as a Foreign Language.

The DILF, like the DELF and the DALF, is based on the Common European Framework of Reference for Languages (CEFR). The DILF assesses a level of competence not part of the CEFR, level A1.1, which is below the Al base level of the CEFR. It was developed in France so that poorly educated migrants and those who have the most difficulty with written French can achieve an official diploma. The DILF represents a crucial stage in the history of the field because it constitutes a common framework for the activity and pedagogical practice for participants in adult education. As institutional frameworks under State control, the DILF and the CAI provide legitimacy to the field of language training for adult migrants. The latest stage in the institutionalisation of the field came from the Department of Welcome, Integration and Citizenship (DAIC) and the General Delegation for French and the Languages of 
France (DGLFLF), which together have created the term French Language for Integration (FLI).

French Language for Integration is primarily a frame of reference for language schools for adults which today constitutes the framework for language training for adult migrants in France. The framework specifies France's policy for integration and also the framework for pedagogy and teaching methods. The FLI framework was introduced with the initial objective of defining quality standards and a certification of the professional organisations involved in the language education of adult migrants.

The framework considers French for Integration as a langue horizon defined not as a language in its own right, or even a level of language proficiency, but as a learning and acquisitional process. FLI is also a teaching approach broadly described in the framework:

a) FLI encourages the learning of practical French, useful in daily life because migrants are linguistically immersed.

b) FLI encourages the learning of spoken French which enables direct interaction with native speakers, but does not neglect the written medium.

c) Following CAI, FLI includes a citizenship dimension in its approach. Parallel to learning French is the development of sensitisation to the values of the host society, and specifically for France, the values of the Republic.

d) FLI stresses professional integration (workforce training and employability).

e) FLI also stresses the relationship between schools and migrant parents, in order to facilitate contacts with the schools.

f) Finally, the FLI as a quality standard concerns the physical conditions of the training provided (quality of the equipment and the materials, location, etc.) and the training of the teachers who must now take a specific course in FLI. Some French universities have started to include courses in language training for migrant adults in their curricula.

\section{The landscape of language training for adult migrants today}

There are nearly 500 organisations involved in language training for adult migrants in France. These organisations are predominantly professional and only a handful rely on unpaid volunteers. Although most of the professional organisations still have charitable status due to the radical history of the training organisations, which they wish to retain for practical managerial or philosophical reasons, they are still subject to civil law like any other charitable organisation. How they consider and 
maintain their charitable status varies considerably from one organisation to another. Since 1995, language schools operate on the basis of grantfunded proposals, which serve to regulate the principles and practices of the people involved. Some organisations complain that the introduction of competition into the field entails a compromise of principles, and in practice, grant funding has considerably modified the landscape: unable to compete with larger organisations, small organisations shut down and training schools now compete with each other. This competition does not however prevent cooperation, or the building of networks and partnerships between the organisations. Furthermore, the end of subsidised programs has accelerated the professionalisation of the organisations.

The current central element of the pedagogical systems, as mentioned earlier, is the Contrat d'Accueil et d'Intégration (Candide and Cochy 2009). Furthermore, the French Office for Immigration and Integration has been the sole State Operator for language training since 2009, and is responsible for making and administering the calls for proposals for FLI training programs. FLI is now well structured by these systems. We should note however that in addition to formal opportunities to learn French, new arrivals acquire competence from direct contact with native speakers in daily interaction. The analysis of language educational contexts for migrants cannot be dissociated from the analysis of informal learning in the social context (Adami 2012).

\section{Political update on language training for adult migrants}

As I write these lines in 2014, some changes appear to be developing in the field of adult FLI training. Former Prime Minister Jean-Marc Ayrault has published a paper (2014) which specifies government policy regarding the way migrants are received in France and reiterates the intentions and principles of French policy over the years, as I have described them. Thus the issue of discrimination that second generation migrants might encounter because of their origins is tackled on the principle of republican equality: a republic of equal citizens cannot tolerate that some of them might endure discrimination because of their foreign origins. Similarly the issue of ethnic diversity is treated in relation to the unity of the nation. The paper states that:

Thanks to our policy of republican equality and integration, it is a vision of a France that is confident in its strength, in the richness of its diversity, in its unity and its place in the world that the government strives to promote ... Our country can impose its republican model of citizenship and at the same time benefit from the diversity of its citizens. 
Diversity is tackled within the framework of the fundamental principle of the republican constitutions: 'France is a Republic that is one and indivisible, secular, democratic and social'. From that perspective, present-day policy belongs to the republican tradition. With regard to linguistic integration, the fundamental principles remain. Thus the paper stresses that 'mastery of French must be guaranteed' and that 'the values of the Republic, liberty, equality, fraternity, tolerance, respect for others and secularism, must be transmitted'. The two dimensions, language and citizenship, are therefore always strongly linked, both in principle and in reality. It would appear furthermore that the minimal level required will not be A1.1 anymore but A1 after a year and A2 after 5 years.

\section{Conclusion}

After years during which the field of language education for migrants was almost completely ignored by academia and researchers in applied linguistics, the development of FLI has provoked heated debate, especially amongst academics. The main bone of contention concerns the place accorded the native languages and cultures of migrants in FLI. This approach stresses the priority of learning French as a means of social, economic and civic integration. Opponents of this approach strongly criticise it on the grounds that migrants' first languages have not been taken into account in the learning strategy set out in the FLI frame of reference. The very concept of integration is challenged because it is regarded as smacking of an assimilationist strategy that denies the linguistic and cultural backgrounds of migrants. This debate however risks spilling over into wider debates about multiculturalism, a contentious and ill-defined concept that has been at issue since the 1970s.

In the social and political context of contemporary France, the question of diversity and differences is a minefield. A multiculturalist approach, which favours respect for diversity and the plurality of languages as against a potentially coercive monolingualism, encounters strong reactions in French society and the political arena. To paraphrase Benn Mickaels (2007), drawing upon their universal republicanism, the French tend to prefer equality to diversity.

\section{References}

Adami, H. (2012) Aspects sociolangagiers de l'acquisition d'une langue étrangère en milieu social. In H. Adami and V. Leclercq (eds) Les migrants face aux langues des pays d'accueil. Acquisition en milieu naturel et formation. Villeneuve d'Ascq: Presses Universitaires du Septentrion, 51-87.

Ayrault, J.-M. (2014) Politique d'égalité républicaine et d'intégration. Feuille de route du gouvernement, 11 February. 
Anderson, B. (2006) Imagined Communities. London: Verso.

Baggioni, D, (1997) Langues et nations en Europe. Paris: Payot.

Benn Mickaels, W. (2007) The Trouble with Diversity. How We Learned to Love Identity and Ignore Inequality. Boston: Holt McDougal.

Candide, C. and Cochy, C. (2009) La connaissance de la langue française un vecteur essentiel d'intégration. Nouvelles orientations et état des lieux. In J. Archibald and S. Galligani (eds) Langue(s) et Immigration(s): Société, Ecole, Travail. Paris: L'Harmattan, 97-109.

De Certeau, M., Julia, D., and Revel, J. (2002) Une Politique de la Langue. Paris: Folio.

Kremnitz, G. (ed.) (2014) Histoire Sociale des Langues de France. Rennes: Presses Universitaires de Rennes.

Leclercq, V. (2010) La formation linguistique des migrants des années 1960 aux années 1980. Education Permanente 183: 173-188.

Leclercq, V. (2012) La formation des migrants en France depuis l'alphabétisation des années 60. In H. Adami and V. Leclercq (eds) Les Migrants Face aux Langues des Pays d'Accueil. Acquisition en Milieu Naturel et Formation. Villeneuve d'Ascq: Presses Universitaires du Septentrion, 173-196.

Lodge, R. A. (1993) French: From Dialect to Standard. London and New York: Routledge.

Noiriel, G. (2006) Le Creuset Français. Histoire de l'Immigration XIXe-XXe Siècle. Le Seuil, Paris.

North, X. (2007) La langue française est l'affaire de tous les citoyens. Enseigner le Français 6: 45-47.

Rivenc, P. (1960) L'alphabétisation des adultes et leur formation professionnelle. Revue du Tiers Monde 1: 221-233.

Thiesse, A. M. (2001) La Création des Identités Nationales. Paris: Seuil.

Todd, E. (1994) Le Destin des Immigrés. Assimilation et Ségrégation dans les Démocraties Occidentales. Paris: Le Seuil.

Weil, P. (2004) La France et ses Etrangers. Paris: Gallimard. 


\title{
Plurilingual literacy practices in a creative writing workshop with adult second language learners
}

\author{
Noëlle Mathis
}

\section{Introduction}

In spite of the Council of Europe's effort to promote it, plurilingual competence is not generally valued in French academic or public discourse. Monolingualism - and the use of standard varieties - is what counts in policy and in practice. This chapter sets out to describe a plurilingual approach to literacies which embraces the expression of plurilingual identities by adult migrants who have crossed geographic, linguistic and cultural borders. It focuses on a creative writing workshop that I created and facilitated with plurilingual learners in a French as a Second Language (FSL) class at a French university, as part of my teaching practice as a FSL teacher. These learners, like many economic migrants, speak historically positioned minority or less commonly taught languages. I will first describe the context of multilingual education established in the writing workshop. Then, I will provide samples of learners' written pieces and discourses that reveal clear evidence of heterogeneity and dialogism in their plurilingual literacy practice. Heterogeneity is understood as the co-existence of diverse and mixed forms of a language in texts, and dialogism as the manifestation of how everything anyone says always exists following what has been said before and in anticipation of what will be said in response. Finally, I will draw links to the expression of plurilingual identities and implications for adult language education.

\section{A case study: a writing workshop with adult learners}

Although multilingual education and the development of plurilingual competence are encouraged in France (Council of Europe 2001; Moore and Gajo 2009), few teachers in adult education are in fact using the plurilingual repertoire of their students as a resource for learning. The writing workshops I facilitate encourage the emergence and use of languages other than the target language as a way to both learn language and increase the development of plurilingual competence. These 
languages and their mixed and heterogeneous use are part of oral interactions in class and literacy practices. Martin-Jones and Jones (2000) suggest that multilingual literacy practices - the use of certain genres, styles and languages - vary according to the context in which they are situated. The writing workshop is set up as an open window to writing 'identity texts' (Cummins and Early 2011) that hold 'a mirror up to learners in which their identities are reflected back in a positive light' (p. 3). I consider learners as having multiple identities, including plurilingual identities (a notion further explored below). Consequently, learners' multiple languages that emerge in texts and in classroom interactions are welcome. During the writing workshops, activities are based on reading published work, individual writing tasks and peer reading of texts composed by the learners. The authors of the published work, from Lebanon, Morocco, Canada and France, all reflect on personal experiences with languages and migration journeys. They mostly write in French but also use other languages in their writing. The writing tasks focus on the learners' own experiences and they engage actively in the writing of short texts using creative writing prompts. Peer reading of the individual texts in class allows further explanation, discussion and feedback from peers and the teacher. End-of-term interviews are conducted with learners to reflect on their practices.

The data presented in this chapter is selected from two writing workshops, which spanned over two university terms in 2009 and 2010. I selected the work of three female participants between the age of 25 and 35 years, Nati, Thich and Alina, who respectively come from Georgia, Vietnam and Spain. I chose them for two reasons: first, their texts expressed clear evidence of heterogeneity and dialogism; secondly, the data allowed links between literacy practices and participants' reflection on them. They registered in the FSL program for more than one term to improve their French language skills for personal and professional reasons, and because they needed a proficiency level to be accepted in a French university for graduate studies. They all completed a college or university degree in their home country. The 3-hour writing workshop that I facilitated was part of an intensive 15-hour per week FSL program for which participation was mandatory in order to receive certification.

\section{Theoretical framework}

Learners in the study are considered plurilingual speakers who use their plurilingual resources and competence intentionally, as a way to reveal themselves as individuals with multiple identities. Moore and Gajo (2009) define the plurilingual speaker 'as a social actor who develops a repertoire made up of various languages and varieties of languages and different forms of knowledge' (p. 142). What is at play is individual agency (Giddens 
1984). Identities are understood as being fluid, dynamic and fragmented, and refer to constant processes of negotiation implying contradiction and tension, but leading to transformation. Links between plurilingual speakers and identities are characterised by Moore and Brohy (2013) this way:

Plurilingual identities are a category of (individual and collective) identity. They are expressed through the ways in which a speaker uses his/her languages and the discourses s/he expresses about them. They are marked by instability and ambivalence. They reveal themselves in different manners according to speakers' choices amongst possibilities, choices that depend, amongst all, on individual life trajectories, social and linguistic categories, interpretations made by individuals about the local circumstances in which they have to negotiate difference and affirm affiliation.

(Moore and Brohy 2013: 297, my translation)

Plurilingual speakers use their plurilingual competence (Coste et al. 1997/2009), which is understood as their ability to act as social actors in situated contexts through the use of their repertoire and languages:

Plurilingual and pluricultural competence refers to the ability to use languages for the purposes of communication and to take part in intercultural interaction, where a person viewed as a social actor has proficiency, of varying degrees, in several languages and experience of several cultures. This is not seen as the superposition or juxtaposition of distinct competences, but rather as the existence of a complex or even composite competence on which the social actor may draw.

(Coste et al. 1997/2009: 11)

The concept of plurilingual competence brings a new light to the definitions of bilingualism and multilingualism currently used in the field of multilingualism. Indeed, plurilingualism offers a terminological switch from multilingualism: with plurilingualism, the focus in on the individual and his/her languages, whereas, with multilingualism the focus is on societal context (Moore and Gajo 2009). Plurilingual competence is understood as 'a full and balanced competence in discrete languages' (Marshall and Moore 2013: 474), instead of separate competences in each discrete language. Plurilingual competence emphasises an individual's abilities to use their language competence according to context, speakers and intentions while identities are given a key role.

I understand writing as a social practice (Street 2000), determined by contexts in which it takes place, by being particularly attentive to 
relations of power and authority inherent to academic literacies (Lea and Street 1998). The concept of multiliteracies (Cope and Kalantzis 2000) builds a link between individual literacy practices and social contexts, especially in educational settings. I am specifically interested in multiliteracies focusing on learners' identities and based on heteroglossia with the work of Fairclough (2000) and Bakhtin's (1978) dialogic approach to language. Additionally, Martin-Jones and Jones (2000) note that multilingual literacies imply a need to 'focus attention on the multiple ways in which people draw on and combine the codes in their communicative repertoire when they speak and write' (p. 7). Canagarajah (2011) maintains that plurilingual speakers 'shuttle between languages, treating the diverse languages that form their repertoire as an integrated system' (p. 401). In other words, plurilingual speakers do not treat their languages as separate and disconnected, but rather perform their languages as a combined system. Furthermore, Marshall and Moore (2013) add: "we see [...] new forms of [hybrid urban pluri-/multilingualism] being performed along a "languaging" continuum where clear borders do not exist between the languages of bilinguals' (p. 477). In other words, limits between languages are questioned, and code-switching is a manifestation of a bilingual speakers' voice, when they alternate between two or more languages. Canagarajah (2006) talks of codemeshing to refer to code fusion and its complex uses in texts: 'code-meshing is a complex discursive act for our learners (one that involves a polydialectal competence - i.e., familiarity with standard varieties, expert use of local variants, and the rhetorical strategies of switching)' (p. 602). Additionally, Creese and Blackledge (2010) refer to 'translanguaging as bilingual pedagogy' (p. 105), inspired by Garcia (2007), to describe classroom practices defined by permeable boundaries between languages. Heterogeneity and the multiple uses of codes is what I attempt to highlight in the plurilingual learners' literacy practices.

\section{Findings and interpretations}

Data from Nati, Thich and Alina were selected to explore the creative ways in which each of them deployed their plurilingual competence and, as a result, manifested their plurilingual identities. A common trait between them was the way in which they negotiated their positioning along continua using their languages (or not) depending on situation, while reflecting on their language learning and literacy practices.

\section{Being plurilingual: Nati (from Georgia/Russia)}

In her written biography, Nati expresses the importance of her languages: 
Qu'est-ce qui pourrait être plus facile à dire que quelques mots sur soi ...? C'est évident! Mais, quand je commence à écrire: 'je suis ...', mon Babylon me fait perdre tous les mots. Les quatre personnes à l'intérieur de moi commencent à parler toutes ensemble dans une langue différente. Elles se bousculent en prétendant atteindre la page la première. So, finalement je dirais: $\mathrm{M}$ e $\mathrm{n} \mathrm{j} \mathrm{a} \mathrm{z} \mathrm{o} \mathrm{v} \mathrm{u} \mathrm{t} \mathrm{[Nati].} \mathrm{I} \mathrm{love}$ ma famille, t s h o v r e b a, et j'espère que c'est mutuel.

(Nati, biographie, 2009)

What could be easier than to say a few words about myself ...? It is evident! But, when I start to write: 'I am...', my Babylon makes me lose all the words. The four individuals in me start to all speak at the same time in a different language. They push each other out to reach the page first. So, finalement je dirais: $\mathrm{M} \mathrm{e} \mathrm{n} \mathrm{j} \mathrm{a} \mathrm{z} \mathrm{o} \mathrm{v} \mathrm{u} \mathrm{t} \mathrm{[Nati].} \mathrm{I} \mathrm{love}$ ma famille, t s h o v r e b a, et j’espère que c'est mutuel.

(Nati, biography, 2009, my translation)

This last sentence using four languages would translate in English as such, except for the non translatable Georgian word tshovreba: 'So, finally, I shall say: my name is Nati. I love my family, t s h o v r e b a, and I hope it is mutual'. Nati introduces herself by personalising her languages, expressing discomfort and tension (my Babylon makes me lose all the words / They push each other out) while, simultaneously, giving voice to the four individuals in [her]', by using a creative mix of languages. Indeed, in the last phrase, she exemplifies her multi-voicedness by code-meshing four languages (French, English, Russian, Georgian) even though the writing activity did not request it. Additionally, she uses space between the letters of the Russian phrase M e $\mathrm{n} \mathrm{j} \mathrm{a} \mathrm{z} \mathrm{o} \mathrm{v} \mathrm{u} \mathrm{t} \mathrm{(My} \mathrm{name} \mathrm{is)} \mathrm{and} \mathrm{t} \mathrm{s} \mathrm{h} \mathrm{o} \mathrm{v} \mathrm{r} \mathrm{e} \mathrm{b} \mathrm{a}$ (a word that refers to Georgian history and redemption), these two languages giving her roots and links to the past. I interpret the stylistic and linguistic choices she makes as evidence of dialogic writing and, consequently, as a way to express her plurilingual identities. In the endof-term interview, Nati expresses the following about the writing workshop:

moi je pense que cet atelier d'écriture c'est très spécial parce nous on a écrit on a parlé nous par rapport à nos langues mais pas les langues par rapport à nous les langues qu'on parle c'est nous comment on est dans le monde des langues et comme on est tous comme soit deux langues soit trois langues soit polyglotte c'est très intéressant c'est c'est expérience unique je veux dire parce nous par exemple si tu habites en Russie et si tu parles russe uniquement tu n'aurais pas besoin d'écrire des choses comme ça.

(Nati, entrevue finale, 2009) 
me I think this writing workshop is very special because we wrote we talked about us in relationship to our languages and not our languages in relationship to us languages we speak it is how we are in the language world like either two languages or three languages or polyglot it is very interesting it is it is a unique experience I mean because we for example if you live in Russia and if you speak only Russian you would not need to write things like this.

(Nati, final interview, 2009, my translation)

Nati evaluates the writing workshop as an open space, which allowed her, as a plurilingual individual, to be at the heart of the writing project (us in relationship to our languages) and not the opposite (and not our languages in relationship to us). She also establishes continua between what she perceives as a plurilingual context (this writing workshop) and a context she considers monolingual (Russia), the former focussing on plurilingual individuals (polyglot) and the latter on monolingual individuals (if you speak only Russian). In other words, Nati's identities manifesting themselves in a personal and intimate relationship to her languages can be expressed because of the pedagogical space that openly welcomes multiplicity.

\section{Being an expert of her Asian languages: Thich (from Vietnam)}

In a narrative about languages, Thich compares her four languages:

Pour moi, le chinois est très intéressant, et il n'est pas la même d'anglais. Si le vietnamien ou l'anglais, le français ont l'alphabet (a, b, c), le chinois a lui-même des caractères (汉字).

(Thich, Mes langues, excerpt 4)

For me, Chinese language is very interesting, and not the same as English. If the Vietnamese, English or French languages have an alphabet (a, b, c), Chinese language has characters (汉字).

(Thich, My languages, excerpt 4, my translation)

She expresses clear appreciation for the Chinese language, which, unlike Vietnamese, French and English languages, uses characters rather than the Roman alphabet. Additionally, she explains her liking of the Chinese language because of language structure:

Notre phrase comme: le sujet + le verbe + le mot indique le temps + l'objet. Il n'a pas de conjugaison de futur ou passé dans notre langue. Par exemple le vietnamien dit 'Tôi đã ăn cơm', le chinois dit 
‘我吃饭了', c'est-à-dire 'j'ai déjà mangé'. Les mots 'đã' et '了' indique le temps du passé.

(Thich, Mes quatre langues, excerpt 5)

Our sentence like: subject + verb + word that indicates time + object. There is no conjugation of future or past in our language. For example, Vietnamese people say 'Tôi đã ăn cơm', Chinese say ‘我吃饭 了' which means 'I've already eaten'. Words such as 'đã' and '了' indicate past tense.

(Thich, My four languages, excerpt 5, my translation)

Thich explains that Vietnamese and Chinese languages use similar language structures: they do not conjugate verbs but use temporal markers to indicate past and future tenses. She gives an example by using a simple phrase (I've already eaten) in Vietnamese, translated in Chinese and French, using Vietnamese alphabet and Chinese characters, while outlining the function of the markers. As such, she code-switches with fluidity and ease using three languages. While explaining and translating the metalinguistic features of her languages, not only does she reach out to the readers, but also positions herself as an expert with regard to her languages. In her understanding of language learning, similarity of culture and language structure allow her to learn Chinese with more ease than French. In class interaction, she states: 'on a la même culturel et quand j'apprends je peux comprendre' (we have the same culture and when I learn I can understand) (class interaction, 28 September 2010, my translation). She makes it clear that learning Chinese is easier for her than learning French. She is particularly aware of learning processes amongst her classmates in the group, as she compares her language learning abilities to other students':

si comme euh quand je je parle j’apprends en français si les les personnes qui viennent Europe ou comme ça ils peuvent comprendre bien les expressions ou quelques mots en français mais moi aussi quand j'apprends chinois je peux comprendre mieux que le français (class interaction 28 September 2010)

if like um when I I speak learn in French if people from Europe or such they can understand expressions or words in French but me too when I learn Chinese I can understand better than in French

(class interaction 28 September 2010, my translation)

Thich, the only Asian learner in the group of participants, equates her ability to learn Chinese, being from Vietnam, with European (or with European background) language learners' to learn FSL. According to 
her, they may have more ease with French language learning than she does. As such, she indirectly expresses the challenges she faces learning French language. More importantly however, the dialogic development of her metalinguistic awareness is to be noted: she gives voice to her identity as a different learner when she learns an Asian versus a European language. Language learners can choose and negotiate different postures and/or roles in participating (or not) in social settings (Norton and Toohey, 2011). By describing metalinguistic features of her Asian languages, she gives herself the chance to (re)negotiate her identities as not only a FSL learner with difficulties, but as an expert of languages that other learners do not know and respect. Throughout the writing workshop, Thich's identities transform, from not participating actively to class activities unless requested, to gradually writing texts in which she displays her plurilingual repertoire.

\section{Being a foreigner in France: Alina (from Mallorca)}

In her biography, Alina, a native speaker of Catalan, writes how she perceives herself as a foreigner in France:

Je suis une étrangère en France, une Majorquine à Avignon (...) Je prétends passer inaperçue mais cela ne marche jamais. Jamais je n'avais dit autant de fois 'je suis espagnole' car en Espagne, on a différentes nationalités sur le même territoire, et on dit plutôt 'je suis catalan, andalous, basque ou dans mon cas majorquine ...' Mais où donc est cette île? Oui, je sais, un point minuscule sur la carte, mais elle est ma terre quand même. (...) Je suis une étrangère en France et maintenant je suis aussi une étrangère pour moi-même.

(Alina, biographie, 2010)

I am a foreigner in France, a person from Majorca (...). I try to go unnoticed but it never works. I have never said as often: 'I am Spanish' because in Spain, one has different nationalities on the same territory, and one says 'I am Catalan, Andalusian, Basque or in my case Majorcan'. But where is this island? Yes, I know, a tiny spot on the map, but it is my land anyway. (...). I am a foreigner in France and now, I am a foreigner to myself.

(Alina, biography, 2010, my translation)

In this text, Alina expresses her impressions as a foreigner in France (foreigner repeated three times), which is particularly emphasised by heterogeneous positioning in writing, according to Bakhtin's dialogic approach to language. Indeed, the 'I' voice carries several meanings: her new self vis-à-vis her old self; herself vis-à-vis the French view of Spain as 
monolingual and; the various Spanish selves. Additionally, the echoes from prior discourses (I have never said as often) and from prospective discourses (But where is this island?) can also be heard, toppled with markers of concession (it is my land anyway), all being different forms of dialogism. As such, if Alina chooses not to switch languages, unlike Nati and Thich, she uses her plurilingual competence to write a text characterised by multi-voicedness. During the end-of-term interview, she explains how she uses her languages in literacy practices:

moi ce que je faisais au départ d'abord c'était de faire comme ehm une traduction comme essayer de faire une traduction de mes pensées en espagnol de mettre en papier et moi je m'ai rendu compte que c'était pas ça le processus qui convient c'est de oublier complètement ta façon de d'écrire dans ta langue maternelle et de plonger dans dans les structures de de la langue que que tu es en train d'apprendre et ça moi je commence maintenant à le faire mais moi je trouve que c'est le plus lourd

(Alina, entretien, 2010)

me what I was doing at first was to do like um a translation like trying to do a translation of my thoughts in Spanish on the paper and me I realised that was not it the process that works is to completely forget your way of writing in your mother tongue and to dive in structures of the language you're about to learn and that it is what I'm starting to do but I find it heavier

(Alina, interview, 2010, my translation)

Alina shares her strategies around her literacy practices in French. She explains first what she was doing before (a translation of my thoughts in Spanish), then proceeds with an assessment (that was not it), offers solution (the process that works is to completely forget your way of writing in your mother tongue) and informs of her current practice (it is what I'm starting to do). She displays as such a transformation in her linguistic identities by adopting new strategies in her literacy practices. Her discourse is characterised by a strong desire for continuity using a linear narrative text structure such as set-up, conflict and resolution. However, this continuity is placed under tension with the discontinuity she exposes about not using her Spanish skills, which she evaluates as being difficult (but I find it heavier). To sum up, Alina, while not translating and code-switching with Spanish or Catalan, nevertheless expresses her multiple identities by adopting heterogeneous voices. 


\section{Discussion}

Following this data analysis, I would suggest considering adult language learners as plurilingual social actors who (re)negotiate their relationship to others and give meaning to their practices, by taking into account the continua along which they navigate and position themselves according to the situation:

In their everyday lives, bi/plurilinguals find themselves at various points along a situational continuum; various positionings on this continuum induce alternative choices and social adjustments, particular language modes (the choice of one language or another, and the possibility of code-switching) and different identities (e.g., the speaker can endorse a monolingual, a bilingual or a learner identity), all within the same conversation.

(Moore and Gajo 2009: 141)

Using their plurilingual competence, social actors take up, in their literacy practices, the positioning of learners to those of experts, and of being monolingual to plurilingual, while expressing tensions and creating new ways of conveying who they are in the world. Furthermore, as Hornberger and Skilton-Sylvester (2000) argue, in relation to the continua of biliteracy, which outline the multidimensional nature of learning and literacy practices of plurilingual learners, there tends to be an implicit privileging of one end of the continua. Indeed, priority is given to texts associated with more power, i.e. texts that are standardised, decontextualised and monolingual. In the creative writing workshop, on the contrary, there is an attempt to balance attention to both ends of the continua by inviting literacy practices geared towards plurilingual and heterogeneous texts, contextualised in the personal experiences of migration, while learning French, the target language. Additionally, it is necessary to research further how the plurilingual repertoires of adult migrants can be valued beyond the writing workshop and in the mainstream.

\section{References}

Bakhtin, M. (1978) Esthétique et Théorie du Roman. Paris: Gallimard.

Canagarajah, A. S. (2006) The place of World Englishes in composition: pluralization continued. College Composition and Communication 57(4): 586-619.

Canagarajah, A. S. (2011) Codemeshing in academic writing: identifying teachable strategies of translanguaging. Modern Language Journal 95: 401-417.

Cope, B. and Kalantzis, M. (2000) Multiliteracies: Literacy Learning and the Design of Social Futures. New York: Routledge.

Coste, D., Moore, D. and Zarate, G. (1997/2009) La compétence plurilingue et pluriculturelle. Strasbourg: Editions du Conseil de l'Europe. 
Council of Europe (2001) The Common European Framework of Reference for Languages. Strasbourg: Editions du Conseil de l'Europe.

Cummins, J. and Early, M. (2011) Identity Texts - the Collaborative Creation of Power in Multilingual Schools. London: Institute of Education Press.

Creese, A. and Blackledge, A. (2010) Translanguaging in the bilingual classroom: a pedagogy for learning and teaching? The Modern Language Journal 94: 103-115.

Fairclough, N. (2000) Multiliteracies and language - orders of discourse and intertextuality. In B. Cope and M. Kalantzis (eds), Multiliteracies: Literacy Learning and the Design of Social Futures. New York: Routledge, 162-181.

Garcia, O. (2007) Foreword. In S. Makoni and A. Pennycook (eds), Disinventing and reconstituting languages. Clevedon, UK: Multilingual Matters, xi-xv.

Giddens, A. (1984) The Constitution of Society: Outline of the Theory of Structuration. Berkeley: University of California Press.

Hornberger, N. and Skilton-Sylvester, E. (2000) Revisiting the continua of biliteracy: international and critical perspectives. Language and Education 14(2): 96-122.

Lea, M. R. and Street, B. (1998) Student writing in higher education: an academic literacies approach. Studies in Higher Education 23: 157-172.

Marshall, S. and Moore, D. (2013) 2B or not 2B plurilingual? Navigating language, literacies, and plurilingual competence in postsecondary education in Canada. Tesol Quarterly 47(3): 472-499.

Martin-Jones, M. and Jones, K. (2000) Multilingual Literacies. Philadelphia, PA: John Benjamins.

Moore, D. and Brohy, C. (2013) Identités plurilingues et pluriculturelles. In J. Simonin and S. Wharton (eds), Sociolinguistique du contact: Dictionnaire encyclopédique des termes et concepts. Lyon: ENS-Éditions, 289-315.

Moore, D. and Gajo, L. (2009) Introduction to French voices on plurilingualism and pluriculturalism: theory, significance and perspectives. International Journal of Multilingualism 6(2): 137-153.

Norton, B. and Toohey, K. (2011) Identity, language learning and social change. Language Teaching 44(4): 412-446.

Street, B. (2000) Literacy events and literacy practices: theory and practice in the New Literacy Studies. In M. Martin-Jones and K. Jones (eds). Multilingual Literacies. Philadelphia PA: John Benjamins, 17-29. 


\title{
English, everywhere and nowhere

\author{
ESOL policies in Ireland
}

\author{
Vera Sheridan
}

\section{Introduction: ambivalence and critique}

The development and deepening of engagement with ESOL, English for Speakers of Other Languages, has a short history in Ireland. English, however, is 'everywhere and nowhere, omnipresent and unnoticed' as remarked in the EU's Language Education Policy Profile on Ireland (2008: 33), and this comment continues to resonate. Five overlapping shifts in attitude can be clearly identified as part of this process of engagement with ESOL: a historical ambivalence towards English, a deficit approach to English language learning, migration to Ireland, social tensions and, finally, the promise of a rights-based approach to ESOL.

Historically, from the foundation of the state in 1922, a perception was promoted in official discourse that Ireland was a homogenous society rooted in a Celtic past where a non-industrialised, Gaelic-speaking society was held as the social ideal. This mythic narrative of the nation influenced educational policy as language issues revolved around Irish, the first language of an ever-smaller minority, in contrast to English, spoken by the majority of the population. The promotion of Irish, as part of a bilingual policy, was a deeply felt matter in the fledgling state as it strove to create its distinctive identity and culture separate from its colonial past and proximity to its English-speaking neighbours. This policy focus on Irish ignores the more complex linguistic reality relating to English in contemporary Ireland (see Bruen 2013 for a review of Irish language policy in general). The English taught in school continues to have an inexplicit relationship to the English used in family life, to social class, to ethnicity. All the while these relationships retain unspoken influences on the development of English language, literacy and, crucially, on a learner's language choices which subsequently affect the presentation and perception of their individual identity. Ambivalence has created a vacuum in English language policy so that quite sudden changes in the social, cultural and communicative landscape have presented great challenges to the development of adult ESOL, which has until recently had no significant presence in Ireland. 
Secondly, early ESOL efforts, which related to refugees and asylum seekers (and their school-going children), developed from a deficit model of language learning and teaching. Such a deficit approach focuses on an individual's lack of proficiency in a specific language despite the individual coming to learning with language(s). This model stands in contrast to the complexity of refugee and asylum seeker groups and to the high levels of social capital of skilled and educated migrants who came to Ireland during the Celtic Tiger years, a period of rapid economic growth and increasing affluence in Ireland. Thirdly, Irish society has changed rapidly in recent decades and, fourthly, increasing diversity has also produced social tensions. Finally, in tandem with these changes, the fifth shift sees ESOL situated in an adult education philosophy of the whole person where education is viewed as a human right.

However, just as a realistic assessment of ESOL need and provision and a clear direction for its development was being implemented, economic disaster intervened and many programs lost funding. State bodies which had become dysfunctional at a time of budgetary excess were re-branded and restructured, directly affecting ESOL development. Sixteen Education Training Boards (ETBs) were set up in the place of the former Vocational Education Committees (VECs) on 1 July 2013, with full change implemented on 1 January 2014. As part of this change, Education Training Boards Ireland (ETBI) replaces the Irish Vocational Education Association (IVEA), the national VEC representative body responsible for policy guidelines. As policy documents in the 1990s and 2000s refer to VECs and the IVEA, these names have been retained in this chapter. These changes have not, however, affected the National Adult Literacy Agency (NALA), an independent organisation whose membership consists of organisations and individuals concerned with adult literacy. NALA has also become involved in ESOL provision, with a specific focus on the development of ESOL literacy.

As a historically rooted ambivalence towards English has been the focus of this introduction, the remaining four shifts in attitude are discussed in more detail in the following sections.

\section{A deficit perspective}

The initial development of ESOL is closely related to the reception and integration of refugees such as the Vietnamese who arrived in Ireland around 1979. The response to adult new arrivals who could not speak English was to confound or conflate language learning with literacy: ESOL provision finally became rooted in a VEC (i.e. adult education) outreach centre in Dublin, where the greatest concentration of Vietnamese had settled. The ESOL budget came from the provision for adult literacy and this financial competition between quite different educational needs 
from the same budget continues in contemporary ESOL resourcing across the state. During this early period, Ireland had also become a destination for refugees seeking asylum, whose numbers had increased from 39 in 1992 to a peak of 10,936 in 2000. Such individuals ranged across a spectrum from qualified professionals to individuals with literacy issues in their first language; they all, however, had to negotiate legal processes and adapt to a new culture, a new language and a new status of 'asylum seeker' regardless of their pre-existing social capital. Such capital includes all their knowledge, including educational attainment, and personal skills (Bourdieu 1986), and some migrants may inevitably struggle to retain and achieve recognition for this capital.

An Interdepartmental Working Group on the Integration of Refugees in Ireland (1999) resulted in a key document which viewed English language education from a deficit perspective, with children viewed as 'non-nationals with English language deficits' (p. 16). Adults are described in terms of their 'lack of English language skills' or 'absence of satisfactory knowledge' (p. 28). As Blommaert et al. (2005: 212) note, individuals easily become 'language-less' when positioned in this way in policy. Courses in the host language for children and adults then focus upon repairing this deficiency, either with the school classroom or an adult's chances of employment in mind. This perspective is well intended, but such good intention ignores linguistic diversity and an individual's selfconceptualisation in relation to language(s) and identity(ies), and positions migrants as beneficiaries of something bestowed, rather than being active agents engaged in shaping their lives like anyone else. From this perspective, integrating English language provision for migrant adults as part of adult literacy provision for first-language speakers of English would appear to be a natural progression as, wittingly or otherwise, it links asylum seekers/refugees with a series of deficits. This link has been maintained to the present, even if contradicted either by migrant profiles or by other policy documents.

Two tendencies are visible in the first government policy document on adult education in Ireland, the education White Paper Learning for Life (DES 2000), set against the background of skills shortages or retraining in order to develop the economy. The White Paper aimed to empower the workforce (p. 17), and recognised diversity and 'the need to provide specific tailored programs and basic literacy and language education for all immigrants as an elementary part of provision' (p. 50). It proposed free access to adult literacy, English language and mother culture support (p. 173) to all asylum seekers, including pre-1999 arrivals who had the right to work. Thus, the White Paper simultaneously proposes empowering migrants and locating them in a basic education framework.

Responsibility for refugees invited to Ireland by the state devolved to a new body created in 1991 by the Department of Foreign Affairs, the 
Refugee Agency, which also moved into language provision in a collaborative EU-funded project, established for the language and employment training of adults. The project was incorporated into a new body, the Refugee Language Support Unit (RLSU), created with funding from the National Development Plan 2000-2006 to facilitate the integration of 'non-EU nationals' who had qualified for Irish residency (p. 192) by addressing their language needs. The resulting top-down approach to language and job skills training foregrounded learner autonomy as the theoretical rationale for the project. It linked prevocational education with Language for Specific Purposes (LSP) locating it within an LSP framework (Lazenby Simpson 2000). Omoniyi (2000) questions the relevance of a narrowly understood LSP to the integration of refugees, noting that research on education programs in socially diverse societies indicates that cultural diversity is a key factor for determining success: such research raises questions around identity, and how refugees interpret, accept or react to state policies. In effect, as Omoniyi suggests, state institutions should be examining the thorny questions of national, ethnic, religious and individual identities and their acceptance. Moreover the language needs of refugees and other migrants are often politicised, and are more complex than an LSP categorisation can provide for.

English for Specific Purposes demands an already specialised audience, and while the approach may have been novel, by its very nature it worked against the aspirations of many individuals who did not yet possess the specific qualities sought in the assessment process. This process focused on language in the linguistics tradition, where a clear division existed between language and all the problematic aspects that an individual's culture, ethnicity and (stigmatised) status raise. These 'messy' matters are brought into the ESOL classroom which is thus not a neutral space but a space of negotiation and (dis)agreement on what should remain inside or outside the ESOL classroom door. The RLSU - by avoiding this complexity - received criticism from linguistics experts and students regarding its materials, teaching methods, restrictive admissions and other policies (Healy 2007). In 2008, a report commissioned by the Office of the Minister for Integration and the Department of Education and Science concluded that the VECs had the necessary national organisational infrastructure to support the development of English language teaching (2008: 97). The RLSU (by then renamed as the IILT) was closed and the VECs took over ESOL provision.

One goal of the 2000 White Paper was to research the needs of the diverse asylum seeker population. The resulting survey of asylum seekers living in Dublin (Ward 2002) challenged the deficit approach to language learning and teaching and also worked bottom-up to engage with the asylum seeking population to find out background information. The 
report acknowledged asylum seekers' first languages to present a linguistic profile of the 63 'mother tongues' of the 767 respondents in the study. Four per cent spoke English as a mother tongue with over 50 per cent claiming to speak English as an additional language. In addition, 74 per cent had experience of studying another language and 37 per cent were learning English in Dublin.

The White Paper also revealed the diversity of social capital represented in this population: 93 per cent of asylum seeker respondents were literate, leaving a small minority of seven per cent with no literacy skills in their mother tongue or another language (though these figures probably do not reveal the true extent of such individuals, either because of nonparticipation or the unreliability inherent in such surveys). Thirty-four per cent had attended third level education (though this figure does not mean that a third of all respondents had completed university); 74 per cent had attended secondary school or technical college for varying lengths of time. Fourteen per cent had completed only five years or fewer of primary school, with two per cent not having attended at all. This diversity of education background illustrates the challenge facing ESOL practitioners in an emerging field. Consequently, addressing the range of educational needs would require a multi-layered approach to help asylum seekers move from isolation to acceptance and integration into Irish society, particularly as Ireland's economy entered a period of spectacular growth and expansion.

\section{Mobility, migrants and English}

Ireland's burgeoning economy was accompanied by a skills shortage which intensified in the 2000s, known as the Celtic Tiger years. Government policy included actively recruiting labour from around the world and opening Ireland's doors in 2004 to the new EU accession states in Central and Eastern Europe. Census data from the 2000s provides evidence of the scale of migration to Ireland and shows that the economic downturn in 2008, following the banking catastrophe, did not result in a mass exodus. Census 2011 gave rise to a series of profile publications (Central Statistics Office 2012) which tracked the development of Ireland's migration profile from Census 2002 and Census 2006. A question on nationality was included in Census 2002 permitting the tracing of migrants or non-nationals, the terminology used officially and which has passed into everyday discourse. In 2002, there were 224,261 migrants and by 2006 this number had risen to 419,733, an increase of 87 per cent. The 2011 Census recorded 544,357 individuals from 199 different nations representing 12 per cent of the population as a whole. It thus appears that Irish society will continue to be transformed by greater diversity (MCRI 2008), particularly as record numbers become Irish 
citizens. The communicative landscape therefore continues to change, particularly in relation to work and home languages, languages in the classroom, language use across the generations and language loss (Sheridan 2007).

While there are greater concentrations of migrants in the capital and other large urban centres in Ireland, migrants have moved to all parts of the country. County Laois has seen a 64.8 per cent increase in its number of migrants since April 2006 (see Doyle, this volume), making it the largest relative county increase (Central Statistics Office 2012: 10). Overall, in April 2011, migrants comprised 15.1 per cent of the workforce $(268,180)$ and the majority of these were Polish or from the UK, accounting for 116,375 workers or 43.4 per cent of the total figure. The second largest numbers of migrants are Lithuanians, Latvians, Indians and Romanians.

Census 2011 asked a question about English language ability and English difficulty. Table 11.1 shows the figures from the census for people who reported that they could not speak English well, by nationality group.

In contrast, the data also showed 82.6 per cent of Nigerians spoke English well (Central Statistics Office 2012: 28). Irish society has changed dramatically in a fairly short period and, importantly, includes speakers of English from around the world. The variety of English used by migrants from countries where English (the former language of a coloniser) has official status such as Nigeria or India needs to be accounted for in ESOL policy and pedagogy. Such English is spoken, shaped and transformed by speakers in relation to the flux of social and cultural forces within their societies, clearly evident in accent, choice of lexis, and grammar. Cognisance of historical language differences among people who find themselves in ESOL classes and the effects of globalisation on their Englishes should be a factor in the training of ESOL specialists and in continuing professional development in this new field in Ireland.

Table II.I Self-report data from Ireland's census on English language ability

\begin{tabular}{ll}
\hline Nationality & Could not speak English well \\
\hline Chinese & $23.9 \%$ \\
Brazilian & $24.3 \%$ \\
Polish & $24.5 \%$ \\
Latvian & $28.8 \%$ \\
Somalian & $29.9 \%$ \\
Lithuanian & $29.5 \%$ \\
\hline
\end{tabular}




\section{Tensions and (partial) resolutions}

Rapid social change is not without problems. People from certain nations, such as Nigeria and Romania, became stigmatised in part due to their 'asylum seeker' status, encountering a range of racisms which could be casual, institutional, the result of ignorance or rooted in a nationalist politics of exclusion. The most significant reaction to social diversity to occur in Ireland has been the 2004 referendum on citizenship. The referendum changed the Irish constitution: previously citizenship had been conferred through birth on Irish soil, the concept of jus solis. In the run-up to the referendum, this principle had been touted in much public and media discourse as having caused an 'influx' of asylum seekers, welfare tourists and other dubious individuals, all arriving in Ireland to avail themselves of superior Irish healthcare, particularly in maternity hospitals (Shandy and Power 2008). Media attention had focused on services being stretched as client numbers grew and black women, a highly visible group, were publicly vilified when they were pregnant. In the referendum the people voted to remove the automatic jus solis framing of citizenship for children born in Ireland to migrant parents, and to replace it with a jus sanguinis approach where one parent must have a connection with Ireland through citizenship. To this day, public discourses and documents continue to use the refrain 'non-nationals', perpetuating a 'them and us' perspective.

Thoughtless, casual racism has been evident in schools where "nonnational' pupils have been segregated by the class teacher. In a developing trend certain schools are becoming 'ghettoised' in their intake. Schools can select pupils on the basis of their religious affiliation, including the demand to see baptismal certificates. Sections of the media and some politicians have contributed to the disparagement of others residing in the state. In contrast, NGOs, community groups, volunteer groups, resident associations, religious organisations, journalists and others have challenged the status quo for better acceptance of sociocultural diversity as well as highlighting the positive contributions asylum seekers, refugees and other migrants make to society. However, a simplistic understanding of social diversity, where short-lived superficial encounters with visibly apparent aspects of cultural difference such as celebrations have been taken as evidence of an integrated society, masks divisions and social isolation of some groups. For example, since 2000 all arriving asylum seekers reside in direct provision centres; some children have spent their entire lives in such settings, which are run at a profit by private companies.

In contrast, a series of government initiatives also began to accompany this new inclusive trend in Irish society. Many such initiatives though were short-lived, particularly in the wake of economic collapse in 2008. Some stemmed from EU activity such as the 1997 designation of the 
European Year Against Racism, following which the Irish government established the National Consultative Committee on Racism and Interculturalism (NCCRI) in 1998. This advisory body to government and NGOs in matters relating to racism and interculturalism provided anti-racism and intercultural awareness training. The Office of the Minister of State for Integration was created in July 2007. The first (and last) Minister of State for Integration launched a policy strategy document, Migration Nation, in 2008. Policy highlighted four key areas relating to successful integration: host language education, interpretation and translation, information provision and funding arrangements. It noted that a dedicated Integration Unit was established in the Department of Education and Science in October 2007 and that over 12,000 migrants were learning English in classes provided by VECs, costing over $€ 10 \mathrm{~m}$. The document stated the need to develop materials for teaching English as a second language and noted that many teachers had participated in an online course on teaching English as an additional language. In effect, policy-makers were beginning to grapple with terminology relating to ESOL. Its location in policy was also an issue: English was of concern to the Department of Education and Science, though it remained linked with the integration of newcomers, thus paradoxically still remaining outside the educational mainstream over the long term.

\section{A rights-based approach}

The Irish Vocational Education Association (IVEA) produced guidelines on ESOL and further education in 2004. This milestone report drew on existing policies and legislation to set out a human rights-based approach to ESOL teaching and learning. This rights-based approach is in keeping with pedagogical philosophy framing adult literacy which focuses on empowering the individual. The report referenced the Department of Education and Science (DES) Action Plan Against Racism (2003) which states that future policies must be developed in a rights-based equality framework so that recognition of diversity as a positive social feature is the norm in education policy-making. The IVEA paper notes the key role of English in academic achievement and in the acquisition of cultural capital for full participation in Irish society. It also highlights the critical concern to address the English language needs of all migrants regardless of their status, so that a cohesive approach to ESOL can be envisaged. The 1998 Education Act in Ireland does not differentiate between citizens and non-citizens as all have a right to receive education, also enshrined in EU law, specifically Protocol 1 of the 1954 European Convention of Human Rights which states that education is a human right. Accordingly, the IVEA document takes an empowering stance towards education provision for ESOL learners, including basic education for the small 
groups of individuals who are not literate in their first or expert language. However, it must be noted that such support for literacy learning in English does not extend to the development of literacy in a student's first language.

Importantly, this IVEA report draws attention to standard language matters in relation to English language speakers from African countries (2004: 27). The IVEA report rightly notes that speaking a standard, in this case Standard English, is to speak a language of power, and recommends that African English speakers develop familiarity with the standard language, although the variety of English spoken in Ireland is not stated. However, while status accrues to certain accents and such accents can be learned, migrants cannot erase their ethnicity. Discrimination on grounds other than language means that they may still not have access to privileges afforded by employment, wealth and status, privileges that they might have assumed would be accorded to speakers of the standard language.

The report also considers that teachers also require training so that they understand and value the Englishes spoken by their students. A user of Nigerian English, for example, might attempt to use the standard variety when settled in their new country, hoping that this will enable them easier access to, for example, employment and educational opportunities. This is problematic when there is no overall agreement about which variety of English is the standard or privileged one. In Ireland, policy regarding the standard variety of English is de facto: while learners of English will possibly recognise privileged varieties when they encounter them, there is no explicit national policy on English, no statement of fact that people speak Irish English, what that standard sounds like and its variants. It follows that language matters, already complex in relation to identity, reside in a vacuum. In effect, this unaddressed question is relevant to everyone in Ireland. Identities and linguistic repertoires are fluid of course, so that an individual draws on different varieties of English and their other languages in communication, for example, in the classroom, with friends, work colleagues or at home (see Sheridan 2013). But not knowing precisely which variety to aspire to in a particular context presents problems in pedagogy for both learners of English and their teachers.

The IVEA also commissioned a key review of ESOL provision in 2007 as it felt that ESOL was not being taught to the desired standard. The initial survey found serious concerns around key areas such as the lack of training for practitioners, lack of materials, inadequate funding with no dedicated ESOL budget, duplication and poor coordination at all levels of ESOL provision. The subsequent Task Force report (IVEA 2008) contained three main recommendations: (i) the development of a national ESOL strategy, (ii) a national service provided through the VECs, and 
(iii) the establishment of a National ESOL Support Office (NESO) to inform, coordinate, support and assure the quality of the teaching of ESOL. Importantly, it also recommended a dedicated budget for ESOL, though retaining allocation and spending flexibility for VECs, and that the Department of Education and Skills should recognise ESOL as a distinct discipline. The report argued that the savings made from implementing a clear system would cover many of the extra costs involved and contribute to better migrant integration and to the highly skilled workforce on which Ireland's economic progress depends.

Turning to the role of the National Adult Literacy Agency, this organisation also recognised the changing face of the adult learner population, with around a quarter of adult literacy students being in ESOL classes. NALA had already developed ESOL policy guidelines in 2003 in conjunction with the Department of Education and Science, the VECs, and other community education providers. Later, in 2007 it added developing ESOL training for tutors as one of its objectives. NALA also approaches education as personal development and social action: it has considered adult literacy to be the major priority in adult education for a number of years, with spending growing to $€ 23$ million in 2006, mainly through the VEC Adult Literacy Service. The DES reviewed adult literacy (2013) to note that the profile of 62 per cent of ESOL learners with upper secondary level education or above did not fit its own remit. This location of ESOL in adult basic literacy provision thus makes a profound statement in relation to the state's perception of such learner identities and their positioning in policy.

Overall, policy from the middle of the first decade of the twenty-first century turned towards a mainstream approach to service delivery and the integration of services, accompanied by attention to terminology. Practitioners whose training had been in literacy development for adults required clarification on these language matters. By 200732 of the 33 VEC Adult Literacy Services provided ESOL classes. The City of Dublin VEC (CDVEC 2007) engaged in clarifying the definitions of ESOL language and ESOL literacy for practitioners: ESOL language being defined as language development for individuals with no literacy difficulties in their first or expert language whereas ESOL literacy referred to language development for individuals with literacy difficulties in their first language. Practitioners had developed expertise in working with adults who generally came from the less affluent part of society. However, their engagement with ESOL also meant engaging with a different, and also diverse, adult student body as well as reconsidering their teaching practice. The VEC, already heavily involved in teaching adult migrants, was, however, the existing body with capacity throughout the state which could offer an integrated service. Nonetheless, funding for ESOL tuition, which comes through the adult literacy budget (DES 2007), continued as 
before with no separate budget for ESOL; VECs continue to have flexibility in how much money to allocate for this purpose from their adult literacy budget.

\section{Concluding remarks}

Ireland's financial bailout by the IMF and the EU in 2010 resulted in necessary cost saving measures, and the full strategic intents of government, the IVEA and other stakeholders in ESOL have not been implemented. A significant casualty in relation to ESOL is the demise of the proposed development of a national English language training policy. Cutbacks in education have affected some but not all initiatives, so the VECs still continue to provide English language classes for adult migrants. NGOs do so as well, with some making a charge and others providing free lessons. Classes for refugees, including literacy classes, were cut at the end of 2012. While the current situation is not conducive to realising policy, cutbacks have to be viewed in the context of funding cuts across all public service sectors, pay cuts and other measures emanating from the dramatic downturn in Ireland's fortunes in 2008. However, policy is still being created in some areas. Despite the Strasbourg Language Policy Division's clear critique of the 'official but lame bilingualism' (Language Education Policy Profile, Ireland 2008: 34) promulgated as education policy, the now Department of Education and Skills has produced a policy on the Irish language, which aims to create Irish and English-speaking bilingual citizens while recognising 'the tremendous advantage to its citizens of fluency in English, the most widely used language in international affairs' (DES 2010: 2).

In contrast, by 2014 there was still no state policy for English as either a first, second or other language; nor was there a revision of the notion that ESOL should be located in a first language literacy context (rather than being recognised as a separate discipline). Nevertheless, the DES recommends that the VECs prioritise those ESOL learners where tuition would bring them to a level of functional competency. It makes no recommendation about the more proficient learners or to any change in the structure of funding (DES 2013: 32). Funding remains uncertain in the economic climate so that the (at times grudging) consolidation effort of recent years is undermined by more recent program cuts. Such cuts can be viewed in the context of the Department of Education and Skills (2011: 50) stating that between 2000 and 2010 the VECs provided classes to over 90,000 ESOL participants.

To conclude, the Expert Group preparing the Language Education Policy Profile on Ireland stated that 'the topic of English was hardly dealt with, except as far as immigrants were concerned' (Language Education Policy Profile, Ireland 2008: 23). This state of affairs remains problematic 
as English is visible in all aspects of daily life in Ireland so it cannot remain confined to migrant language learning. An ethnically and linguistically diverse society requires language policy to address the complexities of English language learning, whether by adult migrants or their (bilingual or multilingual) children. This requires change not only to English language provision but teacher training where English language becomes a discipline in its own right. Such change will occur when long-standing, stale perspectives on the relationship between Irish and English are finally cast aside to pave the way for a national language policy embracing all languages, grounded in the reality of people's lives.

\section{References}

Blommaert, J., Collins, J. and Slembrouck, S. (2005) Spaces of multilingualism. Language and Communication 25(3): 197-216.

Bourdieu, P. (1986) The forms of capital. In J. E. Richardson (ed.), Handbook of Theory of Research for the Sociology of Education. New York: Green Word Press, 241-258.

Bruen, J. (2013) Towards a national policy for languages in education. The case of Ireland. European Journal of Language Policy 5(1): 99-1 14.

Central Statistics Office (2012) Profile 6, Migration and Diversity. Dublin: Stationery Office.

CDVEC (2007) Handbook for ESOL Practitioners at Beginner (AO, A1, Literacy for ESOL) Level. Dublin: City of Dublin Vocational Education Committee.

Department of Education and Skills (DES) (2000) White Paper on Adult Education. Dublin: DES.

DES (2003) Promoting Anti-racism and Interculturalism in Education: Draft Recommendations Towards a National Action Plan Against Racism (unpublished).

DES (2007) Annual Report. Dublin: DES.

DES (2010) 20-Year Strategy for the Irish Language 2010-2030. Dublin: DES.

DES (2011) Annual Report. Dublin: DES.

DES (2013) Adult Literacy Review. Dublin: DES.

Healy, C. (2007) On Speaking Terms: Introductory and Language Programs for Migrants in Ireland. Dublin: Immigrant Council of Ireland.

Interdepartmental Working Group on the Integration of Refugees in Ireland (1999) Integration: A Two Way Process. Report to the Minister for Justice, Equality and Law Reform by the Interdepartmental Working Group on the Integration of Refugees in Ireland, Dublin: Department of Justice, Equality and Law Reform.

IVEA (2004) Pilot framework for educational provision for minority linguistic groups including asylum seekers and refugees. IVEA Working Group Report 3: Further Education. Dublin: IVEA.

IVEA (2008) ESOL: A Survey of its Provision in the VEC Sector. Dublin: IVEA ESOL Task Group.

Language Education Policy Profile, Ireland (2008) Ireland 2005-2007. Strasbourg: Language Policy Division/Dublin: Department of Education and Science. 
Lazenby Simpson, B. (2000) Theoretical and practical issues in the development of LSP courses for refugees and immigrant learners. Teanga 19, The Irish Yearbook of Applied Linguistics, Integrating Theory and Practice in LSP and LAP, Papers from the IRAAL/ALC Conference, March 1998: Part 2, 51-59.

Migration and Citizenship Research Initiative, UCD (MCRI) (2008) Getting On: From Migration to Integration. Chinese, Indian, Lithuanian, and Nigerian Migrants' Experiences in Ireland. Dublin: Immigrant Council of Ireland.

Office of the Minister for Integration (2008) Migration Nation, Statement on Integration Strategy and Diversity Management. Dublin: Ministry for Integration.

Omoniyi, T. (2000) Native holes and alien pegs: LAP/LSP as tools in immigrant and refugee children's socialisation. Teanga 19, The Irish Yearbook of Applied Linguistics, Integrating Theory and Practice in LSP and LAP, Papers from the IRAAL/ ALC Conference, March 1998: Part 2, 61-73.

Shandy, D. and Power, D. (2008) The birth of the African-Irish diaspora: pregnancy and post-natal experiences of African immigrant women in Ireland. International Migration 46(5): 119-142.

Sheridan, V. (2007) Tuyen Pham: caught between two cultures. In B. Fanning (ed.) Immigration and Social Change in the Republic of Ireland. Manchester: Manchester University Press.

Sheridan, V. (2013) A risky mingling: academic identity in relation to stories of the personal and professional self. Reflective Practice: International and Multidisciplinary Perspectives 14(4): 568-579.

Ward, T. (2002) Asylum Seekers in Adult Education, a Study of Language and Literacy Needs. Dublin: City of Dublin VEC and County Dublin VEC. 


\title{
Getting to grips with the English language
}

\author{
Sandra Doyle
}

\section{Introduction}

Learner-centred education underpins good adult literacy work in Ireland because it assists in responding to the real needs of adult learners. Despite the inherent benefits of adopting this approach with learners of English for Speakers of Other Languages (ESOL) it has also proved hugely challenging. While literacy and numeracy issues are apparently at the forefront of government policy, economic constraints and competing priorities consistently impact upon ESOL provision. In practice ESOL learner needs are complex and varied and move beyond the mere acquisition of functional English language skills. However government policy offers restricted English language provision despite the fact that learner needs dictate otherwise. This is further aggravated by the fact that ESOL provision lies under the adult literacy budget and basic skills umbrella, a position which this chapter challenges. (See Sheridan, this volume, for a discussion.)

The Portlaoise Adult Education Centre continually struggles with an economic agenda that favours the reception of low-cost migrant workers during economic prosperity yet lacks the support of a national English language policy and national ESOL strategy. This chapter explores the experiences and challenges of running ESOL classes in the centre given reductions in funding, a situation which gives rise to frustration in a tough economic climate where scarcity of employment already precipitates negative attitudes towards immigrants. In challenging an economic agenda that prioritises labour supply over the development of human capital, our centre aims to support English language learning by providing a space where adult literacy learners, volunteers and immigrants interact. This whole centre approach endeavours to foster an education in diversity to both locals and new arrivals and has resulted in a range of activities that have brought local people and ESOL learners together. Where possible we aim to integrate diversity into the teaching and learning that takes place at the centre and this chapter presents an insight into some of the 
interactions that have taken place locally between Irish people and ESOL students, gradually giving rise to a community level response to new arrivals.

\section{History of the project}

Getting to Grips with the English Language is a project which began in 2007 at the Portlaoise Adult Education Centre to promote English language learning amongst adult migrants accessing part-time English classes. The centre is located in Portlaoise, County Laois, a rural town with a population of 20,145 (CSO 2011) situated in the midlands region of Ireland, 82 kilometres from Dublin. About two decades ago 95 per cent of the town's population was born in Ireland (CSO 1996). This contrasts with 2013, when the Portlaoise Centre catered for 221 students from 32 different countries, representing nationalities including China, India, Pakistan and Romania. The largest numbers came from Poland (36 per cent), Lithuania (17 per cent) and Latvia (9 per cent) with Nigerian, Congolese and Angolan students accounting for 9 per cent of student intake (DES 2013). To date approximately 360 adult learners have participated in this project. Participants' ages range from 18 to 65 years, male and female, studying at levels 2 and 3 on the National Framework of Qualifications (NFQ) (i.e. beginner to elementary level) and learning English as a new language. English language classes are funded under the Adult Literacy Community Education (ALCE) Department of Education and Skills (DES) budget. Any additional costs incurred with this project were partly funded from the ALCE budget and with numerous voluntary hours generously contributed by learners, tutors and management.

The history of Getting to Grips with the English Language is directly linked to Ireland's increase in population size over the last ten years and the fact that our country now plays host to people from a wide range of different cultural backgrounds. Mac Éinrí (2007: 248) noted that Ireland 'has now definitively joined the European mainstream as a society where a population of mixed ethnic backgrounds will be the norm' and 'by the 2020 s it is likely that migrants and their descendants will number up to one fifth of the population'. Education and Training Boards are currently responsible for English language provision for adult migrants through adult literacy schemes. This deficit vision of language learners fails to take into account the social capital, skills and other languages of participants despite the relatively large proportion of educated migrants accessing classes. The Portlaoise Adult Education Centre caters for refugees, asylum seekers, citizens from the EU accession states, non-EU citizens and other migrants who attend English language classes. A small cohort, approximately 10 per cent of these learners, also attend literacy classes designed for ESOL students. Over the last decade, the Portlaoise Adult 
Education Centre experienced a dramatic increase in the number of ESOL learners accessing classes. DES statistics indicate that in 2002 the centre catered for 75 ESOL students: 41 male/ 34 female, with this figure peaking in 2007 to 341 learners: 84 male/257 female. In 2012 numbers reduced to 203 learners: 84 male/119 female, a reduction that reflects funding available for courses rather than the actual student demand. An additional 73 refugees accessed 10 to 20 hours' tuition on the Adult Refugee Program from September 2010 until December 2012 and as these ESOL hours reduced the number of ESOL tutors also reduced from 7 to 5 .

With this overall increase in learners from such varied cultural, language and educational backgrounds it was necessary to take practical steps towards accommodating diversity and English language learning amongst adult migrants accessing classes. The initiatives implemented incorporate creative ways of tackling budget constraints which currently limit learners' access to language classes to a maximum of two to four hours per week. Until funding for the Adult Refugee Program ceased in December 2012, adult refugees received up to twenty hours of tuition per week. Consequently the overall purpose of this project is to compensate for this drastic funding-induced reduction in hours by offering ESOL learners a 'road map' for learning English in Ireland and throwing light on the practical steps they can take to communicate more effectively, become proficient in English and more involved in their local communities.

\section{Assessing learner needs}

According to the National Adult Literacy Agency (NALA) Guidelines for Good Adult Literacy Work, good practice 'starts with the needs and interests of the individual' and 'is concerned with personal development and building confidence as well as technical skills' (NALA 2005: 12). However, very often these values can be at odds with government economic objectives and NALA stresses that "while literacy is clearly linked to economic development and employment it must not be limited to issues of economics' (NALA 2005: 7). While we can never underestimate the importance of up-skilling the labour force to help drive business and employment growth in Ireland, it is also imperative that we acknowledge and cater for the particular needs of the ESOL learner. While migrants may be motivated to learn English to contribute to the economy of the country and enable businesses to make profits, this may not be their only or primary motivation. In the Portlaoise Centre we have tackled this issue by implementing project activities which are learner-centred, where needs and language requirements are identified during informal class discussions with tutors and through a student forum. We have found that through the learner-centred classroom tutors get a good sense of student's 
backgrounds, abilities, interests and goals, which help form the foundation of all activities. These needs may be personal, social, economic and educational; some learners, in particular refugees and asylum seekers, are also experiencing the ongoing effects of trauma and cultural dislocation.

Tutors are trained in ESOL, literacy and adult education, and are predominantly women from Irish backgrounds. The learner-centred approach gives them a greater understanding of their ESOL students, enabling them to encourage participants to strive to reach their full potential as individuals in addition to preparing for employment or completing an accredited module. The approach helps tutors develop an awareness of the influence of culture, gender, class and ethnicity, how these can be different in every home, and how attitudes to work, life and learning can impact on education. It also reminds us as tutors of the importance of being flexible in our approach to accommodate the many different learning needs of students. Tutors are encouraged to act as facilitators who can - in NALA's terms - 'develop materials, approaches and structures which encourage the increasing direction by learners of their own learning' (NALA 2005: 11). For some tutors this is their first real experience with diversity and is an education in itself for them as well as for their students. For example, when ESOL students experienced difficulties understanding letters from their children's school, writing absence notes for their children and problems communicating in English at parent-teacher meetings, they were introduced to the appropriate language needed to ask relevant questions about their child's schooling and communicate with teachers. Meeting with local Home School Community Liaison Officers (HSCLO) became an initiative of the project. Students had the opportunity to meet HSCLOs in person and afterwards felt more comfortable and confident about approaching their child's school and communicating in English.

\section{Challenging racism}

The Guidelines on Anti-Racism and Intercultural Training recognise racism as an issue that needs to be tackled in order to create a more inclusive society and acknowledge interculturalism (to use their term) as an approach that sees difference as something positive that can enrich a society (NCCRI 2001: 6). In County Laois the overall aim of the Laois Anti-Racism and Diversity Plan (2010-2013) is 'to provide strategic direction to combat racism and to develop a more inclusive, intercultural society in Ireland' (Laois County Development Board 2010: 3). However, according to the Anti-Racism and Diversity Plan, 11 per cent of 108 respondents surveyed said they had experienced racism or discrimination because of their ethnic background (Laois County Development Board 2010: 12). 
In addressing this situation we adopt a whole centre approach with activities that help build awareness among all participants. Throughout the year we use cooperative learning activities that encourage interaction and give people the confidence to become more involved in their local community and in society in general. When ESOL learners expressed feelings of isolation and dislocation from their home countries, both learners and tutors organised a Christmas get-together in a local venue. All involved had the opportunity to interact with people from many different countries and share their own experiences of how Christmas, and other important feast days, are celebrated around the world. From experience we have found that affording learners the opportunity in class to discuss and acknowledge important cultural events from their home country helps them respect differences between cultures. Such acknowledgment reassures learners that their cultural identity is neither being overlooked or discounted, but instead sustained and appreciated.

Other activities have been ignited by learners' direct experiences of both living and working in Ireland. When adult migrants expressed the need to combat negative comments in their lives and workplaces, group discussions in classes covered topics such as racism, discrimination, equality and diversity. Tutors become aware of the on-going challenges faced by students and students become aware of communicative strategies in English to deal with these challenges. A female learner from the Democratic Republic of the Congo who has refugee status recounted her personal experience when queuing at the post office:

In the queue and a man standing there he went in first of me and I said you can't be in first of me and he say 'go back to your country'. I didn't say anything. I feel so bad ... I feel sad but what can I do.

Another female learner from Poland and living in Ireland for about eight years described an incident which took place during her work as a parttime cleaner:

I was cleaning the floor, I was buffering and I just touched the table, that buffer. That lady told me 'be careful because you go back to Poland'. She was working there, she wasn't from my company, was working in that office. I just ignored that.

On being asked how this incident made her feel she remarked, 'I don't know ... bad because I didn't do nothing wrong. I just touched leg of the table.' In both examples the learners involved chose to ignore what was said, did not respond to the comments made and did not report the incidents to anyone. One student in class commented 'you don't have the language, the defence'. Such real-life incidents became the basis for role- 


\section{Topic: Challenging racism and discrimination}

\section{Lesson objectives}

- Increase learners' knowledge and awareness of racism

- Support learners in dealing with incidents of racism and discrimination

- Generate real life role play scenarios which focus on challenging racism or discrimination

- Develop useful language in dealing with incidents of racism or discrimination

- Explain where and how to report a racist incident

\section{Learning outcomes to be met during this lesson}

Upon completion of this lesson the students should be able to:

- Have a basic understanding of the terms racism and discrimination

- Deal more confidently with incidents of racism or discrimination

- Identify methods to combat racism and promote interculturalism

\section{Resources}

- Images to display in class 'Kids know nothing about racism' and 'Take a stand on racism' (NCCRI), 'Say no to racism' and 'Show racism the door'

- Worksheets for in-class activity

- Handouts with useful definitions

- Websites

- Computer/interactive whiteboard with internet connection

\section{Lesson content}

Development of lesson

Timing (min.) 80 minutes

- Use images on display as a starting point for discussion on racism

- Share personal experiences of racist incidents witnessed or experienced and use these experiences as a basis for role play scenarios

- Re-enact such experiences focusing on challenging racist or discriminatory behaviour

- Record learners' responses and revisit original scenarios again

- Explain where and how to report a racist incident and distribute information on relevant websites offering information and support

\section{Concluding assignment}

- Students are advised to keep a learning journal of any incidents that take place and how they dealt with each incident

Figure 12.I Lesson plan: challenging racism and discrimination

play scenarios where learners were asked to consider challenging racist or discriminatory behaviour. During role-play some students challenged the comments with verbal responses that encouraged people to question or reflect. In the first example a fellow learner responded by saying 'Do you know how many Irish people live in other countries?' In the second example learners reported the incident to the employer but mentioned feeling nervous about doing so for fear of it affecting their job prospects. 
Learners realised the importance of challenging, where appropriate, racist remarks and insults and reporting incidents, but were anxious about doing so and did not always know who to report to. Some of the strategies and techniques adopted by ESOL tutors in assisting learners to challenge racism and discrimination are outlined in the lesson plan in Figure 12.1. This lesson plan was developed during informal meetings between ESOL tutors at the centre. Tutors recognise the importance of delivering this lesson mid-program when learners are more comfortable and confident about participating in group discussions and expressing personal opinions.

This lesson helps students learn that by tackling racism and reporting racist incidents they are 'creating a social climate where any degree of racism is not tolerated' (Immigrant Council of Ireland 2013: 5). Reflecting on the results of the Laois County Development Board survey learners challenged mind-sets reflecting negative stereotypes or narrow understandings of Irishness. Slogans were created which were directly aimed at combating racism and promoting interculturalism and these included Say No to Racism and Show Racism the Door. The latter slogan Show Racism the Door was chosen to promote European Action Week Against Racism (2012) throughout the centre. Students were photographed, each holding a letter from the slogan, which had an immediate visual impact. Their peers felt that it demonstrated courage on behalf of the students who let themselves be photographed, demonstrating they believed in the slogan. Other students liked the fact that there were real people behind the slogan and it wasn't just a collection of anonymous words.

\section{Generating cross-cultural understanding}

In addition to attending classes, learners and tutors are invited to participate in a variety of activities that take place in the adult education centre throughout the year. Activities either target the specific language needs of ESOL learners or have a whole centre approach which caters for the needs of all learners and tutors accessing the centre. Irish and newcomer adults attend part-time courses at the same centre which provides a suitable space for interacting with each other. This lends itself to natural encounters between newcomers and locals, and without this common space it is debatable whether such positive interactions would take place so easily. This was highlighted during a multicultural coffee morning where everyone across the centre was invited to reflect on the issue of integration and, in particular, how they felt they were integrating and communicating with people from other countries in their everyday lives. Reflections were displayed for everyone to read during the course of the morning and positive contributions from participants helped highlight how willing people are to embrace diversity: 
I live beside an African woman and her two children. We get on very well. I talk to her almost every evening. She gave me the key to her house when she went home for Christmas for five weeks. I looked after her house, turned on and off the lights every day. I got her a little car very reasonable so that she could get in and out of town easily.

(Robert, adult learner, Ireland)

My neighbour is a very nice lady and when she meets me she always asks me about my work, my son and about my problems. Sometimes she gives me very good advice. At Christmas time we made little presents for each other, it is a very nice tradition.

(Ineta, ESOL learner, Latvia)

However, for really successful integration, where immigrants are more involved in their local communities, then communities must be open to such involvement. Therefore, in this instance, learners' work was also exhibited in the public area of the local parish centre where people from the surrounding communities actively engaged in conversation with ESOL learners, viewed this important part of the project and became part of the wider audience.

Many learners at the centre are fearful of making mistakes when using the English language and this needs to be taken into consideration when planning teaching and learning activities and liaising with local groups and outside agencies. In acknowledging this language learner anxiety, recent arrivals get new linguistic and communicative resources in English whilst native speakers need to learn to negotiate with less than fluent speakers of English. In essence, for integration to really work, this accommodation needs to work both ways. We address the particular needs of migrants through intercultural awareness training for tutors, which supports both teaching and learning. Training is provided during the Initial Tutor Training Program for voluntary literacy and language tutors, where participants are given the opportunity to reflect on the issues surrounding second language learning. Numerous adult education practices and methodologies are encouraged, such as the learner-directed approach, peer-mentoring, task based learning, problem solving and learning by doing. Training has also been provided by independent organisations such as the Globe Capacity and Awareness Training Program (2008) which offered specialised training for practitioners involved with immigrant parents. Here Maeve, an ESOL tutor, comments on how the training impacted on her teaching:

For the teaching and learning taking place in the classroom it is important to be aware of the mix of cultures present and over time to 
create an environment where students will trust the tutor and each other and feel able to share their cultural identity in a way that respects each other's differences.

According to Maeve this training helped her deal with hostility or conflict between different ethnic minorities in the classroom and meant that she was better able to deal with situations as they arose. On occasion she has used her training to deal with cultural differences between learners from Eastern Europe and Africa around issues such as timekeeping, parenting styles and attitudes to learning. It should be noted that in recent years ESOL teachers are witnessing some racial tension between groups of newcomers, not just between newcomers and locals. In dealing with these tensions Maeve found that 'exercises such as comparing and contrasting Irish culture with their own is a great starting point for breaking down barriers and getting the students to interact'. She emphasised that the training was useful because it stressed the importance of tutors being capable of identifying cultural issues and, where possible, managing them effectively within the class group.

Getting to Grips with the English Language constantly introduces creative and innovative activities that promote language learning and demonstrate a high level of teamwork and partnership among all participant groups. When adult migrants worked with the artist in residence at Laois County Council they were given an opportunity to express their ideas through writing for a particular publication entitled Seeker. This was a new experience for many of the learners and involved a different approach to language teaching and learning. Seeker, according to writer E. Moore, 'provided learners the opportunity to engage with contemplation via written and spoken conversational exchanges' (Nanigian 2009: 2). In the final publication the artist Theresa Nanigian included personal poetic monologues by migrants living in Portlaoise defining their dream of Eden, inspired by W. H. Auden's 'Everyman in his Eden.' One contributor's dream of Eden describes how 'the material world and status are eliminated. Ego is eliminated.' She explains that 'if we have a need, we exchange our knowledge, our skills, our experiences to fill that need'. In her paradise 'no one sees others and wants more' because 'we only want for more experiences'. Her paradise reflects the skills and experiences she has to offer society. She is willing to share these and also learn from others. Her Eden is the opposite of society's limited view of immigrants as passive and dependent, a view which can very often negatively influence political and economic decisions. What also strikes the reader is the direct contrast between the learner's dreams for the future and the statistics and hard facts facing immigrants across the state. Affording learners from different countries the opportunity to share their personal dreams helped give others a greater understanding of where they were coming from and 
what they were actually seeking in life. The final publication was launched at Laois County Council headquarters, Portlaoise where local citizens attended and read the publication.

\section{Conclusion}

Getting to Grips with the English Language involves language learning inside and outside the classroom, collaboration and co-operation, and enables students access to the language skills and confidence to become more involved in their local communities. It gives tutors and adult literacy students the chance to interact with and better understand the lives of newcomers. As learners' language skills improve, they gradually begin to communicate more confidently, become more settled in their local communities, gain employment and generally are more content with their lives here in Ireland. For example, some mothers who were previously at home with young children and felt isolated now have the confidence to join a local mother and toddler group or meet up with fellow learners in the local library. ESOL learners are more aware of the services that are available to them locally and nationally, and if they have any concern the centre can direct them to the appropriate support service.

Despite major reductions in hours of government funded English language education this project achieves maximum output with minimum expense. It could be argued that the economic climate is totally to blame but budgetary choices must also be questioned. Restricting ESOL provision within the literacy budget is as much a political decision as it is economic. It is the opportune time to tackle ESOL provision and take on board fundamental recommendations that have been reiterated by key stakeholders on numerous occasions. ESOL needs to be recognised as a separate discipline and requires a service based on a national English language policy that is clear, concise and practical, catering for the requirements of all learners (see Sheridan, this volume).

This particular project has helped identify learner needs and promote the importance of language learning amongst the numerous agencies and services involved. With learners participating in tours of Portlaoise library, the library has become much more aware of the particular language resources needed to support students' learning. The project also highlights the importance of keeping the lines of communication open with local agencies and services. An unforeseen outcome of these collaborations is increased contact and exchange between new arrivals, long-term residents and locals.

As learners have become more confident with their spoken English, they can articulate their concerns on an individual basis, approach local community services themselves to promote language learning or develop 
their language competence even further by joining a local sports club, book club, mother and toddler group or ethnic minority support group. The project involves learners from numerous countries and there is great opportunity for intercultural exchange and dialogue between project managers and participants.

The whole centre approach of Getting to Grips with the English Language involves students, tutors and management. It is successful because of the huge involvement from all participants, is sustainable into the future and plays a pivotal role in enabling and empowering ESOL learners to improve their English language; in turn, this helps them to access further educational opportunities locally and nationally. The project was awarded the European Language Label 2010, a European-wide award that recognises creative and innovative ways of teaching and learning languages.

\section{References}

Central Statistics Office (CSO) (1996) Persons Usually Resident in Each Town of 1500 Population and Over, Classified by Birth. Available online at http://census.cso.ie/ Census/TableViewer/tableView.aspx?ReportId=103448 (accessed 15 May 2014).

Central Statistics Office (CSO) (2011) Profile 1 Town and Country. Dublin: Stationery Office.

Department of Education and Skills (2002, 2007, 2012, 2013) DES Statistical Returns for Adult Literacy Portlaoise Adult Education Centre. Dublin: DES.

Globe: All Ireland Program for Immigrant Parents (2008) All Ireland Program for Immigrant Parents Toolkit. Dublin: Globe: All Ireland Program for Immigrant Parents Project Management Committee.

Immigrant Council of Ireland (2013) An Analysis of Racist Incidents Reported to the Immigrant Council of Ireland. Dublin: Immigrant Council of Ireland.

Laois County Development Board (2010) Laois Anti-Racism \& Diversity Strategic Plan 2010-2013. Laois: Laois County Development Board.

Mac Éinrí, P. (2007) 'Immigration: Labour Migrants, Asylum Seekers and Refugees', in B. Bartley and R. Kitchin, Understanding Contemporary Ireland. London: Pluto, chapter 17.

Nanigian, T. (2009) Seeker. Laois County Council, Arts Council of Ireland. Dublin: Frankfort House.

National Adult Literacy Agency (NALA) (2005) Guidelines for Good Adult Literacy Work. Policy Document. Dublin: NALA.

National Consultative Committee on Racism and Interculturalism (NCCRI) (2001) Guidelines on Anti-Racism and Intercultural Training. Dublin: NCCRI. 


\title{
The shifting landscape of Dutch integration policy From LI literacy teaching to literacy in Dutch as entrance criterion to the Netherlands
}

\author{
Jeanne Kurvers and Massimiliano Spotti
}

\section{Introduction}

For some centuries, the Netherlands has been a good destination for refugees and immigrants. During the sixteenth and seventeenth century the wealth and relative freedom of religion in the Netherlands attracted many Protestants from Belgium and France as well as Jews from Spain and Portugal. Immigration declined in the nineteenth century, and the twentieth century saw different periods characterised by different groups of refugees or immigrants entering the country: refugees from Belgium during World War I, Jewish refugees from Germany and Eastern Europe after the implementation of the Nurnberg race laws in 1935, and DutchIndonesian repatriates and Moluccans from the former colony Indonesia after independence in 1949.

From the early 1960s on, guest workers from Southern Europe and later on Turkey and Morocco were recruited for manual labour. The independence of the former colony Suriname in 1975 and the economic situation in Suriname and the Dutch Caribbean brought many Surinamese and Caribbean immigrants to the Netherlands. In recent decades, ongoing immigration from Morocco, Turkey, Suriname and the Caribbean (partly also through family reunion) has been supplemented by asylum seekers and immigrants from global conflict areas in Asia and Africa. In recent years also, due to the expansion of the European Union, many immigrants from Poland, Bulgaria and Romania have been settling in the Netherlands, because European Union citizens and their family members have the right to move and reside freely within the territory of its Member States.

Out of a total population of nearly 17 million people, about 21 per cent falls under the category of 'foreign background'; about 1.5 million originating from the developed west (European countries, the US, Australia and Japan for example) and about 2 million from non-western origin (CBS 2012). The largest immigrant groups in the Netherlands in 2013 are Turkish (and Kurdish), Indonesian, Moroccan, Surinamese (all 
between 300,000 and 400,000) and the Dutch Caribbean (about 150,000). Other larger immigrant groups are from former Yugoslavia (about 80,000), China (50,000), Iraq (about 50,000), Afghanistan (38,000), Iran $(30,000)$, Somalia $(22,000)$, Cape Verde $(20,000)$, Vietnam $(19,000)$ and Thailand $(15,000)$.

Measures to regulate immigration had been taken before the 1990s. Since that decade, however, the Civic Integration policy of the Dutch government has developed from a more or less foreigner-friendly policy, which supported migrants in building a new life in the Netherlands, to a much more restrictive policy. This requires migrants from non-western countries to first pass several exams even before being allowed entry into the Netherlands, and after that, more exams to acquire permanent residence and citizenship. This illustrates that proficiency in the national language has increasingly become a cornerstone of integration policy in the Netherlands (as in other European countries). According to the latest amendments to language-related legislation, to gain access to the Netherlands applicants must have acquired not only some spoken Dutch and knowledge of Dutch society, but also reading ability in Dutch: for unschooled or low-educated migrants this means that proving their linguistic competence depends on their literacy skills. The impact of these changes in legislation on immigrants and practitioners in adult education is discussed in this chapter.

In the section following this introduction we present an overview of the history of the Civic Integration legislation in the Netherlands since the 1990s and amendments to these laws in 2011 and 2012. Then we discuss the consequences of these amendments to the Civic Integration Act: the Dutch Literacy test and (because no courses are provided by the Dutch government in the home countries of the migrants) the self-study toolkit that migrants can buy and use to prepare for the exam in their home country. In the following section we discuss the impact of the current legislation on low-educated migrants and adult second language teaching. Finally we close with the conclusion that the Dutch borders have become increasingly characterised by shibboleths at the entry gate for unschooled and low-educated immigrants.

\section{Legislation on civic integration}

\section{History}

Until the 1990s, there was no language-related legislation for admission and civic integration of migrants in the Netherlands. Preservation of one's first language and culture was part of the official policy, and considered just, because until then guest workers were expected ultimately to return to their home countries. Many migrants, however, did actually attend (literacy) 
courses in Dutch as a second language, provided by adult education centres. In several places, these centres also offered basic literacy courses in Turkish or Arabic; learning to read was considered to be easier in a first language and learning Dutch as a second language might be more successful if people had already learned to read in their first language. To illustrate: the first request Tilburg University received in 1984 from the Dutch State Secretary of Education posed the question why learning Dutch was so laborious for unschooled migrants and asked to investigate whether it would be more effective to start their education with learning to read and write in their first language (Kurvers and Van der Zouw 1990). Starting in 1998, an official integration policy with attendant legislation came into force, which was subsequently repeatedly changed over the next fourteen years. Figure 13.1 presents an overview of the legislation on admission and civic integration in the Netherlands since 1998, including the required levels in Dutch, based on the Dutch version of the Common European Framework of Reference of Languages (CEFR, Council of Europe 2001). The CEFR distinguishes six proficiency levels, ranging from the lowest level A1, the ability to communicate in short and simple sentences in a familiar context, to the advanced and independent level C2, corresponding to near-native use of oral and written language. (See Janssen-van Dieten 2006 for a critical reflection on the implications for low educated learners.)

- 1998: Law on Civic Integration (WIN):

Obligation to participate in integration courses, no requirements with regard to the level to be attained

- 2000-2004: Changes in the public and political climate: preparing new legislation

- 2006: Law on Civic Integration Abroad (WIB)

Admission dependent on passing the exams on Spoken Dutch and Knowledge of Dutch Society

- 2007: Law on Civic Integration (WI)

Residence permit dependent on passing exams on spoken and written Dutch and knowledge of Dutch Society

- Exam: central exam and practice assessments

- 20II: Amendment to Law on Civic Integration Abroad (WIB)

- Spoken Dutch: criterion for passing raised to AI level CEFR

- Literacy test (GBL) added

- No provision of courses, self-study toolbox

- Costs: Toolbox €II0, Exam €350

- 2012 Amendment to Law on Civic Integration (WI)

- Required level of Dutch A2 (future BI?)

- Time-limits reduced to 3 years (+ 2 for unschooled).

- Possibility of applying for dispensation for literacy requirements abolished

- Central exam only

- Funding stops from 2013 onwards

Figure 13.I Dutch legislation on admission and civic integration 
In 1998, the first Law on Civic Integration was passed, which required migrants to participate in courses of Dutch as a second language and familiarisation with Dutch society and work in the Netherlands. All courses were provided by adult education centres with only minor costs for students. Familiarisation with Dutch society and the labour market was regularly offered in a language familiar to the migrants, such as Turkish, Arabic or English.

In the period between 2001 and 2005, the public and political climate changed radically, due to major events like 9/11, the murders of Islamcritical politician Pim Fortuyn in 2002 and the equally if not more critical controversial interviewer/film-director Theo van Gogh in 2004, culminating in the establishment of anti-Muslim and anti-migrant populist political parties like Geert Wilders' PVV (Freedom Party). This change in climate is reflected in two new laws that were much more restrictive with regard to the admission of new arrivals and quite a bit more demanding as far as the requirements for civic integration were concerned than was the case in the 1998 law. These two laws were the Law on Civic Integration Abroad (WIB), which was passed in 2006, and the Law on Civic Integration (WI), passed in 2007. The Minister in the Liberal Party who introduced the new laws (Verdonk) repeatedly stated in the Dutch media that migrants are expected to speak Dutch everywhere and her slogan 'integration starts with language' (language being a synonym for Dutch) became a much-repeated sound-bite.

Among other things the 2006 Law on Civic Integration Abroad required migrants from non-western countries wanting to settle in the Netherlands to pass an exam in spoken Dutch and a test of knowledge of Dutch society. It introduced an entrance examination for the Netherlands: only those migrants who had passed the spoken Dutch test at a level slightly below A1, the lowest level on the CEFR, called A1-minus, and on knowledge of Dutch society, were declared admissible to the Netherlands. In the explanatory memorandum to this law the Dutch government stated explicitly that there would be no test of written Dutch, so as not to discriminate against unschooled migrants applying for admission: 'The aim of the settlement requirements is not to prevent specific categories of migrants, such as illiterates, from entering the Netherlands. Therefore literacy is not required to be able to pass the basic exam abroad' (Verdonk and Bot 2006: 26). Because of this law, the law on foreigners ('Vreemdelingenwet' in Dutch) had to be adapted accordingly (Verdonk and Bot 2006). Next to the requirements about who could be declared admissible (no criminal past, minimal age for marriage, income and housing requirements for the partner etc.) a new article was added: passing the exam.

The exam (a computerised test with a telephone connection that uses automatic speech recognition) is called the basic integration exam and is 
to be taken at the Dutch Embassy or Consulate in the candidate's country of origin. The Exam on Spoken Dutch (TGN) tests oral skills and consists of four parts: sentence repetition, answering short questions, naming antonyms of given words and retelling stories. The exam on Knowledge of Dutch Society (KNS) consists of 30 questions in Dutch (out of the 100 that can be prepared for) based on a booklet with 30 illustrations (stills from the video film 'to the Netherlands') that are to be answered in Dutch as well. The questions include topics like geography, history, the Dutch constitution and legislative system, parenting and education, work and income, the health care system and the Dutch language.

In 2007, the second law was passed, the Law on Civic Integration (WI), which required migrants to pass another three exams after entering the Netherlands before gaining a permanent residence permit: two central exams (oral and written Dutch, and Knowledge of Dutch Society) and a 'practice' exam (using Dutch in real life situations). In these assessments, candidates could choose assessments (by certified assessors or portfolio proofs) that were best suited to their role in daily life (for example related to work or parenting). Adult education practitioners had been lobbying intensively to get this latter exam put in place. Newcomers were required to pass both oral and written exams benchmarked at level A2 on the CEFR, i.e. the level above 'beginner'. For long-term residents, level A1 for written Dutch sufficed. For refugees, only the requirements of the second law (WI) applied. The separate citizenship test, which existed until 2007, was replaced by the Civic Integration Exam. Migrants who had already passed another exam at a higher level (for example a regular high school exam or a State Exam in Dutch as a second language) did not have to take the Civic Integration Exam. That is to say, a demonstration of language competence fulfils the requirements for residence. Migrants with less than elementary education in their home country could apply for an exemption (dispensation) for the written part of the requirements to get Dutch citizenship, provided they could prove they had made a considerable effort trying to reach the required literacy levels. Migrants got three and a half years to pass the exams; unschooled migrants were granted two more years to do so. As a consequence of failure, they would not get their permanent residence permit (although most of the time local authorities were flexible in applying this rule).

\section{Amendments in $201 \mathrm{I}$ and 2012}

In 2011, the Law on Civic Integration Abroad (WIB), which regulates admission to the Netherlands, was adjusted: the criterion for passing the test on spoken Dutch was raised to level A1 (CEFR) and a new test was added: a literacy test (although in 2006 similar literacy requirements had been considered discriminatory by the Dutch government). The exam on 
Knowledge of Dutch Society remained unchanged. Since April 2011, migrants who want to get an entrance visa for the Netherlands not only have to prove that they can speak and understand Dutch, but also that they can read Dutch in Roman script at level Al of the European Framework, i.e., that they are able to read and understand simple and short texts in Dutch. No courses are provided, but instead a self-study toolkit has been developed (by order of the government) to help potential immigrants to learn to read and comprehend written Dutch by themselves, with the help of their relatives in the Netherlands (see below).

Taking the whole test costs $€ 350$, which comes on top of the other costs migrants have to meet to prepare themselves for the exam and to travel to a Dutch Embassy or Consulate in their country or a neighbouring country. The self-study toolkit costs $€ 110$. The website of the Dutch government states: 'You can prepare for the basic integration exam with the self-study toolkit Naar Nederland (To the Netherlands). It contains all you need to learn to speak, understand and read in Dutch and to pass the basic integration exam abroad' (www.rijksoverheid.nl/onderwerpen/ inburgering). The toolkit consists of a DVD with the film To the Netherlands and an accompanying photo book with an audio CD, a workbook, a learner's guide in Dutch and English (or another language if available), a DVD with digital exercises, log-in codes for the online practice program and codes to access two practice exams on spoken Dutch and literacy in Dutch. Students who want extra practice and want to do more practice exams can buy another four practice tests for $€ 75$.

Candidates have to pass all three parts (Spoken Dutch, Knowledge of Dutch Society, and Literacy and Reading Comprehension) to pass the examination in full. 'If you fail any part, you must retake the entire examination', so the official brochure The Dutch Civic Integration Examination Abroad (p. 13) clearly states, and every re-examination costs another $€ 350$ (www.government.nl/issues/integration/integrationprocedure-abroad).

In 2012, the Law on Integration (WI) for migrants who have already been admitted and received a temporary residence permit was also adapted. The obligation to pass the exam now only applies to new residents, and no longer to long-term residents with low levels of Dutch. The time limit allowed to migrants to pass the exams has been reduced to three years (plus another two years for unschooled migrants) and the possibility of applying for exemption from the literacy requirements for migrants with fewer than six years of elementary education has been abolished. According to the ministry, the main reason behind this is that as a result of the adaptations to the Law on Civic Integration Abroad migrants are already supposed to be able to read Dutch at level Al (but see below). Besides this, the funding for integration courses has been terminated completely (as of 1 January 2013 for new arrivals) and there 
is now only one spoken and written exam for Dutch as a second language. Practice-related assessments are no longer valid and the exam is no longer adapted to the several roles migrants have in society (such as workforce, education or parenting).

In sum, since 2013 migrants need to pass exams at level A1 to be able to enter the Netherlands with a provisional (temporary) residence permit, and to get a permanent residence permit they need to pass exams at A2 level within 3 to 5 years of arrival. The Netherlands is not the only country changing its migration policy this way. The same tendencies can be recognised across Europe (see Extra et al. 2009) and the implications of the power of language tests are discussed increasingly widely (see for example Shohamy 2006).

In the next sections, we will explore more extensively the new literacy test and the role of the self-study toolkit intended for migrants who have never been to school and have to learn to read and write by themselves, for the first time in life, in Dutch as a second language.

\section{The 20 I I literacy test}

The literacy test introduced in 2011, called Geletterdheid en Begrijpend Lezen (Literacy and Reading Comprehension) is one of the three tests migrants have to pass in order to be declared admissible and receive a temporary residence permit in the Netherlands. Like the other two parts of the exam (Spoken Dutch and Knowledge of Dutch Society), the exam has to be taken at the Dutch Embassy or Dutch Consulate in the country of origin.

The test consists of five parts: word reading, sentence reading, text reading (all reading aloud), sentence comprehension and text comprehension. These five parts are included in the computerised phone-pass test. The instructions in the learner's guide for practising the phone-pass test first ask the student to enter the telephone number, after which the computer answers in Dutch 'Thank you for calling the Ordinate test system. Please type in your Test Identification Number'. After this, the candidate has to enter a personal TIN-code, follow the instructions for each of the parts, and read out the words, sentences or texts after hearing a tone.

For word reading, the candidate is asked to read aloud four lists of Dutch words, ranging from short monosyllabic words to more complex multisyllabic words. Sentence reading requires the candidate to read aloud eight Dutch sentences. For text reading, the candidate has to read out loud three texts of about 50 words each in 30 seconds. One of the texts is written in a letter font that resembles handwriting. In sentence completion, the candidate is asked to read out loud 28 sentences and to complete the sentence with the appropriate word (to be chosen from three alternatives). For example: Ik heb heel hard gewerkt, maar nu heb ik een 
rustige ... drukte, kast, week ('I worked very hard, but now I have a quiet ... pressure, cupboard, week'). For reading comprehension, the candidate needs to read a text and answer a few questions about the text. An example is presented in Figure 13.2. (All examples are from one of the official practice tests that are included in the self-study toolkit, provided by the Ministry of the Interior and Kingdom relations).

The text informs the reader about Lotte, who got a notebook from her grandmother and invites her friends to write something in it. Lotte is very happy with the notebook and she assumes it will help her remember who her friends were, when she was young. The reader has to answer three questions. From whom did Lotte get the notebook? Who is Lotte's best friend? What will the notebook be for Lotte when she has grown old?

According to the test developers (Van Emmerik et al. 2011), the first (reading aloud) parts measure accuracy and fluency. This part determines 50 per cent of the score on the test. Sentence Completion and Text Comprehension are supposed to measure comprehension and determine the other 50 per cent of the score. The literacy test is a computerised phone-pass test (a speech recognition device automatically generates a literacy score), because it had to fit in with the software and frame of the test already developed for spoken Dutch.

One could argue that perhaps speech recognition is not the most valid and reliable method to measure reading accuracy and comprehension for second language learners. For mother tongue speakers, accuracy and speed in oral reading are reliable predictors of beginning reading proficiency (Adams 1990; Byrne 1998). This however, is not automatically the case for beginning readers in a foreign language. Due to differences in the phonological repertoires of the various languages, a test taker might be able to apply the alphabetical principle easily, but is still unable

\section{Tekst}

Oma heeft Lotte een mooi cadeau gegeven. Ze heeft Lotte een schrift gegeven. Alle vrienden van Lotte mogen erin schrijven. Haar beste vriendin Mila schrijft als eerste in het schrift. Sommige vrienden maken ook nog een tekening, zoals Anna. Zij heeft een paard getekend bij een klein gedicht. Lotte is heel blij met het schrift. Als ze later oud is, is het een mooie herinnering. Dan weet ze nog steeds wie vroeger haar vrienden waren.

Vragen

Van wie heeft Lotte het schrift gekregen?

Wie is de beste vriendin van Lotte?

Wat is het schrift voor Lotte als ze later oud is?

Figure 13.2 Sample text with questions

Source: Ministerie van Binnenlandse zaken 20I I 
to pronounce words as expected when they do not consist of sounds or sound patterns that are familiar to him or her. One indication to this effect is that, compared to other nationalities, Chinese candidates passed the exam least often (59 per cent) in the first half of 2012 (Moroccans showing a pass rate of 79 per cent, Russians of 97 per cent), a situation that is not very common for Chinese students in general (Van Esch et al. 2012).

As mentioned earlier, no courses are offered to migrants who want to join either their partner or family in the Netherlands, but migrants can buy the self-study toolkit Naar Nederland (To the Netherlands) to prepare themselves with the help of their relatives in the Netherlands. Another possibility is to visit the Netherlands on a tourist visa and to take a fourweek course at a Dutch language institute costing around $€ 800$.

\section{The toolkit for self-study}

By order of the Dutch government, a self-study toolkit was developed to enable candidates to prepare for the exams on Spoken Dutch, Knowledge of Dutch Society, and Reading and Reading Comprehension. The toolkit consists of:

- Guidelines with instructions and online translations in several languages.

- For Knowledge of Dutch Society: a DVD with a film on eight topics, a book with stills of the video and 100 questions and answers, one for each of the stills.

- For Spoken Dutch, Reading and Reading Comprehension: a workbook with an audio CD and a DVD (or online exercises), 65 lessons with exercises and a wordlist.

According to the Guidelines, the first 20 lessons introduce the basics of reading and writing in Dutch in the Roman alphabet for unschooled students, and the other 45 lessons aim at supporting the learning of written and spoken Dutch up to the required A1 level. From lesson 21 onwards, the basic content is on reading aloud words and sentences and on sentence and text comprehension. On the DVD and the online version of the program, instructions can be read in one of the five different languages (English being one of them) that are currently available, and it is also possible to get an oral translation of words in one of these languages.

Twenty-five years of research on unschooled adult second language learners has brought ample evidence that learning to read and write for the first time in a new language cannot be done simply via a self-study toolkit (Kurvers and Van der Zouw, 1990; Kurvers, 2002, 2007; Onderdelinden et al. 2009; Kurvers et al. 2010; Young-Scholten and 
Naeb, 2010). Most such learners do not possess the required metalinguistic skills for self-study (such as knowing how to isolate particular words or sounds in on-going spoken language), they do not know many words in the new language and they probably do not understand what the online instructor is talking about. In the first lesson, for example, on Dutch numbers 1-12, the student sees a picture of a boy and two girls with the numbers 2, 3 and 4 next to it. The accompanying online voice in the e-learning program says 'I have three children' and the online instruction asks the student to 'count the words' and tick the right number (Kurvers et al. 2013). An unschooled student would most likely not only fail to recognise word boundaries in his or her own language, a failure that obviously also affects any other language s/he might try to master, but the instruction given is also quite confusing, in that the student would have to tick the number 4 next to a picture with three children.

\section{Impact of legislation on adult education and immigration}

From the 1980s on, experts and practitioners in the field of adult education have been active and innovative in professionalising the field of second language teaching and learning for migrants. The CEFR was adapted to Dutch and a special literacy framework for Dutch as a second language was developed for unschooled migrants (Stockmann and Dalderop 2005), many innovative teaching materials were developed (see Spotti and Kurvers, this volume), a handbook for second language teachers was written (Bossers et al. 2010), teacher training courses were offered and were well attended. Besides, special journals for second language and literacy teachers (LES for second language teachers and ALFA-nieuws for literacy teachers) were established, as was, in 2003, an association of second language teachers.

During the 1990s, the most critically discussed aspect of the legislation was the obligation to attend integration courses, although many practitioners also observed a positive impact of the obligation, especially for women who had previously sometimes been forbidden from attending. In the years after 2006, the most hotly discussed topics (by academics and practitioners) were the entrance exams to the Netherlands, the validity and fairness of the speech recognition-based test for spoken Dutch and literacy, the washback effect of the exams on a teaching system that should prepare migrants for participation rather than drilling them to pass a test and the unlikelihood that unschooled migrants will pass the exams and get a residence permit. The financial consequences for immigrants who have to borrow a lot of money to pay for their own integration courses were also critically discussed.

Evaluations of the exam in the home country (which has to be passed for admission to the Netherlands) in 2010, 2011 and 2012 present 
Table 13.I Average exams per month and pass rates by educational level, before and after implementation of the new entrance exam (I April 20I I)

\begin{tabular}{|c|c|c|c|c|}
\hline & \multicolumn{2}{|l|}{$\begin{array}{l}\text { Before policy change } \\
\text { Jan 2010-April } 2011\end{array}$} & \multicolumn{2}{|c|}{$\begin{array}{l}\text { After policy change } \\
\text { April 201 I-December } 2012\end{array}$} \\
\hline & $\begin{array}{l}\text { Average exams taken } \\
\text { per month }\end{array}$ & Pass rate & $\begin{array}{l}\text { Average exams taken } \\
\text { per month }\end{array}$ & Pass rate \\
\hline Total: & 707 (100\%) & $90 \%$ & 375 (100\%) & $76 \%$ \\
\hline Low-educated & 175 (24\%) & $87 \%$ & 68 (18\%) & $62 \%$ \\
\hline Middle-educated & $350(48 \%)$ & $92 \%$ & 167 (45\%) & $75 \%$ \\
\hline High-educated & $199(28 \%)$ & $95 \%$ & 137 (37\%) & $87 \%$ \\
\hline
\end{tabular}

Calculations based on Van de Grift et al. 2011, 2012; Van Esch et al. 2012.

statistics about the number of examinations taken before and after the implementation of the New Basic Integration Examination on 1 April 2011: the (relative) number of migrants from different educational backgrounds who took the exam, and the pass rates (Van de Grift et al. 2011, 2012; Van Esch et al. 2012). Table 13.1 presents the data on the period before and after the introduction of the new policy. Because the period before covers 15 months (2010 and the first quarter of 2011) and the period after 21 months (April 2011-December 2012), in Table 13.1 the average numbers per month are presented. 'Loweducated' in the table refers to a maximum of six years of schooling, middle-educated to 6-12 years and higher-educated to more than 12 years of education.

The statistics first reveal that the average number of exams taken decreased by 47 per cent (from 707 to 375 ), and that this reduction was much steeper for the low-educated applicants (a decrease of 62 per cent, from 175 to 68 ). On top of that the statistics reveal that the pass rate for this smaller group of low-educated migrants dropped from 87 per cent to 62 per cent. The combination of the two statistics reveals that, compared with the previous year, only about 24 per cent of low-educated migrants managed to gain an entrance visa in the year after the policy was introduced.

\section{Conclusions and discussion: going Double Dutch}

Since the 1990s, Dutch integration policy has shifted from being fairly foreigner-friendly to becoming more restrictive. While early integration policy considered maintaining cultural diversity to be worthwhile, now this diversity is seen as something that obstructs integration. Ability in the Dutch language is considered the most important feature of being a Dutch citizen. 
While until the early 1990s unschooled migrants were even offered mother tongue literacy classes to increase their linguistic awareness in order to facilitate the acquisition of the Dutch language, the current policy is one that is unrecognisably different. To obtain a temporary residence permit, applicants now must have acquired before entrance not only spoken Dutch at A1 level and Knowledge of Dutch Society, but also reading ability in Dutch at level Al. After this, within three to five years, a second examination has to be taken on spoken and written Dutch at level A2 of the CEFR, and a more advanced test on Knowledge of Dutch Society. The free market principle has also entered integration policy: no free courses are provided by the government and from 2013 onwards the migrants have to pay for the whole trajectory themselves (they are entitled to loans, like students in higher education). The selfstudy toolkit developed by order of the government does not take into account the perspective of the true beginner in learning or the double cognitive load involved in having to learn to read and write for the first time, and having to do this in a new language. Research has shown convincingly that learning to read is not just a matter of beginners being supplied with letters, written words and texts, and needless to say the process is obviously complicated further by having to learn to read in an unfamiliar language.

The evaluations that took place after the new legislation was passed seem to reveal that it is not so much highly educated migrants (the knowledge workers) but rather the unschooled and low-educated migrants who are hampered by this new policy. We can conclude that since April 2011, the Dutch borders have been practically closed to loweducated non-western migrants. We called this 'Double Dutch'. Double Dutch, apart from its regular meaning in English, is also the name of a children's skipping rope game in which one rope moves in one direction, and the other in the other direction. Double Dutch also refers to a language game with a secret language like Pig Latin: only those who speak the secret language belong to the in-group, and the rest are excluded. While practitioners and experts in the adult education field have been working very hard for the last twenty years to professionalise teachers and to improve integration of migrants in society, the Dutch government decided in favour of, in our eyes, an extremely restrictive integration policy for unschooled and low-educated migrants.

\section{References}

Adams, M. (1990) Beginning to Read. Thinking and Learning about Print. Cambridge: MIT Press.

Bossers, B., Kuiken, F. and Vermeer, A. (eds) (2010) Handboek Nederlands als tweede taal in de volwasseneneducatie. Bussum: Coutinho. 
Byrne, B. (1998) The Foundation of Literacy. The Child's Acquisition of the Alphabetical Principle. Hove, East Sussex: Psychology Press.

Centraal Bureau voor Statistiek (CBS) (2012) Jaarrapport integratie 2012. Den Haag/Heerlen: CBS.

Council of Europe (2001) Common European Framework of Reference for Languages. Cambridge: Cambridge University Press.

Extra, G., Spotti, M. and Van Avermaet, P. (eds) (2009) Language Testing, Migration and Citizenship: Cross-National Perspectives on Integration Regimes. London and New York: Continuum.

Janssen-van Dieten, A. (2006) Common European Framework of Reference and L2 learners with a low level of education. In I. van de Craats, J. Kurvers and M. Young-Scholten (eds), Low-Educated Second Language and Literacy Acquisition. Proceedings of the Inaugural Symposium. Tilburg 05. Utrecht: LOT, 143-151.

Kurvers, J. (2002) Met ongeletterde ogen. Kennis van taal en schrift van analfabeten. Amsterdam: Aksant Academic Publishers.

Kurvers, J. (2007). Development of word recognition skills of adult beginning L2 learners. In N. Faux and H. Major (eds) Low Educated Second Language and Literacy Acquisition: Research, Policy and Practice. Proceedings of the Second Annual Forum. Richmond, VA: The Literacy Institute, 23-43.

Kurvers, J. and Van der Zouw, K. (1990) In de ban van het schrift. Over analfabetisme en alfabetisering in een tweede taal. Amsterdam/Lisse: Swets \& Zeitlinger.

Kurvers, J., Stockmann, W. and van de Craats, I. (2010) Predictors of success in adult L2 literacy acquisition. In Th. Wall and M. Leong (eds), Low-Educated Second Language and Literacy Acquisition. Proceedings of the Fifth Symposium Banff 2009. Calgary, Alberta, Canada: Bow Valley College, 64-79.

Kurvers, J. van de Craats, I. and Boon, D. (2013) Consequences of the Dutch Integration Policy: literacy as entrance criterion. In: T. Tammelin-Laine, L. Nieminen and M. Martin (eds) Proceedings of the 8th Symposium on Loweducated Second Language and Literacy Acquisition. Jyväskylä: University of Jyväskylä, 145-163.

Ministerie van Binnenlandse zaken en Koninkrijksrelaties (2011) Naar Nederland. Voorbereiding op het Basisexamen Inburgering in het Buitenland [To the Netherlands. Preparation on the Basic Integration Exam Abroad]. Amsterdam: Boom.

Onderdelinden, L., van de Craats, I. and Kurvers, J. (2009) Word concept of illiterates and low-literates: Worlds apart? In I. van de Craats and J. Kurvers (eds), Low-Educated Adult Second Language and Literacy Acquisition, 4th Symposium Antwerp 2008. Utrecht: LOT, 35-48.

Shohamy, E. (2006) Language Policy: Hidden Agendas and New Approaches. London and New York: Routledge.

Stockmann, W. and Dalderop, K. (2005) Raamwerk Alfabetisering NT2. Arnhem: Cito. Van de Grift, M., Remmerswaal, R. and Tazelaar, P. (2011) Monitor Inburgeringsexamen Buitenland 2010. Barneveld: Significant.

Van de Grift, M., Remmerswaal, R. and Tazelaar, P. (2012) Monitor Inburgeringsexamen Buitenland 2011. Barneveld: Significant.

Van Emmerik, J., Schot, I. and Tijssen, M. (2011) Over de ontwikkeling van de toets Geletterdheid en Begrijpend Lezen. Les, September: 35-38.

Van Esch, Th., van de Grift, M. and Tazelaar, P. (2012) Monitor Inburgeringsexamen Buitenland, eerste helft 2012. Barneveld: Significant. 
Verdonk, M. and Bot, B. (2006) Besluit van 17 februari 2006 tot wijziging van het Vreemdelingenbesluit 2000 in verband met inburgering in het buitenland. Staatsblad van het koninkrijk der Nederlanden, nr. 94. Den Haag: SDU.

Young-Scholten, M. and Naeb, R. (2010) Non-literate L2 adults' small steps in mastering the constellation of skills required for reading. In $\mathrm{T}$. Wall and M. Leong (eds), Low Educated Second Language and Literacy Acquisition. Calgary: Bow Valley College, 80-91. 


\section{ICT-based applications for civic integration in the Netherlands}

\section{Policy drivers and limits in practice}

\section{Massimiliano Spotti and Jeanne Kurvers}

\section{Learning to become an integrated citizen}

The importance of language education and digital inclusion is fully recognised by the European Union:

- The basic knowledge of the host society's language, history and institutions is indispensable for integration (Common Basic Principles on Integration, European Commission 2004).

- Language education is a priority topic for the future of migrants' integration in Europe (Handbook on Integration, European Commission 2009).

- Language education for integration in all EU Member States is acknowledged as important (European Ministerial Conference on Integration, Vichy, 3-4 November 2008).

- Non-EU nationals ought to participate in introductory courses either on a voluntary or compulsory basis with the purpose of learning the host country's language as well as its cultural norms and values (Handbook on Integration, European Commission 2007).

- Digital inclusion for all is an EU strategic policy goal (Commission of the European Communities 2005).

- $\quad$ e-Inclusion for all citizens means 'both inclusive ICT for mainstream society and the use of ICT to achieve wider integration objectives' (Riga Declaration on e-Inclusion, European Commission 2006).

- Cultural diversity in Europe should be promoted by "improving the possibilities for economic and social participation and integration, creativity and entrepreneurship of immigrants and minorities by stimulating their participation in the information society' (Riga Declaration on e-Inclusion, European Commission 2006).

Against this background, and given the dearth of empirical evidence on learners' perspectives on the use of ICT for integration, this contribution draws on a qualitative study carried out in 2010 on behalf of the Director 
General for Research of the European Commission. This study focused on the civic integration trajectory of newly arrived non-EU nationals hoping to gain permanent residency in the Netherlands and Sweden (Project Report Number JRC 59774 Technical Note; see Driessen et al. 2011). While here we just focus on the Dutch part of this study, the more general purpose of this comparative enquiry was to discover the drivers and barriers that influence the successful implementation and use of ICT in formal L2 education for civic integration and, on the basis of this, to formulate opportunities for a more holistic use of ICT in integration classrooms. To do so, the Dutch part of this study focused on three ICT applications. These applications were reviewed not only in terms of their technical specifications, learning aims and learning goals. The study also looked at their implementation in integration classrooms, through an empirical interpretive approach that availed itself of ethnographic data collection.

We begin with an overview of the spread of ICT in adult second language (L2) education in the Netherlands. We then provide descriptions of how three ICT applications were used in particular settings. The first application we report on was selected for the research because of its widespread use across integration courses, and because it represents the earliest of steps toward digital learning for Dutch as L2. The second application was selected because of its prize-winning innovative approach to integration through blended learning and because it embodies a consolidating trend in the field, that of contextualised second language learning. The third application was selected because it is representative of an emerging trend - that of adaptive learning - which has not yet spread widely across civic integration classes. Our chapter concludes by inviting the reader to reflect upon the implications that ICT has for migrants. It critiques the way that the transformational power of technology is harnessed to further nation states' own integration agendas. In these agendas, ICT has become the bed-fellow of learning the 'what' and the 'how' to become a citizen. It is seen as a way of enabling the rapid and effective inclusion of migrants into mainstream host societies. At the same time, the 'mainstream' is understood as a static array of norms and values with which new arrivals ought to align.

\section{ICT for integration in the Netherlands}

Back in 2010, the year in which the empirical part of this study was conducted, the Ministry of Housing, Spatial Planning and Environment was the institutional body in charge of the civic integration of newly arrived migrants (see Spotti and Kurvers 2012). The Ministry actively supervised municipal authorities engaged in implementing its integration policy. Municipal authorities, in turn, supplied information to newly arrived 
migrants about their integration trajectory, its cost and funding, and its length. They would also either cover or subsidise someone's integration costs for both courses and examinations and were responsible for applying financial sanctions on those migrants who either did not attend integration courses or who did not manage to complete the process within the 3.5 year timespan set for full integration certification. Until 2007, municipalities had mainly relied on Regional Educational Centres (ROCs) to cater for the integration of newly arrived migrants. After 2007, an entire market developed around civic integration education. Municipalities in fact often put integration projects out to tender, for which parties were invited to submit financially competitive bids. As a result, there is now a wide variety of L2 training materials in the Netherlands, from general language courses to separate tools that have been developed to practise specific language skills, such as listening, grammar and pronunciation for particular groups of students, e.g., highly educated migrants who can function as independent learners. In 2010 'Knowledge of Dutch Society' became a compulsory part of the civic integration examination, and its content often became integrated with that of Dutch as L2 courses (see Kurvers and Spotti, this volume), every one of which would claim to make use of ICT. The definition of ICT used by the Ministry as well as by other educational establishments, however, is very broad. In fact, an 'ICT-assisted method for integration' covers any product that can store, retrieve or transmit information electronically in a digital format. For the study we report on here, the researchers (including the first author of this chapter) considered the full range of ICT tools, courses and applications available on the market in 2010: from more traditional paper-based teaching methods that also contained computer-assisted training materials that ranged from a CDROM or a DVD, to more innovative web-based learning material with an online component. The range of ICT products for L2 learning in the Netherlands extends from small-scale applications for specific purposes or skills to complete courses that cover all language skills across different domains, such as work, education, recreation and childrearing. The year 2010 was a point when the Dutch government was promoting the use of ICT in L2 learning for integration, and it was the government which specified the targets that should be attained through the use of ICT. The opening of the market to commercial parties, as revealed in this study, led to the development and identification of a wealth of digital materials, most of which came at a cost for students, and it highlighted that an ICT commercial market was more favourable to those newly arrived migrants who had financial resources other than those provided by municipal authorities, and who could therefore afford to pay for extra tuition (see Spotti 2011).

In our study of ICT applications for adult new arrival language learners, the first author carried out classroom observations, focus group 
interviews and interviews with individual learners and teachers. In the sections that follow, we describe in turn three applications designed for the learning of Dutch and contextualise these descriptions with extracts from our data.

\section{The most widely used application: IJsbreker}

This section deals with the first case study carried out during our enquiry. The institution used for this case study is a public sector ROC with 18 locations spread across the western part of the Netherlands that offers preparatory courses at the upper-secondary level of vocational training. It also offers training and courses aimed at life-long learning (adult education). The education department of the college describes itself as the region's largest provider of Dutch language courses for newly arrived migrants, and also of professional development for migrants, supporting integration into mainstream society at large. The mission of the college is to "provide educational grounds for the fulfilment of social responsibilities', to inspire learners to give the best of themselves, and to become self-sufficient in the development of their learning process 'in order to become citizens who can look at society with a positive, yet critical, outlook'. IJsbreker (Icebreaker) was developed by ThiemeMeulenhoff (Jansen et al. 2010) as a language learning method for low-educated L2 learners. This application was not developed for the purpose of self-study. Rather, teacher supervision is needed for both its thematic and grammar-based units, with students' independent work comprising but a small component. IJsbreker consists of three parts. Parts 1 and 2 prepare students for the civic integration examination. Part 1 leads to level A1 (beginner), and part 2 to level A2 (elementary) on the Common European Framework of Reference for languages. Part 2 is divided into two separate programs, depending on the candidate's needs: Wonen in Nederland (Living in the Netherlands) and Werken in Nederland (Working in the Netherlands), with the latter being more often used by men and the former by women. Once learners reach A2 proficiency level, they can move on to level B1 (intermediate) by following part 3 of the application entitled Op Koers (On Track). This part prepares students for the Dutch State Exam, part 1 (see Kurvers and Spotti, this volume), an exam for a level of proficiency in Dutch above A2. All packages contain a workbook, a dictionary of frequent words, a teacher's manual and a CD-ROM version of the application. There is also a web-based version. The ICT component of this application is marketed as being useful in that students can practise their listening, reading, pronunciation and vocabulary knowledge independently on the computer. 


\section{Putting words in the right order}

The episode that follows, although not fully representative of the functional and notional approach that informed this method and its later versions, deals with a student called Bejan and sees him engaged in ordering words according to the Dutch alphabet. Bejan is a 54-year-old man from Iraq who after 10 years in the Netherlands was granted a residence permit and was put on a municipality-sponsored integration course for 18 months. This episode sheds some light on what drives the use of ICTs for second language learning in this integration classroom, and illustrates some of the shortfalls:

After completing the exercise assigned to him in the textbook, Bejan then moves to the PC to carry out those exercises that are part of its grammar-based study unit. One of the exercises requires him to put a series of words in the right alphabetical order. The words are: Rood (Red), Rechts (Right), Rem (Brake). The correct order is Rechts / Rem / Rood.

As Ms Lineke, his teacher, put it, Bejan has to learn not to look just at the initial letter of a word but to move on to the second, third, then fourth letter of the word. He finds it difficult to grasp this principle, as the feedback that he gets from the ICT application is not only in Dutch but it is also rather limited as it states either goed (right) or fout (wrong). Ms Lineke is moving from one student to another to check that everyone is on task as well as to answer the students' questions, and she arrives at Bejan. They look at the first line of the exercise together and repeat the words that are on the screen: Rood, Rechts and Rem. Ms Lineke then points out that he should move beyond the beginning of the words in his attempt to put them in the right order. He tries and the result is again incorrect. Ms Lineke then invites him to think about the letter that follows the first letter and to see whether, if all the first letters are the same, the second letter gives any indication of which word comes first. When asked to write down the alphabet as an aide memoire though, it transpires that Bejan only knows the first eight letters of the Dutch alphabet. Ms Lineke suggests to him that if he does not know the alphabet by heart, then there is very little that she can do about it and there is also very little that the computer can do to help him. Bejan then tries once more. Ms Lineke tells him that the alphabet is basic knowledge and that, at this stage, he should know it by heart. ICT, in the words of Ms Lineke, cannot bridge this gap as it requires prior knowledge and literacy skills that Bejan, like many others, does not have.

Bejan's case stands as an emblem for what we term click-tive learning. This is an approach to language learning that, rather than actively 
engaging the learner with how language is actually used, bases its results on the number of exercises and clicks that someone manages to get right during their independent ICT learning activities.

\section{The prize-winning application: De Virtuele Wijk}

The second application is De Virtuele Wijk (The Virtual Neighbourhood) developed by ITPreneurs in Rotterdam. This application is part of the method Thuis in Nederlands (At home in Dutch) (ITPreneurs 2008), aimed at low-educated women following the integration trajectory, and has received an educational award for catering for blended learning, which in this case means blending together language learning with content that has immediate societal relevance. The application's goals are to have learners gather information about the facilities and services that are located in their environment, and allows them to find their place in the local spaces that they inhabit.

Often learners are limited by their lack of confidence as well as by a lack of Dutch when asking for information in formal situations. The learner sees on their screen ten buildings, for instance the municipality building or a library, where different types of formal interaction can be tried out with a virtual interlocutor. The chats deal with topics that learners face in daily life. They are presented as scenarios, for instance 'at the library desk'. During a chat, the text appears on the screen and the sentences are meant to be read in full and out loud. The designers suggest that the proficiency level that a learner needs is Al. As in real life situations, interactions are both formal and informal. Learners can also chat live with other people in the neighbourhood, although this activity also needs to be carried out under the teacher's guidance. At the beginning of their trajectory, every learner builds a profile based on personal information, e.g., their job, as well as their hobbies. Learners can communicate with 'real' people in their own neighbourhood, according to the postcode that they type in their profiles. People who have registered and who are currently online are listed on the learner's screen. Furthermore, learners can retrieve information about community centres and health centres in their own neighbourhood. The use of this information though can only happen through schools that have set up a link with these institutions in advance and have asked them whether they can access their information.

\section{Learning in and about the virtual neighbourhood}

The Dutch language courses provided at the centre that used this application are split in two: Dutch Language (Nederlandse Taal) and Integration (Inburgering). The Dutch Language course is further divided. The first course is for Dutch language skills for learners of Dutch. The 
second aims at the improvement of reading and writing skills for learners who have Dutch as their mother tongue. The integration course is for newly arrived migrants on an integration trajectory. The preparation for the integration exam has a multimedia component where the learner 'learns the Dutch language with the help of exercises and films on the computer', and implies that learning through a computer can be carried out both in class and at home. The classroom, on the other hand, is pictured as a place for formal learning where learners get the chance to try out their Dutch in short dialogues with other learners, as well as by dealing with the vocabulary of everyday life situations. Learners preparing for the integration exam are assigned to a profile that is meant to correspond with their route to integration. This profile is determined during the learner's initial assessment at the centre. For each profile there is a matching method for learning Dutch. As stated in the school's introduction booklet:

in order to be integrated students must learn the Dutch language and build knowledge of Dutch society. Integrating means being able to function in practical situations, like - for instance - a talk with your GP, with a teacher or with your employer.

If the learner wants to work, she or he is assigned to the profile Inburgeren en Werk (Integration and Work). She or he then uses the method Nederlands aan het werk (Dutch at work). If the learner is engaged in child rearing and home-related activities then she is assigned to the profile Inburgeren en OGO (Integration and Pedagogical Support). At the time of this study, it was assumed that only women would be accessing this profile.

The following insights were gathered from focus group interviews which the first author had with 15 users of this application during their integration trajectory. A first obstacle when trying to obtain optimal results from this ICT application is its technical implementation. In the lesson observed, the teacher's own knowledge of this application is sound. She first introduces her students to a video that deals with the task that they are attempting during the lesson, i.e., using the municipal library and stimulating their children to read. Furthermore, the teacher uses this video as a basis for questioning her students about what they will be doing in the Virtuele Wijk. However, this well-thought-out lesson fails technically in that the application does not recognise the postcode of some of the students, who are led to a different library rather than to the municipal library in their neighbourhood. Setting this aside, when students are engaged in responding to the prompts given by the Virtuele Wijk, it emerges that the activities do not enable them to develop communication and pronunciation skills. In an interview with Amar and Sera, both refugees from Iraq who came to the Netherlands 11 and 13 years ago, 
and Rana, who originates from Afghanistan and who came to the Netherlands 12 years ago, we hear the following:

Amar: $\quad$ I use it [Virtuele Wijk] for all sorts of things, also for Dutch.

Rana: Yeah, yesterday, yesterday, you know, yesterday I used it for the exercises of the integration program, but I love talking and with Virtuele Wijk you cannot talk.

Sera: Yeah.

Rana: And also the accent counts, we cannot practise accent and then when we talk, we are foreigners, it is a matter of accent, they don't understand.

Tamusa and Arzoo are tangible proof of this. Tamusa came to the Netherlands for the first time in 1999 because of her husband's job and she was scheduled to complete her integration trajectory and sit for an exam in 2010. Arzoo arrived in 2002 as a refugee from Afghanistan; she is Russian speaking and she is now following an integration trajectory which she too was scheduled to complete in 2010. Tamusa adds:

You can read a lot with the Virtuele Wijk. Me and Adela [another Russian speaking student in this class], we read, we read but speaking, well you cannot really and the answer is already there, so you try to understand but speaking just does not happen.

Tamusa, Arzoo and Muhlise feel they have to learn both questions and answers by heart in order to achieve the language interaction goals of the application. This learning by heart does not provide the opportunities needed to actively produce language, and so does not contribute to the development of their oral competence and vocabulary growth. During the focus group discussion, they report the following:

Tamusa: This unit about the library was easy. I know it well.

Muhlise: Yes, yes, we know the language of the library. We go there with our children.

Tamusa: Yes.

Muhlise: But the insurance company was difficult, very difficult.

Arzoo: $\quad$ Yes, the language was difficult, the terms were weird.

Finally, the students point out that when they were given the opportunity to work with the Dutch language, they gravitated towards grammar. Grammar gives them security in that for them grammar 'is either right or it is wrong'. What this application brings to the learners is therefore paradoxical. While the application is intended for the development of language skills in real-life situations, its aims are regarded as ambiguous 
by the learners. It is not always clear to them how the language introduced in the application relates to the real life situations they encounter, and whose language demands they need to meet. Nor is it clear to them whether the answer is right or wrong, unlike the activities that they carry out which practise grammar.

\section{The innovative application: NT2 Nieuwslezer}

We now move to the third and last application. This is a demonstration of how the development of ICT for L2 can become more than solely digital based, and can focus on adaptive learning. The NT2 Nieuwslezer (the Dutch as L2 Newsreader) is a direct outcome of research carried out at the University of Tilburg. Research has demonstrated that both young Dutch people and (newly arrived) migrants can reap enormous benefits in the development of the breadth and depth of their vocabulary by reading articles taken from newspapers on a daily basis (van der Werf et al. 2008; van der Werf and Vermeer 2008). To be of benefit, such newspaper articles should not be older than 24 hours, but nonetheless can deal with any topic. It is then up to the user to choose which article she or he wishes to read. The NT2 Nieuwslezer selects texts automatically and decides which level of language proficiency these texts are suited for. The NT2 Nieuwslezer then selects and adapts the articles that learners are given access to. This access is established on the basis of a test that learners carry out before opening the application. This test measures both their reading proficiency and vocabulary knowledge. When the learner encounters an unknown word, the application supplies a short explanation of the word's meaning as well as its translation. In this way, reading articles about current affairs in mainstream Dutch society not only stimulates an increased vocabulary but also motivates the migrant to build knowledge of Dutch culture. The Ministry of Home Affairs in 2010 selected the NT2 Nieuwslezer as one of the ten most successful innovations in the Public Sector (EDIA 2010).

\section{On being 'computer very very literate'}

Here follow the views gathered from two learners who used the NT2 Nieuwslezer in 2008. The interviews with the learners took place in English. The first learner, Harry, came from Colombia to the Netherlands in 2008. He is a qualified veterinarian who has now started his own business as a photographer and graphic designer. He reports that because of his job he can do almost anything with a computer, specifically with graphics and animations. On the NT2 Nieuwlezer he says: 
The news items were not interesting because they did not match what I was looking for, I am searching for technical vocabulary for design and photography.

Yet this lack of specialist vocabulary contrasts with a more positive opinion that focuses on what he has achieved through this application:

I think it is a good tool in as much as it allows you to learn a lot of new words but it has to be subject specific.

The second learner, Goodluck, comes from Nigeria and has worked in the field of international development for more than a decade. He used to live in New York and now runs a web-based development organisation. $\mathrm{He}$ is in the Netherlands because of his wife's job. In expressing his insights about this third application, Goodluck states:

I think it was good. It was good because I could read and learn about where I live and what people do. There is some crazy stuff out there man. But I liked it and I did not have to ask for help when I was studying.

He mainly focuses on the autonomy that a learner achieves by using the NT2 Nieuwslezer. Autonomy in learning a language is relevant to ICT and L2 learning at large. He says:

If you are not computer literate then you are gonna find a problem. You will be confronted with how to do two things at the same time, studying how to use a keyboard, and then I tell you, if I don't know how to use a keyboard then I have difficulties. And sometimes, one is just confronted with the basic difficulties or better the basic challenges of learning. I have a very great advantage, I am computer very very literate. More than average of course because I write, so when you have that advantage you are able to listen and to concentrate on the language. It is not appropriate to go to the class for me. I am gonna save time, I am gonna exercise judgment, be independent. I don't want any friction in terms of human relations, I can go on and on. So I think, this for me is perfect. Then people can learn two, three languages. I prefer to learn the basics and expand before I go to the class. If there is a book the book is pronouncing it for you but here you have a button, you can click on it. The computer is very perfect but they [other learners] should be exposed to computers first, then to language then go to the classroom.

Goodluck first focuses on computer literacy, on the lack of these skills, and on the consequences that this might have for someone learning a 
foreign language. In his view a learner has to master these skills first and then she or he can move on to working on language skills. He also suggests a pedagogy that sees people starting with the computer, grasping a language through ICT and then coming into the classroom. He, in fact, is working on his own, in front of the PC all the time. He is well aware of his computer literacy and general literacy, as he reports being 'very very literate'. It is open to question whether Goodluck's approach - an approach which seems to align well with the application - would suit all students: although the application is adaptive to leaners' level of competence, not every learner is able to manage an independent approach to learning in the way Goodluck and Harry do.

\section{Conclusions and discussion}

As we have shown, migration, integration and ICT merge into what Appadurai has described as a global technoscape (Appadurai 1996). This is a world where migrants need to handle increasingly complex systems of information that allow them to participate in multiple communities, communities where inclusion is understood in different ways. Rather than being something formal, stable and related to the start of a new life in the host country, learning to become an integrated citizen turns out to be part of a continuous cultural and linguistic encounter that the migrant has to negotiate in order to function within the overlapping socio-cultural, socio-economic and socio-political spaces that she or he inhabits.

The three applications we have examined here demonstrate the emergence of a number of features that characterise ICT and Dutch as second language learning. The first is the continuously evolving face of ICT. The first application showed an example of digitalised learning, the second of contextualising learning, and the third, and most recent, of adaptive learning.

There is also the co-option of ICT into a particular institutional discourse. This relates to a tendency to respond to cultural and linguistic diversity and difference from the mainstream by developing a culture of drilling and control over someone's identity and someone's conduct in society. In this account language learning and learning mainstream norms and values are viewed as pivotal to success in the host culture. While such a reaction may be difficult to avoid, we need to bear in mind that ICT is not a fast track to integration. We also bear in mind that migration can no longer be considered as a linear move from home country A to host country B, and with no further links to country A. It is thanks in part to ICT, indeed, that migrant networks have become more mobile, and less anchored to the host country, rendering integration a flexible and dynamic activity. 
In acknowledging this, educators and policy-makers alike still need to be aware of classroom processes and of differences in literacy and e-literacy competence among migrant language learners. They still need to ask: 'is this application too inaccessible for a student?', 'What does this tell me about what the student can realistically achieve?' and - in terms of learning through ICT: 'what has my student actually learnt from the application, through the clicking, through the feedback received?' As Snyder and Prinsloo (2007: 174) warn us, the logic of bridging the gap in the digital divide often 'overemphasises the importance of the physical presence of computers and connectivity to the exclusion of other factors that allow people to use electronic media for meaningful ends'.

The results of these three case studies leave us with one last consideration. No set of rules and procedures can solve the personal linguistic, cultural and ethical dilemmas people face in their lives as migrants: they can only highlight them. What is needed, in our view, is a profound reflection on the ethics of what is asked of migrants, of how authorities engage in relationships of trust and fostering of civic responsibility with newcomers. There are forces in society that define living in a receiving country as a purely professional set of activities, revolving around clear lists of procedures and standardised criteria of performance, and assessment as focusing upon the replication of uniform patterns of conduct that lead to integration. The weaknesses of this view are eloquently demonstrated every day.

\section{References}

Appadurai, A. (1996) Modernity at Large. University of Minnesota Press: Minnesota. Commission of the European Communities (2005) i2010: A European Information Society for Growth and Employment (SEC(2005) 717). Brussels: European Commission.

Driessen, M., van Emmerik, J., Fuhri, K., Nygren-Junkin, L. and Spotti, M. (2011) ICT for Learning the Host Country's Language by Adult Migrants in the Netherlands and Sweden. Report submitted to the European Commission - DG Research. Ref: J04-IS AF/sw ARES 2010, 161965.

EDIA Education Technology (2010) NT2-Nieuwslezer. Amsterdam: Boom.

European Commission (2004) Common Basic Principles on Integration. Available online at http://ec.europa.eu/ewsi/en/EU_actions_integration.cfm (accessed 4 April 2014).

European Commission (2006) i2010 - First Annual Report on the European Information Society, COM(2006)0215 - Riga Declaration on e-Inclusion. Available online at www.age-platform.eu/images/stories/EInclusion_Riga_20060611.pdf (accessed 4 April 2014).

European Commission - Director General Justice, Freedom and Security (2007) Handbook on Integration for Policy-makers and Practitioners (2nd edition). Available online at www.migpolgroup.com/public/docs/17.IntegrationHandbookII_EN_ 05.07.pdf (accessed 4 April 2014). 
European Commission - Director General Justice, Freedom and Security (2009) Handbook on Integration for Policy-makers and Practitioners (3rd edition). Available online at http://ec.europa.eu/ewsi/UDRW/images/items/docl_12892_ 168517401.pdf (accessed 4 April 2014).

ITPreneurs (2008) Thuis in Nederlands. Rotterdam: ITPreneurs.

Jansen, F., Huizinga, M., Liemberg, E., Van der Poel, J. and Tholen, B. (2010) IJsbreker 1, 2 en 3, IJsbreker plus. Utrecht: ThiemeMeulenhoff.

Snyder, I. and Prinsloo, M. (eds) (2007) The digital literacy practices of young people in marginal contexts [Special Issue]. Language E Education 21(3): 171-270.

Spotti, M. (2011) Ideologies of success for superdiverse citizens: the Dutch testing regime for integration and the online private sector. In J. Blommaert, B. Rampton and M. Spotti (eds), Language and Superdiversity. Special Issue Diversities Journal 13(2): 39-52.

Spotti, M. and Kurvers, J. (2012) Een kwestie van meedoen: Een analyse van het Nederlandse toetsregime voor integratie. In Chr. Timmerman, N. Clycq and B. Segaert (eds), Cultuuroverdracht en Onderwijs in een Multiculturele Context. Antwerpern: Academia Press, 44-59.

Werf, R. van der and Vermeer, A. (2008) Online kranten, een model van de (tweede-) taalleerder en het genereren van adaptief lesmateriaal. Toegepaste Taalwetenschap in Artikelen 80: 49-61.

Werf, R. van der, Hootsen, G. J. and Vermeer, A. (2008) Automated user-centred task selection and input modification. ITL: Review for Applied Linguistics 155: 1-22. 


\title{
English language learning for adult migrants in superdiverse Britain
}

\author{
James Simpson
}

\section{Introduction: a history of inward migration}

Over the past few decades English language learning for adult migrants in Britain has changed rather radically. Change has come in response to the variety that characterises contemporary societies: English language learners are a far more diverse group than hitherto. Change has also arisen as a result of government policies related both to how language learning opportunities for migrants are provided and funded, and more broadly to immigration itself. This chapter discusses these policies, and the ideologies, discourses and social realities that have contributed to their development.

Since the late nineteenth century Britain has experienced successive waves of migration: Jewish refugees fleeing persecution in Eastern Europe in the 1880s; escapees from German-occupied Belgium in 1915; opponents of fascism in Spain and Germany in the 1930s; and large numbers of people from across Europe in the aftermath of the Second World War (Rosenberg 2007). The mid-twentieth century saw the arrival of migrants from the former colonies who had a right to settle in Britain - particularly the Indian sub-continent and the Caribbean - in response to the post-war demand for labour. Migration today differs in range and scale from these earlier waves, at least in part due to processes of globalisation associated with late modernity (Appadurai 1996; Giddens 1999). These include increased mobility, and movement of people towards the developed west. Hence Britain in recent years has seen inward migration from places such as Ethiopia and Eritrea, Somalia, Congo, Iraq and Afghanistan, where the political and economic situation has forced people to uproot. Migration is never straightforward, however, and nor is policy. The policy response to migration has on the one hand concentrated on how to accommodate ethnic minorities through 'integration' of various kinds, and on the other on ways to control and limit it. Britain's asylum laws and curbs on non-European immigration mean that people from war-torn regions on the global periphery find it 
ever more difficult to enter the country. At the same time migration from Eastern European countries such as the Czech Republic, Slovakia and Poland has risen, a shift associated with an enlarged European Union.

Britain's superdiverse urban centres now host multilingual and multicultural populations from potentially anywhere in the world. Likewise, any particular group of adult migrants learning English will be equally diverse. Baynham and colleagues (2007), writing before the most recent expansion of the European Union, describe an intermediate-level class of English for Speakers of Other Languages (ESOL) in North London with students from Spain, Brazil, Somalia, France, Turkey, Columbia, Albania, Chad, Congo, Cyprus and India. In 2013 an equivalent class at the same college again has students from Brazil, Somalia and Turkey, but also from Yemen, Eritrea, Ethiopia, Angola and China. The profile of these classes reflects the fast-changing patterns of migration. That there are no students from the European Union also points to the various constraints faced by potential students as they attempt to find a place in an English language class. The picture also varies from city to city, town to town, neighbourhood to neighbourhood. An intermediate ESOL class elsewhere in London, or in a large regional city such as Leeds, or in a rural county like Norfolk, would most likely exhibit a very different profile.

Moreover, diversity extends beyond countries of origin and first languages claimed. In a survey of over 500 ESOL students in the same study, Baynham et al. (2007) found 58 countries of birth and 50 different first languages represented in the sample. In addition:

- 63 per cent were women; 37 per cent men.

- Just under 80 per cent were below the age of 40 .

- 14 per cent said they were unable to read in their 'first' language.

- 19 per cent had university level education.

- 28 per cent were currently in employment.

- 20 per cent had been in the UK for $6+$ years.

This chapter concerns policy response to linguistic diversity, as it relates to the provision of opportunities for learning English. Below I consider how language and migration are talked of in the political and public spheres, noting how certain ideologies inform public discourse. I then turn to the trajectory of provision of ESOL classes in England, Scotland and Wales in the second half of the twentieth century. The following section examines the Skills for Life policy, a major government initiative within which ESOL in England and Wales was located for a decade at the beginning of the twenty-first century, and its legacy for both learners and teachers. The final section takes stock of how the field of ESOL is addressing the diversity of the student population in policy and practice post-Skills for Life, and 
how ESOL as a distinct sector of adult education provision is facing a threat to its very existence.

\section{'A separateness that may be unhealthy': language and migration in political debate}

The linguistic diversity of the UK is a fact of life. Though sometimes celebrated, in much popular opinion and in political rhetoric the country's multilingualism can be a source of tension, is even presented as a threat to national unity and is usually regarded as a problem that needs to be managed - as indeed is migration itself. Moreover, the position of English in the construction of national identity, that is, the connection of the English language to the notion of 'Britishness', informs the calls in some quarters that migrants be compelled to learn English. Although Britain is very obviously multilingual, its representation as a monolingual state, or one that at best tolerates a degree of regional bilingualism in Wales and Scotland, allies with the powerful ideology of 'one nation one language' (Kroskrity 2001; Spotti 2011). The association of the national community with English is underpinned by a belief that in order for British society to be strong and stable, its population must share a common language. This ideology is evident not just in Britain of course: monolingualist discourse is a key feature of the modernist project of building nation states everywhere. And in Britain as elsewhere, this ideology stands in sharp contrast to the multilingual reality 'on the ground'.

In the twenty-first century the use of English has been associated with social cohesion in Britain, and conversely the non-use of English with social disorder. Events in the early years of the century both in the UK (street disturbances involving Asian and white youths and the police) and on the world stage (' $\left.9 / 11^{\prime}\right)$, were followed by sustained rhetoric insisting that migrants have an obligation, rather than a right, to learn English. Politicians and commentators have frequently connected the use of languages other than English, and of non-standard vernaculars, with a breakdown of social cohesion and the threat of extremism. For example, the position of the Prime Minister David Cameron in 2011 was that immigrants who don't speak English cause 'discomfort and disjointedness' in their own neighbourhoods (reported in the Daily Telegraph 14 April). This echoes a comment by an earlier Prime Minister, Tony Blair, who in the aftermath of terrorist bombings in London in 2005 said: 'There are people who are isolated in their own communities who have been here for 20 years and still do not speak English. That worries me because there is a separateness that may be unhealthy' (reported in The Guardian, 6 April). In this and other such pronouncements, it is notable that people's competence in English is talked about as a feature of difference in terms that could not usually be 
used to discuss issues such as race or ethnicity: language is sometimes used as a stand-in for other things.

In order to legitimise their discourses and to distance themselves from extreme right-wing ideologies, politicians who make the connection between multilingualism and social disorder usually couch their talk in 'liberal' terms. That is, English is necessary for everyone to access their rights, to be able to fully participate in British society and to avoid being economically and socially marginalised. This is well illustrated by Eric Pickles, the British Government Communities Secretary, who in 2013 said, 'If your kids don't have English you're condemning them to a limited life' (reported on Sky News, 15 January). An insistence that migrants have an obligation, rather than a right, to learn English is presented as a means of promoting social cohesion, as demonstrated by Ed Milliband, the opposition leader, in 2012: 'If we are going to build One Nation, we need to start with everyone in Britain knowing how to speak English. We should expect that of people that come here. We will work together as a nation far more effectively when we can always talk together' (reported on $B B C$ News, 14 December). And increasingly the use of English is seen as part of the contract immigrants enter into when they come to Britain, or even explicitly as a tool for immigration control. Nick Clegg, the Deputy Prime Minister, said in 2010: 'If they want to play by the rules, pay their taxes, speak English, that is a smart, fair effective way of dealing with immigration' (reported in the Daily Telegraph, 22 April).

Invoking competence in English in debates about Britishness strengthens a position that the nation is limited by finite boundaries, linked by a common culture and language. The reality of multilingualism in the daily lives of many, and the superdiversity and transnational movement associated with globalisation, challenges and perhaps threatens this notion. It is difficult to disagree that competence in English is important, and most people, migrants included, regard it as an advantageous resource. Its role as the language of equality and social cohesion is somewhat overstated though, and political rhetoric over-emphasises language in debates about migration and society, at the expense of a focus on the more tangible problems that beset poor minority communities.

The political stance that linguistic diversity and multilingualism (and by extension immigration) are problems to be managed is adopted in a range of debates, including those concerning the public funding of translation services, bi- and multilingual education in primary schools, and the provision of non-English language children's books in public libraries. Nowhere however does the Britishness debate rage more fiercely, nor is the role of English more contentious, than in the discussion of language requirements for immigration and citizenship. Since 2002 these requirements have in different ways involved English language classes, language testing and a 'citizenship' test - the Life in the UK test. 
When it was first introduced, this test was administered to those applying for citizenship or naturalisation. Today individuals from outside the EU have to pass it if they want to gain leave to remain in the country; in other words, it has become an obligatory test for anyone wishing to settle in the UK, regardless of whether they ultimately apply for citizenship. Tracing the trajectory of the test reveals a progressive tightening of requirements:

- 2002: According to the 2002 Nationality, Immigration and Asylum Act, applicants for British citizenship must show 'a sufficient knowledge of English, Welsh or Scottish Gaelic' and have 'sufficient knowledge about life in the United Kingdom'. The Life in the UK citizenship test is introduced: a multiple choice test taken on computer, with a pass mark of 75 per cent. Applicants who are not competent users of English have the option to follow an 'ESOL and Citizenship' course in lieu of the test.

- 2007: The same requirements are extended to Indefinite Leave to Remain (settlement).

- 2009: A 'tiered' system for immigration is introduced: points are awarded for English language proficiency.

- 2010: An English language requirement is introduced for the issuing of spouse or partner visas prior to entry into the UK.

- 2013: People applying for settlement are required to pass an English language examination at level $\mathrm{B} 1$ on the CEFR (i.e. intermediate level), in addition to the Life in the $U K$ test.

- 2013: The entitlement to take ESOL and Citizenship classes in lieu of the Life in the UK test is scrapped.

As a result English language education for migrants has become closely intertwined with policy on immigration and citizenship, and migrants and potential migrants are subject to language testing as a mechanism of immigration control (see McNamara 2012; cf Kurvers and Spotti, this volume). It is important to note that none of these strictures apply to EU citizens, making it difficult to argue that the testing is being done in the name of community cohesion.

Without doubt the relevance of competence in English is appreciated by migrants themselves, as noted earlier, though English is far from 'the only game in town'. Multilingualism, though, is generally viewed in British public discourse as a positive attribute only in a limited way. While competence in European languages and certain other languages (e.g. Japanese) is admired, the day-to-day use in the home or workplace of other languages as part of a multilingual repertoire is not valued, as the quotations from the politicians above suggest. And in England if not in Scotland or Wales there is scant attention paid in policy to the UK's 
other languages, be they historically well established or more recent. Also held in low esteem are the varieties of English that are not Standard British English. People educated through the medium of English in former British colonies in Africa, the Indian sub-continent and the Caribbean seem to cause particular problems when institutions attempt to classify them, for example when deciding which area of educational provision they 'belong' to. They are also subject to erroneous ideas about their linguistic repertoires and the varieties of English they use, which are widely regarded as being deficient. Thus migration entails not simply a shift of location, but also a move to a place where one's variety of language may be valued less highly than it was before. The inequalities faced by multilinguals and users of non-standard varieties of English become visible when monolingualist ideologies play out in practice. This happens, for example, when people are confronted with teaching and testing regimes which fail to recognise either their polylingual local environments or the diversity of their everyday language practices, and which judge them by their failure to write according to the norms of a small culturally specific (i.e. middle-class, academic, English) elite. Moreover, the preoccupation that politicians have with linguistic diversity obscures the more concrete sources of inequality in British society. In the second decade of the twenty-first century the country is far more divided by housing, wealth and income than it is segregated according to ethnicity, or indeed its proxy, linguistic repertoire (see Dorling 2012).

\section{'Anomalies, inconsistencies, unhelpful restrictions': post-war ESOL in the UK}

Despite the rhetoric from politicians supporting the learning of English by migrants, opportunities to attend English classes have never been freely available to all new-arrival adults who want or need them. There exists a contradiction: on the one hand the strident insistence in public and political discourse that 'migrants must speak English' contrasts with the denial of possibilities to do so. Behind this apparent paradox lie the issues both of the types of migrant privileged in UK migration policy, and how migrants who are English language learners are positioned within such policy. To illustrate this, we can note that free English lessons for migrants in the UK tend to come with strings attached, in that entitlement to such lessons is limited to certain categories of migrant, and that the content of those lessons is often restricted, for example to job skills-related topics. In this section I examine how the shifting understandings of the position of migrants in society in the post-war years, together with the actions of governments and policy activists, have helped to shape the nature of English language provision for new arrivals. 
The 1950s and 1960s was characterised by the implicit, then explicit, racialisation of immigration policy. Post-World War Two the vast majority of migrants to the UK hailed from the former British colonies in the Indian sub-continent and the West Indies, recruited from the home country to work in industry and the public sector, and allowed to enter the UK under the 1948 British Nationality Act. Migrants from the mid1950 s experienced racially motivated tension on Britain's streets. A policy discourse developed through the 1950s positioning the new arrivals 'coloured people' - as somehow incompatible with the British way of life and linking them to unemployment, housing shortages and crime (Carter et al. 1987). Racialised immigration control was enshrined in law in the early 1960s. 1962 saw the first large-scale immigration control in the UK, the Commonwealth Immigrants Act, introduced by the Conservative government of the time. The 1968 Act of the same name also contained an explicitly racial dimension, distinguishing between British citizens descended from British-born parents and those who were citizens because of a connection with a former or existing British colony. As Don Flynn, the Director of Migrants' Rights Network, says (2012): 'By the late 1960s these ideas of distinction and difference were embedded across the political spectrum. Whether from the mainstream of the left or the right, ethnicity was thought of as a key component of citizenship.'

By the mid-1960s immigration policy included an articulation of the need for new arrivals to learn English. In 1965 the government's Education of Immigrants pamphlet advised: 'The Secretary of State considers that, even though adult immigrants may not intend to settle permanently in this country, they should have an induction course in English ways of living and learn to speak intelligibly' (DES 1965 quoted in Rosenberg 2007: 89). Soon after, central government funding for ESOL was introduced for the first time in England and Wales under Section 11 of the 1966 Local Government Act. This provision, according to Sheila Rosenberg (2007: 92), contained 'anomalies, inconsistencies and unhelpful restrictions'. For example, despite the changing nature of the ESOL population, it was only extended beyond New Commonwealth citizens in 1993, by which time its funding had been cut substantially.

The 1970s saw an increase in the number and diversity of migrants arriving in the UK, for instance Ugandan Asians in 1972 and Vietnamese boat people in 1975. That decade witnessed not only an expansion of ESOL teaching, but also a nascent critical and activist approach among some ESOL practitioners. In 1978 NATESLA, the National Association for Teaching English as a Second Language to Adults, was founded, affording coordinated lobbying for ESOL provision on a national scale. The London Literacy Unit, established in 1980, also played a key activist role until its disbandment in 2010. Nonetheless, despite the rise of policy activism and a growing demand for English language lessons, provision 
remained ad hoc and fragmented through the 1970s and 1980s. Some areas were better organised than others, notably London, where the Inner London Education Authority (ILEA) supported much ESOL practice until its abolition in 1989.

During this period ESOL practice and materials began to better reflect the realities of the daily lives of ethnic minority migrants, as materials developers - often practitioners themselves - attempted to counter the discrimination faced by many. Noteworthy initiatives included BBC TV programs aimed at adult migrants and their teachers: Parosi (1977), for Asian women, and the series Speak for Yourself (1981). The BBC also broadcast Crosstalk (1979), produced by the National Centre for Industrial Language Training. ILT was initially funded under Section 11, and in the fifteen years from 1974 offered ESOL training and training in multicultural awareness in workplaces, as well as hitherto under-explored understandings of language as a dimension of racial discrimination (Roberts et al. 1992; Roberts 2005; Agar 1998). Although influential at the time, the work of ILT is little known by today's policy makers and practitioners.

In policy the Bullock report $A$ Language for Life (DES 1975) developed the concept of language across the curriculum; it also stressed the importance of the maintenance of the mother tongue. But funding and coordination of ESOL was still largely ignored on a national level. Dwindling and partial Section 11 funding together with piecemeal funding from the Manpower Services Commission was augmented in 1984 when the field of ESOL came under the remit of the Adult Literacy and Basic Skills Unit (ALBSU), in effect positioning of ESOL as a 'basic skill', and linking it with Adult Literacy and Numeracy. ALBSU, though limited in its effectiveness, did manage to get ESOL included in the list of courses that attracted statutory funding from the Further Education Funding Council in the 1990s by labelling it as 'vocational' (Hamilton and Hillier 2009). Its linkage in policy with adult literacy, though, contributed to the trajectory of ESOL as separate from other branches of English Language Teaching.

The identity of ESOL as a distinct field is strengthened by its position vis-à-vis immigration. That is, ESOL is viewed in public and policy discourse as 'a compensatory education program to aid the assimilation of immigrant communities into what is perceived as a traditionally monocultural, monolinguistic heritage' (Hamilton and Hillier 2009: 8). This distinctiveness is problematic: ESOL is treated differently in policy, and differs culturally, from 'international EFL'. In later years this distinction was regarded as being unhelpful (Williams and Williams 2007) or at least to an extent redundant (Baynham et al. 2007), a perspective informed by the reality of the ESOL student population in the twentyfirst century. In many cases ESOL classes began to resemble international 
EFL classes, populated as they were by relatively well-heeled and mobile European migrants as well as by people from poorer parts of the world. Yet the policy understanding of ESOL as 'different' was crystallised when the sector, after intense lobbying from practitioners, was included under the Skills for Life umbrella in 2001.

\section{'Buying control of ESOL': Skills for Life and its legacy}

Early in the first New Labour government, a review of basic skills (DfEE 1999) had recommended implementing a national strategy to reduce the number of adults with low levels of basic skills, literacy and numeracy, named Skills for Life, which was funded until 2009. ESOL was not originally included as a 'skill for life' but activists viewed its inclusion as a chance for proper funding, as well as an opportunity for professionalisation. This goes some way towards accounting for the compliance of ESOL practitioners in aligning with the policy over the subsequent decade. Yet it is argued that the marginalisation of ESOL in terms of policy and funding that continues to the present day results in part from its positioning as a 'skill' (Cooke and Simpson 2008, 2009; cf. Auerbach 1991), one which aims to prepare students for menial employment and a service role in socioeconomic structure. Employability is tightly connected to the skills agenda: if English is a 'skill', and 'skills' are deemed necessary to become employable, ESOL students will be viewed primarily in terms of how they can become more economically productive.

Establishing it as a 'skill for life' also strengthened centralised government influence on ESOL, as well as widening its separation from international EFL. Skills for Life brought with it the creation of a national curriculum for ESOL, classroom materials to support that curriculum, new teacher-training and inspection regimes, and qualifications mapped against national standards. A statutory curriculum dictates the nature of the English language education that migrants can gain access to, and the way they are positioned in formal education. As Cooke and Simpson maintain (2009: 22), 'by bringing ESOL under the Skills for Life umbrella, the government effectively bought control of ESOL.' The Adult ESOL Core Curriculum (AECC; DfES 2001) was statutory under Skills for Life, and to the present day provides a framework for syllabus planning for ESOL practitioners in England.

The AECC applied only to England and Wales. Elsewhere in the UK, ESOL in policy followed a somewhat different trajectory in the early twenty-first century. In Scotland, where there have long been settled ethnic minority communities, the demand for ESOL classes has experienced something of a boom in recent years. Glasgow in particular became host to a sizeable number of refugees seeking asylum who were removed from London and the South East of England under a program 
of dispersal after 2000. The other major rise in numbers came after the extension of the European Union in 2004 when workers started to come to Scotland from the new accession states. In addition, the strictures of the Life in the UK test apply equally to residents in Scotland, leading to an increase in demand for ESOL classes for 'New Scots'. In response the Scottish Qualification Authority (SQA) has ratified a suite of qualifications which come under the same framework as mainstream Scottish education, with levels entitled Access, Intermediate and Higher. Moreover, the ESOL Higher qualification is accepted as a university entrance level language qualification, which is particularly helpful for school-age ESOL students.

In 2007 The Adult ESOL Strategy for Scotland was introduced: its main work was to prepare a national curriculum (Scottish Government 2007). With its tradition of a 'social practices' approach to adult literacy, Scotland's curriculum is different in conception and principle to that in England and Wales, and avoids some of the problems that have attracted criticism there, namely that it is prescriptive and too skills-based. The Scottish Adult ESOL Curriculum Framework is flexible, and is oriented towards guidance rather than prescription. More recently the Welsh Government distanced itself from ESOL policy in England with the release of an ESOL Policy for Wales (Welsh Government 2014).

\section{From 'cohesion' to 'austerity': current concerns, future directions}

In 2009 the then New Labour Government signalled the end of the position of ESOL as a central component of Skills for Life. The 'New Approach to ESOL' required ESOL to be coordinated locally, at the level of local authorities and councils. Under the Conservative-dominated coalition government, from 2010 attention to ESOL in policy shifted from 'community cohesion' to 'austerity measures'. This coincided with cuts to local government funding, which severely compromised local authorities' ability to fulfil their obligations to coordinate English language provision for adult migrants. Responsibility increasingly became shouldered by the voluntary sector, where teachers are often inexperienced and untrained, centres are poorly resourced, and provision lacks cohesion (Simpson 2012).

The response to recent policy moves from practitioners and students has been vocal and at least partly effective. The Action for ESOL movement, formed in 2010 in response to that year's funding cuts, involves practitioners and students themselves. The movement lobbies for access to funded ESOL classes for a broad swathe of students upon their arrival in the UK, not just those who have been in the UK for a certain amount of time, or those in receipt of certain types of unemployment benefit. Its 
Manifesto (www.actionforesol.org) is a statement of core principles which provides a reference point for activist practitioners. A related group is ESOL-Research (www.jiscmail.ac.uk/ESOL-Research), a vibrant online discussion forum connecting ESOL practitioners over the internet. NATESLA has become NATECLA - 'English and Community Languages' - and retains a role in providing a platform for practitioner and student resistance to the excesses of policy. And NIACE, the National Institute for Adult and Continuing Education, is a somewhat critical voice speaking to policy. The practitioner response to multilingualism remains paradoxical: when they respond critically to government policy, practitioners understandably invoke the benefits of English language education in an English-dominant society. But the debates are Janus-faced: a policy privileging English language education for migrants might also preclude attention to students' expert languages. For example, while beginner literacy remains a special challenge for many new arrivals, there is still a lack of focus in policy and in practice on potentially transformative first language literacy programs for non-literate migrants.

The renewed prominence of community-based classes, often taught by volunteers, has had one possibly unintended consequence, as teachers find themselves freed from the strictures of curriculum and the bureaucratisation that plagued ESOL during the Skills for Life years. This has afforded the nascent and very welcome emergence of new Freireaninspired critical and participatory pedagogies for ESOL (see Hamilton et al. 2012; Mallows 2012; Cooke and Winstanley, this volume). These may in turn lead to the development of multilingual approaches to adult migrant language education that are appropriate for students in superdiverse contemporary Britain.

More broadly, current migration policy aligns with the dominant concern in the developed west of keeping poor migrants out. At policy level, the UK is a reluctant host state; immigrants are needed but not welcomed, and its political leaders present any fall in the numbers of inward migrants as a victory for 'tough' policies. In place, however, is a system which encourages freedom of movement for goods and capital while denying it to human beings (Harding 2012), which is inequitable from any perspective. Anti-immigrant rhetoric remains shrill, and from outside Europe in particular only certain types of migrant are favoured. Finally, when it comes to entitlement for a free state-provided ESOL class, despite the best efforts of activist practitioners and students, only limited categories of people have access.

\section{Conclusion: a more pressing material plane}

This chapter maintains that since the 1950s, ESOL students have been positioned as deficient in relation to an Anglo-dominant norm; this orientation 
is underpinned by a modernist ideology of monolingualism which is out of kilter with the daily language experience of many. At the same time, the demand to learn English has always been greater than state provision of opportunities to do so, even during the early years of the Skills for Life policy. In fact ESOL as a field has typically existed on the margins of mainstream adult education. In response, the ESOL profession has since the 1970s included a strong seam of activism, which has recently involved students themselves. I have also noted that in recent years, English language education and testing have become progressively intertwined with immigration policy: English language professionals have - usually unwillingly - found themselves involved in questionable and problematic testing practices, ones in which test scores are employed for immigration control.

Finally I have suggested that the diversity associated with globalisation presents challenges to the identity of 'ESOL' as a field. I do not propose that the sustainability of English as the dominant language of the UK is in doubt. It is clear however that the debates about the tension between a monolingualist ideology and a multilingual reality will continue to rage. Recent (and not so recent) work in Sociolinguistics and Applied Linguistics has raised critical questions relating to these tensions. For instance:

- To what extent does English fulfil the role of 'language of equality and opportunity' that is so often claimed (Pennycook 2007)?

- Do the varieties of English used in the English-speaking west (e.g. Standard British English) continue to be ascendant (Kirkpatrick 2010; Canagarajah 1999)?

- In the superdiverse globalised world is it more appropriate to consider language in terms of individuals' communicative repertoires, rather than languages understood as discrete entities (Gumperz 1982; Blommaert and Backus 2011)?

Meanwhile, however, contemporary Britain is witnessing a shift to a more pressing material plane, invoking work and housing, and the inequalities inherent in these domains. Such concerns, rather than deliberations about language, tend to be at the forefront of migrants' minds.

\section{References}

Agar, D. E. (1998) Language Policy in Britain and France. London: Continuum.

Appadurai, A. (1996) Modernity At Large: Cultural Dimensions of Globalization. Minneapolis: University of Minnesota Press.

Auerbach, E. (1991) Politics, pedagogy, and professionalism: challenging marginalization in ESL. College ESL 1(1): 1-9.

Baynham, M., Roberts, C., Cooke, M., Simpson, J. and Ananiadou, K. (2007) Effective Teaching and Learning ESOL. London: NRDC. 
Blommaert, J. and Backus, A. (2011) Repertoires revisited: knowing language in superdiversity. Working Papers in Urban Language and Literacies. King's College London, Paper 67.

Canagarajah, S. (1999) Resisting Linguistic Imperialism in English Teaching. Oxford: Oxford University Press.

Carter, B., Harris, C. and Joshi, S. (1987) The 1951-1955 Conservative Government and the racialisation of black immigration. Policy Papers in Ethnic Relations 11. University of Warwick Centre for Research in Ethnic Relations. Available online at www2.warwick.ac.uk/fac/soc/crer/research/publications/ policy/policyp_no.11.pdf (accessed 16 December 2014).

Cooke, M. and Simpson, J. (2008) ESOL: A Critical Guide. Oxford: Oxford University Press.

Cooke, M. and Simpson, J. (2009) Challenging agendas in ESOL: skills, employability and social cohesion. Language Issues 20(1): 19-30.

Cooke, M. and Simpson, J. (2012) Discourses about linguistic diversity. In M. Martin-Jones, A. Blackledge and A. Creese (eds), Routledge Handbook of Multilingualism. London: Routledge.

Department for Education and Employment (DfEE) (1999) A Fresh Start - Improving Literacy and Numeracy (The Moser Report). London: Basic Skills Agency.

Department for Education and Skills (DfES) (2001) Adult ESOL Core Curriculum. London: Basic Skills Agency/DfES.

Department of Education and Science (DES) (1975) A Language for Life. London: Stationery Office.

Dorling, D. (2012) Editorial - inequality and injustice: some news from Britain. Urban Geography 33(5): 621-629.

Flynn, D. (2012) Marking 50 years of Commonwealth Immigration Controls. Available online at www.migrantsrights.org.uk/blog/2012/01/marking-50-years-common wealth-immigration-controls (accessed 16 December 2014).

Giddens, A. (1999) Runaway World: How Globalization is Reshaping Our Lives. London: Profile.

Gumperz, J. (1982) Discourse Strategies. Cambridge: Cambridge University Press.

Hamilton, M. and Hillier, Y. (2009) ESOL policy and change. Language Issues 20(1): 4-18.

Hamilton, M., Tett, L. and Crowther, J. (eds) (2012) More Powerful Literacies. Leicester: NIACE.

Harding, J. (2012) Border Vigils. London and New York: Verso.

Kirkpatrick, A. (ed.) (2010) The Routledge Handbook of World Englishes. London Routledge.

Kroskrity, P. (2001) Language ideologies. In J. Verschueren, J-O Österman, J. Blommaert and C. Bulcaen (eds), Handbook of Pragmatics. Amsterdam: John Benjamins.

Mallows, D. (ed.) (2012) Innovations in English Language Teaching for Migrants and Refugees. London: British Council.

McNamara, T. (2012) Poststructuralism and its challenges for applied linguistics. Applied Linguistics 33(5): 564-581.

Pennycook, A. (2007) The myth of English as an International Language. In S. Makoni and A. Pennycook (eds), Disinventing and Reconstituting Languages. Clevedon: Multilingual Matters, 90-115. 
Roberts, C. (2005) Teaching English to speakers of other languages (ESOL) in the workplace. In E. Hinkel (ed.) Handbook of Research in Second Language Teaching and Learning. New Jersey: Lawrence Erlbaum Associates, 117-136.

Roberts, C., Davies, E. and Jupp, T. (1992) Language and Discrimination. Harlow: Longman.

Rosenberg, S. (2007) A Critical History of ESOL in the UK, 1870-2006. Leicester: NIACE.

Scottish Government (2007) The Adult ESOL Strategy for Scotland. Available online at www.esolscotland.com (accessed 16 December 2014).

Simpson, J. (2012) 'Bits here and there' - fragmented ESOL provision in Leeds. Language Issues 23(2): 32-45.

Spotti, M. (2011) Modernist language ideologies, indexicalities and identities: looking at the multilingual classroom through a post-Fishmanian lens. In Li Wei (ed.) Applied Linguistics Review, 29-50.

Welsh Government (2014) English for Speakers of Other Langauges (ESOL) Policy for Wales. Available online at http://wales.gov.uk/docs/dcells/publications/140619esol-policy-en.pdf (accessed 16 December 2014).

Williams, E. and Williams, A. (2007) ESOL and EFL: An Unhelpful Distinction. Reading: CfBT Education Trust. 


\title{
Chapter 16
}

\section{Whose integration?}

\section{A participatory ESOL project in the UK}

\author{
Melanie Cooke, Becky Winstanley and \\ Dermot Bryers
}

\section{Introduction}

We are the people who live in this country. We are the community. You understand?

If we have education, we have eyes, we can see the world.

These words, spoken by two Bangladeshi students in London, point to several themes underlying the work we describe in this chapter. The first is the struggle in which many migrant communities are engaged for recognition and equality. The second is the importance of access to educational spaces within which they can explore their common experiences and develop the skills they need to engage in this struggle. We describe a small but growing movement of teachers involved in participatory approaches to language education who are working with students of English for Speakers of Other Languages (ESOL) on these issues in their classrooms. Inspired by the writing of the Brazilian Marxist educator Paulo Freire in books such as Pedagogy of the Oppressed (1972), and others such as Elsa Auerbach in the USA, participatory approaches to ESOL critically explore the shared concerns and resources that learners bring to the classroom. As an integral part of language and literacy development, participatory approaches involve reflection on the material conditions of learners' lives and experiences and, where appropriate, involve students in action to effect change. As such, although not by any means new in itself, participatory pedagogy is a radical departure from current mainstream ESOL practice in the UK (Simpson this volume; Cooke and Simpson 2008).

Most teachers in mainstream state-funded ESOL provision in England and Wales are required to prioritise institutional and bureaucratic demands such as assessment regimes, audit and inspection and a centralised curriculum. For this reason, participatory approaches have tended to be adopted in classes held in the voluntary and charity sectors. 
However, in recent years a growing number of practitioners in the UK have attempted to implement participatory approaches within mainstream settings. In this chapter we focus on projects which took place in both contexts. We begin the chapter with a brief description of the main features of participatory pedagogy and how it has been adapted for the teaching of ESOL to adults in the UK, mentioning in passing earlier projects which have helped to promote the approach in that country. Our main focus is a project called Whose Integration? (Bryers et al. 2013) which we present as an example of an 'emergent' syllabus. We end with some reflections on the strengths of participatory approaches in contrast to dominant ESOL practices, and their potential for language and literacy development and social action.

\section{Participatory ESOL in the UK}

Participatory pedagogy has been practised by a minority of educators in the UK since the 1970s, particularly in the teaching of adult literacy, and was advocated for the teaching of ESOL in the 1980s (see for example Baynham 1988). It has only recently, however, been taken up seriously by a number of ESOL educators around the UK, thanks largely to the efforts of Reflect ESOL, a program initiated by the international charity, Action Aid (see Moon and Sunderland 2008). Reflect ESOL itself was inspired by a literacy program which is used extensively in developing countries (see for example Archer and Newman 2003). In sharp contrast to current mainstream approaches which require a pre-designed syllabus (the scheme of work), Reflect ESOL advocates that participants set their own agenda, devise their own learning materials, take action on the issues which they identify as important and evaluate their progress and the effectiveness of their programs as they go along. The syllabus, therefore, is not brought along by the teacher but rather emerges from class to class; the direction of the instructional process is, as Auerbach (1992: 19) puts it, 'from the students to the curriculum rather than from the curriculum to the students'.

In order to achieve some of these aims in ESOL, we as participatory practitioners use various techniques adapted from Reflect and other traditions. For example, in order to draw out the knowledge of students and to facilitate meaningful dialogue, we create a representation of a theme that is important to the group in the form of a drawing or a photo, video or audio recording. These codes, as they were called by Freire, can then be understood and analysed by using problem-posing, a technique which helps a group to arrive at a deeper understanding of an issue (we discuss these below in the section about Whose Integration?). We also use participatory tools developed by Reflect ESOL, for example, graphics such as community maps, trees (for exploring the roots and consequences of a problem), rivers 
(for exploring narratives or the chronology of a series of events), icebergs (for exploring what lies beneath the surface of an issue) and so on. The joint construction of a graphic involves extended discussion about a key issue in the learners' lives and generates vocabulary, grammar and discourse which then comprises the emergent language syllabus. Additionally, as trained language teachers, we regularly use standard techniques such as process and group writing, tasks which focus on linguistic form, and games and other activities which foster a safe inclusive learning environment.

\section{Emerging Worlds, Emerging Words}

A growing number of practitioners in the UK use a broadly participatory approach in their teaching, although it is probable that many do this only to some extent, using the tools and techniques occasionally rather than as a wholesale approach to their courses. However, one Reflect action research project, published as Emerging Worlds, Emerging Words (Winstanley and Cooke 2015), was an attempt by a group of ten teachers in colleges in London to design their entire courses along participatory lines. These teachers were all, to a degree, dissatisfied with some of the practices expected of them in their workplaces and felt that these tended to constrain and silence students. A pre-written scheme of work, for example, does not offer a means of exploring topics which arise during the course or issues which are directly affecting students. The teachers had a strong intuition, born of experience, that basing lessons around students' own concerns would foster higher levels of motivation, and consequently more effective language and literacy learning. One of the main objectives, then, was to explore alternative, participatory ways of planning ESOL courses and lessons, to develop a scheme of work which emerged rather than one which was pre-determined, and to observe the impact of this on language development, teacher/learner hierarchies and evaluation.

During the project the teachers therefore set aside their usual syllabuses and instead documented three areas as they emerged in the course of the lessons:

- $\quad$ emerging topics (what they were and how they arose);

- emerging language and literacy (what spoken and written language students produced);

- $\quad$ emerging action (changes which occurred e.g. shifts in power relations in the class; any social, political or community action the participants took as a result of their discussions).

The project produced a large, rich set of data, observations and reflections which we have written about more fully in Winstanley and Cooke (2015). Obviously, there was a variety of stances amongst the teachers and no 
unanimous agreement about everything which occurred during the project; some, for example, found this a demanding way of working which needed a lot of thinking about in advance whilst others, although committed to the approach, had to abandon it to prioritise preparation for exams. Some general points on which we did agree though can be summarised as follows:

- Our ESOL classrooms came to be regarded as 'discourse communities' in their own right, rather than as mere rehearsals for the world outside the classroom.

- By working collaboratively with visual tools, students were able to build communities in which everyone contributed, even those who were less confident readers, writers and speakers of English.

- Topics and themes which arose from students' concerns appeared to generate a higher degree of involvement than those chosen in advance by the teacher.

- Language produced by students - both spoken and written - was more complex and of a higher 'level' than the designated level of the class. The texts students wrote arose directly from their own needs: for example the Action for ESOL campaign (see Simpson this volume) required the production of minutes, posters, reports etc. We observed that when writing for an urgent purpose such as this, students lost their anxiety about spelling, punctuation and grammar but at the same time created texts which were more accurate.

- At some points the hierarchy normally present between teachers and students was broken down, especially when we were all engaged in the same objectives. For example, when teachers and students were all involved in the Action for ESOL campaign against funding cuts we were engaged in the same discussions and debates and needed to produce the same types of texts for our meetings, the media, for lobbying and so on.

- Some of the topics which emerged were highly political or personal in nature. Rather than avoid these themes we allowed them to become central to our lessons. In this way we acknowledged that the majority of our students come from working class communities with genuine hardships which they wish to explore and that many of them are politically aware and engaged citizens.

\section{Whose Integration?}

These observations formed the basis for the design of a subsequent project, Whose Integration? which was funded by The British Council and carried out by a small London-based charity, English For Action (www. efalondon.org). Whereas Emerging Worlds, Emerging Words spanned a 
whole academic year, involved a number of teachers and was largely exploratory, Whose Integration? lasted only 5 weeks and involved just two classes. By working with a specific theme and with tools and techniques we were by now familiar with, Whose Integration? allowed us to sharpen our focus and to research more closely a concrete, time-bound example of participatory ESOL in action.

The aims of the project were, firstly, to examine the theme of integration from the perspective of ESOL students, i.e. to discuss with them aspects of a debate which is about them but about which they are rarely consulted. Secondly, we set out to explore the efficacy of participatory teaching methods when used to address a theme of this kind in the classroom. In this chapter we are concerned primarily with our pedagogic approach rather than the theme of integration itself, although of course theme and method are tightly linked. In particular, we discuss in some detail how we worked with a syllabus which emerged as the course unfolded. As we suggested above, we consider this to be one of the defining features of participatory ESOL and, along with the essential political nature of the approach, one which distinguishes it from more mainstream approaches.

We carried out Whose Integration? in two different classroom contexts: a class at a large publicly funded college of Further Education in East London, Tower Hamlets College, and a community class in a children's centre in Greenwich, South London, set up by English for Action, a charity which does not receive statutory funding. The Tower Hamlets class was largely made up of intermediate level Bengali and Somali students, the majority of whom were legal residents in receipt of state benefits and with recourse to public funds, whilst the community-based class was quite heterogeneous in terms of language level, social class, immigration status and country of origin.

Whose Integration? was not planned in detail in advance, although we did have some idea about the linguistic elements that might emerge, probably the language of discussion and debate. As we argue above, we consider that the very nature of advanced planning implies that control of classroom topics and 'target language' lies exclusively in the hands of the teacher. We did, however, follow an over-arching process that guided us in our week-by-week emergent planning which we divided into three stages, and which we describe briefly here.

\section{Stage I: making meaning}

The first two sessions, which we later named the 'making meaning' stage, aimed to be as open as possible and to allow students to generate their own ideas and share their experiences and opinions without being exposed to other material first. This is in contrast to practices in mainstream ESOL classes in which 'input' material is usually brought 
along by the teacher, meaning that students are required to respond to and interpret the ideas of others without first being given the space to explore their own. This is common-sense practice in ESOL and few practitioners seem to question it; furthermore, classroom texts are not often held up to critique, and the ideological stances encoded within them are rarely made explicit.

In the first stage, therefore, rather than 'input' materials we used tools and techniques which allowed students' own thoughts and ideas about integration to be generated first. These included, amongst other things, asking students to choose a picture and say what it suggested to them about integration and creating a 'card cluster' of words and concepts associated with the term. A card cluster is a way for a class to pool knowledge and to lay out the elements of a particular issue. Each student is asked to write three different things about the topic onto cards, e.g. information, opinion or personal experience. These are then clustered into themes and a summary of the statements is created. The activity provides a wealth of opportunities for language development work, as well as themes for further exploration. Inevitably at the beginning stage of the project, students struggled with the topic of integration and frequently asked us for a definition; the initial exploratory discussions, however, flowed without too much direction from the teachers and laid the ground for the subsequent sessions, 'going deeper' and 'broadening out', in which we explored together the problems of defining such a complex term.

\section{Stage 2: going deeper}

The second stage, sessions three and four, we termed 'going deeper'. In this phase we selected those topics which had emerged in the 'making meaning' stage which were complex or urgent and which had generated strong opinions and feelings. The tools used, such as problem-posing around a code, served to provoke in-depth discussions in which students explored the underlying causes of some of the emerging issues and were challenged to imagine alternatives to problems. In this stage students and teachers were engaged in dialogue about serious topics related to integration, i.e. gender, multiculturalism, religion and culture, and we were required to test the strength of our ideas and to explain, analyse and justify our views. This stage was arguably the most powerful and productive in terms of the development of language, critical thinking, argumentational skills and the understanding of alternative perspectives.

\section{Stage 3: broadening out}

The final stage, 'broadening out', introduced texts on the topic from outside the classroom, including quotes from politicians talking about integration 
which were in marked contrast with the students' own stances on the theme. It was a deliberate choice to hold back these 'expert' opinions until the students were comfortable with the topic and familiar with some of the major arguments in the debates. We observed that the way in which students approached the texts and critiqued the politicians' opinions demonstrated that they now had a sense of ownership of the debates and developed their thinking during the process; arguably, students would not have engaged with these texts with the same authority and expertise had they been presented with them at the beginning of the course.

\section{What emerged}

Although the process we followed in Whose Integration? was relatively structured, neither the themes nor the 'target language' were designed in advance. It was particularly telling that although both groups followed the same process and made use of the same participatory tools, the language and topics which emerged over the five weeks were quite different; for example, racism was a recurring theme for the community group in Greenwich and less so for the Tower Hamlets group, perhaps because many of the students in the Tower Hamlets class live in large 'settled communities' where everyday racism and hostility can seem less of a problem. In addition, we would argue that very few, if any, of the emerging themes could have been slotted into a traditional ESOL scheme of work; they were either large concepts such as 'the meaning of culture', 'the role of religion in schools' or 'generational change within communities' or small snippets of people's lives such as how to tie a headscarf. By way of example, we include here a brief description of a theme which emerged which none of the teachers could have predicted but which caused a long, in-depth discussion amongst students and came to form a key part of the Whose Integration? project.

\section{She's gone modern: problem posing with a code}

Just before session three at Tower Hamlets College, there had been an animated discussion about women riding bicycles and the students had brought up various tensions, particularly in relation to cultural expectations of local Bangladeshi women. They coined the term 'gone modern' to describe women who challenge what is expected of them by conservative elements in their community. Although this was not a topic we could have predicted, it was clear that students wished to explore it further. We decided to represent 'gone modern' as a code. This was a drawing which we, the teachers, made of a woman in a hijab cycling past disapproving 'community leaders' (Figure 16.1). We then explored the underlying meanings of the code using problem-posing questions. 


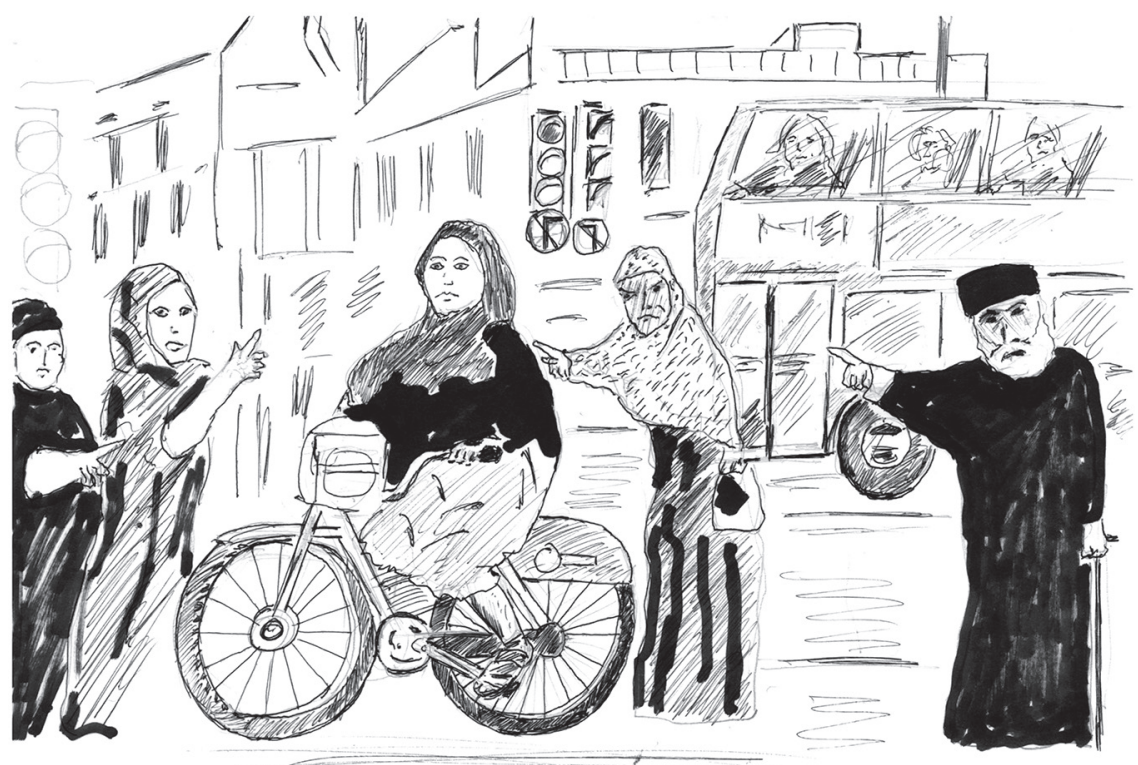

Figure I6.I 'She's gone modern'

Problem posing questions are graded and stimulate a deepening analysis of the code. The questions are posed by the teacher/facilitator and the discussion takes place among the group of participants. The technique works by edging the discussion deeper and deeper in a systematic way rather than a free-for-all open discussion. Auerbach (1992) suggests five stages:

1 Describe the content - what do you see?

2 Define the problem.

3 Personalise the problem.

4 Discuss the problem.

5 Discuss the alternatives of the problem.

This systematic questioning led to an hour-long exploration and negotiation of ideas and generated a large amount of language as well as a high level of participation and engagement from the whole group, and led in turn to further - sometimes heated - discussions about gender and the role of tradition in some communities.

\section{Language development in Whose Integration?}

During the 'gone modern' debate, and other similar discussions, we observed students developing important strategies for arguing, getting 
their voices heard and listening to others' points of view. Although our main focus was to explore students' opinions and feelings about integration itself, students' language development was also inevitably a focus. Of the observations we made, a striking one was that students produced complex language (both thematically and linguistically) which went far beyond the level ascribed to them upon enrolment. For instance, by the end of the course students were able to analyse and critique genuine samples of political texts in English (see Bryers et al. 2013: 24).

We also observed that students were especially open to explicit instruction when they needed particular strategies to help them participate more effectively in their debates. At the same time as we were having discussions with students about serious issues, we were also having 'discussions about discussions' e.g., about equal participation, strategies for taking the floor, putting forward a point of view, agreeing and disagreeing and reaching a compromise. There was evidence of students using discourse strategies they had been taught explicitly when the need arose, such as restating and then countering an opponent's arguments ('so what you're saying is ...'), and partially agreeing before moving on to a more fundamental disagreement ('well, I see what you mean but ...'). In the 'gone modern' debate we describe above, students employed a number of strategies for getting their voices heard, justifying an opinion in the face of criticism from other members of the group and - sometimes reluctantly - accepting someone else's viewpoint.

\section{A shared lexicon}

Another observation concerned the lexical development of students. The meanings of new words were often negotiated with the class and not provided by the teachers. For example, in a discussion about the difference between prejudice and stereotype, we all put forward a working definition. In contrast to the teachers' attempts, a student's definition was by far the most useful and accurate: 'stereotype comes from outside' she explained. 'Prejudice comes from inside. You use stereotype to example your prejudice.'

We also noticed the emergence of what we came to see as a shared lexicon: words and expressions which were born during our discussions and which reappeared in subsequent lessons. In week 1 the phrase 'leave at the door', came up in relation to culture and religion and what you can and can't talk about in different situations. As we have already seen, in the second week 'she's gone modern' emerged, a phrase that was recycled throughout the course and even entered the teachers' lexicon for a while. From Greenwich we got the term 'open gates' to refer to the opposite of 'barriers' to integration. As we stated earlier, in our work in participatory ESOL we have come to view the ESOL classroom not as a rehearsal for 
the outside world but as a community of practice in its own right. Coining phrases and recycling language seemed to reinforce the bond of the group, in the ongoing development of our own speech community. It sent the message that students could be creative and innovative with language and that the teachers could learn language from the students. The new phrases were also brought to and from the two classes via the teachers, as well as on a shared blog, and created a form of dialogue between the groups.

\section{Conclusion}

It has long been recognised that an effective ESOL class reflects the lives and experiences of students (Auerbach 1992; Baynham 2006; Cooke 2006). Our projects extend this concept further and show that the participatory ESOL class itself is an important part of students' lives and is not just a rehearsal for life outside the classroom. As such, we suggest that it can play a part in shaping the life experiences of those who participate, and importantly, this can be done on students' own terms. At a time when speakers of other languages are being positioned in political and popular discourse as either unwilling or unable to participate fully in democratic processes, our work has suggested to us that the converse is true. During the two projects we have reported on in this chapter, we noted that the intensity of discussion in the classroom led some students to stimulate the same debates at home and with friends, and as teachers we found ourselves discussing the issues which arose in class long after the sessions were over.

Taking part in class discussions about serious contemporary issues such as integration - of which ESOL students are often the referents, but about which they are rarely asked their opinions - allowed students to develop skills which are immediately transferable to life outside the classroom. In our conversations with students towards the end of this course they told us they felt they were much more likely to take part in discussions going on around them, and even to initiate or lead them. 'Participation' in genuine democratic processes requires that citizens partake in debate and have their voices heard, and education has long been seen as a forum for enabling people to acquire the skills to do this successfully. We hope that Whose Integration? went some way in supporting our students - and indeed us as teachers - to develop and extend these skills.

\section{References}

Archer, D. and Newman, K. (2003) Communication and Power: Reflect Practical Resource Materials. Action Aid/CIRAC. Available online at www.actionaid.org. 
uk/sites/default/files/doc_lib/190_1_reflect_full.pdf (accessed 22 December 2014).

Auerbach, E. R. (1992) Making Meaning Making Change: Participatory Curriculum Development for Adult ESL Literacy. Washington: Center for Applied Linguistics/ ERIC.

Baynham, M (1988) Action and reflection: the Freirean argument in ESL. Language Issues 2(1). Reproduced in R. Bhanot and E. Illes (eds) (2009) The Best of Language Issues. London: LLU+, 409-419.

Baynham, M. (2006) Agency and contingency in the language learning of refugees and asylum seekers. Linguistics and Education 17(1): 24-39.

Bryers, D., Winstanley, B. and Cooke, M. (2013) Whose Integration? ESOL Nexus, British Council. Available online at www.kcl.ac.uk/sspp/departments/education/ research/ldc/publications/workingpapers/abstracts/WP106-Whose-integration. aspx (accessed 22 December 2014).

Cooke, M. (2006) When I wake up I dream of electricity: the lives, aspirations and 'needs' of adult ESOL learners. Linguistics and Education 17(1): 56-73.

Cooke, M. and Simpson, J. (2008) ESOL: A Critical Guide. Oxford: Oxford University Press.

Freire, P. (1972) Pedagogy of the Oppressed. New York: Continuum.

Moon, P. and Sunderland, H. (2008) Reflect for ESOL Evaluation: Final report. LLU + at London South Bank University and Action Aid. Available online at www.reflect-action.org (accessed 22 December 2014).

Winstanley, B. and Cooke, M. (2015) Emerging Worlds, Emerging Words: Report of the Reflect ESOL Planning Project. London: Action Aid. 


\title{
Green Card English \\ New possibilities and enduring challenges in US immigration reform
}

\author{
Heide Spruck Wrigley
}

\section{Introduction}

In spite of the large number of foreign-born immigrants and refugees in the United States today (38.5 million as of 2010, US Census Bureau 2015), the US does not have a coherent immigrant integration policy; nor is there a federal language policy that guides national, state and local efforts to provide language access and facilitate social, economic and linguistic integration. Surprisingly, there has never been a federal law establishing English as the official language of the United States. In place of such a policy, we find a patchwork of laws, mandates, Acts and guidelines developed over 300 years by various federal and state entities with everchanging goals and priorities, as well as state laws that are often in conflict with a national commitment to civil rights.

Immigration policies and language policies have always been tightly interwoven. The tensions over Immigration Reform potentially offering amnesty to 11.5 million unauthorised youth and adults who are lacking legal immigration papers are a case in point. One of the flashpoints in this debate is a potential requirement that makes English a pre-requisite for obtaining permanent residency (known as a Green Card), stipulating that legal status must be 'earned' and reserved for those willing to get an education. Low-income families, including undocumented teenagers and young adults who came to the US as young children with their parents, are disproportionally affected by these requirements. While these young immigrants are now offered an opportunity to get relief from deportation and obtain a work permit, the strict educational requirements associated with this relatively small step toward a Green Card present a formidable challenge not just for individuals but for the adult education system designed to serve English Language Learners through English as a Second Language services. Although these policies are worthwhile in their intent to provide an alternative to deportation and an eventual path toward citizenship, they call into question a national commitment to include the poorest and least educated in immigration reform. 
This chapter describes US language policy that establishes the literacy and English requirements for migrating to the US, acquiring a Green Card and attaining US citizenship. It explains the tension between a federal government that has never declared English as the nation's official language and individual states eager to promote an English Only ideology in their jurisdiction. The second half of the chapter examines the role of English in citizenship and 'earned' legalisation, with a special emphasis on the strict educational requirements that 'unauthorised youth' need to meet in order to gain even provisional legal status. A critical discussion of the involvement of foundations in public policy follows, including a description of a new model that integrates student support with second language acquisition through collaborations of a diverse set of providers.

\section{Immigration and language policy in the United States}

Declaring that the US is and has been a 'nation of immigrants' ever since the first settlers came ashore on Plymouth Rock is a cliché accepted the world over. The perception of the US as a welcoming immigrant nation was immortalised in 1903 on the base of the newly erected Statue of Liberty: 'Give me your tired, your poor, your huddled masses yearning to breathe free.' But these were far from the definitive criteria for immigration policy then or now.

Shortly after the conclusion of the American Revolutionary War in 1783, the newly minted United States sought to define itself through its immigration policy. The 1790 Naturalization Act decreed that only free, white adults could become citizens. There was no requirement of literacy in the Act. As demographics shifted in the late 1800s and early 1900s toward increasing numbers of immigrants from poorer countries in Eastern Europe and from Southern Italy, fears of being overrun by the 'great unwashed' surfaced in policy discussions that resulted in Congress amending the Naturalization Act to include a literacy requirement for entry into the US. Although the literacy required was minimal (you only had to sign your name), the mandate for literacy nevertheless sent a powerful symbolic message that the tired and poor and huddled masses yearning to breathe free should at least be able to read and write.

After the Civil War, with increasing concern about economic and social impacts of various immigrant populations, some states began passing their own immigration laws. However, in 1875, the US Supreme Court ruled that immigration was the responsibility of the federal government. That year, the nation's first federal immigration law, known as the Page Act or the Chinese Exclusion Act, limited the number of Chinese immigrants for the next ten years. Several extensions followed. In 1891, Congress spelled out more detailed immigration constraints, excluding along with the Chinese: 'all idiots, insane persons, paupers or persons likely to become a public charge' as well as 'polygamists and others 
convicted of crimes of moral turpitude ...' This set the precedent for including good moral character in requirements for citizenship and now in the legalisation of undocumented youth.

At the beginning of the twentieth century, The Immigration Act of 1903, also known as the Anarchist Exclusion Act, added four new classes of inadmissible immigrants: anarchists, people with epilepsy, importers of prostitutes and beggars. This was the first time that immigration law was used to exclude immigrants on the basis of political ideology. Today, current or former membership of the Communist Party (for example in China or Vietnam) may be grounds to deny entry or citizenship. The Naturalization Act of 1906 for the first time required immigrants to speak English to become naturalised citizens. In 1907, the congressionally appointed Dillingham Commission published a 40-volume analysis of immigration over the prior three decades. The commission concluded that immigration from Southern and Eastern Europe, where literacy rates were relatively low, should be greatly reduced because it was a 'serious threat to American society and culture'. The commission's work promoted the strategy of using a 'reading and writing test as the most feasible single method of restricting undesirable immigration'. It also suggested capping the annual number of immigrants from any country at 3 percent of the total number of people from that country living in the United States in 1910, making it difficult for immigrants from non-Western European countries to increase in number. Later the Immigration Act of 1924 barred all immigration from Asia, continuing the racist and xenophobic tendencies of previous Acts.

The US no longer limits admission of immigrants based on race, religion or nation of origin. Today's immigration policy focuses on family reunification, employment and humanitarian issues. Although English proficiency remains a prerequisite for naturalization (as I outline below), for many years now, neither English proficiency nor literacy in any language has been required to become a legal resident of the United States. Anyone, even those who speak no English or cannot write their names, can acquire permanent residency and receive a Green Card as long as certain other conditions are met. In that regard, US language policy is generous compared with a growing number of countries where proficiency in the language of the receiving state must be demonstrated before a non-refugee is allowed to enter as a migrant (see Nicholas, Kurvers and Spotti, this volume).

The US has enacted a set of Acts, Memoranda and laws, often developed ad hoc, rather than as part of a coherent explicit national language policy. More often than not, measures are put in place in response to economic interests, public pressure (for better or worse) and pronouncements on who deserves to be American. A desire to control outsiders, and strongly held beliefs and attitudes regarding the role of English and of other languages, have tended to influence these impromptu language policies. 


\section{This is not a test: English requirements for citizenship}

Since the Naturalization Act of 1906, the US has mandated some form of English proficiency as a prerequisite for naturalization, the process by which a citizen of another country can obtain US citizenship. For the most part the naturalization process is straightforward. Any legal permanent resident of the US can apply for citizenship if certain requirements are met, including the stipulation that the applicant be of good moral character (no felons) and show attachment to the US Constitution (no communists). A test consisting of a hundred questions on US history and civics and an assessment of basic English literacy and face-to-face communication skills determine whether citizenship is granted.

On the face of it, the US naturalization test is relatively benign: it has a pass rate of over 90 percent. The answers to the hundred history and civics questions can be memorised, and an applicant only has to answer 6 out of 10 questions correctly (USCIS 2014). To document literacy in English, applicants are asked to correctly write 1 out of 3 sentences the examiner dictates (minor grammar problems or spelling errors are ignored) and then read one of the sentences aloud in a way that is comprehensible (pronunciation errors not interfering with comprehensibility are also ignored). The entire process is administered face to face by an examiner who is an official of the US Citizenship and Immigration Service (USCIS), a branch of the Department of Homeland Security. Although there are guidelines, the examiner still has leeway in determining an acceptable level of literacy, a provision that can either work for or against an applicant.

Oral English (speaking and listening) is tested in rather inexact ways as well and discretion again can be used by the examiner. The application submitted by the immigrant serves as a basis for determining proficiency, and the examiner typically asks questions related to personal information (name, address, family and marital and work history, past trips outside of the country). To establish the applicant's 'good moral character', examiners will ask questions about criminal convictions (public intoxication, prostitution). Questions why a person wants to become a US citizen are also asked and a wide range of answers are accepted as long as they indicate an 'attachment to the Constitution'.

Underlying the exam are two broad assumptions: English is required for active civic participation; and proficiency can be determined through answers given during a short face-to-face interaction. These assumptions reflect a reductionist view of fluency that seeks to determine how much language is enough without taking into account the contexts in which language might be used. Proficiency is seen as dichotomous: either you speak English or you don't, ignoring the continuum of proficiencies and the variation of social practices that exist in civic life, including the use of 
multiple languages typical of migrants. The question of how much English is enough (and who should decide) suggests that the language needed for active citizenship can be pre-determined and measured. In the end, governmental decisions specifying the amount and type of English required to receive the 'keys to the kingdom' are more arbitrary than scientific. Meeting language and literacy requirements is seen as a way to earn a civic badge, proof that an effort has been made toward assimilation into mainstream culture and society, or as a convenient way to discourage those with less education from applying.

The US naturalization exam might seem straightforward, but in requiring the study of abstract civic concepts (instead of active civic engagement) and demanding that applicants explain what often is a complicated personal past, it privileges immigrants with higher levels of education who come from an English speaking country or have studied English in school, while disadvantaging those with few years of schooling. Lower educated immigrants not only must acquire proficiency in the new language (however minimal) but in many cases must learn to read and write for the first time in any language in order to meet the literacy requirements of the citizenship test. For those who have gaps in their education, the task of understanding and explaining theoretical concepts such as Constitution, Branches of Government and Balance of Power in a language they are still learning is highly complex. Preparing for citizenship can be a lengthy and burdensome process given the work and family responsibilities that most immigrants experience. In policy discussions little thought is given to using alternative indicators of civic engagement, indicators that might include civic involvement such as supporting children's schooling, participating in neighborhood groups, joining an immigrant support or advocacy group, and connecting with others around community issues such as the need for child care, early childhood education, mental health services, recycling and well-lit parks.

\section{Perceived threats to the prominence of English}

Nearly all US immigrants agree that speaking English is important and that opportunities are limited for those who don't speak it well. Even if one lives in areas where the lingua franca of the community is sufficient for basic employment and the demands of daily life (e.g., on the long US-Mexico border and in cities such as Chicago, San Francisco and New York), it remains difficult to defend one's rights, enter higher education and training, and gain access to well-paid jobs without strong English proficiency. At the same time, civic participation and economic success are not necessarily language-dependent. Thousands of immigrants have been able to organise and advocate for immigration reform and community improvements using a language other than English. 
Throughout US immigration history, non-English speaking immigrants have been able to find work, enroll children in school, start businesses and navigate social systems. The success of immigrant entrepreneurs is often the result of hard work and knowhow that was acquired in another language. Although higher levels of literacy are associated with higher wages, limited civic participation and lack of economic success are often less the result of failed efforts to learn English and more of limited opportunities due to social class and institutional barriers.

A popular myth about immigrants from Mexico or Central America is that they don't acquire English as fast as their predecessors, implying that they are not as smart and are lazier, or are conspiring to diminish English and replace it with Spanish as a national language. Spanish language media along with bilingual programs in the schools are regarded as slowing down the acquisition of English by new immigrants. However, studies indicate that today's immigrants are acquiring English at a faster rate than ever before (Tse 2001; Anderson 2010). Immigrants follow a typical pattern of second language acquisition: first generation immigrants with little education, struggling to make a living and sustain a family, have little time and few resources needed to become fluent in English. Their children and grandchildren though, raised in the US and attending US schools, acquire English at rates similar to native-born Americans. Comparative studies of the speed of English acquisition between earlier immigrant groups, such as Germans in Wisconsin and Latinos in the Southwest, show more rapid acquisition of English in today's immigrants. For example the Pew Research Hispanic Trends Project (Lopez and Gonzalez-Barrera 2013) shows that fewer than one-quarter of first generation Hispanic adult immigrants (those born in another country) report that they speak English very well, compared with 88 percent of their US born children. This research, as one would expect, also indicates that the more highly educated the immigrant, the more quickly he or she acquires English. A critical barrier to language acquisition in the US today is a lack of resources to meet the growing need for effective, high-quality instruction for adult immigrants who need to advance economically. We know that learning another language well takes time and sufficient stability to be able to focus on learning. Requiring that adults who lead challenging lives and need to work attend an educational program in order to gain legal status seems punitive at best.

\section{Contested ground: tensions over 'English Only'}

Language rights are a contested issue in the United States, often pitting liberal federal policy makers against conservative state politicians (Wiley 2014). The same duality that characterises the US political system (Republicans vs Democrats, blue states vs red states, conservatives vs progressives) also shapes language policy. The result is a confusing array 
of laws and regulations that both programs and individual immigrants must navigate. The status of English at the national and the state level is a case in point. No administration has ever declared English the official language of the United States although it is recognised as the de facto national language and is acknowledged as the dominant language.

As the Constitution stands, it would be difficult to put an English Only policy in place at the federal level, since such legislation might abridge the rights guaranteed under the Civil Rights Act of 1964, landmark legislation that outlaws discrimination based on race, color, religion, sex or national origin. Although language rights are not specifically mentioned in civil rights legislation, they are thought to be protected under the nationality provision. Protection is offered in areas that pertain to the federal government and agencies receiving federal funding (for example, public schools cannot require children to speak only English in the playground). Civil rights also extend to prohibitions against employment discrimination and employers cannot demand that immigrant workers speak only English during their breaks. Language rights are also protected under the federal Voting Rights Act that demands that bilingual ballots be used in localities where a certain percentage of language minority adults live in order to guarantee equal rights to vote. All other election materials provided in English must also be provided in other languages that are affected by the Act and must be made available before the election. These requirements are consistently attacked by pro-English groups as redundant (you must already speak English to be a citizen), and wasteful (most naturalised citizens don't vote), as well as burdensome and expensive for states to implement.

Language policies have also been enacted through Executive Orders issued by the President. Presidents Clinton and Obama have signed Executive Orders on Language Access, guaranteeing the right to translation and interpretation for all non-English speaking individuals seeking services to which they are entitled. This right only extends to services provided by a federal agency or an institution receiving federal funding, though.

Since Executive Orders are not binding outside the federal government and beyond those bodies receiving federal support, states can ignore these directives. To broaden access for immigrants and refugees, some states have enacted their own language access legislation to ensure equal treatment in areas such as health care, education, the courts, criminal justice and government. But states may establish laws that may run counter to the spirit of a federal policy as long as they do not violate Civil Rights legislation. In some states, English Only declaration laws are merely symbolic (a state still has to print bilingual ballots) yet they are disrespectful and intended to exclude and punish. Acting on public resentment of immigrants and a deep-seated mistrust of anyone who uses a language 
other than English, the majority of states (33 in all) have enacted some kind of English Only legislation and conservative members of Congress have sought (unsuccessfully) to pass a federal law that prohibits the use of any language other than English in the business of the nation. For non-English speaking adults, particularly the undocumented, geography can mean destiny. On the positive side, cities like San Francisco, Los Angeles and Salt Lake City have declared themselves Sanctuary Cities where local police do not cooperate with immigration officials and do not request proof of legal status from anyone. New York City affords all residents, documented or not, the same access to city services and no municipal office is allowed to ask for immigration papers. Conversely, we find cities like Atlanta, where police work closely with Immigration and Customs Enforcement (ICE) officials. As a result, immigrants in English Only states often do not have access to services offered in other languages, while those who live in more liberal states (or cities) do.

\section{Murky waters: access to free ESL and job training courses for those without papers}

One remedy to equalise the differential treatment that immigrants receive in different states has been to bring a lawsuit and let the courts decide. The result has been Supreme Court Laws that establish the right of children with limited proficiency in English to educational services that meet their need (bilingual education or ESL services) and the right of 'unauthorised' children to public education. However, the right to access state and federally funded adult ESL programs has not been established for adults who are undocumented, and the situation remains unclear.

Since in the United States education is the domain of the states, different states can set different policies as long as they do not violate federal law. In some states, such as Arizona and Georgia, immigrant adult students must have legal status in order to participate in state- and federally-funded ESL classes, while in other states (California, New Mexico, Texas) everyone, documented or not, may participate in publiclyfunded adult education classes.

While the general guidelines published after the Immigration Reform and Control Act of 1986 (IRCA) decreed that adults without legal status were not eligible to receive federally funded services (such as job training), it has never been clear if this directive applies to general adult education and adult ESL services. This ambiguity presents a critical dilemma for states with high levels of immigrants. If undocumented adults were barred from the federally funded Adult Education System, ESL services in states like California and Texas, where a high percentage of ESL students do not have official papers, would collapse. Without access to ESL classes, many immigrants would find it very difficult to navigate the legal, health and 
educational systems that their families depend on and integration would be seriously impeded. Since even undocumented individuals have rights guaranteed under federal law, a certain level of English is necessary to understand and fight for these rights. If access to ESL classes for the undocumented is prohibited, these rights are effectively denied. In contrast to the states, the US Department of Education has not taken a stand on whether undocumented adults can be served with federal funds; instead it is operating under a 'don't ask, don't tell' rule that ignores state policies.

\section{English requirements for legalisation}

Although English proficiency is required for citizenship, it is not a prerequisite for permanent legal residency (i.e., a Green Card). No English requirement exists for those who entered legally by joining family, marrying a US citizen, winning the Green Card lottery (now abolished) or those securing education or business visas. But quite different rules apply for youth and adults who entered the country illegally and want to gain legal status. Ever since the passage of the first Immigration and Control Act in 1986 which offered amnesty to unauthorised individuals, there has been a strong sense that these 'immigration lawbreakers' should be made to learn English before they are awarded the privilege of becoming Americans.

Almost thirty years later, there is a need for a new round of Immigration Reform and old issues are being revisited. The debates over the legalisation of the 11.5 million undocumented youth and adults have carried on unabated as conservative Republicans make the case that the government should not provide amnesty for 'illegal aliens' who have 'flouted' US laws (Rosenblum 2011). These forces contend that if new legalisation laws are to be passed, they must include a penalty including a mandate to speak English. Progressives and liberal Democrats on the other hand argue against an English language mandate and suggest expanding the system to offer those who want to learn English voluntarily the opportunity to do so. In contrast, the language of the laws proposed by the Senate and by the House of Representatives maintain any legalisation must be earned, and one way of doing so is to learn English. In these views, 'illegal' immigrants are law-breakers who should not be rewarded. This perspective also reflects an entrenched and often aggressive monolingualism that sees English as the only language that counts (Wiley 1997).

\section{Words matter}

As public debate on Immigration Reform rages, various terms are used to describe families, youth and children who came across the border for a better future but did not have legal permission to do so. These individuals 
are commonly referred to as 'unauthorised' (the designation used by official government sources), 'undocumented' (used by advocates and most educators), 'inmigrantes indocumentados' (used by the Spanish media) and 'illegal aliens' (used by about 90 percent of the general press). 'Lawless criminals' and other slurs are put forward by many anti-immigrant groups. Many immigrants who crossed the border without proper documentation simply say they are 'sin papeles' (without papers). Declaring undocumented immigrants 'criminals', as the right-wing press has done, has been challenged by the highest court in the US. In 2014, the Supreme Court struck down an Arizona effort to criminalise violations by making it a state crime to be undocumented. The ruling made it clear that a person becomes subject to deportation through administrative procedures and not through criminal prosecution, highlighting that those without papers are not and never have been ipso facto criminals (no more than someone receiving a parking ticket is a criminal).

The use of emotionally charged, racially offensive terms to describe immigrants is not a new phenomenon. The word used for non-citizens, documented or not, has long been the unfortunate term 'alien'. In official parlance, the term is often extended to 'deportable' or 'removable alien' to make the point that even permanent residency status can be revoked under certain circumstances. For many, the commonly used term 'illegal alien' conjures up images of an outer space invasion, and 'illegals' is the most commonly used term to refer to adults without official papers. Unfortunately, Elie Wiesel's admonition that 'no human being is illegal' has done little to eradicate the term from popular language or media reports.

There is general agreement in policy circles that some form of immigration reform is inevitable. There is not yet a definite answer as to what shape an English requirement as part of such reform might take and the costs of providing ESL services have yet to be calculated. Yet there is little doubt that a majority voice in the US wants its immigrants to speak English and there is every indication that immigrants themselves see English as an important aspect of immigrant integration (Dowling et al. 2012), The issue at stake is: should English be mandated as a prerequisite to legalisation, work authorisation and permanent residency (and not just for citizenship as it is now)? Mandating English proficiency has tremendous implications not only for the applicants themselves, the majority of whom are not English-proficient, but also for the education and training systems that will have to absorb thousands if not millions of additional students.

\section{How will the system make resources available? Where will the money come from?}

Requiring that immigrants learn to speak English raises questions. Who will pay for substantially increasing the capacity of an overburdened 
adult education system to render it capable of absorbing millions more students? How would such a system be administered so that quality is maintained? How much English is enough? How will the level be assessed? Will the English requirement be set at the current level needed for citizenship (high beginner/upper elementary) or will levels be set even higher, at the GED (General Educational Development, or High School Equivalency test) level for example? Who will bear the cost of ascertaining the proficiency of millions of adult English learners? How will this be measured, and by whom? Given the complexity and cost of measuring English competence, lawmakers may step back from requiring a certain level of English and mandate that applicants be enrolled in an English class for a certain amount of time before being considered for legalisation.

\section{Who will be responsible for millions learning English?}

Another important policy issue that is likely to generate controversy is the question of who will administer the legalisation program and ensure that educational requirements are met. The most recent Senate Bill recommends that the legalisation program be run by the US Citizenship and Immigration Service (USCIS), a branch of Homeland Security. Seeing Homeland Security in charge of transitioning unauthorised adults to legal status makes many advocates, educators and policy analysts nervous. They see Homeland Security associated with border control and deportations, not with supporting educational opportunities. Many fear that asking applicants to contact Homeland Security and identify themselves as 'illegals' may have a chilling effect on their willingness to come forward and face potential deportation if requirements are not met. In the minds of many, reporting to an immigration officer may raise the question, 'If I don't learn enough English, will I be deported?' An alternative proposed by the Migration Policy Institute would be to create a National Office of Immigrant Integration. This office would coordinate the efforts of the various governmental departments that 'touch' immigrants, such as the Departments of Education, Labor, and Health and Social Services. Such an office could create a framework for immigrant integration that supports the building of new integrated systems for immigrants that work in conjunction with legalisation.

\section{Inching toward immigration reform: Legalisation for early childhood arrivals}

As noted above, a consensus regarding the need for immigration reform has emerged. However, one key aspect remains in question: will reform 
efforts be truly comprehensive, offering a path to full citizenship to all individuals, or will reform roll out in a piecemeal fashion, offering legal status to some groups but not others and not guaranteeing citizenship for anyone? The current picture is pointing toward a gradual group-bygroup approach, although immigrant communities have been firm in their insistence that the legalisation process should be inclusive and unifying, rather than fragmentary, patchy and divisive. Whether reform will be piecemeal or comprehensive, we can expect that education and language requirements will be part of the expectations that applicants must meet. In fact, that process has already begun. Efforts to legalise a subgroup of unauthorised young people who were brought to the US as young children by their 'illegal' parents are underway. Since these youths simply followed their parents, they could be considered innocents who deserve Green Cards so they can work legally, get driver's licenses and be eligible for state and federal financial aid when they enter college. Yet the Republican-controlled Congress has steadfastly refused to pass a measure that would give legal standing for young people qualifying for college.

\section{Baby steps for those who stay in school}

The disappointment that the American public feels over Congressional inaction has galvanised many, including thousands of undocumented young people, to make their voices heard. Advocacy groups, such as the Fair Immigration Reform Movement, continue to march on Washington to protest. Yet over the last decade reform advocates have achieved only two small wins: (1) state legislation addressing relief for undocumented college students as part of the DREAM Act and (2) Deferred Action for Childhood Arrivals (DACA), a directive to Homeland Security in the form of a federal memorandum signed by President Obama. The Memorandum directs immigration enforcement officials to halt the deportation of youth who came to the US as young children and meet certain eligibility requirements, including attendance in an educational program such as a GED or ESL course for anyone who has not completed high school or received a high school equivalency diploma. The two legislative actions are discussed in turn below.

\section{The DREAM Act}

Although the DREAM Act would affect only a small portion of the 11.5 million undocumented immigrants, it did not pass in Congress and is not a federal law. Nevertheless, as of this writing, 15 individual states have adopted the DREAM Act allowing undocumented college students residing in their state to pay for in-state tuition and be eligible for state financial aid (Batalova et al. 2014) instead of having to pay the much higher out of state tuition fees previously charged. Once again, there are consequences for the poor: although 
eligible college students might qualify for some of the state-funded scholarships available, they still cannot work legally and state financial aid merely offsets the cost of an education but does not pay the full amount. Since the Act is not yet a federal law, 'Dreamers' (as students call themselves) are not eligible for the kind of financial support that would benefit them the most - federal grants designed to make college affordable for low-income students. For those with limited resources - most would-be students - a college education is not likely to become a reality and remains a dream deferred (McHugh 2014).

\section{No Green Card quite yet: \\ Deferred Action for Childhood Arrivals (DACA)}

As Congress continues to debate Immigration Reform, but refuses to pass the DREAM Act, the Executive Branch has taken matters in hand and issued an executive Presidential Memorandum. This directs Homeland Security to stop deportations of unauthorised young people who came to the United States as young children and meet certain requirements. The policy known as DACA (Deferred Action for Childhood Arrivals) allows adolescents and young adults between the ages of 16 and 30 to apply for a reprieve from deportation. Those eligible will be given authorisation to work legally, provided they show good moral character (i.e., no significant misdemeanors), have been in the US continuously since 2007 and meet specific educational requirements. These requirements are strict. To qualify a person must have graduated from high school or have a GED. In the absence of a diploma, evidence is required that the individual is in high school, a job training program or an adult education program, including English as a Second Language (ESL). Those who qualify are eligible to receive a permit that allows them to work legally, get a driver's license and not face deportation for two years, at which time they can ask for an extension.

The numbers are startling. As of 2014, 2.5 million unauthorised immigrant youth could potentially gain provisional legal status. Twenty percent of these would have to stay in school or find a program to attend (Batalova et al. 2014), a difficult requirement to meet for those who are working full time to support themselves and their families. An administrative fee of $\$ 465$ must be paid by each individual, threatening to exclude young people from poorer families who have limited formal schooling.

\section{The challenge for English language learners}

In spite of the obstacles inherent in applying for DACA, thousands of young people without a high school diploma are waiting to enroll in an education program so they can qualify for exemption from deportation and obtain work authorisation. This group includes both bilingual students who say they speak English very well (60 percent of all DACA 
applicants) and those who have been designated as 'limited English proficient' (LEP). Individuals in this group who are required to be in school number in the thousands: 400,000 according to estimates by the Migration Policy Institute (Batalova et al. 2014).

Some may wonder why so many of these young immigrants who grew up in the United States do not already speak and write English fluently. In fact, this is not uncommon for young people who were born in another country but schooled in the US. These young people tend to speak a language other than English at home and may appear fully bilingual. But they often lack the academic skills necessary to succeed in a skills training program or transition to college. Academically, many of these young people share characteristics of both first generation immigrants and second generation immigrants who were born in the US and attended US schools (Batalova and Fix 2011). Known as Generation 1.5, they speak both English and the home language but may not be fully proficient in either language (see also Harklau et al. 1999). They need educational support different from that generally delivered in conventional ESL classes focused on life skills. In most areas, few adult programs offer rigorous transition courses designed for bilingual youth hoping for acceptance to a college so they can eventually qualify for a Green Card once the DREAM Act passes Congress. This group could also benefit from bilingual courses that prepare young adults for working as technicians and professionals serving monolingual English speaking clients as well as customers who prefer communicating in their home language. Yet across the US only a handful of these courses exist. Given the bilingual nature of commerce on the US-Mexican border where most undocumented families reside, focusing solely on English as the language of opportunity appears myopic, short-changing both individuals and communities. And not only are specialised courses extremely rare, few programs currently exist that offer academic transition courses or access to vocational technical training. Since securing a job that pays a living wage demands high-level skills, DACA students will also need digital literacy including the ability to access information electronically, and to work with new technology in specialised English. The few rare programs that integrate technology, work preparation and ESL have shown success (McHugh 2014; Wrigley in press).

\section{Youth not yet fluent in English}

Of greatest concern to educators and advocates are out-of-school immigrant youth with the lowest English skills who may miss the opportunity to enroll in school and therefore will not have a chance to gain even provisional legal status. Such young people vary in their educational experiences. Some have attended but not completed secondary school; others may never have been 
to high school in the US because they went directly to work after crossing the US border. They may never have acquired the 'learning how to learn' skills that keep students attached to a program and may drop out early. Young people in rural areas and working in agriculture are particularly vulnerable to exclusion, being unaware that they are eligible for a change of status, and even those who do know this may not have access to classes that fit their schedules. Thousands more are at risk of not meeting the educational requirements either because of a lack of knowledge or confusion about the process. Formidable barriers remain even when these young immigrants have correct information and are motivated to adjust their status. Given that most undocumented migrants are among the working poor, they often lack the financial resources to pay the high DACA application fees.

Fear and mistrust of La Migra (the immigration control service) are factors as well. In the minds of many young people, self-identifying as unauthorised carries a risk they are not willing to take. They are keenly aware that in order to qualify for permission to stay, they have to provide papers documenting that they have lived in the US illegally since June 2007. They now find themselves in a peculiar situation: they are asked to come forward to prove that they are 'illegal' to the very agency in charge of deporting 'illegals'. Understandably, many fear that providing names and addresses to Homeland Security officials could jeopardise unauthorised members of their families. In additional, those who have long worked as part of the underground economy may have difficulty documenting the residency requirements and may end up in a bureaucratic Catch 22 that requires that they document having been undocumented as a prerequisite for obtaining legal documentation.

Given the hurdles to DACA participation, it comes as no surprise that out of school youth have been slow to apply. Two years into the program, only 41 percent of those potentially eligible have come forward. Thousands of young adults who are unconvinced of their ability to succeed in school may decide to forego the application process because the challenge of meeting the educational requirements is too overwhelming, and they consider the pay-off (permission to work legally) too small to warrant the effort. Yet young people who do not apply forfeit their chance to gain at least temporary legal status, get an education and improve their employment prospects. Given what is at stake for young immigrants, one would think that every effort is being made to create opportunities to meet their educational requirements. Yet the US Adult Education field and the ESL field in particular are far from ready to meet the challenge of offering classes to young immigrants who must be enrolled in school. Very few programs have the capacity to respond to the multiplicity of challenges involved in serving limited English proficient DACA youth including providing high quality ESL designed to transition students to a GED, to training or to other forms 
of postsecondary education. Community colleges and community-based organisations may each be ready to take on part of the challenge but neither appears ready to offer the combination of rigorous English language instruction, legal assistance, personal advising and support services that undocumented youth need.

\section{Private and public partnership focused on DACA youth}

If close to half a million young people are to meet the educational requirements by attending ESL classes, it will take millions of dollars in public and private investments so that appropriate programs can be created and appropriate legal assistance offered. The adult ESL system, overburdened and underfunded, cannot absorb even a fraction of those who should attend, given that even pre-DACA the system was able to meet less than 20 percent of the country's need for English language services. Since there is no funding tied to DACA (the $\$ 465$ application fee only covers administrative expenses incurred by the Immigration and Citizenship service), additional resources must be found.

Aware of the tremendous challenges that young immigrants face in moving even a relatively short distance toward work authorisation, a number of foundations are taking action to make a (small) difference. The involvement of foundations in immigrant integration is not new. The Ford Foundation spent many millions of dollars to support the Immigration Reform Act of 1986, and funded hundreds of community-based organisations to set up ESL classes to help Green Card applicants meet English requirements. The Carnegie Foundation is funding the Migration Policy Institute's Center on Immigrant Integration and its many projects. To support strategic thinking, members of the philanthropic community are organised around issues related to Immigration Reform through Grantmaker's Concerned with Immigrants and Refugees (GCIR). The coalition sees legalizing over 11 million youth and adults as critical. They publish Issue Briefs on the DREAM Act and DACA, and fund policy analysis and needs assessments while investing in the implementation of programs. By creating initiatives focused on individuals who speak a language other than English, these private foundations are in effect creating their own language policies. For many this is worrisome in that it relieves those in charge of making public policy of their obligation to plan strategically, create workable programs and provide the resources necessary to run them.

\section{English innovations: helping undocumented youth meet educational requirements through technology}

In the absence of government support for the educational component, the Bill and Melinda Gates Foundation is making a $\$ 2.5$ million investment 
to support DACA youth not yet proficient in English. A partnership has been set up consisting of an immigrant advocacy group (One America, based in Seattle), a national coalition of non-profit organisations providing assistance to immigrants seeking legalisation or citizenship (Partnership for New Americans), and a university (the Learning Games Network at the MIT). The partnership is designed to build the capacity of communitybased organisations (many working in collaboration with established ESL providers) to deliver services that integrate community outreach, legal support, instruction in ESL and computer literacy, and provide referrals to support services such as child-care. The program will adapt English Innovations, a blended learning model developed and tested in Seattle.

The English Innovations model is noteworthy inasmuch as it is not simply a stand-alone ESL program to help English language learners meet the 'go to school' requirement. Rather it is an integrated service model designed to shepherd young immigrants through the DACA process while offering English language learning opportunities appropriate for teenagers and young adults. Yet, while funding a $\$ 2.5$ million adult education program specifically designed for undocumented immigrants still learning English will help the hundreds who can participate, it does not come even close to meeting the needs of the thousands who don't have access to classes. However, it might serve as a model for new ways of supporting English language development.

While the immediate goal of the investment by the Bill and Melinda Gates Foundation is to keep LEP youth from being deported by helping them meet the education requirements, the long-term goal is to refine and advance a blended learning model that can be adopted in both formal and informal learning environments. These might include after-school programs for parents, public libraries, workplaces, community centres or places of worship where teachers or trained coaches can guide youth and adults through both structured in-class and self-access out-of-class learning. The model is meant to set the stage for education under eventual immigration reform, when over a million youth and adults may be confronted with a whole new set of provisions, including educational requirements.

\section{High stakes and high burden}

If DACA youth cannot access educational programs, they will continue to be unauthorised, and if they are apprehended and deported, they will have forfeited any chance to ever gain legal entry into the United States. Without the opportunity to learn English and further their education, undocumented youth cannot secure an economic future for themselves and their families. Conceived as a benefit to undocumented young people who may need encouragement to get an education, the combination of 
educational requirements and high fees may make it nearly impossible for those with limited resources to adjust their status. Using education simultaneously as a carrot and a stick may convince cynics that the program was never meant to provide opportunities for the least educated; instead it was meant to weed out the most vulnerable. While DACA confers substantial benefits and allows for greater social and economic integration, it does not solve all the problems of the undocumented. It is still only a suspension of deportation and, even when a temporary stay is granted, recipients are still in legal limbo. They do not have permanent residency and cannot petition for legal status of family members. Having one person in a family free of deportation does nothing to diminish the constant threat of deportation that parents, siblings and friends who are not DACA-eligible will continue to face every day (Gonzalez and Terriquez 2013). In that light, setting burdensome educational requirements in exchange for a relarively small gain toward the legalisation of millions underscores the often punitive nature of language policy.

\section{Conclusion}

Language policies mandating English proficiency as a prerequisite for entry, for citizenship or for a change of legal status have rarely had the desired effect of turning the country into a nation of English speakers. Adults who participate in required classes seldom reach the level of fluency envisioned by those who insist that everyone learn English. Even if hundreds of thousands of undocumented adults were to participate in ESL classes, Language Access directives and bilingual ballots would still be necessary, and language diversity would thankfully continue to be characteristic of American life.

History has taught us that immigrants will continue to be engaged in civic affairs in their communities and will make their voices heard on issues that concern them. And the vast majority will acquire English on their own terms and in good time, as they always have. If the country wants to live by its creed of welcoming the 'tired and poor', broad initiatives will be needed to provide the support and resources necessary so new Americans can build the skills they need for family-sustaining jobs and for success in post-secondary education. Requiring a high school diploma (and years of English to get there) in exchange for a work permit or a driver's license seems a cynical proposition designed to exclude rather than include poorer young immigrants who came as children. Equally cynical seem proposed laws to have immigrants 'earn' a Green Card by going to school to learn English in a system that cannot possibly accommodate them. Human concerns for all who are here should trump the political desire to extract penalties, and pursuit of happiness should not be dependent on one's ability to speak English. 


\section{References}

Anderson, S. (2010). Immigrants and English. Immigration Reform Bulletin. Washington, DC: Cato Institute.

Batalova, J. and Fix, M. (2011) Up for Grabs: The Gains and Prospects of First- and Second-Generation Young Adults. Washington, DC: Migration Policy Institute.

Batalova, J., Hooker, R. and Capps, R. (2014) DACA at the Two-Year Mark: A National and State Profile of Youth Eligible and Applying for Deferred Action. Washington, DC: Migration Policy Institute.

Dowling, J. A., Ellison, C. G. and Leal, D. L. (2012) Who doesn't value English? Debunking myths about Mexican immigrants' attitudes toward the English language. Social Science Quarterly. doi: 10.1111/j.1540-6237.2012.00850.x.

Gonzalez, R. G. and Terriquez, V. (2013) How DACA is Impacting the Lives of Those Who are Now DACAmented: Preliminary findings from the National UnDACAmented Research Project. Washington, DC. Migration Policy Institute and the Center for the Study of Immigrant Integration.

Harklau, L., Losey, K. M. and Siegal, M. (eds) (1999) Generation 1.5 meets College Composition: Issues in the Teaching of Writing to US-educated Learners of ESL. Mahwah, NJ: Erlbaum.

Lopez, M. H. and Gonzalez-Barrera, A. (2013). What is the Future of Spanish in the United States? Washington, D.C.: Pew Research Centre.

McHugh, M. (2014) Diploma Please: Promoting Educational Attainment of DACA Youth and Potential DREAM Act Eligible Youth. Washington, D.C:. Migration Policy Institute.

Rosenblum, M. R. (2011) US Immigration Policy since 9/11: Understanding the Stalemate over Comprehensive Immigration Reform. Migration Policy Institute Report. Available online at www.migrationpolicy.org/research/RMSG-usimmigration-policy-cir-stalemate (accessed 1 June 2014).

Tse, L. (2001) Why Don't They Learn English Separating Fact from Fallacy in the US Language Debate. New York, NY: Teachers College Press.

United States Census Bureau (2015) Foreign Born. www.census.gov/topics/ population/foreign-born/about.html (accessed 27 February 2015).

US Citizenship and Immigration Services (USCIS) (2014) The Naturalisation Test. www.uscis.gov/us-citizenship/naturalization-test (accessed 27 February 2015).

Wiley, T. (1997). Myths About Language Diversity and Literacy in the United States. Center for Adult English Language Acquisition Digests. Available online at www.cal.org/caela/printer.php?printRefURL=http\%3A//www.cal.org/caela/ esl_resources/digests/myths.html (accessed 30 May 2014).

Wiley, T. (2014) Critical Language Analysis and the Ongoing Need for Advocacy in the Post-Civil Rights Era. Distinguished Scholar and Award Presentation. Portland, OR: American Association for Applied Linguistics.

Wrigley, H. S. (in press). Education and Training for Adults with Limited Proficiency in English: Conventional Models and New Alternatives. Chicago, IL: Illinois Coalition of Refugee and Immigrant Rights. 


\title{
Educational programming for low-literate adult migrants in the US
}

\author{
Marguerite Lukes and John Lyons
}

\section{Introduction}

Lin, Fatima and Gabriel emigrated to the US as adults and share a common status as English Language Learners. Each has sought out education and training opportunities to learn English, gain credentials, and improve job options. Lin came as a young adult from China after completing a university education. She has found a white-collar job with access to education and training for advancement. Fatima arrived in the US with her young children and husband from Yemen having completed only primary school. She speaks Arabic, but has difficulty reading and writing. When she tried to attend English classes, she found the schedule difficult to manage, affordable childcare hard to find and the class's pace overwhelming. Gabriel entered the country from Mexico in his early twenties and has worked washing dishes, in construction and stocking shelves in a deli. His schooling ended after third grade when he began working to earn money for his family. He has enrolled in English classes, stopped and started again, but demonstrated little progress.

The differences among these three adults reflect the vast diversity among adult migrants. Immigrants in US contexts differ from one another not only in language and country of origin, but also across a spectrum of educational backgrounds, home language literacy skills, workforce experience and English proficiency levels. In many urban areas across the US, the adult immigrant population comprises individuals with extremely high levels of specialised training and education along with an increasing number of low-skilled migrants with limited experience of formal education like Fatima and Gabriel. Some excel in professional positions while others struggle to read written instructions in their native languages or decipher the calculations on their paychecks.

The archetypal nuclear physicist from Russia who drives a taxi because he cannot speak English holds the popular imagination. However, less well known are the realities of adults on the other end of the skills spectrum, those such as Fatima and Gabriel with emergent literacy and 
basic skills who come to the US having attended school for only a few years in their countries of origin. Their interrupted schooling does not stem from a lack of interest in education, but is the result of institutional and structural constraints in their home countries, including limited access to adequate educational programs, economic hardships, war and violence, internal migration and displacement. Upon arrival in the US, these adults receive scant attention in the policy sphere. Minimal research has been conducted with them and their educational concerns. Few programs are designed to serve them explicitly. Insufficient public investments have been made to meet their needs. Because public discourse in the US paints the immigrant population with broad strokes, few details about immigrants with emergent literacy come to light, and they continue to be overlooked in policy.

This chapter discusses the educational needs of adult US immigrants with emergent literacy in both their home language and English. Wrigley (2007: 223) notes 'the need for services that reflect the bilingual, bicultural nature of life and work' in multilingual communities. Our own opening position is that adult learners without foundational literacy in an expert language are well served in their efforts to acquire literacy in English when they are in bilingual literacy programs. Such programs enable them to gain access to literacy in an expert language before transferring the skills acquired to literacy learning in the new language. We provide background on policies governing the provision of first language literacy and bilingual education services for migrant adults, including a discussion of political and ideological factors that impact upon the provision of opportunities to develop adult literacy in languages other than English. We examine educational programs and services that provide options for this group of migrants, highlighting the significance of pre-migration educational attainment for program design in adult education. In the second half of the chapter are examples of two more-or-less successful bilingual literacy programs designed to meet the needs of this population: we sketch out the challenges which the program providers faced vis-à-vis policy, funding and long-term sustainability. Overall, the chapter highlights ways in which a pervasive ideology of monolingualism leads to educational policies that undermine bilingual approaches, creating persistent barriers that impede the design of effective services for a large and growing population of low-skilled adult migrants.

\section{Background}

Why should migrants with emergent literacy in English and in their native languages concern us? Census data reveal a growth trend in the number of low-skilled migrants in the US with limited formal education, and demographers project that the coming decades will bring an increase 
in their numbers (Capps et al. 2013). Low educational attainment is not an uncommon or isolated issue in the US. According to the 2012 American Community Survey (ACS), over 12 percent of the United States' population aged 25 and older was estimated to lack a high school diploma, with estimates much higher among immigrants. Slightly more than 10 percent of US-born adults have not completed high school, compared to 32 percent of foreign-born adults in the US. The rate among Hispanic immigrants - the largest linguistic minority population in the US - is nearly 50 percent (Ryan and Siebens 2012).

A persistent challenge for educators in contexts ranging from adult education and workforce development to K-12 education is how best to address the needs of students without literacy skills in their native language, who have missed years of formal schooling or might never have attended school at all. Migrants in this growing population have overcome many obstacles to reach the US. Once here, they face - and often address - complex problems in their daily lives yet lack the literacy skills needed for workforce advancement and upward mobility. They live in communities where multilingualism is a bonus and literacy and proficiency in the native language is both a commodity (sometimes a scarce one) and a necessity. These migrants often work for wages below the poverty level and have scant options for education and training. Nearly 20 percent of all adult migrants live below the poverty level, and they struggle to access financial and academic resources to support themselves and their families (Lobo and Salvo 2013). Labeled as high school drop-outs, the younger generation of this population in truth face institutional barriers to their educational advancement. Economic factors, often in the shape of family responsibilities, force them into the labor market before they are able to finish school. These individuals tend to work in low-skilled jobs and number among the lowest wage-earners on average, with limited opportunities for advancement.

In the deficit view that pervades public discourse, the bilingual population is often described as 'linguistically isolated', implying that because their English is less than proficient their lives are very marginal. Yet in immigrant communities, literacy in the home language is an asset in commerce and for engagement with local and transnational media. It is not desirable to supplant it with English: a bilingualism and biliteracy which allows competence in both languages is the optimum. According to the monolingual ideology that is dominant in the public and policy spheres, however, the goal of maintaining non-English literacy for immigrants is seen as suspect, if not downright subversive. At the same time, despite the recognition of the threat of isolation brought by reduced access to English, publicly funded services to address English-learning needs for adult migrants (working in jobs such as cleaning, construction, restaurants or lawn care, often with other 'linguistically isolated' workers) 
are scant, with little opportunity to learn even social English, let alone the powerful varieties such as academic English.

A substantial body of research suggests that for immigrant students whose first language is other than English, prior education and formal academic skills in the first or expert language correlate strongly with the development of the English proficiency necessary for educational success (Burt and Peyton 2003; Cummins 2009; Thomas and Collier 2003). Students with academic skills from their home countries can flourish in English as a Second Language classes. However, a significant cohort of students with interrupted schooling and emergent literacy are destined to repeat ESL classes multiple times, often as a result of ineffective program design. We argue that an effective pedagogic response to this state of affairs is to capitalise on students' home languages. The use of students' expert languages in class can provide invaluable support in the language learning process. Well-implemented multilingual instructional models have been shown to promote high achievement and enable immigrant students to solidify their skills in the home language while strengthening their academic English (August and Hakuta 1997; Cummins 2009; García 1999; Goldenberg 2008; Thomas and Collier 2003). An examination of studies of young adult and adult learners highlights a compelling link between strategies that focus on building students' native language skills and enhanced English language development (Burt and Peyton 2003; Condelli et al. 2003; Lukes 2009). In the US, a diverse array of public, community-based, and for-profit educational programs provide education and training services for immigrant adults seeking to learn English and gain skills for employment, yet few incorporate bilingual approaches designed for adults with only emergent native language literacy resulting from interrupted formal schooling.

Broad-brush quantitative OECD research shows that immigrants with low levels of education have correspondingly weak skills in literacy, numeracy and problem solving (OECD 2013). This is persistently felt by educators of migrant adults, who understand the impact of limited L1 literacy on student participation and progress. Foundational policy literature on these adult learners has tended to focus on classroom instructional strategies (e.g. Bigelow and Schwartz 2010), rather than on programmatic models, however. Yet the challenges do not exist solely in the classroom. From an economic perspective, adults with emergent literacy comprise a sizeable portion of the nation's workforce. By providing adequate, systemic funding at the level of curriculum and program, the US could better address the needs of migrant workers, which in turn benefits the population as a whole.

Continuing the employment theme, of all low-educated workers aged 25 and older employed in New York State in 2008, 61.9 percent $(484,511)$ 
were immigrants. At the national level, immigrants accounted for 47.5 percent of non college-educated and 15.4 percent of college-educated employed workers (Migration Policy Institute 2008). These numbers are supported by national and international surveys of adult literacy. General though these numbers may be, masking local variation and the texture of people's lives, they still show that the more educated a person is, the higher his or her income is likely to be (Baer et al. 2009; OECD 2013). This disparity is particularly striking for those at the upper and lower ends of this distribution. People in households with incomes of $\$ 10,000$ or less were ranked more often than not at the NAAL's lowest literacy level, while those in households with incomes of over $\$ 100,000$ tended to be ranked in the highest band (Baer et al. 2009). Results from the Program of International Assessment in Adult Competencies 2012 (PIAAC) survey point to these disparities persisting and possibly even worsening (OECD 2013). One discouraging finding from this survey shows no difference in the English literacy abilities of new immigrants as compared to immigrants who have been in the country for 5 years or more, with both groups trailing far behind the ability of native speakers. This is particularly significant, as average US literacy levels on the PIAAC survey were among the lowest of the 23 countries surveyed.

\section{Existing programming trends}

The findings in the following sections are drawn from research conducted in New York City by the authors between 2008 and 2011 at 10 NYC programs that serve immigrant English language learners. Surveys, interviews and focus groups were conducted at each site.

In the 2011-2012 program year, 733,624 immigrant adults in the US were enrolled in federally funded English as a Second Language classes (NRS n.d.), only a tiny fraction of the country's estimated 21.6 million limited English proficiency (LEP) adults (Capps et al. 2009). Although there is not a vast body of research in this area, existing studies indicate that adult immigrants tend to be most successful in ESL programs when they have a solid academic foundation and, conversely, adult immigrants with emergent literacy skills in their first language tend to struggle and make limited progress in these same contexts (Burt and Peyton 2003).

Designed as a means to improve labor market skills and promote upward mobility, workforce development is often off-limits or inaccessible to many immigrants in the US due to the level of English proficiency required to qualify for participation. The linear design of such programs requires that students be relatively proficient in English before they enter a workforce development track. As a result, much of the workforce development offerings for adult English learners by their design exclude adults with interrupted formal schooling and emergent literacy, 
consequently rendering workforce development training inaccessible to large numbers. In fact, high school equivalency, a very long-term goal for people with emergent literacy skills, is a benchmark needed to progress out of many US workforce training programs because it is a requirement of so many employers.

Workforce development program designs tend to reinforce pervasive deficit views that immigrants with emergent English and emergent literacy have limited potential, feeding into learners' own sense of inadequacy upon enrolling in classes and after failing to make progress or achieving short-term attainable milestones. For service providers that receive public funding in the US, workforce training is measured by students' attainment of higher-level employment, an outcome rarely attainable given the requirement of high school equivalency. In addition to being enrolled in English or literacy courses, students have very tangible familial responsibilities. These adults face a daily struggle as workers in low wage employment, parents and community members to overcome obstacles presented by literacy.

Another central factor determining which employment skills program an individual might attend is their immigration status. Much existing funding restricts enrollment to individuals with a 'legal' immigration status. There are an estimated 11 million unauthorised immigrants currently in the US, with the vast majority (72 percent) of working age and nowhere near retirement (Capps et al. 2013). This cohort of immigrants could benefit greatly from workforce development but is essentially denied workforce training services despite its overrepresentation in low-skilled jobs in many sectors of the US economy.

\section{Programming and practice}

Three types of challenges - fiscal, structural, and pedagogical - emerge when considering the design of effective programs for adult immigrants with limited literacy in either their expert language or in English.

On the fiscal side, the level of public funding for adult education programs depends on documented student gains in English, high school equivalency or workforce skills. This is regardless of students' prior literacy, educational background or legal status. Students' progress within native language literacy (BENL or Basic Education in the Native Language) is considered 'not measurable' and cannot be used to demonstrate student growth. As a result, publicly funded programs shy away from providing native language or bilingual programs for adults. Those programs that do use federal funds for BENL instruction are forced to offer blended ESOL/BENL courses in order to show students' development in English. 
Program design issues are central to services for immigrant adults who attend classes by choice. Adult students have limited time, and are under pressure - from potential employers, from those around them and indeed from themselves - to 'just learn English'. A native language literacy class, especially one without a practical component such as 'job readiness', can seem irrelevant to them. Moreover, although students from diverse linguistic backgrounds can benefit from native language classroom support, examples of bilingual approaches to adult literacy education are limited to contexts with a majority population or 'critical mass' of one particular language (such as Spanish in New York, Los Angeles or Chicago).

Of course, adults from all language groups can benefit from native language curricula, and program design is key to avoiding the exclusion of individuals for whom such a service might be appropriate. Yet programs must also be creative and flexible enough to adapt to changing needs and circumstances, recognizing that populations differ. Instructionally, programs grapple with how to address the needs of adults with emergent literacy in ways that neither infantilise nor bore the students. It is easy to forget that students with emergent literacy and basic skills are competent adults who manage work and family. Instructional materials for emergent literacy need to be interesting and engaging, but these are limited in availability, which often compels teachers to create their own materials.

Unsurprisingly, adults with highly developed native language academic skills use their educational foundations to succeed in English as a Second Language courses. However, for students like Fatima and Gabriel who struggle with reading and writing in their home language due to limited native language schooling, traditional adult classes are not a good fit (Burt and Peyton 2003; Rivera 1990), as they often focus on oral skills and assume a basic level of reading and writing. Programs designed for adults who have interrupted schooling must also address socio-emotional factors including students' deeply held sense of incompetence (Comings et al. 2000). Few programs are designed to teach basic literacy in an engaging way without demeaning adult students who may not know how to write simple words. Even fewer integrate L1 literacy development as an aim. In courses that are not appropriate for their specific needs, students like Fatima and Gabriel with emergent literacy skills often experience frustration and lack of progress that feels sadly familiar, prompting them to abandon their studies.

We turn now to two examples of effective programs which had been successful, but which ultimately closed down, to illustrate the issues around policy, design, funding and sustainability of bilingual literacy provision for adult migrants. 


\section{Examples of success}

\section{Service Providers del Barrio}

One example of a program that experienced significant success is Service Providers del Barrio (SPB), a community-based social provider in one of Manhattan's most densely populated Hispanic neighborhoods. SPB circumvented restrictions created by public funding policy mandates by using private foundation funding and donations to support its Spanish literacy program. Comprehensive education services targeted a population of Mexican and Central American immigrant women, most with children in public schools and many with three years or fewer of formal schooling. The students in this free program entered basic literacy classes in Spanish, learned computer skills and could enroll in ESL, parenting, entrepreneurship and high school equivalency classes. Students who had not yet learned the alphabet - who made up a significant proportion - worked collaboratively to develop the skills to read and write simple texts. Approaches included a language experience approach in Spanish to writing personal narratives and poetry, and incorporating computer skills in even the most basic classes. Students, many with small children, wrote autobiographies, using a participatory problem-posing approach to explore the structural obstacles to their education, learned basic math to make a family budget and learned to navigate the public school and health care systems. Paid teachers and volunteers participated in monthly professional development as part of a citywide network of Spanish literacy providers, where they learned effective instructional approaches, lesson planning, goal-setting and assessment and discussed successes and challenges of their work. At its peak, SPB had an enrollment of 200 students, and over the course of the 16 years in which it ran, educated nearly 1,000 students in classes ranging from basic literacy, computer skills and English as a Second Language. SPB shut its doors on literacy and education services in 2013. This was a major loss to the surrounding community. The recession, challenges in fundraising and changes in leadership led to discontinuation of services that had been provided to the community for more than a decade.

Learning to read and write as an adult takes time and effort. Typically attendance and retention rates on adult literacy programs are very low, due to the extended study time needed to progress through a program. Over the years that SPB provided literacy services in Spanish and English, persistence among its student population exceeded that for many traditional adult literacy providers, who often experience dropout rates of up to 50 percent (Fitzgerald and Young 1997). The majority of SPB's students maintained attendance rates of upwards of 80 percent. Classes, staffed with multilingual community members and assisted by volunteers 
who were or had been students themselves, met multiple times per week. Persistence over the years was feasible in SPB's community-based setting, with an emphasis on relationship-building and personal attention. Program impacts included not only literacy, basic skills and oral English, but improved self-esteem and self-efficacy. The loss of SPB's services after so many years left a significant gap in the community.

\section{Urban Community Services}

Another program that attempted to address the needs of low literate, non-English-speaking adults in New York is Urban Community Services (UCS), a large, multi-service community-based organisation. UCS serves immigrant and low-income communities of Washington Heights, Inwood and the Bronx, home to many Spanish-speaking immigrants, and an area with the lowest levels of high school attainment and highest levels of poverty among immigrant subgroups in New York City (Bergad 2013). UCS's adult education program took a different approach to offering literacy services in the home language of its students. Federal law does not prohibit instruction for adults in the native language. However, all approved assessment tools for documenting adult students' progress are in English. This creates a fine line in relation to compliance. Rather than assigning all students to ESL classes, the program used a native-language literacy-screening tool to identify students who could benefit from literacy services. With a creative combination of public and private funding, UCS staff designed basic literacy classes to address literacy needs and practical life demands. They found that students were not interested in classes that taught them to read and write only in Spanish, so they created hybrid classes offering both native language literacy and basic ESL instruction. All classes met for a minimum of 10 hours a week.

UCS's hybrid classes leaned heavily on an ESL curriculum that mirrored National Reporting System (NRS) levels and which encouraged critical and creative thinking, problem solving and interpersonal skills. The curriculum was content-based and modular. Teachers had the option of selecting modules best suited to their students. The native language literacy classes were conducted bilingually in Spanish and English, and also employed new technology. Teachers followed a thematic modular framework. As students graduated from the hybrid class, they had the option of transitioning either into a pre-GED class in Spanish to prepare for a high school equivalency diploma, or into an ESL class. Neither class was an ideal transition, but it was the best that agency could offer. Additionally, the program offered weekend small group literacy tutoring and conversation classes in English.

UCS was fortunate to have one of the larger programs in the city and, because it had substantial funding for all its adult education offerings, 
regular and paid professional development was provided in-house in the form of workshops, teacher share sessions, peer support and constructive observations. Additionally, teachers and administrators were encouraged to participate in citywide professional development courses and workshops. For native language literacy instruction specifically, UCS's teachers participated in the same citywide support network as SPB.

Because UCS received public funding, the program was required to document student growth in English literacy skills. Practically speaking, out of the nearly 40 classes offered by UCS, only three were for BENL and Spanish pre-GED. An increase in the number of BENL hybrid classes would have negatively impacted upon their accountability measures as per the state programmatic report card (the assessment system by which funding is calculated), as academic progress in English was typically slow for BENL students. The Spanish pre-GED classes were funded solely with private money. After several years of offering those classes, the program lost the private funding and could no longer offer Spanish language instruction. Sensitive to the remaining need, the service continued to offer support to teachers around how to address basic literacy needs while teaching ESL. The administrators of the program were aware that this was far from ideal but could find no alternative.

The program continued to offer adult ESL and GED classes until June 2013 when it lost over one million dollars of annual federal funding that was allocated through the state. This loss came as a shock to the agency and across the city as the program had historically ranked among the highest in state report card scores. The state had decided not to use their mandated report card system for the scoring of the proposals in response to a request from the federal Office of Vocational and Adult Education (OVAE 2013). This decision led to some of the highest performing programs, as measured by the programmatic report card system, losing funding while some of the lowest performing programs received funding. This decision by the state government has led to a loss of ESL and GED classes in some of the greatest need and immigrant communities across NYC. Despite these losses, UCS continues to offer educational services, though these are greatly reduced. As committed partners in their community, they work to rebuild their educational offerings.

\section{Discussion and implications}

Not unlike trends in K-12 education, where schools are penalised for failing to demonstrate academic progress of the hardest to serve students, adult education providers receiving public monies are judged based on documented progress of their students in English. This is a reflection of a monolingual ideology that ignores the value and potential of multilingualism among rapidly growing immigrant populations of US 
English learners at the lowest levels of proficiency and with only emergent literacy in their home language. These students struggle to make progress in traditional English as a Second Language classes, where reading and writing skills are often at the core of instruction. In reality, there are few fiscal or policy incentives for programs to serve low-literate immigrant adults and existing accountability structures may create disincentives. With an eye toward sustaining services and procuring funding based on past performance, program administrators may be put in the position of excluding the adult learners who are already the most marginalised, and who risk not demonstrating progress in English based on existing accountability measures.

As shown in the examples above, well-designed programs - including bilingual programs - that serve emergent literate adults exist, but funding restrictions can undermine their sustainability. Key to addressing the needs of the twenty-first century workforce is the importance of attending to sustainability for creative programs that struggle to meet the needs of hard-to-serve populations, increase capacity and address workforce development not only for those who can easily make a transition, but also for those with emergent English and literacy (Fix and Capps 2010). Heide Wrigley and colleagues put it best when they wrote: 'Virtually all of our nation's new workforce growth for the foreseeable future will come from immigration, so failure to assist immigrants in improving their language and job skills is likely to hurt workforce productivity over the long term' (Wrigley et al. 2003). Failure to attend to this growing population will likely lead to a growing immigrant underclass stuck at the bottom rungs of the labor market. The long-term ramifications of insufficient education and workforce training to foster upward mobility will be seen through their negative generational effects on the children of US immigrants, on the communities in which they live and, ultimately, on the US economy. The issues mentioned in this chapter - policy, funding and sustainability - must be addressed in creative ways to directly address challenges that undermine bilingual approaches while providing incentives for effective programming.

\section{References}

August, D. and Hakuta, K. (1997) Improving Schooling for Language-Minority Children. Washington, DC: National Academy Press.

Baer, J., Mark, K. and Sabatini, J. P. (2009) Basic Reading Skills and the Literacy of America's Least Literate Adults: Results from the 2003 National Assessment of Adult Literacy (NAAL) Supplemental Studies (NCES 2009-481). Washington, DC: National Center for Educational Statistics, Institute for Educational Statistics.

Bergad, L. (2013) Trends in Median Household Income among New York City Latinos in Comparative Perspective, 1990-2011. City University of New York: Latino Data Project, Report 54, October 2013. www.gc.cuny.edu/CUNY_GC/ 
media/CUNY-Graduate-Center/PDF/Centers/CLACLS/Trends-in-MedianHousehold-Income-Among-New-York-City-Latinos-in-ComparativePerspective,-1990-2011.pdf (accessed 18 December 2014).

Bigelow, M. and Schwartz, R. L. (2010) Adult English Language Learners with Limited Literacy. Washington, DC: National Institute for Literacy. Available online at http:// lincs.ed.gov/publications/pdf/ELLpaper2010.pdf (accessed 18 December 2014).

Burt, M. and Peyton, J. (2003) Reading and Adult English Language Learners: The Role of the First Language. Washington, DC: National Center for ESL Literacy Education.

Capps, R., Bachmeier, J. D., Fix, M. and Van Hook, J. (2013) A Demographic, Socioeconomic, and Health Coverage Profile of Unauthorized Immigrants in the United States. Washington, DC: Migration Policy Institute. Available online at www.migrationpolicy.org/pubs/CIRbrief-Profile-Unauthorized.pdf (accessed 18 December 2014).

Capps, R., Fix, M., McHugh, M. and Lin, S. Y. (2009). Taking Limited English Proficient Adults into Account in the Federal Adult Education Funding Formula. Washington, DC. Available online at www.migrationpolicy.org/pubs/WIALEP-June2009.pdf (accessed 18 December 2014).

Comings, J., Parella, A. and Soricone, L. (2000). Helping adults persist: four supports. Focus on Basics 4(A).

Condelli, L., Wrigley, H., Yoon, K., Cronen, S. and Seburn, M. (2003) What Works Study for Adult ESL Literacy Students. Washington DC: US Department of Education.

Cummins, J. (2009) Literacy and English language learners: a shifting landscape for students, teachers, researchers and policy-makers. Educational Researcher 38(5): 382-383.

Fitzgerald, N. and Young, M. (1997). The influence of persistence on literacy education in adult education. Adult Education Quarterly 47(2): 78-92.

Fix, M. and Capps, R. (2010) Still an Hourglass? Immigrant Workers in Middle-Skilled Jobs. Washington, DC: Migration Policy Institute. Available online at http:// my.migrationpolicy.org/images/2010.9.20-MPIPowerpoint-Immigrant Workers in Middle-Skilled Jobs.pdf (accessed 18 December 2014).

García, O. (1999) Educating Latino high school students with little formal schooling. In C. Faltis and P. Wolfe (eds), So Much to Say: Adolescents, Bilingualism and ESL in the Secondary School. New York: Teachers College Press, 61-82.

Goldenberg, C. (2008) Teaching English language learners. American Educator 37(3): 8-44.

Lobo, A. P. and Salvo, J. J. (2013). The Newest New Yorkers (2013 edn). New York: New York City Department of City Planning. Available online at www.nyc.gov/ html/dcp/pdf/census/nny2013/nny_2013.pdf (accessed 18 December 2014).

Lukes, M. (2009) We thought they had forgotten us: research, policy and practice in the education of Latino immigrant adults. Journal of Latinos and Education 8(2): 161-172.

Migration Policy Institute (MPI) (2008) MPI Data Hub Immigration Statistics by State: New York. Washington, DC: Migration Policy Institute.

NRS (n.d.) National Reporting System Program Aggregate Tables Program Year 20112012. Available online at http://wdcrobcolp01.ed.gov/CFAPPS/OVAE/NRS/ reports/ (accessed 18 December 2014). 
OECD (2013) OECD Skills Outlook 2013: First Results for the Survey of Adult Skills. Paris: OECD Publishing.

Office of Vocational and Adult Education (OVAE) (2013) Adult Education and Family Literacy Act of 1998: Annual Report to Congress, Program Year 2010-11. Washington, DC: OVAE. Available online at www2.ed.gov/about/offices/list/ovae/resource/ aefla-report-to-congress-2010.pdf (accessed 18 December 2014).

Rivera, K. M. (1990) Developing native language literacy in language minority adults. ERIC Digest. Washington, DC: National Center for ESL Literacy Education. (ED 358 747)

Ryan, C. L. and Siebens, J. (2012) Educational Attainment in the United States: 2009. Washington, DC: US Census Bureau. Available online at www.census.gov/ prod/2012pubs/p20-566.pdf (accessed 18 December 2014).

Thomas, W. and Collier, V. (2003) A National Study of School Effectiveness for Language Minority Students' Long-term Academic Achievement. Santa Cruz, CA: Center for Research on Education, Diversity and Excellence, University of California.

Wrigley, H. S. (2007) Beyond the life boat: Improving language, citizenship, and training services for immigrants and refugees. In A. Belzer (ed.) Toward defining and improving quality in adult basic education: Issues and challenges. Mahwah, NJ: Lawrence Erlbaum Associates, 221-239.

Wrigley, H. S., Richer, E., Martinson, K., Kubo, H. and Strawn, J. (2003) The Language of Opportunity: Expanding Employment Prospects for Adults with Limited English Skills. Washington, DC: Center for Law and Social Policy. Available online at www.sbctc.ctc.edu/college/education/career_pathways_wrigley_ language_opportunity_rpt_june07.pdf (accessed 18 December 2014). 


\title{
Afterword
}

\author{
Marilyn Martin-Jones
}

The chapters in this volume make a significant contribution to our efforts to develop a new social and applied linguistics of globalisation. They focus on a field of research and practice that has, hitherto, received insufficient attention in mainstream sociolinguistics and studies of language education. There is much to be learned from research and practice in this particular sector of education. Language education programs for adult migrants figure prominently among the new contact zones of the global order (Pratt 1991; Martin-Jones et al. 2012). Within these particular contact zones, the challenges and opportunities of contemporary mobilities are keenly experienced, by adult learners and by the practitioners (and volunteers) who work with them. Taking a close look at the day-to-day practices and lived experiences of teachers and adult learners in such language education programs - and at the discourses about migration policy, about language and about pedagogy that confront them - gives us a powerful lens on the processes of political, social and linguistic change taking place in the wake of globalisation.

The volume as a whole gives us a critical, historical and comparative perspective on contemporary policies and practices related to adult language education and migration. It spans policy and practice in nine nation-states: Australia, Canada, France, Finland, Ireland, the Netherlands, Spain, the United Kingdom (UK) and the United States (US), including two autonomous regions: Catalonia and Quebec. The chapters chart the shifts over time in national policy with regard to linguistic diversity, showing very clearly how these responses have been bound up with shifts in wider political discourses about inward migration, national identity and citizenship. We also see the consequences of these shifts on the ground, that is, the consequences for individuals crossing borders, taking language and citizenship tests, or attempting to gain access to spaces where they can learn the language of their new places of residence and/or work and where they can develop new language and literacy capabilities, extending their existing communicative repertoires and their available designs (Kern 2000). 
Moving across scales - from national political arenas to local ones; from national to supranational institutions, such as the European Union (EU), and then back down to local classrooms, to teachers and to particular groups of adult learners - the eighteen chapters and the substantial Introduction by James Simpson and Anne Whiteside provide us with revealing insights into responses to linguistic and cultural diversity and to the new mobilities of the twenty-first century. They take account of both policy and practice and identify both commonalities and differences across contexts. Looking across the national and regional contexts featured in the volume, we see that language has, indeed, become a new basis for discrimination between different categories of people - albeit in different ways and to different degrees. The accounts of the situations in the Netherlands (Chapter 13) and the UK (Chapter 15) draw the bleakest pictures of developments in policy-making and statutory educational provision. In other contexts, we see the impact of the absence of policymaking on adult migration education, either as a result of historical ambivalence to English in Ireland (Chapter 11) or as a result of an entrenched English-only ideology in the US (Chapter 17) and a legislative impasse due to pressures on legislators (at federal and state level) from an electorate that is polarised between liberal and highly conservative views on immigration.

A critical perspective has been incorporated into all the chapters. It is, of course, indexed in the title of the volume and in the double-entendre of the initial phrase: challenging agendas. The new policy agendas and their demands on practitioners and learners are, indeed, challenging and impose considerable difficulties and hardships. But the title of the volume also indexes the intention of the authors to engage in critique, to unpack policy agendas and to lay bare the ideological basis of these agendas and their consequences for pedagogy.

In his research on language-in-education policy in the US, Johnson (2009) made a useful three way distinction between the different processes involved in policy-making. These include: policy creation, policy interpretation and policy appropriation (or contestation or subversion). This distinction is cited in the Introduction to the volume and in the chapter by Sari Pöyhönen and Mirja Tarnanen (Chapter 7). Looking across the volume, we see how the discursive processes involved in policy creation on one scale get interpreted and appropriated on other scales.

Take, for example, the contemporary framing of adult migrant education policy and practice in terms of the notion of 'integration'. This has been a recurring trope in EU policy creation processes since the late 1990s; that is, on a supranational scale of policy creation within Europe. As we see from this volume, this discursive trope has been interpreted and taken up in different ways in the national policies of different member states. It is underpinned by particular ideologies about language, nation 
and identity and by the simplistic representation of nations as distinct, relatively homogeneous entities, embracing - across their different regions - groups of people with 'shared' sets of values. The contemporary salience of this discourse about 'integration', in Europe and elsewhere, stems from the increasing political unease about the erosion of the power and stability of nation-states in the wake of the far-reaching changes taking place in the global political and economic order.

However, it is important to bear in mind that, along with other discourses about 'host societies', this currently dominant discourse about 'integration' is embedded in a much older, modernist discourse about immigration that was articulated as long ago as the 1960s. That discourse was widely critiqued (e.g. Mullard 1982; Troyna and Williams 1986), but in the light of the more intensely discriminatory discourses circulating in the twenty-first century, reference to 'integration' now indexes - for some - a relatively moderate politics of inclusion. Nevertheless, it is vital for us to remain alert to the different ways in which this term is still used and interpreted. In their Introduction to the volume, James Simpson and Anne Whiteside offer valuable reflections on unthinking uses of the term, asking the crucial question: 'Integration into what?' and interrogating the relevance of this notion in a global age, when the urban contexts of many nation states have become so diverse.

In six of the policy chapters in this volume, we see some of the narrow ways in which this dominant EU discourse about 'integration' has been interpreted and appropriated, on national and regional scales. There are commonalities across these national and regional contexts, especially in countries like France, the Netherlands and the UK, which all have a long history of in-migration. There are, for example, commonalities in the shifts away from a broad concern with the language rights of refugees and migrants and with providing support for language learning, to an increasing neo-liberal focus on gearing language education provision to preparation for employment and to 'skilling up' migrants entering the workforce. There are also differences across EU member states: whilst elements of policy-making in Finland remain relatively supportive of different forms of provision for adult migrant education in terms of funding, in the Netherlands and the UK there appear to have been sharp shifts in policy towards new and unduly harsh regimes of language involving the imposition of charges for language courses and the marketisation of educational provision, while, at the same time, cutting benefits and social welfare.

In the six chapters on policy in EU member states, alongside countryspecific accounts of the interpretation and appropriation of EU policy discourses about 'integration', we also see new political and social processes of exclusion at work and an intensification of pressures from far-right political groups on immigration. The discourses and practices of exclusion 
differ in degree and complexity in different member states of the EU and they differ in the ways in which aspects of language education provision and forms of assessment are co-opted in the service of immigrant policy. These new practices are most visible in the context of the Netherlands and the UK, in the general tightening of restrictions on inward migration; in the ways in which language is employed as a means of restricting inmigration, in the introduction of citizenship tests and in the gradual replacement of geographically defined national borders with virtual ones. The most striking developments lie in the heavy reliance on the use of new technology in the administration of language and citizenship tests in the Netherlands, and in the design and running of language learning provision (for provision of both a mandatory and optional nature). Here, we see a nation-state drawing on what Appadurai (1996) has called the new 'technoscapes' of our globalised world to articulate a response to the rapidly changing 'ethnoscapes' of the same world.

I have focused thus far on policy creation processes on the supranational scale of the EU and on national and regional scales in EU member states. However, the geographical scope of the volume and the scope of the policy analysis undertaken here is much broader. This breadth of coverage is one of the strengths of the collection. All nine policy-related chapters provide illuminating accounts of the ways in which different nation-states or autonomous regions, on three different continents, have attempted to create policies, infrastructure and pathways around inward migration and to make provision for language and literacy education for adult newcomers. In all these chapters, we see that policy creation processes have been conducted with a view to defining and reproducing the language-nation-identity nexus in terms that are as uniform as possible. Together, the eighteen policy and practice chapters capture the tension between these top-down ways of creating policies that are guided by concerns about unity and homogeneity and the actual complexities involved in developing provision for language support for highly diverse groups of adult migrants. They also show how a neo-liberal agenda is increasingly guiding policy on immigration and on provision for adult migrant education and support for newcomers. In addition, they depict the mismatch between narrowly conceived monolingual language education provision and multilingual realities and diversities 'on the ground' which are due to the increasing porosity of national borders.

In contrast to the chapters on policy, the nine chapters on language education practice present vivid illustrations of the ways in which creative and resourceful practitioners interpret and appropriate adult migrant language education policy on a local scale, navigating policy shifts and making space for innovative ways of engaging with and supporting adult learners. We see practitioners working against the grain, posing challenges to different policy agendas, refashioning programs to fit local conditions, 
dealing with complexity and difference, aiming at the fostering of what Douglas Fleming calls 'participatory' and 'justice-orientated' citizenship (Chapter 4), and opening up alternative possibilities for practice possibilities that are better attuned to the specific needs of adult learners. The authors of these chapters engage in critical reflection on practice, charting out new directions and envisioning what Alastair Pennycook (2001) called 'preferred futures' in his book on Critical Applied Linguistics.

Laura Chapman and Alan Williams (Chapter 2), Sandra Doyle (Chapter 12) and Melanie Cooke, Becky Winstanley and Dermot Bryers (Chapter 16) demonstrate the advantages that accrue from engagement with local communities and from dialogue with adult migrants about their learning needs, about the ways in which they deal with the new conditions in which they find themselves and about wider issues related to cultural values, citizenship, race and class differences. These authors show us how discussions of this kind can lead to recalibration of approaches to teaching and learning and to the development of new kinds of teaching and learning resources.

Maria Rosa Garrido and Xavier Oliva (Chapter 6), Noëlle Mathis (Chapter 10) and Marguerite Lukes and John Lyons (Chapter 18) challenge the profoundly monolingual bias in adult migration language education programs, indicating how spaces can be made for adult learners to draw on the range of communicative resources available to them (in speaking, reading and writing) - spaces characterised by a range of hybrid and translingual practices of the kind described by Canagarajah (2013).

Laura Chapman and Alan Williams (Chapter 2), Minna Intke-Hernandez (Chapter 8) and Sandra Doyle (Chapter 12) show how adult participants in particular kinds of programs can build on the learning they have done outside the classroom. These authors also reveal the value of locally generated curricula and teaching/learning scenarios where learners have a voice and can take a lead in pursuing particular topics and activities. Minna Intke-Hernandez points to the value of such approaches in working with groups who are off the radar of those promoting a workplace-related policy agenda, such as stay-at-home mothers.

Several authors of practice-related chapters (e.g. Laura Chapman and Alan Williams, Maria Rosa Garrido, Xavier Oliva and Melanie Cooke, Becky Winstanley and Dermot Bryers) make explicit reference to the work of Paulo Freire, the Brazilian educator (Freire, 1972) and to critical pedagogic practice based on his writing. In keeping with Freirean pedagogic principles, they characterise the practitioner's role as that of a learning mentor, supporting adult learners as they develop critical awareness of the social conditions in which they find themselves and as they gain access to the forms of linguistic capital they need to address these conditions and to work for change.

I have cited just a few examples above, but in all of the practice chapters, we see very different ways of construing adult migration education from 
those inherent in the top-down language education programs and predesigned syllabuses promoted on a national scale. These alternative local accounts of innovative practice entail a very different understanding of 'integration'. As James Simpson and Anne Whiteside put it so well in their Introduction, in these examples of innovative practice, 'integration' is reimagined as a 'two way street' - one in which there is extended dialogue and engagement involving practitioners and learners.

The overall editors of this volume, James Simpson and Anne Whiteside, have shown considerable vision in incorporating chapters on policy and on practice, side by side. As they state on the first page of their Introduction, they set out to reveal, in this way, the mismatch between 'national government responses to the language learning needs of adult migrants' and 'what actually happens on the ground'. The policy chapters provide us with detailed, informative accounts of the commonalities and differences in the discursive processes involved in policy creation across the nine national contexts featured here, showing how the creation of language education policies has been shaped, historically, by political and economic conditions in each nation-state or autonomous region and by powerful discourses about migration and national identity. They have also shown us how political tensions, policy shifts and drastic postrecession funding cuts have impacted on language education programs and on innovative forms of provision for adult migrants. The broad picture that emerges from these chapters is a rather stark one, especially in those chapters that deal with contexts where policy developments are most clearly driven by a neo-liberal agenda.

In contrast, the picture that emerges from the chapters about language education practice, in local classrooms and in local gatherings and activities, inside and outside the classroom, is a much more heartening one. We see what can be achieved locally, by confident, committed and experienced practitioners, in working against the grain and in charting out preferred futures. As readers of these chapters, we are reassured that there is still room for agency and for opening up spaces for alternative ways of working, albeit in challenging contemporary conditions. The critical approaches to practice set out in these chapters and the depth of policy analysis provided by all authors (and the two editors) clearly stems from a deep compassion and concern with the increasing social and linguistic inequalities in countries that are current destinations for migration. This is what makes the volume such a gripping read.

\section{References}

Appadurai, A. (1996) Modernity at Large: Cultural Dimensions of Globalization. Minneapolis: University of Minnesota Press. 
Canagarajah, S. (2013) Translingual Practice: Global Englishes and Cosmopolitan Relations. New York: Routledge.

Freire, P. (1972) Pedagogy of the Oppressed. New York: Continuum.

Johnson, D. C. (2009) Ethnography of language policy. Language Policy 8: 149-159.

Kern, R. (2000) Literacy and Language Teaching. Oxford: Oxford University Press.

Martin-Jones, M., Blackledge, A. and Creese, A. (2012) Introduction: a sociolinguistics of multilingualism for our times. In M. Martin-Jones, A. Blackledge and A. Creese (eds), The Routledge Handbook of Multilingualism. Abingdon, Oxon: Routledge, 1-26.

Mullard, C. (1982) Multiracial education in Britain: from assimilation to cultural pluralism. In J. Tierney (ed.) Race, Migration and Schooling. London: Holt, Rinehart and Winston, 120-134.

Pennycook, A. (2001) Critical Applied Linguistics. Mahwah, NJ: Lawrence Erlbaum. Pratt, M. L. (1991) Arts of the contact zone. Profession 91. New York: Modern Language Association.

Troyna, B. and Williams, J. (1986) Racism, Education and the State. Beckenham, Kent: Croom Helm. 


\section{Index}

Aboriginal Australians 27

acculturation, citizenship education and 70-1

Action for ESOL campaign 209-10, 217

Adult ESOL Core Curriculum (AECC) 208

adult literacy 150, 158, 164-5, 207, 244-56

Adult Literacy and Basic Skills Unit (ALBSU) 207

Adult Migrant Education Programs

(AMEPs) 23-4, 30-1, 35-41

AECC see Adult ESOL Core

Curriculum

Afghan migrants 23

African languages 95, 96

ALBSU see Adult Literacy and Basic Skills Unit

Alina, plurilingualism case 145-6

AMEPs see Adult Migrant Education Programs

Anarchist Exclusion Act (1903), US 227

Anglophones, Quebec 50

Appadurai, A. 197

Arzoo, Dutch language learner case 194

Asian migrants 24, 27

asylum-seekers 109, 150-3

Atlanta 232

Australia: Aboriginal Australians 27; adult English language learning policy 19-34; Adult Migrant

Education Programs 23-4, 30-1, 35-41; Afghan migrants 23; Asian migrants 24, 27; Beginning Life in

Australia booklet 36; British colonization 21; Commonwealth Office of Education 23, 24; contentbased instruction 37-8, 41-2; critical language teaching 11 ; cultural diversity 19-20; cultural identity 26, 27; cultural pluralism 27-8; employment of migrant learners 36, 37; ESL policy 19-34; German-English bilingual schools 22; Get Wise teaching materials 38; Hands on English program 39-41; health content information 45 ; history 21-3; human rights resources 41-2; immigration policies 21-7; language tests 21-2; legislation 21-2, 24-5; Living in Australia website 36; low literacy background ESL learners 35-48; monolingualism 20; multiculturalism 20, 25-30; plurilingualism 26, 28, 30-1; Water Safety Program 43-4; work placements 36, 37; Young Migrant Education Program 43-4 authenticity ideology, Catalan language 103-4

Barcelona 95

Barère, Bertrand 129

Barton, Edmund 22

Basic Education in the Native

Language (BENL) 249, 253

BBC 207 
Beginning Life in Australia booklet 36 Bejan, Dutch language learner case 191-2

BENL see Basic Education in the Native Language

bilingualism 96, 230, 238, 246, 250-3

Bill and Melinda Gates Foundation 240-1

Blair, Tony 202

BNAA see British North America Act

Bosch, Xavier 88

Bot, B. 176

Bouchard-Taylor Commission report 60

Britain see United Kingdom

'Britishness' debate 202-5

British North America Act (BNAA) 52

Brohy, C. 140

Bullock report 207

CAI see Contract for Welcoming and Integration

Cameron, David 202

Canada: citizenship education 66-81; employment 68, 69; ESL learners 66-81; Francophones 50, 51, 53;

French language education policy 49-65; immigration policies 49, 51-2, 60; justice-oriented citizenship education 66-81; population 49, see also Quebec

Canadian Citizenship Act (1946) 52

Canadian Language Benchmarks: ESL for Adults 67-70

Capable Parent project, Finland 119, 120-6

Catalan language: authenticity ideology 103-4; collaborative processes in language teaching 100-2; critical literacy approach 98; cultural debates in language classes 104; education policy 82-93; functional literacy in language programs 97-100; language courses 87-91; Language Volunteering program 90; linguistic background 82-3; linguistic welcome approach 85-6; multilingual approach in language teaching 101, 102-4; nationbuilding 3-4; nongovernmental classes 94-106; social goals in language programs 97-100; teaching materials 100-2

Catalonia: African language speakers 95, 96; Catalan language education policy 82-93; Catalan Statute of Autonomy 84; Consortium for Language Normalisation 86, 89-91; homeless migrant project $94,95-7$; immigration policy 84-7, 94-5; integration policy $85,88-9$; linguistic requirements for immigrants 87-9; multiculturalism 96-7; nongovernmental Catalan language classes 94-106; Spanish language in 83, 86, 96

Catholic committee, Department of Public Instruction, Quebec 53-4

CBI see content-based instruction

CBL see Canadian Language Benchmarks...

CEFR see Common European Framework of Reference for Languages

Certificates of Spoken and Written English (CSWE) 40, 44, 45 charities, French language teaching 134-5

Charter of the French language, Quebec 56, 62

Chinese Exclusion Act (1875), US 226

Chinese language 143-4

citizenship education, France 136

citizenship education/training: acculturation 70-1; Canadian Language Benchmarks 68-70; civic roles 71-2; concept of citizenship 70-1; ESL teacher research 72-9; justice-oriented citizenship 66-81; modern citizenship 70; participatory citizenship 75-6; Quebec 51-5; types of citizenship 71-2 citizenship tests: questions 5-6; United Kingdom 203-4; United States 228-9 
Civic Integration legislation,

Netherlands 174-9, 182-3

civil rights legislation 231

classroom practices, innovative

techniques 9

Clegg, Nick 203

click-tive learning 191-2

Coalition Government, UK 209

codemeshing 141

codes 215, 220-1

Common European Framework of

Reference for Languages (CEFR)

6-7, 133, 175, 176, 182

Commonwealth Immigrants Act 206

Commonwealth Office of Education 23,24

community sector: ESL/ESOL 210, 252-3; Fitzroy Learning Network 44-6; low literacy background ESL learners 35-48, 252-3;

regeneration projects 40-1; Water

Safety Program 43-4

competence in national language 4

computers see ICT-based language training

Consortium for Language

Normalisation, Catalonia 86,

89-91

content-based instruction (CBI) 37-8, 41-2, 46-7

Contract for Welcoming and Integration (CAI), France 133

Coste, D. 140

creative writing workshop, plurilingualism case study 138-48 critical literacy approach: Catalan language 98; ESL teacher research 73-9

cross-cultural understanding, ESOL case study 168-71

CSWE see Certificates of Spoken and Written English

cultural debates, Catalan language classes 104

cultural knowledge/skills 125

Cummins, J. 99

curricula: Adult ESOL Core

Curriculum 208; Finland 112, 113
Deferred Action for Childhood Arrivals (DACA) 236-40, 242

DELF see Diploma for Studies in French

De Virtuele Wijk (The Virtual Neighbourhood) ICT-application 192-5

DILF see Initial Diploma in French

Dillingham Commission 227

Diploma for Studies in French (DELF) 133

discrimination: Ireland 165-8, 170; United Kingdom 206, 220; United States 234

'Double Dutch' 184

DREAM Act 236-7

Dublin 152-3

Dutch language teaching materials 178, 181-2, 187-99, see also Netherlands

Eastern European migrant workers 109

Eden dream 170

Education of Immigrants pamphlet 206

Emerging Worlds, Emerging Words project 216-17

employment: Australia 36, 37; Canada 68,69 ; citizenship education and 68, 69; discrimination 166-7; low-educated workers 246-8; poverty-level wages 246; Quebec 59, 61; racism 166-7; training programs 249; work placements 36

England see United Kingdom

English Innovations model 240-1

English Only states, United States 230-3

English as a Second Language see ESL

English for Speakers of Other Languages see ESOL

ESL (English as a Second Language): Australia 19-34; citizenship education 66-81; low literacy background learners 35-48; multilingual instruction 247; program design 249-50; Service Providers del Barrio 251-2; students' native language skills 247; United 
States 232-3, 240-1, 246-54; Urban Community Services 252-3

ESOL (English for Speakers of Other Languages): Action for ESOL campaign 209-10, 217; adult literacy 158; assessment of learner needs 164-5; and Basic Education in the Native Language 249, 253; classroom topics 218-23; community-based classes 210; cross-cultural understanding 168-71; curriculum 208; deficit perspective 150-3; Emerging Worlds, Emerging Words project 216-17; ESOL-Research 210; Ireland 149-72; language/lexical development 221-3; participatory approach 214-24; racism 165-8; Reflect ESOL program 215; rightsbased approach 156-9; training programs 169-70; United Kingdom 201, 205-1 1, 214-24; Whose Integration? project 217-23 ethnic minorities 5

European Union (EU): integration policy 258-60; language education 187

Exam on Spoken Dutch (TGN) 177

Executive Orders on Language Access, United States 231

FAS see Fonds d'Action Sociale pour les Travailleurs Étrangers

Fatima, English language learner case $244-5,250$

Fichte, Johann 70

Finland: 'active immigration policy' 110; adult migrant language education 119-27; Capable Parent project 119, 120-6; 'contested immigration' 110; Eastern European migrant workers 109; Finns Party 111; food culture 125-6; immigration policy 107 , 109-12; Ingrian Finns 109; integration policy 107-18; language teaching 112-16; legislation 109-12; National Core Curriculum
112, 113; Participative Integration into Finland project 107-8; Promotion of Immigrant Integration Act 110-11; refugee migrants 109; Transforming Professional Integration project 108 Finnish language teaching: cultural knowledge/skills 125; curriculum and pedagogy 112-16; issues 114-16; Mother and Child group 121-6; stay-at-home migrant mothers 119-27

Finns Party 111

Fitzroy Learning Network (FLN) 44-6

FLI see French Language for Integration

FLN see Fitzroy Learning Network Flynn, Don 206

Fonds d'Action Sociale pour les Travailleurs Étrangers (FAS) 132 food culture 125-6

foundations, role in US immigration policy 240-1

France: citizenship education 136; colonies 130; Contract for Welcoming and Integration 133; Fonds d'Action Sociale pour les Travailleurs Étrangers 132; French Language for Integration 134; French language training 128-37; immigration 128, 130-1; integration policy 132; pedagogical framework 131-6; plurilingual literacy practices 138-48; regional languages 129, 130, see also French as a Second Language

Francization programs, Quebec 55-9, 60,61

Francophones, Canada 50, 53, 55

Freire, P. 100

French Canada Overseas Service 54-5

French language education policy, Quebec 49-65

French Language for Integration

(FLI) 134, 135

French Office for Immigration and Integration 135

French Revolution 129 
French as a Second Language (FSL) 128-37; Alina, case 145-6; charities' role 134-5; Diplomas 133; Nati, case 141-3; plurilingualism 138-48; Thich, case 143-5

functional literacy, Catalan language programs 97-100

'funds of knowledge' concept 125

Gabriel, English language learner case 244-5, 250

gender roles 220

Generation 1.5, United States 238

Georgian language 142

German-English bilingual schools 22

Getting to Grips with the English Language project 163-72

Get Wise teaching materials 38

global technoscape 197

Goodluck, Dutch language learner case 196-7

Green Card applicants, US immigration reform 225-43

Greenwich community class, ESOL 218,220

Grégoire, Henri 129

Harry, Dutch language learner case 195-6

Haydon, Peter 25

health content information 45

Helsinki 119

Hispanic immigrants to United States 230,251

Holland see Netherlands

Homeland Security, US 235, 237

homeless migrant project, Catalonia $94,95-7$

homogeneism 3

human rights resources 41-2

ICT-based language training 187-99; De Virtuele Wijk application 192-5; Ijsbreker application 190-2; L2 learners 189, 190, 195; NT2 Nieuwslezer application 195-7 Ijsbreker (Icebreaker) ICT-application 190-2 immigration: Australia 21-7; Canada 49, 51-2, 60; Catalonia 84-7, 94-5; Eastern Europe 109; Finland 107, 109-12; France 128, 130-1; illegal immigrants 233-5; Ireland 150-4, 163; legalisation of undocumented youth in United States 235-42; Netherlands 173-4, 182-3; policy diversity 7; Quebec 52, 56-9; racialisation of 206; second language acquisition pattern 230; United Kingdom 200-1, 206, 210; United States 225-43

Immigration Act (1903), US 227

Immigration (Education) Act, Australia 24-5

Immigration Reform and Control Act (IRCA) (1986), US 232

Immigration Restriction Act, Australia 21-2

information computer technology see ICT-based language training Ingrian Finns 109

Initial Diploma in French (DILF) 133 integration: Catalonia 85, 88-9; classroom practice 114-16; critical approach 10; debates about 115 ; ESOL students' perspective 218-23; European Union policy 258-60; Finland 107-18; France 132; Ireland 169; language learning and 4-5; Netherlands 173-86, 187-99; pedagogical practice 114-16; Quebec 56-9, 60; ‘two-way integration' principle 116 ; Whose Integration? project 217-23

interculturalism 165

IRCA see Immigration Reform and Control Act

Ireland: citizenship referendum 155; discrimination 165-8, 170; English for Speakers of Other Languages 149-72; English used by migrants 154; immigration 150-4, 163; integration policies 169; Learning for Life White Paper 151, 152, 153; National Adult Literacy Agency 150, 158, 164-5; national identity 
149; racism 155-6, 165-8, 170;

Refugee Language Support Unit 152; refugee migrants 150-3;

Vietnamese migrants 150;

Vocational Education Committees 150

Irish English 157

Irish language 4, 149

Irish Vocational Education Association (IVEA) 150, 156-8

It's Your Right teaching resource 41-2

IVEA see Irish Vocational Education

Association

jus sanguinis (right of the blood) 70, 155

jus soli (right of the soil) 70, 71, 155

justice-oriented citizenship education $66-81$

Kahne, J. 71-2

Knowledge of Dutch Society (KNS) exam 177,189

L2 learners, ICT-based language training 189, 190, 195

labour rights 68

Landcare 40

language laws, Quebec 56, 62

A Language for Life (Department of

Education and Science) 207

language policies, definition 28-9

language rights, United States 231

Language for Specific Purposes (LSP) 152

language tests: Australia 21-2; for citizenship 5-6; Netherlands 174, 177, 179-82; United Kingdom 203-4; United States 228-9

Language Volunteering program, Catalonia 90

Laois Anti-Racism and Diversity Plan 165

Laurier, M.D. 59

Learning for Life White Paper 151, 152, 153

legislation: Australia 21-2, 24-5; Civic Integration legislation 174-9,
182-3; civil rights legislation 231;

Finland 109-12; Netherlands

174-9, 182-3; Quebec 56; United

States 226-7, 236-7

LESLLA see Low Educated Second

Language and Literacy Acquisition

Life in the UK test 203-4

Lin, English language learner case 244

literacy programs: United States

244-56, see also adult literacy

Living in Australia website 36

LLB see low literacy background

local learning contexts see community sector

low-educated migrants: ESL learners 35-48; Netherlands 184, 192;

United States 244-56

Low Educated Second Language and

Literacy Acquisition (LESLLA) 10

low literacy background (LLB) ESL

learners 35-48

LSP see Language for Specific

Purposes

Manhattan 251

Martin, J. 28, 29

Meehan, E. 28-9

Melbourne 44-6

MICG see Ministry of Immigration and Cultural Communities

migration see immigration

Milian, A. 87-8, 91

Milliband, Ed 203

Ministry of Housing, Spatial Planning and Environment, Netherlands 188

Ministry of Immigration and Cultural Communities (MICC), Quebec 58-9

monolingualism 2, 3, 20

Montreal 50, 53, 55, 61, 62

Moore, D. 140

Moore, H. 30-1

Mother and Child group, Finnish language learning 121-6

Muhlise, Dutch language learner case 194

multiculturalism: Australia 20, 25-30; Catalonia 96-7; ethnicity and 27-8; monolingualism and 3 
multilingualism: United Kingdom 202-5; United States 247

multiliteracies concept 141

\section{Naar Nederland (To the Netherlands)} self-study toolkit 178, 181-2

National Adult Literacy Agency (NALA) 150, 158, 164-5

National Core Curriculum, Finland 112,113

national ideology 7

national policies $2-4$

Nati, plurilingualism case study 141-3

Naturalization Act (1790), US 226

naturalization test, United States 228-9

Netherlands: adult migrant education policy 259, 260; anti-Muslim sentiment 176; Civic Integration legislation 174-9; 'Double Dutch' 184; Dutch language teaching materials 178, 181-2, 187-99; Exam on Spoken Dutch 177; ICT-based language training 187-99; immigration 173-4, 182-3; integration policies 173-86, 187-99; Knowledge of Dutch Society exam 177; language tests 6 , 174, 177, 179-82; low-educated migrants 184, 192; Ministry of Housing, Spatial Planning and Environment 188; municipal authorities 188-9

New Labour Government, UK 208, 209 Newsreader ICT-application 195-7

New York City 232, 248, 251-3

NGOs see nongovernmental organizations

Nigerian English 157

Niveaux de Compétence Linguistique Canadiens: Français Langue Seconde pour Adultes (Canadian Centre for Language Benchmarks) 67 nongovernmental organizations (NGOs), Catalan language classes 94-106

North Yarra Community Health (NYCH) 45
NT2 Nieuwslezer (Newsreader) ICTapplication 195-7

NYCH see North Yarra Community Health

'one nation one language' ideology 2-4, 202

overview of chapters $12-17$

Page Act (1875), US 226

Participative Integration into Finland project $107-8$

participatory citizenship 75-6

participatory pedagogy 214-24

Pickles, Eric 203

plurilingualism: Alina, case 145-6; Australia 26, 28, 30-1; Catalan language 104; creative writing workshop case study 138-48; definition 139; French as a Second Language learners 138-48; 'monolingual' view of 28; Nati, case 141-3; plurilingual competence 140; Thich, case 143-5; translanguaging 102

Portlaoise Adult Education Centre, Ireland, ESOL case study 162-72 poverty 246 problem-posing technique 215, 221 Promotion of Immigrant Integration Act, Finland 110-11

Quebec: Anglophones 50; Catholic committee 53-4; Charter of the French language 56, 62; citizenship education 51-5; employment 59, 61; English language classes 54; Francization programs 55-9, 60, 61; Francophones 50, 51, 55; French language education policy 49-65; French language in 51; immigration policies 50-1, 52, 56-9; integration policies 56-9, 60; language laws 56, 62; Liberal Party 57; Ministry of Immigration and Cultural Communities 58-9; population 49, 59-60; Quiet Revolution 55 
racism: Ireland 155-6, 165-8, 170;

United Kingdom 206, 220; United

States 234

Rampton, B. 82

Reflect ESOL program 215

Refugee Language Support Unit

(RLSU) 152

refugee migrants $109,150-3$

regeneration projects $40-1$

Renan, Ernest 70

RLSU see Refugee Language Support Unit

Russian language 142, 143

Sanctuary Cities, United States 232

Scotland, ESOL classes 208-9

second language acquisition pattern 230

Seeker (publication) 170

self-study toolkit, Dutch language 178,

181-2

Service Providers del Barrio (SPB) 251-2

Settlement Course, Adult Migrant

Education Program 38

'She's gone modern' classroom topic 220-1

Shohamy, E. 29

Skills for Life strategy 208

social goals in language programs,

Catalonia 97-100

Spanish language: in Catalonia 83, 86,

96; in United States 230, 253

SPB see Service Providers del Barrio

Spolsky, B. 29

Standards Linguistiques Canadiens

(Canadian Centre for Language

Benchmarks) 67

stay-at-home migrant mothers,

Finnish language teaching 119-27

'subtractive assimilation' 4

Swedish language 113

Tamusa, Dutch language learner case 194

Tas(mania)TAFE: Hands on English program 39-41; Young Migrant

Education Program 43-4

teaching practice, challenges to $7-9$ technoscape, global 197

television programmes 207

TGN see Exam on Spoken Dutch

Thich, plurilingualism case 143-5

To the Netherlands self-study toolkit 178, 181-2

Tower Hamlets College, ESOL class 218, 220-1

transformative pedagogy 99-100

Transforming Professional Integration project, Finland 108

translanguaging 102, 141

'truncated repertoires' 9

'two-way integration' principle 116

UCS see Urban Community Services

United Kingdom (UK): adult migrant education policy 259,260 ;

'Britishness' debate 202-5;

citizenship test 203-4;

discrimination 206; English

language learning for adult migrants 200-13; English for

Speakers of Other Languages 201, 205-11, 214-24; immigration 200-1, 206, 210; language tests 203-4; multilingualism 202-5; political debates 202-5; racism 206

United States (US): citizenship test 228-9; civil rights legislation 231; Deferred Action for Childhood Arrivals 236-40, 242; DREAM Act 236-7; early childhood arrivals' legalisation 235-42; English Innovations model 240-1; English language policies 225-43; English language threat perception 229-30; English Only states 230-3; ESL program access/provision 232-3, 240-1, 246-54; excluded immigrant categories 226-7; Executive Orders on Language Access 231; foundations' role in immigration policy 240-1; Generation 1.5 238; Hispanic immigrants 230, 251; Homeland Security 235, 237; illegal immigrants 233-5; immigration 
reform 225-43; language rights 231; legalisation of immigrants 233-5; literacy programs 244-56; low-educational attainment 246; low-literate adult migrants 244-56; naturalization test 228-9; racism 234; Sanctuary Cities 232; undocumented youth 235-42; youth not yet fluent in English 238-40

Urban Community Services (UCS) 252-3

VECs see Vocational Education Committees

Verdonk, M. 176

Victoria, Australia 41-2

Vietnamese language 144

Vietnamese migrants 150
De Virtuele Wijk (The Virtual Neighbourhood) ICT-application 192-5

Vocational Education Committees (VECs), Ireland 150

Voting Rights Act, US 231

Water Safety Program 43-4

Westheimer, J. 71-2

Whose Integration? project 217-23

Woolard, K.A. 85

work placements 36

Young Migrant Education Program (Y-MEP) 43-4

Zubrzycki, J. 29-30, 31 